al. $W$

391

ROSCi49 $189 \%$

Invert. 2001.

Reroncial, I.

Beitrage Zur Fauna Gronlanñs. Ergeuniss; Iiner

In Jahe 1890 in Gronlancis Vorcenommenen

Forsckungsreise. I. Zur Rotatorienfauna Gron-

lands (mit sechs tafeln)

Iunds Univ. Arssikr. To . yXXVIII. 1832

pp.1-180. pls.1-6 4 to

Farrint collection

(1)

are.

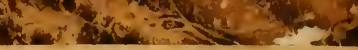
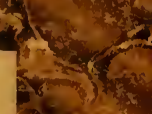

-

Ts

a.t.

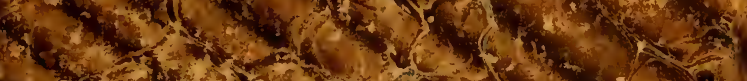

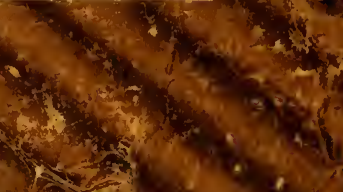

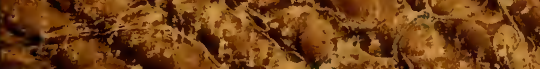

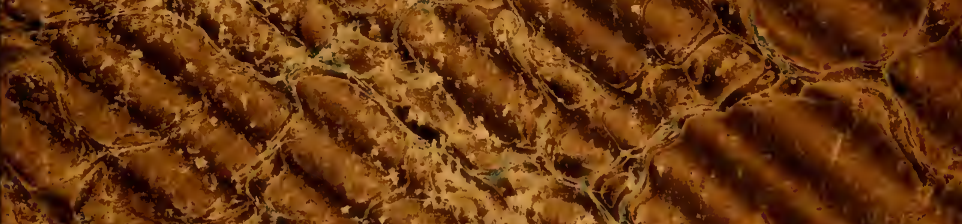

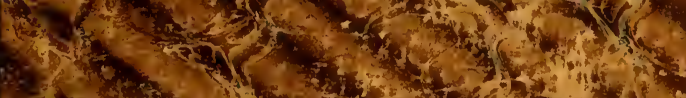

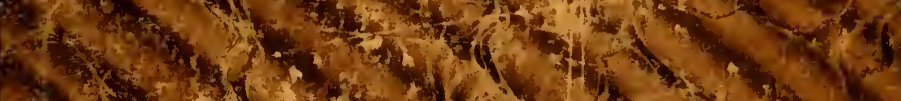

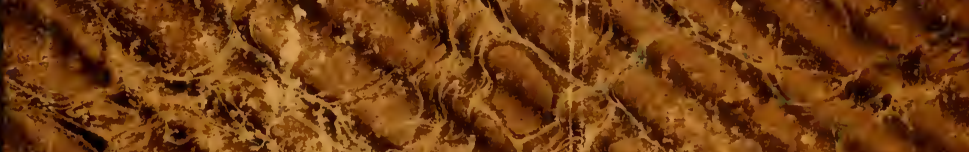

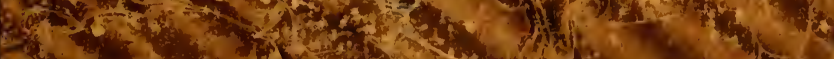

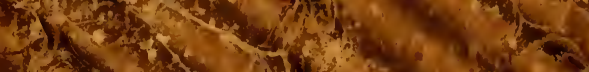

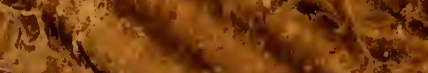



MARRI ULLECTON 

R\&B. $8+4$

isink

\section{BEITRÄGE ZUR FAUNA GRÕNLANDS.}

ERGEBNISSE EINER IM JAHRE 1890 IN GRÖNLAND VORGENOMMENEN FORSCHUNGSREISE.

D. BERGENDAL.

I.

ZUR ROTATORIENFAUNA GRÖNLANDS.

(MIT SECHS TAFELN.)

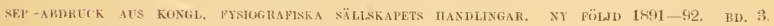
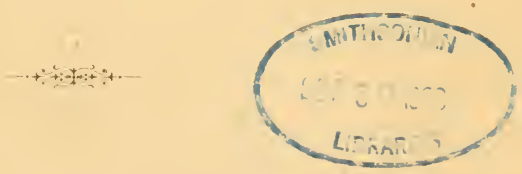

LINI) $18 \% 2$.

BERLINGSKA BOKTRYCKERI- OCII STILEJUTERI-AKTIEBOLAGEY. 



\section{Ehrenbergs Euchlanis Lyneeus wiedergefunden?}

$$
\text { Von }
$$

\section{I). BERGENIAl.}

In einem vor eingen Tagen der sehwedischen Akarlemie der Wissenschaften eingereichten Aufsatze: Gastroschiza triacantha n. g. n. sp., cine neue Gattung and Frmilie der Rärlerthiere habe jeh zwei rigenthümliche Räderthiere beschriehen. I lie eime ist:

Gastroschizu triecunther n. Q. n. sp). Eine loricate Form mit gefurchtem, unten gespaltenem Panzer, der vorn drei Hörnchen trägt. Kopf mit zwei fingerförmigen Tasterm. Fuss bauchständig, geringelt, nicht gegliedert, mit zwei Zehen. Mastax gross mit sturken Kiefern. Auge schwarz, nackenständig.

Dieses einem Lyncrus sehr ähnliche Räderthirr steht EmrExbers's Euchlanis Lyuceus ausserordentlieh nahe.

Ich habe darum seine Art als eine zweite Species, die dureh zurei Iörnchen ausgezeichnet ist, zu meiner Gattung ciestroschiza gestellt.

In einem Moortümpel mit Śphugnum bej Rönns Mölla. Sehr selten.

Diese eigenthümliche Form muss, wis jeh in moiner erwälnten Arbeit zeige, eine eigene, neue Fimilic bilden, deren Verwandtsehaft mit anderen, sehon früher bekannten Fumilien nicht gerade sehr angenscheinlieh ist.

Die andere Crattung entbehrt des Fusses, hat einen ebenen Panzer, ohne Ilörnchen, zeigt abor in gewissen anderen Hinsiehten mit Gustroschiza Ïhnlichkeit. Ich habe diexe Form Auums ovalis n. g. n. sp. genamnt. Dieselbe Localität. Noch viel seltener als die vorige.

Lunds Univ. Ărsskrift. Tom. XXVIII. 
Gastroschiza triacantha oder sehr nahe stehende Formen sind ausserdem vor kurzem in der Nähe von Stockholm gefunden worden, wie ich eben heute ron meinem Fremule, D):rn L. JägERskiöL1, vernehme. Er hatte auch diese Formen studirt, gezeichnet und beschrieben, war ausserdem schon im Begriffe eine Schrift darüber dem liologisehen Verein in Stockholm einzusenden, als or aus dem in den Tagesblättern veröffentlichten Titel meines genannten Aufsatzes vermuthete, dass unsere Formen identisch sein könnten. Einige seinem Briefe beigelegten skizzen zeigten num aurh, dass dirse Vermuthmo vollkommen richtig war.

Ls ist gewiss ein sonderbarer Zufall, dass dieses während balet 60:0r Jahre mehrmals vergebens gesuchte Räderthier in zwei versehiedenen, weit entfernt liegenden Gegenden schwedens, hrinahe gleichzeitig wiedergefunden wird.

Vielleicht sind ähnliche Formen in der letzten Zeit auch anderswo gefunlen. Um nun langweiligen und mangenehmen Prioritätsstreiten vorzubeugen, habe ich diese kurze Notiz nierlergeschrieben, muss aber für nähere Angabon und Zeichnnngen auf meinen erwähnten wohl ziemlich bald erseheinenden Aufsatz hinweisen.

Lund 17 sept. 1892. 


\section{Einleitung.}

$W$ ie ich an anderer Stelle kurz berichtet habe, nahm ich auf Aufforderung der ligl. dünischen Kommistion für die geologisehe und gengraphische Untersuchung Grönlands eine zoologische Reise nach Grönland vor ' $)$. Der mir gegebene Auftrag war hauptsïchlich solche Thiere zu untersuchen, welehe nicht recht gut an Spiritusmaterial untersucht werden können. Diese Thiere im lebenden Zustande zu untersuchen und wenn möglich auch nach modernen Methoden für spätere gründlichere Untersuchung zu konservieren war deshalb meine Hauptaufgabe. Der Plan war, dass ich mich hauptsächlich mit der Mecresfauna beschäftigen sollte, und hatte ich ganz besonders gedacht die Nemertinen und Turbellarien für nähere und eingehendere Studien auszuwählen.

Dieser Plan wurde indessen darlurch vollständig umgeändert, dass äussere Verhältnisse - cine sehr lange Reise sowie stürmiges und regniges Wetter während des ganzen Spätsommers - einerseits meine Arbeitszeit stark abkürzten umıl andererseits Mecresuntersuchungen sehr oft schwer oder unmöglich machten.

Ich konnte mir deshalb oft genug nicht Arbeitsmaterial aus dem Neere verschaffen und fing dann an der Süsswasserfanna ziemlich grosse Anfmerksamkeit zuzuwenden. Bald schien mir auch die Thierwelt der süssen Gewässer sehr wohl einer Untersuchung werth. Die folgenden Studien wären deshalb vielleicht besser Beitrüge zur Süsswasserfauna Grönlands zn nennen.

1) Bergexpal, f. Kurzer Bericht über eine im Sommer 1890 muternommene Zoologische Reise nach Nordgrönland.

Bihang till K. Srenska Yet. Akad. IIandlingar. Band 17. Afl. IV. N:o 1.

Lụnds Univ. Årsskr. Tom. XXVIII. 
D. Bergendal.

Weil ich jedoeh ein wenig zur besseren Kenntniss der Fauna des Meeres beitragen kann, habe ich den obigen Titel gewählt.

Auch habe ieh meine Untersuchungen fast mur in Norlgrönlanıl vorgenommen. Indessen habe ich auch studien ïber einige bei IJolstensborg eingesammelten Thicre gemacht, und diese Kolonie gehört bekanntlich Sïdgrönland an.

Ich bitte den Leser folgender Aufsätze ausdrüeklich diese Umstände in Gedächtniss zu behalten. Sie kömnen die sich leider zu oft vorfintende L'nrollständigkeit meiner Studien erklären und meiner Ansicht naclı auch entschuldigen. Wenn man sowohl Einsammlungsarbeiten wie mikroskopische Studien iiher mehrere wenig verwandte Thicre in kurzer Zeit vornelmenen soll, kamn die Gründlichkeit der Forschung nieht sehr gross werden. Bei Einsammhngsarbeiten, welche mit Hülfe nicht geïbter Grönländer vorgennmmen werden, muss man selbst oft-mitfahren und dadurch geht riele Zeit verloren. Es gelang mir zwar sehliesslich einen jungen sehr intelligenten Grönländer in Egedesninde so einzuülen, dass er ganz gut gewisse Einsammlungsarbeiten selbst besorgen konnte und auch ganz gut die Thiere auszusuchen lernte, da aber war eben die Zeit für meinen Aufenthalt in dieser Kóonie zu Ende, und ich fand an den anderen Stellen, wo ich nur kürzere Zeit blieb, keine so gesclickte Leute.

Einige allgemeine Notizen über die Reise habe ich in dem oben angeführten Bericht geliefert. Itier werde ich eine kurze schilderung der Loealitïten, wo ich hauptsächlich die folgenden Studien vorgenommen habe, mittheilen.

Die längste Zeit brachte ich in Egedesminde zu, wo ich anderthalb Monate hlieb. Die grosse Sehwierigkeit in der Zeit, wo ein Sehiff im Iafen liegt, Arbeitsleute zu finden maehte im Verein mit anderen Umständen, dass ich nur während eines Monats ruhig arbeiten konnte; die ersten vierzehn Tage waren alle Rüumlichkeiten besetzt, und Hochzeits- wie Confirmations-Feierlichkeiten i. d. gl. $\left.{ }^{1}\right)$ machten, dass man sich eher an einem kleinen Badeort irgend wo in Europa als in einer grönländischen Kolonie zu befinden glauben konnte.

1) Die Dänen in Grönland sind ja die längste Zeit des Jahres nicht nur von Europa, sondern auch nicht selten von einander ganz abgesperrt, und deshalf ist die kurze Zeit, тo die Sehiffe im Ilafen liegen, eine Zeit der Freude, welche Frende auch die Fingebornen recht gründlich zu theilen scheinen. 
Nach dieser Unruhe kam dann eine schöne ruhige Arbeitszeit und ich werde immer die ebenso grossartige wie herzliche Gastfreiheit des Kolonieverwalters und seiner Frau in dankbarer Erinnerung bewahren.

Das Land in der Nähe von Egedesminde ist nicht sehön. Diese Gegend billet ein flaches in viele Inseln zertheiltes Küstenland, wo die Hügel selten mehr als wenige Hundert Fuss hoch sind. Im Sommer findet man deshalb selten Schnee und Eis in dieser Gegend. Selbstverständlich kommen doeh im Meere damn und wann Eisberge vor, wem sie auch $1 \mathrm{~m}$ in der Discobucht zn sein selten und gewöhnlich klein genamnt werden müssen.

Wie fast überall in Grönland sicht man anch hier im Frühling und Vorsommer eine grosse Zahl von kleineren umd grösseren Wasseransammlungen, die zum grossen Theil beim Sehmeeschmelzen entstanden sind und später nicht selten vollständig anstrocknen. Wenn es aber, wie es im Jahre 1890 eintraf, im spätsommer viel regnet, troeknen nur die kleinsten Wasseransammhugen, cine kuze Zeit aus, und nicht wenige führen den ganzen sommer Wasser.

Die Vegetation dieser Gewässer besteht fast regelmässig aus einigen sehwimmenden Moosen, unter und auf denen versehiedene Algen wachsen. Das gewöhnlichste von diesen Moosen ist wohl Hypnum fluitans. Sphagnumarten sind viel seltener, und ich habe von denselben nur kleinere Rasen an den Ufern einiger kleinen Seen beobachtet. Von den phanerogamen Wasserpflanzen wicht man oft genug Eriophorum-arten und Hipjuris. Viel seltener habe ieh ein sprarganium benerkt. In einigen schr seichten Gewässern treten Ranmenlusarten - wohl hyperboreus und pygmaus auf. Die Algenvegetation kam mir sehr arm vor. Zygnemaarten, die doch gewöhnhch steril waren, sah ich sehr oft. Seltener und im Verhältniss zu der Vertheilung dieser Pflanzen in unseren Wasseransammlungen auffallend viel seltener habe ich spirogyren beobachtet. Einige Confervaceen kamen mir zwar oft genng vor Augen, aber auch diese Algen waren einförmig und wenig ïppig.

Bolbochaete tritt in kleinen Exemplaren reeht oft auf, wogegen ich sehr selten Oedogonien bemerkt labe. Fadenalgen sind überhaupt in den von mir gesehenen Gewässern nicht allgemein.

Diatomaceen und Desmidieen haben überall reeht viele Vertreter. Die Zalıl der letzteren schien mir indessen bei weitem relativ grösser. Von Protococcacen habe ich besonders oft Pediastrum notirt. In vielen bald austrock- 
nenden Gewässern sehien mir die letzte Algenvegetation aus grossen Massen von Nostoeaceen zu bestehen.

Die jetzt besprochenen Gewässer sind jedoch alle recht seicht. Werden die Wasseransammlungen etwas tiefer, versehwindet die Vegetation sehr sehnell, und die auf allen Inseln vorkommenden kleineren und grïsseren seen zeigen fast keine Vegetation, wenn sie nicht sehr seichte Buchten besitzen. Auch die Thierwelt der Seen ist mit derjenigen der kleineren Gewässer verglichen recht arm.

Die allgemeine Beschaffenheit der Wasseransammlungen ist so ziemlich dieselbe an den drei Stellen wo ich meine studien vorgenommen habe.

Weil ich jedoeh eine nicht so wenig abweichende Süsswasserfauma bei Egedesminde fand, will ich noch einige Worte auf die versehiedene Natur dieser drei Stellen opferm. Egedesminde N. Br: $68^{0} 42^{\prime} 23^{\prime \prime}$ W. L. 520 $44^{\prime}{ }^{1}$ ) liegt au einer Insel an der sïdlichen Mündung der grossen Diskobucht. Der Abstand von der Kolonie lis zu dem Rande des Inlandseises beträgt um 12 Meilen. Auch in Jahren, in welchen andere Theile von Nordgronland sonniges Wetter haben, herrscht oft ein ziemlich kaltes, nebeliges Wetter bei Egedesminde.

Das Meer ist ziemlich seicht in der nächsten Nähe von Egedesminde und zeigt auch ziemlich versehiedene Beschaffenheit des Bodens. Für Mceresuntersuchungen ist diese Kolonie gewiss gut geeignet, obgleich das schlechte Wetter mein Arbeiten im Jahre 1890 so bedentend hinderte. Ebenso glaube irh, dass bedentende Strecken der inselreichen Küste zwixchen Egedesminde und IIolstensborg eine gründlichere Durchforschung gut lohnen würden. Leider komnte ich auf der Barkenfahrt ron IIolstensborg nach Egedesminde nicht dredschen, weil die Barke ganz voll Gepäck war und neine schleppnetze ete. noch nicht fertig waren, aber manehmal sals ich eigenthïmliche, seichte Meeresbuchten, die anderartig waren als diejenigen an irgend einem anderen von mir besuchten Theile der grönländischen Krïste. Iuch Ilolstensborg selbst schien mir ein selır geeigneter Platz für zoologiselue Studien zu sein. Dies gilt sowohl die Meeresbuchten als auch und ganz besonders die vielen und zum Theil eigenartigen Sien und Wasseransammlungen des abwechslungsteichen Küstenlandes.

1) JExsex, J. A. D. Astronomiske Ohservationer og Undersögelser over Vandets Salt. holdighed. Meddelelser om Grönland, lleft 2, s. 196. 
Jakol, harn N. Br. $69^{\circ} 13^{\prime} 04^{\prime \prime}$ W. L. $50^{\circ} 59^{\prime} 33^{\prime \prime}{ }^{1}$ ) liegrt auf dem Festlande an der östlichen Seite der I)iskobucht, ummittelbar nörellieh von dem Isfjord ähnliches Namens. Dats eisfreie Land ist viel schmäler als bei Egedesminde, nur um 3-4 Meilen ${ }^{2}$ ) breit. Die Berge wenn anch noch niedrig steigen indessen mehrmals zu einer Höhe von beinahe 1000 Fuss, aber nur schr wenige z. B. ein Gipfel anf dem Gebirge Kakkarsoeitsiak (1236) erreichen etwas grössere Höhe. Das Heer ist von der kleinen Hafenbucht abgesehen weit mehr offen als bei Egedesminde. Nicht nur die Mündung des tiefen Eisfjords ist von Ilunderten oft am Boden stehenden prachtvollen Eisbergen fast erfüllt, somdern schr oft ist dic ganze lleeresoberflïehe ïberall in der Nähe dieser Kolonie mit kleineren und grösseren Eisstüeken bestreut, die znerst von den grösseren Eisbergen abgebrochen nachher durch Abschmelzung und wiederholte vom Wellenschlag verursachte Zerspaltung und '/erbrechung verkleinert worden sind. Manchmal kamn nicht einmal ein kleines Boot vorwärts gerudert werden ohne jerlen Augenblick gegen diese Eisstücke zu stossen. Die meisten sind ju so klein, dass dieser Zusammenstoss gar nicht geführlich ist. Gefährlich werden die genamnten oft sehr scharfen Eisseherben fïr das pelagische. Netz. Nur selten wirl das Netz zersehnitten, aber fast immer erhält man Massen von dieser Eisseherben ins Netz, und diese besehädigen leicht viele von den empfindlichen Thieren, welehe man eben mit dem pelagischen Netze zu nehmen sueht.

Ritenbenk N. Br. $69^{\circ} 44^{\prime} 0 \mathrm{I}^{\prime \prime}$ IT. L. $\left.51^{\circ} 1 \underline{2}^{\prime} 36^{\prime \prime}{ }^{3}\right)$ liegt wieder anf einer kleinen Insel etwas wïdlich von Torsukataks Isfjorel in der nordöstlichen Eeke eler Diskobucht an der ästlichen Seite der Mündung des Wraigat. Ihre Naturrerhältnisse erinnern ja zum grosien Theil an diejenigen bei Jakobshavn. Eisberge sind nicht so zahlreich aber immerhin gewöhnlich genug und die Grönländerimnen versehaften sich keinen Vorrath ron süssem Wasser, sondern nehmen dieses, sobald sie es braurhe'n, von den fast immer nahe am I'fer feststehenden klemeren Eishergen und Eisstïcken. Indessen habe ich dis Meer

1) Hammer, R. R. J. Undersögelse af Grönlands Vestkyst fra $68^{\circ} 20^{\prime}$ till $70^{\circ} \mathrm{N}$. Br Meddelelser om Grönland. Kjöbenliavı 188!). IIeft. 8, s. 31.

$\left.{ }^{2}\right)$ Siehe Rısk, H. Grönland geographisk og statistisk beskrevet. Bd. I. K jöbenhavn 1857. Sid. 118.

3) H.MMER, l. c. 
hire nicht so unt Fisseherben bestreut gesehen wie es gewöhnlich bei Jakobshavn war.

Die lierge in der Nähe von Ritenbenk erreichen einu grössere llöhe als bei den beiden vorher genannten Kóonien der Gegend der Diskolneht. So besitzt der nahe liegente sehönc Bery. Kangek auf dem Arveprindsens Eilaud eine llähe von ungefähr 2000 Fuss und die weiter nördlich an Wraigat liegenden Berge und Gebirge sincl un vieles liöher als dieser.

Die Wetter- und Temperaturverhältnisse Grönlands betreffend werden ja genatue Beobachtungen an versehiedenen Kolonien gesammelt und deshalb marhe jeh nur wenige Bemerkungen darüber, dis jetoch als Beispiele der Verhältnisse, unter welchen die naehstehend gesehilderten Thiere leben, vielen Lesern willkommen sein diirften.

1)er 17 Juli war einer von den wärmsten Tagen, die ich in Eggedesminde erlebt habe. Die Tagestemperatur der Lnft war im Sedatten hördstens $\left.12-14^{01}\right)$

i0 Uhr 15 Nachts.

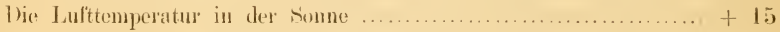

Die Temperatur der Erele of (tm. tiel $\ldots \ldots \ldots \ldots \ldots \ldots \ldots \ldots \ldots \ldots$ । 9,5

11 Uhy 30 Nachts.

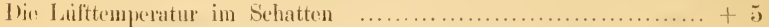

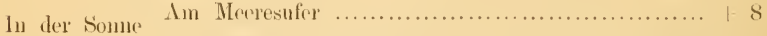

100 Fiden rom Uler.........................

Die: Wassertemperatur in einem sehr langsam flirstemelen biache 11

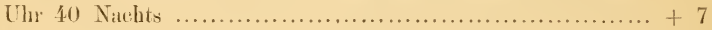

In Mloose mebenbei....................................

11 Uh. 50 Nachts.

Die Wassertemperatur in einem kleinen Teiche $\ldots \ldots \ldots \ldots \ldots \ldots \ldots+$.

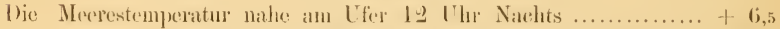

Am 24 Juli war der Morgen riemlich angenehm unit sehwachen sonnenseluin:

11 Uhr Vormittags.

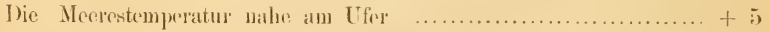

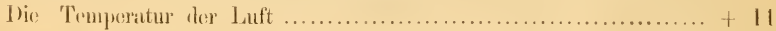

1) Ich benutzte ('elsii hundertgradigen Termonetrr. 
1 Uhr nachmittags (nelelige Luft).

1)ie Heerestemperatur (anch nahe am Ufer aler ant etwas tieferem

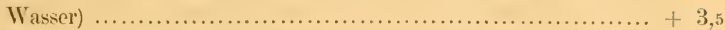

I) Temperatur der Luft am Meer ........................ + 4,5

Im Angust war die Luftemperatur bei Fgedesminde gerwöhnlich 5-s oder böehstens $10^{\circ}$. Die Temperatur ale Süsswasselansammlungen betrog 5 9-11.

Bei Jakobshavn arbeitete ich vom 19-31 Aug. Wenige Tage waren sonnig die meisten kalt und nebelig. Der 29 Aug. war ein sonniger, sehüner Tag. Ich gebe hier einige Matsse an, welehe ieh diesen Tag genommen habe. In der vorigen Naeht war die Temperatur sehr niedrig gewesen. Das Wasser der Hafenbucht war mit reeht dickem Eise belegt worden, welehes noch nach zehn Uhr Morgens grösstentheils da lag, obgleich die Sonne diesen Tag gnte Wärme gab. Aneh mehrere Süsswasseransammlungen waren selhstverstïndlich mit Eis bedeckt. Nicht weit ron der Wohnung des "Koloniebestyrers" finden sieh zwei mittelgrosse Teiche, aus denen ich manche von den Thieren holte, welehe ich in Jakobsharn untersuchte. I) Vegetation war relativ stark, die grösste Tiefe cirea 2-3 Fuss. Das Ufer war theils von Erde und Moos theils von Felsen gebildet.

Das Wasser des einen Teichs zeigte um 7 Uhr 40 Morgens bei starkem Sonnensehein ............................... 7

8,45 Morgens. Das Wasser ............................... $+8,25$

Zwisehen den Mnosen am Rande des Teiehs ................. $+6,25$

In der Erde, $12 \mathrm{Ctm}$. tief................................ $+6,5$ 8 IThr 30 Morgens.

Die Temperatur der Luft in der Sonne......................... 17

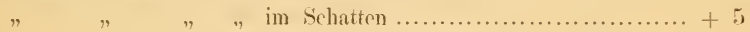

$" \quad "$ des Wassers in einer sehr kleinen Borgpfütze $\ldots+5,25$

Die Temperatur des Wassers in einer kleinen Bucht drsselben Teriehes welche mit Eis bedeckt war..................... + 3,

Dis Temperatur des Meeres im Hafen unter dem Eise ........... + 3

I'm $1 \mathrm{Th}$. Nrachmettags desselben Tages nahm ich folgende Maasse:

l)ie Tenuperatur der luft in der Sonne ...................... 20

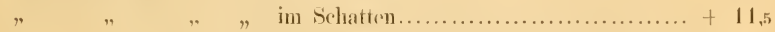


Die Temperatur des Wassers oben genamnten Teiches $\ldots \ldots \ldots \ldots+12$

Zwischen den Moosen am Rande........................... + 11,5

Während der folgenden sehr regnigen, stïrmischen und nebligen Tage war die Temperatur des Tages $11 \mathrm{~m} \quad 5-7$ oder $8^{0}$, aber die Temperatur der Näichte war auch nicht niedriger als 4 oder $5^{\circ}$.

Ich nehme hier aus Rink's oben eitirter Arbeit, die wohl immer die beste Quelle für Belehrung über Grönlands Natur n. Volk bleiben wird, die folgenden Angaben über die mittlere Temperatur in Jakobshavn nach Beobachtungen, welche im Aug. 1842 angefangen und bis Juli 1846 fortgesetzt wurden. Die Grade sind hier Réaumur.

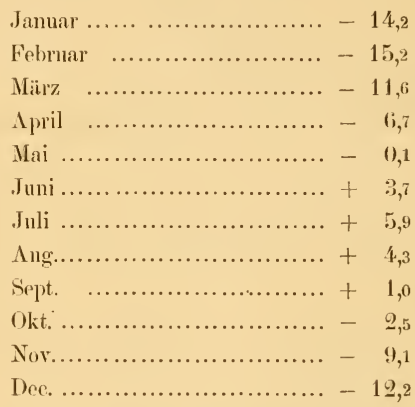

Danach wird die mittlere Jahrestemperatur - $4,73{ }^{1}$ ).

Hammer gibt einige Zahlen über die Temperatur der Erde im Vinter 1879-80, was hier von besonderẹm Interesse sein kann, weil ja die meisten Wasseransammlungen sehr seicht sind, und diese Thiere ja alle Wasserthiere sind. Iels habe aus seinen Zahlen die mittlere Temperatur bereehnet.

Seine Maasse sind im Lehmboden genommen, und die Observationszeit ist 9 Uhr Norgens.

Im Oktoler 1879 war die Lufttemperatur - 5,48 (max. 0,0; min. - 13,0).

Die Temperatnr der Erle auf ein Fuss Tiefe - 0,35 (max. - 0,1; min. - 0,8). $" \quad " \quad " \quad " \quad$ zwri $" \quad, 1-26$ Okt. $-0,4 ; 27-30$ Okt. $-0,5 ; 31$ Okt. $-0,4$.

'j R זк, I. c. Bd. I, s. 39. 
Im November: Lufttempratur - 7,5 (max. + 3,2; min. - 18,4).

Die Temperatur der Erde in ein Fuss Tiefe - 0,9 (max, - 0,5; min. - 6,5). " $" \quad " \quad$ zwei $" \quad$ " $\quad 1,5$ (max. $-0,4 ; \min$ - 3,1).

Im Deeember: Luftemperatur - 13,4 (max. + 4,8; min. - 23,3).

Die Temperatur der Erde in ein Fuss Tiefe - 6,7 (max. - 1,6; min. - 10,5). $" \quad " \quad " \quad$ " zwei $" \quad$ " $" 5,1$ (max. $-2,0: \min .-8,4)$.

In Januar 1880: Luftempicratur - 17,2 (max. + 1,0; min. - 33,3).

Dic Temperatur der Erde in ein Fuss Tiefe - 10,3 (max. - 6,9; min. - 12,7).

$" \quad " \quad$ " $"$ zwei $" \quad-9,7$. Diese Bobbathungen wurlen indessen nur bis zum zwölften Januar gemacht. Da war die Temperatur in dieser Tiefe - 10,5.

Im Februar ${ }^{1}$ ): Luftemperatur - 18,9 (max. - 2,5; min. - 32,5).

Die Temperatur der Erte in ein Fuss Tiefe - 15,5 (max. - 12,6; min. - 18,8).

Voun März sind wenige Beobachtungen mitgetheilt nur rom 1:ten bis b:ten, aber diese Zahlen sind die höchsten.

Die mittlere Lufttemperatur dieser 6 Tage war $-34,9$,

und die mittlere Temperatur des Bodens in ein Fuss Tiefe $-18,4^{2}$ ).

Setze ich damn weiter hinzu, dass man auch im sommer an viclen orten sehon in ein Fuss Tíefe den Boden gefroren findet, und dass die Erde in grösserer Tiefe nie aufthaut, so dürften die für eine Auffassung der Verhältnisse, unter welehen die Süsswasserthiere in Nordgrönland zu leben haben, nöthigen Notizen gegeben sein.

Nur noeh die Bemnerkung dass das Klima in Südgrönland wohl milder ist, insofern dass die mittlere Temporatur des Jahres etwas höher ist, abor diese Verschiedenheit rührt viel mehr von geringerer Kälte im Winter als von grösserer Wärme in Sommer her. Darum kann dieselbe anch wenig Einfluss auf die Betrachtungen üben, welche iiber das Vorkommen der Thiere in Nordgrünland hier an einigen Stellen eingefügt werden. Jedoeh dürfte das Sommerklima in den weit nach innen liegenden Thälern in Südgrönland relativ sehr gut genannt werden dürfen.

Von Ritenbenk, wo ich nur sehr kurze Zeit verweilte und wo ich keinen brauchbaren Arbeitsplatz finden konnte, weil eben um diese Zeit Untausch vou

1) Im Februar wurden nur von 12:ten bis 29:ten Observationen genommen.

$\left.{ }^{2}\right)$ ILмmer, R. R. J. Undersögelser ved Jakolshavus Isfjord og narmeste Omegn i Vinteren 1879-1880. Heft. 4. Kjöbenhavn 1883. Tabel 5, sid. 65.

Lunds Univ. Årsskr. Tom, XXVIII. 
"Koloniebestyrer" stattfand, habe ieh wenige Temperaturangaben, weil ich da wenige Wasseransammlungen untersuchte. Die ganze Zeit, als ich mich da befand, 1:ten-6:ten S'eptember, war es ein schönes, sonniges, aber recht kühles und zum Theil stïrmisehes Wetter. Ieh nahm meine meisten Prohen von einem reeht grossen Binnensee. Das Wasser zeigte 11,30 Morgens einige Mreter vom Rande +7 . Am Strande zwisehen den Moosen +6 . Meerestemperatur $+2,5-3$.

In Holstensborg N. Br. $66^{\circ} 55^{\prime} 52^{\prime \prime}$, W. L. $53^{\circ} 42^{\prime}{ }^{1}$ ) holte ich meine meisten Proben aus zwei kleinen Bächlein, welehe ihr schncll fliessendes Wasser zum grossen Theil von nahe liegenden schmelzenden Sehneemassen bekamen. Die Temperatur derselben war am 19 Juni, cinem sehr somigen sehönen Tage:

10 Ǔhr 30 Morgens kleines Bäichlein ............... 9

etwas grösseres,$\quad \ldots \ldots \ldots \ldots \ldots+\mathrm{s}$

11 Uhr Nachts kleines $\quad, \quad \ldots \ldots \ldots \ldots \ldots \ldots+3$ etwas grösscres $\quad, \quad \ldots \ldots \ldots \ldots \ldots \ldots+3,25$

Meerestemperatur in der nahe liegenden sehr seiehten Hafen-

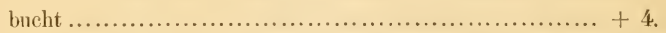

Fliessendes Wasser kommt ja im Frühling bei der Schneesehmelzung sehr reichlich vor. Grössere Ströme hatte ich keine Gelegenheit zu untersuchen. Solehe sind ïberhaupt recht selten, demn die vielen Buchten und langen Fjorde lassen das Wasser gewöhnlich kurze Wege zum Meere finden. Bei Jakobshavn chenso wie bei Egedesminde leiten grössere Bäche das Wasser von einigen Binnenseen in das Meer. Sie werden dänisch Elve genannt. Die Vegetation und die Thierwelt ist sehr arm. Sowohl Infusionsthiere wie Rotatorien waren nur vereinzelt zu finden. An einigen Felsen fand ieh ziemlieh bedeutende Mengen von Zygnemen die alle steril waren. Die "Elve" seheinen mir wie die Binnenseen, deren Wasser sie abführen, wenig lebendes zu enthalten. Sogar die sonst überall befindlichen Miiekenlarven waren hier selten.

Das oben angeführte mag zusammen mit dom vorher verüfentliehten Brricht eine genügonde Tmralımung für die folgenden Untersuchungen ausmaehen, und jetzt gehe ich deshalb zu den Speeialuntersuehungen uiber und theile zuerst meine Untersuchungen über die Rotiferen mit.

1) J KNsex, J. A. D., 1. С., \&. 196. 


\section{I. \\ 'Kur Rotatorienfauna Grönlands.}

Obgleich ich mich zu IIase? gar nicht speeiell mit dieser Gruppe beschäftigt hatte und deshalb natiulich nicht beabsichtigt hatte naeh diesen Thierformen besonders zu suchen, glaubte ich recht bald zu funden, dass die Wasseransammlungen in Grönland sehr roieh an Repräsentanten dieser Gruppe waren. Nach meiner Rückkehr habe ich anch diese Vermuthung bestätigt gefunden. Die meiste Zeit, welche ich in Grönland am Mikroskope zubringen konnte, habe ich mich mit diesen Thieren, die mir bald sehr lieb wurden, besehäftigt. Leider war meine mitgebrachte Literatur nicht mit Rüeksicht hierauf ausgewählt. leh hatte also mu Lumwas Bearbcitung von Leuns' synopsis, IBd. II. Ilamnover 1886. S. 812-820.

libocumans, F., Die mikroskopisehe Thierwelt des süisswassers. Branschweig 1886. S. 89-112. Taf. Vill, die mir sehr oft zu einer sehnellen Bestimmung half, und

Erksters, K., Die Rotatorien der Umgegend von Giessen. Zeitsehr. f. wissenseh. Zoologie. Bł. XXXIX. Leiprig 18S3. \$. 342-441, eine Arbeit die mir nicht nur in Grönland, sondern ebense vicl nachher bei der bearbeitung meiner da gemacliten Notizen sehr nützlich gewesen ist.

Weil meine Literatur so unvollständig war, konnte ich nicht immer eine genïgend sichere Bestimmung da vornehmen, sondern musste Zeiehmungen und 
Notizen machen um eine nähere Bestimmung nach der Rückkehr vorzubereiten. In einigen Fällen hat es sich gewiss nachher gezeigt, dass ich den gesehenen Formen grössere Aufmerksamkeit lätte widmen sollen, aber bei meinen Arbeiten in Grönland betrạchtete ich es sogar als eine Pflicht mich nur so lange mit einem Thiere zu besehäftigen, bis jch es so gut, wie die Verhältnisse es möglich machten, bestimmt hatte. Hätte ich da biologische, anatomische oder entwicklungsgeschichtliche Studien machen wollen, hätte ich in der kurzen Zeit kaum irgend welche Beitrïge zur Fauna Grönlands zusammenbringen können, und meine Aufgabe galt doch hauptsïchlich der Ausforschung der Fauma. Glücklieherweise kann man mikroskopische Thiere nicht einmal oberflächlich für Bestimmung studieren ohne manchmal interessante Seiten der Organisation selbst kennen zu lernen. Aher einige für die Bestimmung sehr wichtige Organe vor allem die Kiefer konnte ich nur selten eingehend genug studieren, eben weil das Studium so zeitraubend ist, ein Verhältniss, das den Rotiferenforsehern gut bekannt ist, und welches auch bewirkt hat, dass bei der ersten Beschreibung auch der meisten europäischen Formen die Angaben über die Kieferbildung gewöhnlich unvollständig und nicht selten auch unrichtig gewesen sind. Die Kenntniss von dem Bau und der systematisehen Bedeutung dieser Organe war ausserordentlich mangelhaft, bis Gosse in seiner schönen Arbeit darüber Licht verbreitete ${ }^{1}$ ).

Die frühere Literatur über die Rotatorienfauna Grönlands ist sehr schuell mitgetheilt. So viel ich weiss existiren nämlich nur zwei kurze Notizen. Levinsen, der über so viele Thiere Grönlands, schätzenswerthe Arbeiten geliefert hat, hat auch einige Tage den Rotiferen gewidmet. Bei Egedesminde, wo er sich die meiste Zeit von den zwei Jahren, welche er in Grönland zubrachte, aufhielt, fand er nur ganz vereinzelte Individuen dieser Gruppe, aber bei Jakobshavn sah er eine grössere Anzahl Rotiferen konnte sie doch wegen Mangel an Literatur nieht näher bestimmen, er machte aber einige Skizzen md Notizen, und hat nach der Vergleichung derselben mit Ehrenbergs Hauptwerk folgende Formen angeben kömen.

Flosculuria sp., Diglena sp., Notommatu sp., Furculuria sp., Philorlina aculeatu, Honocerca rattus, Euchlanis sp., Dinocharis sp., Stephanops lamellaris,

1) Gosse, P. II., On the structure, functions and homologies of the manducatory organs in the class Rotifera. Phil. Transactions of the roy. Soc. London Vol. CXLVI. 1856. 8. 419 . 
Colurus sp. Ansser diesen Formen hatte er auch andere gesehen, welche in Ehrenberws Arbeit nicht beschrieben waren. Er sehlägt die Zahl der von jhm in Grönland gesehenen Rotiferen zu gegen 30 an ${ }^{1}$ ).

J. DE Guerne und J. Ricinard haben die Bestimmung der von $\mathrm{CH}^{*}$ RABor wïhrend seiner im Jahre 1888 vorgenommenen Reise in Grönland eingesammelten Thiere ausgefülurt. Derselbe hatte vorzugsweise an zwei Stellen Einsammlungen gemacht, in dem Bimnense auf der Egedesmindeinsel, wahrseheinlieh im sogenannten "Större Indsëen" und in Tasersuak in der Nähe von Julianehaab N. Br. 60", 45'. Derselbe hatte da recht viele Krebsthiere gresammelt und auch, was ms hier interessiert, einige Rïderthiere. In der von den beiden genannten Verfassern gelicforten Mittheilung liest man dariber Les Rotiferes suivants vivent en assez grand nombre dans le lace d'Egerlesminde. Triarthra longiseta Enkвg, Asplanchna helvetica Iниов, Anura

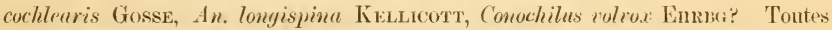
ces espiees sanf la dernière se rencontrent également dans le Tasersuak, on $A s$ planchur helectica est extremement commun. La presence de ces animanx est signalèe iei pour la première fois a Groenland ou l'on ne connaissait qu'un petit nombre de Rotifer's reeuillis sur les algues par Levinsen" ${ }^{2}$ ). In einor Anmerknng wirl zugesetzt: "M. (Th. Rabot a recueilli les mîmes Rotiferes dans l'Imandra en 1885. Ils n'ont jamais été signalés à une latitude anssi clevé".

Diese Angabe bietet ein besonderes Interesse dar, weil ieh in meinen Notizen keine Triarthra odes Asplanchna notirt hatte, und weil ich von Anurou nur ein später zu besprechendes Exemplar gefunden latte. leh muss jedoch bemerken, dass ich in dieser Boziehung vielleicht später crgänzende Bemerkungen werde veröflentlichen können, weil jeh cinige Gläser von mit pelagrischem Netze in einigen seen eingesammeltem Material habe, das ich jedoch bis jetzt nicht näher habe untersuchen können. Indessen traten diese Thiere im Sommer 1 s90 keineswegs massenhaft im See bei Egerlesminde auf.

Nach der Erfahrumg Levixsex's komnte ieh nicht erwarten bei Egoxlesminde viele Räilerthiere zu finden, aber weil ich doch immer damn und wamn sobald

1) Levinsex, (x. M. R. Smaa Bidrag til den grönlandske Famna. Vidensk. Meddelelser fra deu naturhistoriske Forening i Kjöbenhavn, 1881. Separatahdruck, s 5-6.

$\left.{ }^{2}\right)$ DE Gurnse, Jules et Ricunin, Jules. Sur la faune des eaux douces du Groenland Comptes fiendus 1889 . S. $630-632$. 
es möghich wurde Neeresuntersuchungen vornehmen musste, und Egedesminde hierfür besser geeignet ist wegen der so versehiedenartigen Beschaffenheit des Meeresbodens an versehielenen Stellen ganz nahe an der Kolonie, und weil ich anch in Egedesmincle sehliesslich gute Gelegenheit zu arbeiten gefunden hatte, blieb ich längere Zeit da und konnte nachher nur knappe 14 Tage für Jakobshavn disponieren. Die in der Nähe der Wohmung des Pfarrers gelegenen Wasseransammlungen, welche Levinsen da untersucht hatte, habe ich anch gesehen. Sie waren aber bei dieser Jahreszeit ziemlich arm - ich fand nur einige Philodiniden - wahrseheinlich weil sie früher im Sommer ausgetrocknet gewesen, und erst vor ziemlich kurzer 'Zeit wieder gefüllt worden waren. Dagegen fand ich ein reicheres Thierleben in anderen näher dem Hanse des "Kóoniebestyrers" befindliehen etwas grösseren Teichen, die wenigstens in diesem fenchten Sommer gar nicht ausgetroeknet gewesen waren. Ich glaube wohl dass diese Wasseransammlungen reieher waren als manehe solehe auf der Insel wo Egedesminde liegt, aber auch da habe ich viele Rotiferen gesehen. Ganz besonders reich war eine sehr seichte Wasseransammlung auf Räfön bei Egedełminde, die mit schwimmenden Nloosrasen fast ganz bederkt war. In derselben Wasseransammlung kamen sowohl Hydra sp. als Mesostomum personatum massenhaft vor.

Weil ich doch meine Studien in Jakobshavn ziemlieh spät anfangen konnte, kann es wohl möglich und sogar wahrseheinlich sein, dass ieh die Versehiedenheit in der Artenzahl in den Gewässern in der Gegend von Jakobshavn und in derjenigen von Egedesminde viel grösser gefunden hätte, wenn ieh frïher Gelegenheit die Gewässer, bei Jakobshavn zu stutieren gehabt. Jetzt find ich die Verhältnisse ungefähr gleieh. Einige Gewässer waren ziemlich reich, andere dagegen ausserordentlich arm. Indessen muss ieh bemerken, dass ich weder in Jakobshavn noch in Egedesminde noeh anderswo in Grönland ein massenhaftes Iuftreten der Rotiferen-Arten beobachtet habe. Vielleicht künnte ich schon hier Hydatina senta als die einzige Ansmahme anfiihren aber davon werde ich später das nähere berichten. Ich kounte wohl von versehiedenen Rotiferen mehrere Individuen auf dem Objektträger in einem Tropfen bekommen, aber solche Mengen wie man in der Literatur manchmal angegeben findet, kenne ich gar nicht aus eigener Ansehanung. Ieh habe sie anch nicht bei den vergleichenden Untersuehungen welehe ieh im Ilerbste des Jahres 1890 
hier in Lund rornahm, bemerkt, aber die grossen Mengen sollen wohl öfter in Frïhling und Vorsommer auftreten.

Meine Studien nahm ich in der Weise vor, dass ich fast immer sowohl die eben genommene Probe als dieselbe, nachdem sie rinige Tage in einer mit Deckel rersehenen Glasschale gestanden, untersuchte. Bokanntlich ändert sich dadurch die mikroskopische Thierwelt sehr oft fast vollständig. Zuerst durchsuchte ich unter dem Präparirmikroskope einen Tropfen und suchte daraus die nie fehlenden Müekenlarven wegznpflücken, und dann brachte ieh densolben mit Deckglas bedeckt unter das Mikroskop. Weil verschicdene Moosblïtter und Algenfäden da zurück blieben, hatten die Thiere fast immer gute Gelegenheit sich zu bewegen. Waren mehrere Individuen da, suchte ich gewöhnlich sogleich diesclhen $\mathrm{zu}$ isolieren. War dagegen nur ein einzelnes Individumm vorhanden, so suchte ich immer zuerst eine Skizze zu verfertigen, che ich zu der immer recht abentenerlichen Isolirmng schritt. Für die Isolierung benutzte ich entweder eine gewöhnliche Pipette, oder suchte ich manchmal und besonders, wenn das Thier sehr selten war, die Algen und Moose wegzunehmen und liess das Thier anf dem Objektträger ruhig bleiben. Diese unter dem Prïparirmikroskope vorzunehmenden Arbeiten waren sehr zcitraubend und mehr als einmal ging mir trotz aller Tmsicht bei dieser Arbeit ein werthvolles Thier verloren. Um den Druek des Deckglases aufzuliebron orler zu vermindern benutzte ich entweler Haare oder und oft mit grösserem Vortheil kleine Streifen von Fliesspapier.

Ich fand bei diesen Arbeiten mein Nachet-sehes Mikroskop ganz ausgezeichnet. Nicht nur sind die Linsen sehr scharf, sondern vor allen Dingen besitzen diese Objektive rine bedentende Objektlistanz, ein wenigstens beim Irbriten mit lebendem Materiale kaum zu hoch anzuschlagender Vorzug tieser Mikroskope. Ich hatte auch ein Paar Hartnacksche Linsen miturebracht, konnte sie aber selten ohme bittere Erfalırungen benutzen.

Nach meiner Rüekkehr habe ich meine Zeichnungen und Notizen mit den Angaben in der wichtigeren Literatur verglichen und glaube meistenfalls eine ziemlich sichere Bestimmung erreicht zu haben. Weil ich ja nicht früher nit Rotatorien gearbeitet habe, werde ich möglichst vicle von meinen Zeichnungsskizzen lier mittheilen. Dieselben sind zum grössten Theile mit Camera ausgefülıt. Irh habe für die meisten Figuren dieselbe Vergrösserung (ungefähr 250) benutzt, so dass sie sich direkt vergleichen lassen. 
Bei der systematischen Anordnung der Rotiferen folge ich meistentheils der Anfstrllung Hunsoxs ${ }^{1}$ ) in seiner schönen zusammen mit Gosse lierausgegebenen Arbeit. Wohl glaube ich, dass manche bedeutende Veränderungen dabei vorgenommen werden müssen, aber meine bisherigen Studien berechtigen mich nicht in diesem Falle als Reformator anfzutreten, und es gibt keine andere Arbeit, die so vollständig ist wie die eben genannte, welehe jelenfalls einen grossen Fortschritt hezeichnet.

\section{A. Ordnung Rhizota.}

\section{a. Fam. Flosculariaceæ.}

\section{Gattung Floscularia Oken.}

Ich habe kaum eine grönländische Wasseransammlung untersuclit ohme auf Reprisentanten dieser Gattung zu stossen. Sie kamen in den Seen gleich wohl, wie in den Teichen und kleinen Pfützen vor. Wie viele Arten in Grönland vorkommen, scheint mir etwas zweifelhaft, um so mehr als die Bestimmung mancher dieser Arten überhaupt wohl etwas unsieher ist.

Flosculuriu sp. steht schon in Levinsen's Verzeichniss.

1. Fl. ormata Ehrbg.

('erearia n. sp. O. F. Müller Naturforseher 1776. s. 409.

Fl. ornata Ehrbg. ${ }^{2}$ ) 1. c. s. 408 , Taf. XLVI, Fig. II.

$" \quad, \quad$ Bartsch, ${ }^{3}$ ) 1. c. s. 24 \& 25.

$" \quad$ "Hudson, 1. e. Vol. I, s. 50, Pl. I, Fig. 9.

1) The Rotifera or Wheel Animalcules by C. T. Hudson assisted by P. H. Gosse in two volumes. London 1886. Supplement 1889.

$\left.{ }^{2}\right)$ Eurznberd, C. G., Die Infusionsthierchen als vollkommene Organismen. Leipzig 1838.

$\left.{ }^{3}\right)$ Bartsin, S., Die läderthiere und ihre bei T'ühingen beohachteten Arten. Inaug. diss. Stuttgart 1870 . 
2. Fl. cornuta Dobie.

Fl. appendiculata Leyelig ${ }^{1}$ ) 1. c. s. 3, Taf. I. Fig. 6.

\begin{tabular}{|c|c|c|}
\hline & $"$ & Bartsch l. c. s. 24 \& 25. \\
\hline & " & $\begin{array}{l}\text { Eekstein l. c. s. 344, Taf. XXIII, Fig. 1-4. } \\
\text { Blochmann 1. c. s. 112, Fig. 223. }\end{array}$ \\
\hline
\end{tabular}

Fl. eornuta Iluckon 1. c. Vol. I. s. 51, Pl. I, Fig. 7.

3. Fl. campamulatu Dobie.

Fl. proboscidea Ehrbe. 1. c. s. 40s, Taf. XLV'T, Fig. I.

Fl. proboscidea (renacher ${ }^{2}$ ) 1. c. s. 4.83.

Fl. campannlata Eckistein 1. с. s. 3 4.

\begin{tabular}{|c|c|c|}
\hline & $"$ & Blochmann l. c. s. 119. \\
\hline & $"$ & $\begin{array}{l}\text { Hulson 1. c. Tol. I. s. 52, Pl. I, Fig. } 1 . \\
\text { Weber }{ }^{3} \text { l. e. 9. Pl. XXVI, Fig. 1.- 3 }\end{array}$ \\
\hline
\end{tabular}

leh kamn nieht sicher sagen, welehe von theses drei Arten die allgemminste ist, oder ols sie alle gleich olt auftreten, dem ich hatte selten \%oit genauere leobachtumgen anzustellen.

Die Floseulariaarten sieht man ja meistentheils in eingezogenem Zustande, und es geht oft recht lange \%oit bis sie sich ausstrpeken, so dass man guto lioolachtungen machen kann. Dewhalh kounte ich nur selten Keit auf die beobachtumg dep Versehiedenheit dieser Formen verwenden. Ieh ghanbe jedoch, dass F7. rompumulata die gemeinste war und dass F7. cormuta seltener gesehen wurle.

Während der ganzen \%eit meines Aufenthaltes in Grönland sah ich Eier in den Crallerthülsen dieser Formen. Im spätsommor sah ich öfter mehrere Eier in der Jü̈se, wogegen ich in den Jüiken der bis. Mitte Juli geselıenen Exemplare fast immer nur ein rinziges beobaclitete.

1) Lerpu, F., Ïber den Ban der Räderthiere. Zeitschr. f. w. Zool. Bd. VI, 1855, s. 1-120. 1eh führe unter den Artennamen gewöhnlich nur IHudsons \& Ehrenbergs Synonymen an sowie die Namen, welche die Arten in den oben angegebenen Arbeiten tragen, welehe ich bei dem Studium der lebenden Thiere in Grönland benntzen konnte. Von anderen spüter benutzten Arbeiten werde ich gewöhnlich nur die sehr wichtigen anführen, wenn nicht ein besonderer frund vorliegt.

$\left.{ }^{2}\right)$ (irficiner, H. Einige Beobachtungen ïber Räderthiere. Zeitsclır. f. w. Zool. Bd. XIX 1869 , s. $483-497$.

$\left.{ }^{3}\right)$ E. F. Werer. Notes sur quelques Rotateurs des Environs de fienève. Archives de Biologie, Vol. XIII. Liége 1888. lch citire den Separatabdruck.

Lunds Univ. Ärsskr. Tom. XxviII. 


\section{Fl. corometta Cubitt?}

Fl. coronetta Itudkon 1. c. Vol. I, s. 49, Pl. I, Fig. 5, II Fig. 2.

Einmal habe ich bei Jakobshavn eine Flos'ularia gesehen, die mir länger aungezogene Zipfel zu besitzen schien als Fl. cormuta und ormata, und die ich deshalb unter dem obigen Namen anfïhre. Weil indessen die anderen beiden Arten in dieser Beziehung ziemlich grosse Variation zeigten und ich keine Maasse genommen habe, setze ich das Fragezeichen dabei.

Aneh will ich hier eine Bemerkung über eine eigenthümliche Form machen, welehe ich nur einmal sah, und die mir verloren ging, ehe ich die Organisation derselben genïgend studirt hatte. Sie wurde in derselben Wasseransammlung, wie die vorige gefunden und gehört offenbar zu dieser Ordmung und wahrscheinlich anch zu der Familie Flosculariadx. Ich habe das Thier nur von oben gesehen. Bei meinem Versuch eine Profilansicht zu bekommen zog das Thier sich sehr stark zusammen und konnte nicht weiter beobachtet werden.

Auf 4 rundlichen Lappen sassen starke sich nicht bewegende Cilien, und etwas weiter nach innen stand ein ovaler Kranz von etwas sehwächeren auch unbeweglichen Cilien. Diese Rotifere besass eine gewisse Ähnlichkeit mit derjenigen Form, welehe Hudson Floscularia Hoodii genannt hat, l. e. Vol. I, s. 55, Pl. II, Fig. 5. Das Räderorgan ist wirklich sehr ähnlich. Dagegen habe ich nichts gesehen, das den zwei mäehtigen tasterähnlichen Organen bei der angeführten Art entsprechen kömnte. Auch finde ich bei Fl. Hoorlii kcinen inneren Cilienkranz. Wahrscheinlich liegt hier eine mit Flosenlaria rerwandte neue Gattung vor. Für die Aufstellung einer solehen reichen indessen meine Beobachtungen gar nicht aus, weshalb ich mur diese Form anderen Beobachtern empfehlen kamm.

\section{b. Fam. Melicertadæ.}

\section{Melicerta Ehrbg.}

5. M. Tubirolaria Hudson.

Tubicolaria Naias Ehrbg. 1. c. s. 399, Taf. XLV, Fig. I.

Tubicolaria Naias Leydig l. c. s. 14, Taf. I, Fig. 7.

Tubicolaria Naias Blochmann l. c. s. 111, Taf. V'II, Fig. 220.

Nelicerta Tubicolaria Hudson I. c. s. 72, Pl. V, Fig. 3. 
Von diesem, nach der Literatur zu urtheilen schr seltenen Räderthier fand ieh d. 22 August einige Exemplare in dem kleineren von den beiden Teichen nahe an dem Wohnhause des "Kolomicbestyrers" in Jakobshavn.

Die Länge des ausgestreckten Thieres war 625 Mik. Bei diesem wohl recht jungen Thiere war die Gallerthïlse noch ganz hell und durehseheinend. Ieh konnte auch zwei kleine schwer sichthare Pigmentflecken ganz sieher heohachten. Weil die Gallerthïlse so hell war, musste man aus den sehwïrzlichen Körnem, welehe zu geringer. Zahl in derselben eingebettet waren, auf die Existenz lerselben sehliessen. Dic Hülse war entschieden nieht quergeringelt. Ich finde meine Zeiehnung und meine Notizen über das Räderorgan genau mit IIudsons Schilderung dieses Organs stimmend.

Sehr deutlich komnte ich fünf Wimpertrichter sehen. Die zwei lagen vor den 'Tastern, und die drei anderen gleich hinter denselben. Die Nervenstrüinge, welelı zu den langen Tastern zichen, sicht man ungewöhnlielı klar, und eben an der Stelle, wo diese Stränge die Taster prreiehrn, liegt anch ein Wimpertrichter. Bei gewissen Lagen des Thieres kommt es deshalb vor, als läge ein Trichter im Basalstücke dess. Tasters. Eine contractile Blase konnte ich ebensowenig wie LEYDIG und IIunson bemerken.

Ich habe hier den Namen gebrancht unter welehen Hunson vorliegendes Rüılerthier anfülnt. Es scheint mir jedoch fraglich, ob nicht EnRExberas Gattung Tubicoluviu aufrecht gehalten werden darf. Mag auch der Bau der Thicre sehr älnnlich sein, so sind doch die IIïlsen sehr verschieden. Wenn man bei anderen Rotiferen so grosses Gewicht darauf legt, ob die Hant gepanzert ist oder nieht, scheint es mir kaum bedentungsloser, wie das vom Thire selbst gebaute Haus gemacht ist.

Die anderen Melicertu-arten zcigen ja alle eine charakteristisehe Bauweise, welehe wohl bei Melicerta Janus etwas abweichend ist, aber democh ein Melicerta-Ilaus ist. Auch scheinen mir die Beschaffenheit der Hülsen bei ('plutlosiphon und Limnias für die systematische Bedeutung dieses Verhältnisses ein Zengniss abzulegen. Weil ich jerloch nicht längere Zeit diese Formen studiert habe, will ich keine neue Änderung vornehnen, nur mit diesen Worten daranf hinweisen, dass unter diesen Thieren die Beschattenheit der llülse reeht berleutungsvoll zu sein scheint.

Webers Art Limnias granulasus zeigt auch in oberen Theil der 1lülse einige solehe Körner, wie sie sonst nur den Melicertaröhren eigenthümlich 
sind, und katnn also grewissermaassen für Ilvnsoss Benennung unserer Form spreehen $\left.{ }^{1}\right)$.

\section{Conochilus Ehrbg.}

6. C. Volevex Ehrbg.

C. Volvox Ehrbg. 1. e. s. 393, Taf. XLIII, Fig. VIII.

$" \quad " \quad\left(C_{n}{ }^{2}\right.$ ) l. e. s. 197, Taf. XX, XXI, Figg. 1-20.

$" \quad$ Eekstein 1. e. s. 351.

" " Blochmann l. c. s. 111, Fig. 218.

$" \quad$ " $\quad$ Plate $^{3}$ ) 1. e. s. 9-13, Taf. I, Fig. 1 и. ¿.

" "Hudson l. e. Vol. I, s. 89, Pl. VIII, Fig. 3.

C. Volvox? de Gueme \& Richard l. c. s. 639.

Diese luïbsche Form wurde d. 14 Aug. in dem grösseren Binnensee der Egedesminde-Insel gefunden. Sowohl einzelne jüngere Individuen wie ganze Colonien fanden sich dort. Lir Farbe der Thiere war schwach gelblich. Das Augenpigment war schwarz, wie es anch Innor ${ }^{4}$ ) für die ron ihm im Zugersee gefundenen Individuen dieser Art angibt. An anderen Stellen scheinen dic Augen đieser Thiere gewöhnlich rothes Pigment zu besitzen, wie es anch sowohl Ehrenberg wie Hudson schildern.

Hudson äussert einigen Zweifel, ob nicht die Organisation von Connchilus von dem Banplan der Familie Melicertude so viel abweicht, dass eine besondere neue Fanilie für diese Gattung zu bilden sei. Hunson lässt indessen die Gattung in dieser Familie verbleiben. Mir seheint es absolut nothwendig für diese Gattung eine neue Familie aufanstellen, wemn man überhampt die Molicertadx als besondere Familie von der Floseulariadie tremnen will.

1) WeBEr, 1. c. s. 13 , Taf. XXVII, Fig. $1-4$.

$\left.{ }^{2}\right)$ Conv F., Bemerkungen über Lïderthiere IIl. Zeitschr. f. wiss. Zool. Bd. Xll 18ti3, 8. $197-217$.

3) PLıte, L., Beiträge zur Naturgeschichte der Rotatorien. Jen. Zeitschr. f. Naturw. Bd. XIX 1886.

4) Ixnor, O., Studien zur Keuntuiss der pelagischen Fauna der Schweizerseen. Zool. Anzeiger 1883, s. 469. 


\section{B. Ordnung Bdelloida.}

\section{c. Fam. Philodinadæ.}

IV. Philodina Ehrbg.

7. I\%. erythrophthatma Ehrbg.

lh. erythophthalma Ehrbg. 1. e. s. 499, Tat. LVI, Fig. IV.

Blochmann l. e. s. 105.

Bartsch 1, c. s. 46 .

8. Th. roseola Ehrbg.

Ph, roseola Ehrbg. 1. e. s. 499, Taf. LXI, Fig. I.

Zwej Formen, die nit diesen Arten gut stimmen, wurden laum und wann bri Egedesminde und Jakobshavm beobachtet. Eigontlich häufig kaunen sie niemals vor. Bei Ritenbenk sils ieh im Anlang september nur rinige seltene Exemplare von $T \%$. exythrophthalmu.

Bej Jakobshaven waren sie seltener als $1 \%$. aculeuta, nul bej Euredesminule wurden sie nieht so oft gesehen wie $T \%$. tulurvenlutu. Fast immer salh ieh dats Angenpigment gelbröthlich, nicht so tief dunkelsoth wie bei den Rotifer-arten.

\section{Ph. aculecata Ehrbg.}

Ph. aruleata Elıbg. s. 501, Taf. LXI, Fig. IX.

$" \quad$ Eekstein 1. e. s. 352, Fig. 15.

$" \quad$ Blochmann 1. c. s. 105.

$" \quad$ Hudson 1. e. Vol. I, s. 101, Pl. IX, Fig. 5.

Wie oben angeführt wirde, luatte sehon Levissen diese Art bei Jakobshavn gexelen. Anch mir kam sie bei meinem Anfenthalt in dieser Kolonie olt vor Augen. Bei Egerlesminde habe ieh demmoch auch I\%. aculcatu gesehen. Sie kam nicht in den Teiehen und Wasserpliitzen vor, aus denen ich daselbst die mejsten anderen Räderthiere holte. leh fand sie erst ziemlich spät im nommer unter den Moosen in (iner Beropfiitze, die auf einer früher ganz trockenen stelle nach einem lange dauesuden Regon entstamelen war. Einmal habe ich sie auteh auf oder in selowimmenden Rasen von Ilypumm Huitans in 
einer seichten Bucht eines Sees beobachtet. Bei Ritenbenk ${ }^{1}$ ) sah ich ebenso eine nicht geringe Zahl dieser leicht kemntlichen Art.

Die Körperform der grönländischen Exemplare stimmte besser mit Hudsons als mit Ecksteins Abbildung. Dagegen sah ich gewöhnlich die Riickenstachel ziemlich schmal, wie der letztere sie zeichnet. Sowohl an grönlänlisehen wie an hier in Lund unterstehten Individuen habe ich eine ziemlieh geringe Zahl solcher Haken gesehen. Die Farbe des Augenpigments habe ich bei dieser Art öfter dunkelroth gesehen als bei den vorigen.

\section{Pl. tuberculata Gosse. Fig. 1, 2, 3.}

Ph. tuberculata Gosse Hudson 1. c. Vol. I, s. 102.

In dem 1886 ausgegebenen Theile seiner Arbeit führt IIunson eine Art unter diesem Namen an. In dem 1889 gedruckten Supplement findet sich dagegen s. 102 eine P\%. macrostylu Ehrbg, von der Hudson sagt: "Ehrenbrorgs specific eharacters are "Body white smonth; eyes oblong; spurs very long", But I have no doubt that this Rotifer is Mr Gosse's P. tuberculata the specific character of which I now give to. it". Demnach wiirde der Namen $P$ h. tuberculata als Synonyme stehen, und der riehtige Namen des Thieres wäle P\%. macrostyla Ehrbg. 1. c. s.

Im Supplement Taf. XXXII Fig. (j theilt Hunson eine von Gosse gezeichnete Abbildung des Thieres mit. Nach einer Ammerkung IIUdsos's anf der siebenten Seite sagt Gosse selbst in einer ron seinen letzten Notizen " $I$ '. tubereulata has no tubereles".

Wenn ich dennoch Gosse's Namen bis auf weiteres behalte, so gesshicht es, weil ich erstens nicht ganz sicher auf dic volle lberemstimmung meiner Form mit der Ehrenberysehen Art bin, und weil ich zweitens auch nicht überzeugt bin, dass die Angaben im Supplement richtiger sind als die früher gelieferten.

1) Weil jch so wenige Arten für Ritenbenk angeben kann, muss ich ausdrücklich noch einmal erimern, dass ich nur kurze Zeit da war und unter sehr ungünstigen Verhältnissen arbeit'n musste. Meine mikroskopischen Arbeiten mussten anf dem Schiffe, wo das licht nicht gerade gut war, vorgenommen werden. Noch viel weniger als für Jakobshavn und Egedesminde kömnen deshalb meine Notizen über bei Ritenbenk auftretende Räderthiere auf Vollstandigkeit Anspruch machen. Übrigens haben meine Notizen von Ritenbenk insofern ein hesonderes lnteresse, als das Thierleben wegen der Kälte bald für das Jahr vollständig scluwinden sollte. 
Dic Form, welehe jch untw den obigen Namen vorführe, war in mehreren Wasseransammlungen hesonders bei Egedesminde recht hänfig. Dic Thiere waren eben so gross oder noch grösser als $T h$. aculerta. Die Augen waren auffallend gross. Die IIaut des Körpers ist braungelb sehr raub und kïrnig: Die Tuebenheiten zeigten sich mehr oder minder deutlich in viereckigen Figuren angeordnet. Der Fuss zeigte an vorletzten filiede zwei sehr lange etwas gebogene Sporne Fig. I und endete mit zwei grossen Zehen, neben welehen zwei kleinere Nubenzehen deutlich sichtbar waren. Der vor den Angen stehende Taster ist ungewöhnlich dentlich dreigliedrig, und das äusserste Glied trug drei blattrörmige Lohen, die fast blüthenäbnlich zusammengestel]t waren, Fig. 2. Die Kiefer zeigten ausser den kleineren Zähnen 3 grrosser an joder Seite. Wie man sicht, bietet diese Form grosse Übereinstimmung mit Gossess 1. tuberculate dar. Nur scheinen die Sporne noch länges zu sein und auch die Zehen weichen etwas zu viel von Gosse's Abbikhungen ab. Lejder finde ich in meinen Anfzeichnumgen keine Notizen werler über die Zah] der Fussghlieder noch über den näheren Ban des Rüssels. Jeh glaube jerloch ammelımen zu mïssen, dass diese bejelen Formen zu derselben Art gehören und will nicht anf meine unvollständigen Notizen eine neue Art griunden. Gexwiss sah iuh nicht die braune Bekleidung oder Hölle unter ganz dersolben Form, wie Gosse sie gesehen hat. Ich sah mu rauhe Körner aber keine solebe Massen von spitzen Auswächsen, wie seine Abbildang darstellt.

Nach dem was ich von dieser Form gesehen habe, seheint es mir nicht wahrseheinlieh, dass sie sich ihren rauhen Hautheklojdung nach Belicben entkleiden kann. Eine solehe Abstreifung sah ich nie, obgleieh ich die Thiere recht oft und auch in reinem klarem Wasser gefunden und beohachtot habe. Kamn Gosse's 1\%. macrostyla sich wirklich von ihrer Bekleidung dureh eine Schlcimauflösumg befreien, so möchte ich wohl glauben, dass die grönlïndisehe Art verschieden und dureh cine eigenthïmlich rauhe Ilant ausgezoichnet sei.

Die Abbildung Fig. 3 zeigt die Form welehe das zusammengezogene Thiou' gewöhnlich zeigte. Ieh glaube nämlich gefunden zu haben, dass diesen Zuständen werthwolle systematische Merkmale entnommen werten können. I)ie drei zu dieser Art gehörenden Abbildungen sind etwas schematisirt. 


\section{Ph. hexodonta n. sp.}

Von dieser Form habe ich nur eine besehränkte Individuenzahl untersucht und auch keine Zeichmmg gemacht. Nichts destoweniger seheinen mir meine Notizen die Aufstellung einer neuen Art ganz unumginglich zu maehen. Der nicht gerale grosse Körper ähnelt demjenigen der Ph. roseola, ist aber nicht röthlich. Die Augen waren eher klein als gross, und stark violettroth. Dir Kiefer trugen of stürliere Zïhne, die deutlich hervortraten. Der Fuss liesass am rorletzten Gliede zure liurze, am Basultheile sturk angeseluwollene Sporme. Die Haut des Mittelkörpers hatte viele und dichtstehende Längsfalten. Die Länge eines gemessenen ausgestreckten Thieres war 400 Mik.

Dieses Thier wurde in Ende Angust unter den Moosen eines kleineren sogenannten Sees nahe dor Kolonic Jakohsharn gefunden. Dis Zahl der Zähue macht es ummöghich diese Art mit irgend einer bisher besehriebenen mir brkannten zu vereinigen. Alle in der mir zugängigen Literatur behaudelten Philodinaarten haben 2 oder höchstens 3 Zähne. Hurlson gibt auch in seiner Beschreibung der Gattung an, dass die Zähne zwei oder drei sind. Ieh kann es aber nicht zweifelhaft finclen, dass meine Form zur Gattung Philodina gehört. Die Lage der kleinen aber stark gefärbten Augen war die für Philodina charakteristische. Die von Gosse heschriebene $P$ h. microps ${ }^{1}$ ) besitzt in der Kürpelform eine gewisse Ähnlichkeit mit dieser Art. Sie hat aber bleichrothe Angen. Ton den Zïhmen wird niehts angegeben. Gusse wïrde auch gewiss nicht die eigenthümliche Sporne merwähnt gelassen haben. Ton den Spornen sagt er nur: "spur's rather small, separated by a horizontal elge", was von meiner Art nieht gesagt werden kann. Gewisis waren sie kurz, aber die angeschwollenen Basaltheile lieferten keinen Platz fïr "a horizontal edge". Ich machte meine Aufzeichnung ohne Ahnung davon, dass meine Notizen später die Aufstelhmg einer neuen Art veranlassen wïrden. Meine eben in den Tagen stark heanspruehte Zeit machte es mir unmöglich vou allen gesehenen Formen vollständige Notizen aufzuschreiben. Die meisten Male hat es sich gezeigt, dass ich mit kurzen Notizen früher gut bekamnte Arten abgefertigt habe. Dirsmal habe ich leirler auch einer eigenthümlicheren Form nur wenige Worte geopfert.

1) Gosse, P. II., Twenty-four more new species of Rotifera, Journ. of lioy Micr. Soc. London 1883 s. 801. 
Irox die bihdung des Fusses dieser Gattumg seheinen dis Verfasser ver-

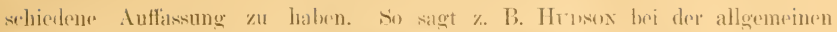
Sehildermeng der Gattung I'hiludime: "the theres soft toes, rendered sticky by a

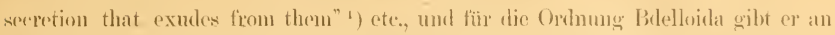
"an foot ... ending almost invariably in three toes" ${ }^{2}$ ). In einer diesell Worten hejgefïgten Inmerkung heisst es "Ill the known British species have three toes". Ecksterx liefirt dagegen vom Fusse der I\%. aculeatu die folgende Ingabe ${ }^{3}$ ). Jer Fuss . . endigt mit vier śpitzen, ron denen zwrid schwäeher simb als die andren mol immer fither dingerogen werden als die stärkeren”.

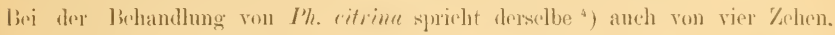
die ansgestreckt werden kömnen. Über 1\%. merrostyla sedureibt sogar Hndson sclbst später ${ }^{3}$ ): The last joint of the foot divicles into two equal branehes, anch carying a pair of mexpal toes; the onter of which is the larger of the

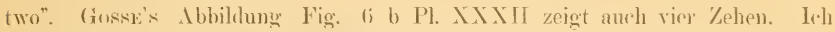
babe deu bau des Fusses bei meiner I'h. tuberenlata Goswe? (Ph. macrostyla Ehrby:) so gesehen, wie die etwas sehematisirte Fig. I es darstellt. Man kam da ron zwei oder von vier Zelen sprechen. Von drej kann aber hier, so viel irh verstehe, keine Rede sein. In ähnlieher Weise schrint mir aurle der Bau

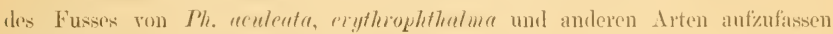
z.11 soin.

I) as obenstehende hatte ixh im vorigen IIerbst (1890(1) gescliricben. I hamals war mir noch nicht Webers Arbeit zugingig; in weleher irh jetzt folgende Bemerkmng finde: "Gosse et IIudson, dans leur ouvrage sur les Rotifiress anglais, prétendent que toutrs les Philodines ont trois doigts a l'extrimite ilu pied; il n'en est pas ainsi: les Philodina proprement dites ont toutes quatre doigts, les liotifer trojs. Aetimurus trois, (allidina trois". - Treber I. ؛. s. 69 .

1. c. Fol. 1 \&. 98 .

2 1. c. Vol. I s. 45.

3) 1. c. ‥ 352 .

4) 1. e. s. 353.

- 1. c. Supplement - 7 .

Luml- Truiv. Arsokr. Tum, XxүII. 


\section{Rotifer (Schrank) Ehrbg.}

\section{R. rulyaris (Schrank) Ehrig:.}

Torticolla Rotatoria (). F. Niiller $\left.{ }^{1}\right)$ J. e. s. 256, Tab. XLII, Fig. 14, 15. Rotifor rulgaris Ehrbe. 1. c. s. 484, Taf. LX, Fig. IV.

$\begin{array}{lll}" & \text { Eckstein 1. c. s. 35., Taf. XYIII, Fig. 6-12. } \\ . & \text { Rlochmann 1. c. s. 105. } \\ ., & \text { " Hudson 1. c. Vol. I, s. 104, Pl. X. Fig. 2. }\end{array}$

Dicse wohl fast übrall allgemeine Art, wmrle auch in viclen Wasseransammlungen Giönlands grefunden. Indessen sals ioh dieselbe weeler im Frein noch in den son mir hereingeholten Wasserproben, die nicht selten recht lange stehen blieben, in solehen Massen wie es dic Litriatur so oft anfïhrt, und wio:

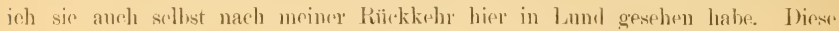
Massen traten aber anch hier nicht im Frejen auf sondern in Gofüissen, welchw

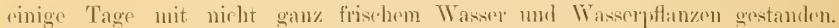
Dass bej dieser späten Jahreszeit die Rotiferatun nirht dransion massenulaft auftraten, kamn wohl kaum auffallemt sein.

In Grönland wurden die Rotiferarten in der ersten Hälfte des sommers nicht sehr oft geschen. In dieser \%eit sah ich vicl öfter ander Philodinaden. So beobachteto ieh im Anfange des Juli nur veremzelte Exemplaren der Rotiferarten. Im August wuden sie riel gewöhnlicher und lwi Jakohshavn habe inh sie sehr gemein genannt.

Nicht selten habe ieh Individuen heobachter, deren Augen aufgelöst waren. Den 6:ten Angust sah ich bei Kgedesminde in riner Probe fast abenso viele Indiviluen mit anfgelisten l'igmentflecken wie solehe mit normaler Augenhildung. Fig. \& zeigt pin solches Thier. Bei rinem anderen waren die hinteren kleineren Pigmentflecken beilerseits gleich weit rom vorleren entfernt. Bei noch einem anderen waren dir Iugen in mehrere kleine Flecken aufgelöst, fast wie IIndsous Fig. 1 a Pl. I es für Restifer tardus zeigt. Ieh habe aneh diese Form als $R$. rulyaris gedeutet und moine Notiz'n geben keinen

1. (1ти Frmerkers Müluer, Animalcula Infusoria Fluviatilia et Marina ete. opus Postlummm . . C. Cura Othonis Fabricii. Havniw 1786. Ich hahe diese Arbeit des berühmten dïnischen Furschers citint weil sis grundlegend war, md weil seine Arbeiten bisher die ein-

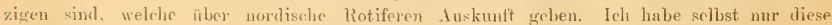
Arbcit benutat ben "Naturforsher" citire ich ant einigen Stellen nach knarberes. 


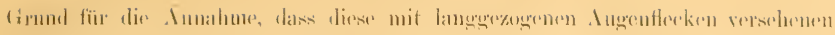
Formen rine andere dit vorstellton.

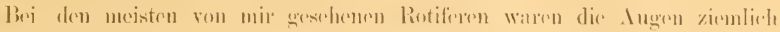
klein, rundlich. Aneh bei drujenigen, welehe moluere Pigmentflecken besissen,

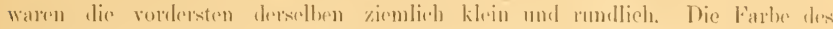

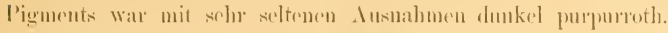

\section{1.). R. murvmins (s.hrauk) Ehrlog:}

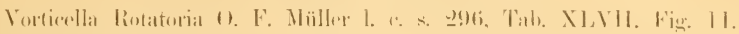

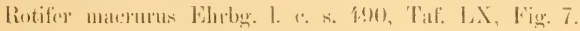

Eckistein 1. (2.s. :3.it.

Blochmann I. (… 10.5.

Hudson l. e. Yol. I, s. I07, PI. X, Fig. 4.

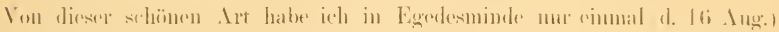

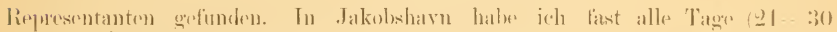

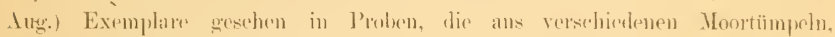
Teichen usul kleineron sinen goholt waren, und anch in litenbenk wurden im

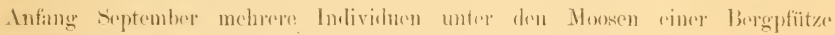
notirt.

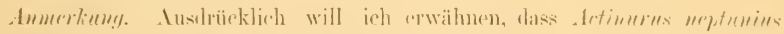
niemals in firounland von mir gesehen worde. Hier in Lamel kommt derselhe

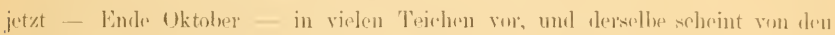

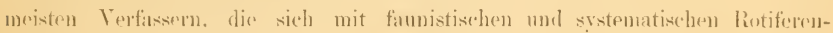

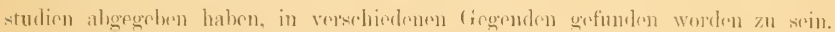

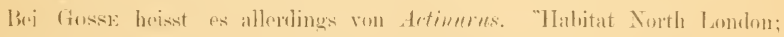
Leanington; ('oversham: rather rare" 1). Irh finde ibn aber bej vielen anderen Virfixisell notirt.

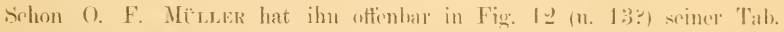

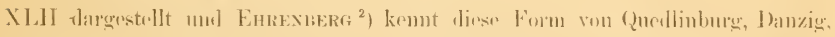

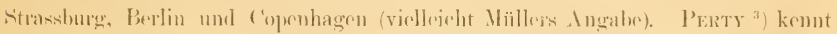

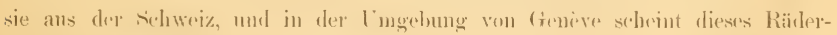

1) Honsex 1. c. Vul. I. s. 108.

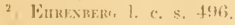

Pratr: M. \%ur Kenntniss kleinster Lebensformen. Bern 1852, \&. 44. 
thier anch von Welsel: beobachtet worden zu sein. B.ARTsen ') hat Artimum in der Umgebung von Tübingen gefumlen, Tи́ти rechnet ihn unter den 22:3 Rotatorien, welche (ar in der Umgebung von Pest-Ofen beobachtert hat, auf ${ }^{2}$ ). Bei Petersburg ist diese Form von WeIsse gesehen "). In Eуғектн's Arbeit kann man nicht dentlich sehen, welche Arten er selbst untersucht hat, und welche er nach der Literatur anführt. Von Actimurus sagt er: "In Aufgüssen mit Wasser selten auftretemd, zuweilen aber zahlreich". In der Ungegend von Rostock ist er von Tessin-B̈̈tzow beobachtet werden "). mad Barrois sagt ron dem Antreten dieser Art auf den Azoren ${ }^{5}$ ). "Assez commun dans certains mares telles que le Charyuinho da Calçada, par exemple et dams le petit Lagoa do Peixe". Schon früher war er auf derselben Inseggruppe von J. DE: (fuerxe bei Ponta-Delgada gefumlen ${ }^{7}$ ). Plate nemnt ihn wohl nit wollem Recht nebst Rotifer als eines von den gemeinen Räderthieren. Aus Australien und Indien ist diese Gattumg auch bekannt ${ }^{\circ}$ ).

Hier in Lund war bei dieser Zeit die Temperatur des Wansers ungefähr dieselbe wie während des Hochsommers in den meisten grönlandischen Wasscransammlungen. Es ist nicht möglich, dass ieh diese so charakteristische Art übersehe'n habe, und deshalh finde ich diese Thatsache ganz merkwïrdig, demn hier in Lund kommt diese Ait eben mit Ph. aculeutu, Rotifer marrums und cnlyuris zusammen vor. Diese wurden ja alle in sehr vielen (iewässern Grönlands gesehen. Nach meinen über eine recht grosse Landstrecke reichenden Frfahrumgen ist deshalb das Fehlen dieser Form in (trönland eine Eigenthiumlichkrit, auf die jeh hesonders hinweisen wollte. Möghicherweise liegt darin

1) ВАктsсн 1. с. s. 49 .

${ }^{2}$ Тотн, A. Rotatorien ma l)aphien der [mgebung von I'est-ofen. Verh. der k. k. zool. but. (iesellsch. zu Wien X1, 184i1, s. 183, 184.

"Wriss. J. F., Yerzeichniss von 155 in St. Petersburg heobachteten Infusorienarten

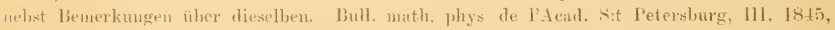
$\therefore 19-26$.

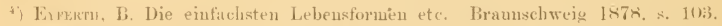

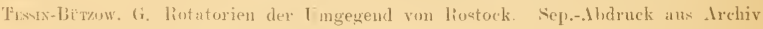
43 il. Fr. d Naturg. i Mecklenb., s. 139

6) Barrors, Tr. Materianx pour servir ì l'étude de la Faume des eaux donces des leores. Lille $1888,8,1$.

7) DE (rTwne, J. Excursious zoologiques dans les iles de Fayal et de Sau-Miguel (Agores) Paris 1888, angefüht nach liarrois.

8) lie hetroftenden Arbeiten werten im Shlusse the Abhandlung etwas niher berührt mul da werden auch dic Titel angegehen. 


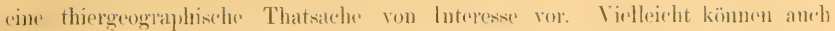

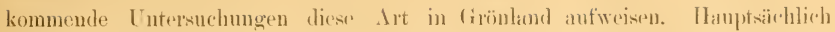
um die kommenden Lntersucher zu veranlassen nach dretinurus zu surben habe ich sehon hier diese bemerkung gemacht.

\section{Callidina Ehrog.}

Von diesser frattung wurden in fiönland nieht weniger als vier oder vielleicht fünf Arten notirt. Wrurden die nächsten Verwandten_diesier F'ormen im späitsommer ind Herbste gemeiner, so waren die Callidinen ganz im Gegrntheril in der ersten Hälfte des sommers gewöhnlieher und wurlen im Ilerbste nur ganz vereinzolt muter den dam im grösscrer Kahl anftretenden Philodinen and Rotiferarten angetroffen. Ich heohachtete Repräsentanten dioxer Irten im

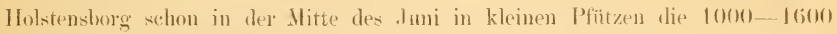
Fuss herch gelegen waren, und in denen bei dieser \%eit ansserdem mm eimge wenige Ijatomareen mol Desmidien das Leben fristeten. Leicler komnte joh eben in dieser. \%oit ") nicht in Rule arbeiten, weshalb anch meme Notizen über die Arten der (rattung C'allieliun selne mangelhaft sind.

\section{4. (: eleyars Ehrog.}

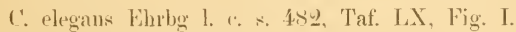

" $"$ Blochmamn 1. e.

$"$ Huikous 1. (. Vol. I, s. 10!.

Wurke in Holskemshorg, Egedesminele und Jakobshavo beobachtert.

\section{C'ullidime leris n. sp).}

Jie so genamnte lit bietet in mehreren Hinsirhten grossere Öhnlichkeit mit C: birlens (rosses (l. c. s. I0!), P’l. X, Fig. s) dar, darf jedoch nicht mit

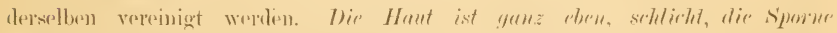

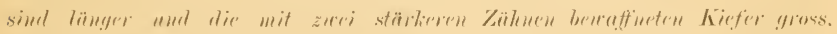
besomelers broit. Ther Nackentaster ist nicht lang, und die Zehen sind gleichfalls ziemlich kurz.

1. First nach dem 14 Juli komutu ixh ungresëtt arbeiten, und dam wurden andere Irten näher studirt als dic Callidinem. 


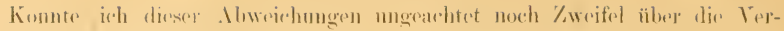

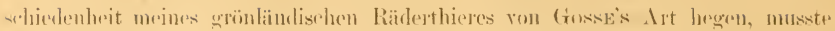
dieser gleich sohwindent, als ich bei Gosse von der Lebenswrise seines Art das folgende lax: "It is, if I may use the trom, very wild, shooting about with swiftness in an impationt mamer with a peculiar mingling of swimming and crepping . . It is much bolder than the other members of the family, -keeping its wherls in rotation all the time it is attached; and thongh a sudden jar, or the impart of another animal, will fause it to elose them it is but for an instant. I have nover soen it contract on alarm inter a short romol bull,: far lexs remain quisesent in surh a comdition for hours as fintifer and l'hilodina do". Ganz im Gegentheil zeigt vorliegente Form sich vies träger als die anderen rallidinen mol liegt oder sitzt wie es nir sehien sehr gem zusammen-

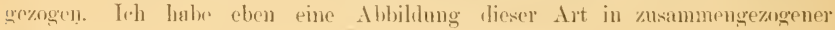
stellung skizxirt. Fig. 5.

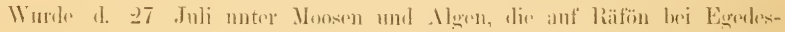
minde ringenammelt waren, gefinden.

\section{6. (!. tentaculata n. sp.}

Diese Art ist 8 : alegums sehr ähnlich. kamm aber sicher rom dersellon untersehieden werden dureh einige viel stärkere vordure Zähno. Dir /ähl drrselben kamm nicht ganz genan angegehen werklen, wen weil verschiedene Exmmplare darin eimen Werhsel zeigten. Einige waren immer von don hintrn

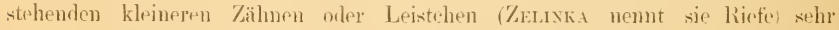
dentlieh moterschieden, aber zwischen diesan grossen Zähmen ind den Leisten standen immer rinige, welche sehwächer warrn morl les C̈lorgang vermittelten. so habe ich ron einem Thiere notirt, dass drej rordere Kalmpare sehr stark waren, die durch drei Paar etwas kleinere von den hinteren leistenfürmigen weriennt waren. Bei amleren Individnen habe ich nur dio Notiz gemasht: Tordere stärker Zahmpane dureh Überoünge mit den hinteren verbumlen.

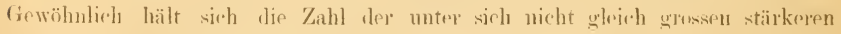

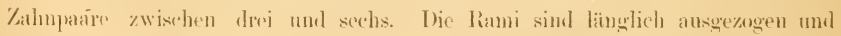
ziemlich schmal').

1) (Hbuleich ich keine Notiz darüber finde, darf ich nus der lirimerung zusetzen, dass. die stärkeren Zähne nicht inmer an den beiden Seiten gleich viele waren Bekamtlich 
Wer Kö̈per zeigte weit ans einander stehende Querfalten. Thie läingstalten stehen einander viel näher. Die Farbe des Kürpers war hell rosa, aber vor dem mastax war dis Farbe sehr schwarh. Zum Theil riihrte die stärkere Farbe des hinteren Kärpertheiles rom Jarminlalte her. Einige Exemplare, die ich derselben Iit zureclnete, hatten einen mehr gelbliehen Farbenton. I)r Körper war selor durchscloinend und hätte ich längere \%eit gehaht, wäre licse Art woh] deshalb für eingehendere studien sehr geeignut gewsesen. Iner herdentend lange Fuss hatte drei kurze \%ehen, und die sporne des vorletzten Glierles waren auch zienulich kurz.

Die Indivilnen, welche ioh zu diesel Art zähle, waren sehr lebhaft und krochen ohne liuhe auf dem Objekträger herum. Dabei zeigten sie imdesson don Fuss mogewhihnlich wenig. Nur eimen kurzen Augenbliek wurde dorselbe ausgestrerkt, wenn el gegen den nach hinten grongenen Riüssel geführt wurde. wonach der Kö̈rper fast blitzschnell nach vorn geworfen wurde. Soltenl habo ich diese Art mit hervorgestrektem Räderorgan sehwimmen sehen. -- Ïher die Form des Riiderorgans habe ich keine Notizen.

Wurde anch zum ersten Mal gegen Emle des .Juli in Moortümpeln auf Räaön beobaclitct, jerloch später anch in einigen anderen Wasscransammulumgen notirt.

Die Länge des Kärpers ohne Fuss, der nicht gemessen werden konnte. war 300 Mik. Dic Länge des dursalen Tasters wall über 30 - 40 Mik.

I $\cdot h$ hahe dieser leidor mgenügend untersuchten drt einen Namon zu geben gewagt, weil ich in der Literatur kaum Formen gefunden luale, mit denen sie verwerhselt werien këmnte. Die grosse Zahl der stärkeren Zalumbaare erimnert an (': Lritgrloii Zelinka. Nher mit derselben kann sio wegen der Grösse, der Furm der Kehen und der I,ehensweise ummöglieh identisch sein.

hat Zelinka in seiner ausgezeichneten Nomographie über Callidinu symbintira und (. Leitgrbii gezeigt. dass diese beiden Arten konstant eine verschiedene Zahl Zähne in den heiden Kieforn besitzen.

Zetrks's schöne Studien über die ('allidimen zeigen mir noch dentlicher, wie lïckenhaft meine Xotizen ehen über diese frattung sind. Aber kaum geringer als die Verschiedenheit in der Behandlungsweise dürte die Verschiedenheit in den Verhältnissen sein, unter welehen dif studien gemacht worden sind.

Zsuska, ('. Studien äher Räderthiere 1. İber die Symbiose und Inatomie von liotatorien ans dem (ienus Callidina. Arbeiten aus dem 7ool. Inst. Graz, 1 Bid. n:r 2 auch $\%$. f. w.

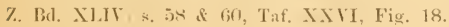


Wem irh älore die sristematische stellung der vorigen Formon cine bestimmte Ansicht haben lionnte, se ist dies mit den anderen gesselenen ('allidinem nieht der Fall.

\section{7. ( $(. s p$.}

Oft sah ich eine andere Form, die mit der nächstonigen nicht geringe Ähnlichkeit darbot, iiber die iels aber nur die Notizen finde, lass sio kleiner war und sich in ganz anderer Weise bewegte.

Ammerknny. Mäglieherweise sah ich dazı noch eine fünfte Art, demn

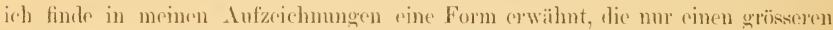
\%ahn anfzeigte. Ith hatte beabsichtigt diese Form später zu mutersmehen, fimel aber keine felegenheit. Es wäre denkhar, dass diese Form eine $C$ : trutuenlutu gewesen, bei weleher der esste Zahn eine ungewöhnlich starke Entwicklmng gezeigt. Sehr warscheinlich finde ich jedoch diese Erklärung nicht.

(insse hat C. bideus empfindlich gegen Lieht gefunden '). Freilich ist dir Untersuchungsweise ctwas grob gewesen. Ton zwej frefïssen, in welehen diese Art sich befand, wurle das cine in ein Fenster, das andore in eine dunklo Ecke gestellt. Nach füuf Momaten fanden sich im letzteren viele c'allirlinen, im erstaren dagegen keine einzige. Über das Terhältniss der von mir gesehenen Irten zum Licht weiss ich natïrlich niehts, kann aber nicht umhin daranf hinzuzeigen, dass diese Irten mir während des lichtstarken Vorsomners be-

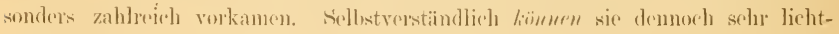
sehell srin.

\section{Ordnung Ploima.}

\section{Unterordnung Illoricata.}

Anmerliung: Ich nehme hier die ron Raвот gesammelten Asplanclina lielceticn Inhof und Triurthra longisctu blorbg auf. um alle von Grönland bekamnten Fotiferen anch in diesem systematischen Verzeichniss zu erwïhnen. Vugl. davon oben s. 13.

1. Iluckson 1. c. S. 110 . 


\section{d. Fam. Mikrocodidæ.}

\section{Mikrocodon Ehrbg.}

18. M. clarus Ehrbg.

Mikmorolon rlavus Ehrog 1. e. s. 396, Taf. XLIV, Fig. I.

frenaclep 1. e. s. 4s:3-49s.

" Blochmamn I. (. s. 102, Fig. 232.

"Hulson 1. e. Tol. I, s. 118, Taf. XI, Fig. 1.

,. Weber 1. e. s. IS-23, Taf. XXIX, Fig. 1-i.

Diese, wie es scheint, in vielen Cregenden seltene Art fand ich in lirounland zum ersten Male d. 25. Juli unter Moosen und Algen, die ron finem Montiimpel anf Raifö̈ bei Furedesminde genommen worden waren, und von demsolben Locale sah ich auch später einige Thiere. Ins $2: 3$ Aug. beobachtote ich wiedor diese Art in den schwimmenden Hypnumrasen eines kleinen tipes mabe an der Kolonie Jakobshavn, und von denselben see kamen auch dir folgenden 'Tage énige Individum auf den (Objektträger. șo viel ich weiss. ist diese form nur you linrenberg, Perty, Grenacher, C'ollins, Tóth, Gusse mul Weber gresehen worden. Gosse hatte seine Exemplare vom Misi 1) Aves erhalten. Hrosos sagt von diesem Thier: "It has, however, escaperl the notien of the majority of ohservers during the last fifty years, in some measure no doubt owing to its small size". Ich will das kaum glauben, dem.

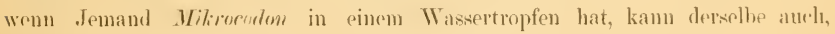
wenn die Untersuchumg hej sehwacher Tergrösserung gesshicht, kanm ïberselen werden. So charakteristiseh und auffallend ist das Benohmen dirses schönen Thieres. Am genanesten ist das Thier von Grexacher und IVEBzo stmdirt. Die Verfasser sind jedoch üher verschiedene Fragen nieht rinig. Irh hatte keine amblere Literatur als Blochmamm Diagnose mol komute deshall, nicht rinsehen, ïber welche Terhältnisse ieh besonders Buobachtungen sammelu miisite.

Die Länge eines gemessenen Thieres war 123 Mik. Dor Fuss war (it) Mik, von denen auf das erste filied 21, auf das zwpite 39 und anf das letzte (i Mik kamen. Ich glaubte an jedrm ramus mehr als tünt' /älın's schen zu können. Hensox sprieht sieh nicht über die Kahl der Zähne ans. hino

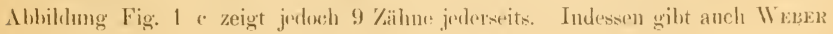
Lunik Univ. Arsskr. Tum. Xxvitt. 
wie Graxicher fünf Zähne an. Sieht man aber IVEuER's Figur :3 'al. XXIX an, welche den mastax darstellt, erhilt man, wemn ich anders diese Abbildung richtig verstehe, eine ganz andere Auffassung. Da sohe ieh am einen uneus neun und am anderen zehn Zähne. Ein Missverständniss dieser Abbildung ist kaum wahseheinlich, denn die Zähne sind mit g bezeichnet. Nach meines Erinnerung mörhte ich glauben ziemlich reife Eier gesehen zu haben, was ich hier nenne, weil Eier bei den europacischen Exemplaren hisher nicht gesehen zu sein scheinen.

C̈berhaupt nahm Mikrocodon sellsst, so schön und interessant er auch ist, nifht lange meine Autmerksamkeit in Anspruch, denn die Bestimmung war ja in diesem Falle sehr Jeicht. Erst als irh in Jakohsharn ein anderes Rärlerthier gefunden hatte, das dem Mikrocodon im Anftreten beinahe täuschend ähnlich war und sich jedoch von tlemselben in selur wichtigen Baurerhältnisson untersehied, hekam ich einen Grund mirh mit ihm zu beschäftigen Viele Zeit konnte ich dennorh nieht dem Mikrocodon selbst widmen. Lange schien es mir sehr zweifelhaft, wie diese andere form aufzufassen sei, ob uls trin monströser Nikmeodon, oder als ein Entwirklumgsistalium desselben, oder als pine neue Art und Gattung. Weil ich indessen gegen die beiden rsten Vorschläge genügende (iründe anführen kann, muss ich eine newe fattumg anfstellen, und nenne dieselbe eloen wegen der Ähnlichkeit mit Vikiocodon

\section{Mikrocodides n. $g$}

und die Art 19. M. Autrims n. sp. Figg. s, 10, 11.

Derjenige Leser, dem Mikrocodon wohlbekamt ist, und der seinen Blick aul meine Abbildung Fig. \& wirft, wirl gam\% sicher diesen /weifel eben so erstaunenswerth wie unbegründet finden, und nichts desto weniger habe ich ihn noch nicht ganz ïberwunden.

Freilich entbehrt diess Form des für Mikrorodon so dharakteristischen Fusses und zeigt cinen gewöhnlichen Rotiferen-Fuss mit zwei Zehen, und as wird gowiss nieht leicht sein einzusehen, welcher Umbildung diese Form unterliegen musste $1 \mathrm{~m}$ die andere entstehen zu lassen. Trotzdem können zwej Thiere kaum ähnlicher sein, als diese beiden es waren. Bewegungsweise, Köruerform ınd Räderorgan zeigen ungewöhnlich grosse Übereinstimmung. 


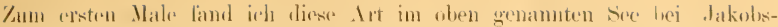
haven d. 21 dug., tand seitdem beobachtete ich noeb einige Exemplates. Den 2:) Ang. sah ieh mehrere Exemplare dersulben Form, die jedoch zum Thuil abweichend waren. Iten s. Ang. fand ich die viel kleinere Form, welehe irlı in der Fis. 7 wiedergegeloen habe. Ich neigte nämlirh dazo diese Form als ein kleineres Individum von meinem Mikrocodides aulizufinsien.

Als ieh das Mikrocodides genannte Rädorthier zum ersten Male silı, kam is mir ganz nell and sonderbar vor. Irh machte die Keichnung Fig. s und beschrieb ziemlich kurz das Iussehen des Thirres. Am folgenden Tayer kam dam Mikrocodon selbst wieder muter das Mikroskop, unt ich komnte nachlere

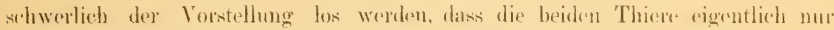
zu rinex und dersolben speries gehörtens.

loh habe von awei grösseren Thieren Abbildungen verfertigt, von denen

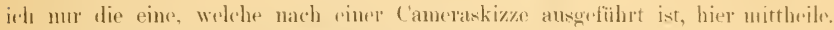
leh habe anch anderer lieschäftigungen wegen nur diese swei Thicre rinugehrender untersuchen kömmen.

1) Kö̈rjer ist kegelförmig und zeigt einen vorderen, bïheren Theil. Iher hintere 'Theil des Rärkens laillt riemlich steil vom vorderens ab, was jerlewh nach dem . Iusfïllumg-zustambe des Magens nieht so wenig werhselt. Meine

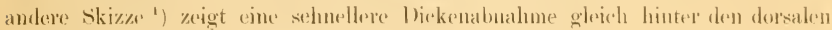
'Tasteru. Der lianch zeigt rine fast gerade Grenzlinie, die an Skizze " noeh schärfer hepourtritt. Der Fuss bildet die hintere Fortartzung des Körpers und besitzt nur ein Glied. Die Zehen sind wie sehon angefiiht zwei, von denen aber fast immer die pine grösser ist mul beinahe die gam\% llinterfläche des Fussglienles anfinimmt. Es sicht aus, als ob diese \%alle die ummitrelbare Fortsetzung des linses bildete. Die andere viel kleincre Zele steht gregen dir.

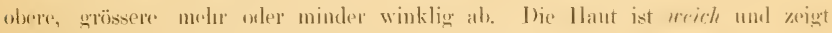

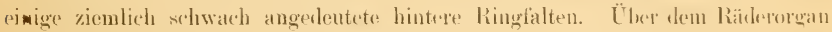
salh irh sehr oft rinen hakenförmigen Fortsatz wie es Fig. s' zeigt. Auf śkizze " ist derselbe nicht angedentet und war bei dem Thiere niclit so dentlich. Das Räderorgan sehien mir von vorn grachen rinen ringförnigen Cilienklanz

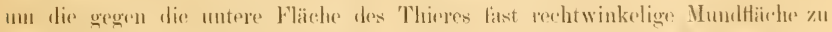
bilden. Die Fig. II steflt das ein wenig shematisirte Jussehen des Räder-

1) Weil ich mehrmals diese Skizze citiren muss, neme ich dieselbe Skizze " 
organs vous rorn gesthen dar. Bei einigen Individuen war der Ramb otwas ansgebuchtet wie es Fig. s' zeigt. Die skizze "zeigt wieler einen ganz ringförnigen Cilienkranz. Das cingulum sah ich ohne Enterbrechmo die etwas rorstebende Lippe der Vordertläche umkränzen. Oben sah jeh entschirden einen zusammenhängenden Cilienkranz, und anch unten habe ich ihn vollständigr gezeichnet. Die Cilien dieses Kreises - les cinguhum - waren recht krältig. Etwas näher dem C'entrum der ziemlich platten Vorderfläche stand der trochus. Diesel Cilienring ist nach unten unterbrochen. Die unteren schenkel des trochus konvergieren grgen das obere Ende einer faltenförmigen Einsenkmug, in deren Boden die Mundöffnmng liegt. Nach oben ist der trochus nicht ganz runi, somlem an beiden seiten lassen sich Ecken ähnliche Stellen unterscheilen. Eben da stanclen längere schmale Cilien, die sich kaum oder selten bewegten, und mïglicherweise entweder simmeshare sind orler nu bej gewissen Bewegungen benutzt werten. Dis unteren seitlichen Cilien des trochus waren viul kürzer als diese oberen in den Ecken stehenden. Zwischen den Exkencilien sab ich an ten beiten genaner untersuchten Exemplaren ganz zweifellos Cilien, die sich fast immer lebhaft bewegten. Möglicherweise ist der trochns auf meiner sehematischen Figur II etwas zu gross und zu weit vom ('intrum entfernt. Auf dieser Fignr sind einige Cilien zwischen dem cingulum um dam trochus angedeutet. Ich glaubte oft solehe swhr dentlich zu sehron, darf jedoch nicht ganz verneinen, dass dieses bild möglicherweise dureh die Bewrgungen der anderen (rilien entstehen koumte.

1)rei Taster treten recht deutlich hervor. Der dorsale bildet rine kleinr Erhebung unmittelbar vor dem Auge. J)ie lateralen Taster sitzen sejtich am Rücken ziemlich genau gleich entfernt vom Hinter- und Vorderente. [a sind ziemlich grosse Erhebungens sebr dentlich. Ebenso konnten die Tasthaare sehr leicht beobachtet werden.

Das Auge liegt ziemlich tief unter dem hinteren Theil des grossen Gehirus mol oben am mastax. lis ist stark gefärbt.

Ëber die immeren Organe kamn joh wenig sagen. Der mastax ist sehr gross mit ziemlich wohl entwickelten ob auch nicht starken Kiefern. Das auf Fig. 8 unter dem mastax sichtbare Organ war mir zweifelhaft. Wahrsebeinlich ist es ein verschobener. Theil des mastax, denn an der skizze " sehe juh nichts entsprechendes. Beim lebenlen unbeschädigten Thicre komste ich die Kiefer nicht dentlich genng sehen, Als ich das 'Thier', seitdem ieh ïber' die gröberen 


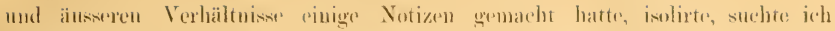

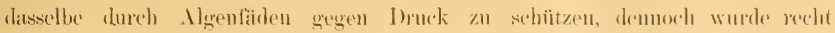
bald das Vorderende seiner Hähe wegen zordriekt, mol dabei kam der mastax dentlich hervor. Die Abbildung Fig. 7 stellt den etswas verschobenen Kiefiele

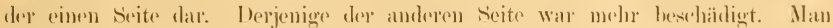
sieht ein spitzes fulerum mod am lamus mehrere Yähne, ron domen die unteren viel lïnger sind als die oheren. Nach aussen von dem ramus sah ich ein getelogenes nach vorn angeschwollenes stiiek, das jch als einen uncus deutete. Diese Abbildung, wemn anch mangelhaft (so habe ich von dem ramus mur dron

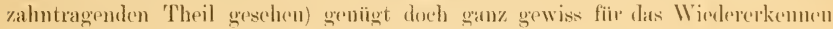

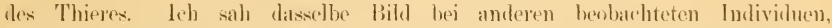
obgleich ich nicht clie fïr eine nähere Lntersuchmo nöthige \%eit spätm finden

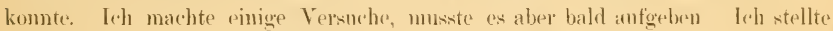
mir nämlich sehen in frönland vor, lass diese form riner genaneren Intor-

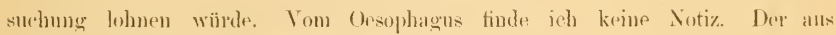

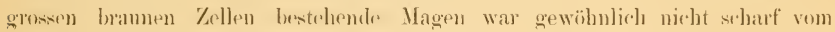

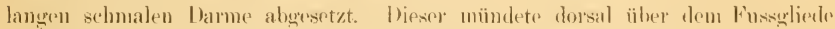
aus. Zwei weisisliche pankreatisehe brïsen lagen vor dem Magen und sehionen

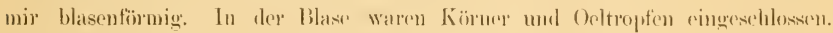
leh sah dentlieh, wie der lnhalt drs Darmkanals dureh cilienbeworgung hermmgerollt wurde.

Dif Geschlechterlibise lag unten und seitlich am Darme mul zeigte beim abgrabildeten Thiere kleinere Korne in einer dunkelgranes) (irmudmasse. Boi den anderen, anf skizze "dargestellten Thiere sah ich grosse Blasen in rines. etwas helleren körnigen Grmulmasse. leh babe beile als verseliedeno stadien des Dotterstockes aufgefaxst. Nach hinten ron diesem Organ salı ich bei einem Thiere einen schmalen Körper, der zwishen dem Darme mol der Blase lag mo sich bis zor cloake streckte. Im voreleren Ende sebien ar mir mit lev (reschlechtsdrüse zusammenzuhängeı.

the Blase war gross und in gofoüllem Zustame oval bis biruförmig. Ihr hinteres Ende bog sich narh oben un dic cloake zu erreishen. Im Texte habe ich nirhts ïber die iibrigen Theile des Exkretiomsaplarates notirt, und anch finder sich an der skizze n nichto davon angegeben. An der Fig. sieht man eine otwas ereschlängelte linire, lie sioh kanm anf was anderes bezielsen kamn. Die zwri Kitudrüsen lagen im Fusigliede und die rine 


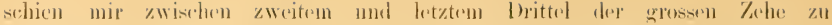
miinden.

Über die Muskulatur habe ich mur bemerkt, dass keine Muskelfascru im Fusse entdeckt werden komnten.

Soviel kamm ich iiber den Ban dieses Thieres mittherilen. IIoffontlieh werden diene Notizen erlanben wenigstens eine vorläutige Autfassung des Thieres und dessen stellumg im System der Räderthiere zu begrünrlen.

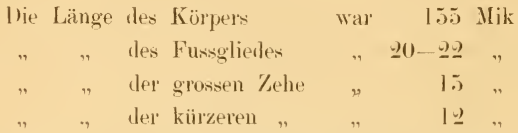

Das Nugu lag is Mik vom vorderen Raude des Räderorgans antfernt. und dis seitliehen Taster standen 75 Mik nach hinten von demselben.

Die so herdentemde. Länge, die ja nicht wenig bedententer ist als diejenige van Miknordom seheint wobl die Auffassmo diesel Form als ein Jugendstadium vom Mikrocodon von vorn herein so ziemlich auszusebliessen, denn mehrere Exemplare zeigten beinahe dieselbe Grösse. Tie grosse Ïhnlichkeit zwischen diesen beiden Irten zeigt sieh im Rïderorgan, in der Lage mod Beschattenheit

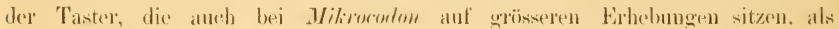

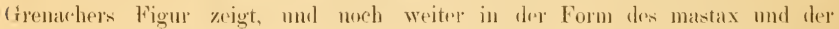
Ḱiefer und schliesslich in der allgemeinen Körperlorm ${ }^{1}$ ). Dic letztere ist ganz besomeler auf Wesers Abbildungen von Mikrocodon noch wehr abweichend vom der extremsten For'm des Mitrocodides, aber ich möchte eher Grenacher's. Abbildung der liörperform des von mir in Grönland gesehenen Mikrorodon entsprechen lassen als Mebers. Iuch betreffend die Lage des dorsalen Tasters fand ich die Gromacher'sche Abbildung naturgetreu. Kwar kannte ich weder in Cirönland, noeh als ich zurest meine Notizen bearbeitete, Weaters Abhamilung und komnte deshalb keinen Veroleich vornohmen, aber meine brinnerung und meine Notizen lassen mich ziemlich sicher hieriiber ein Urtheil abgeben. Buncumaxs hat eine Kopie der Grenather'schen Figur, die mir anch

1) Ju der Lage des luges schien mir auch aine Thulichkeit vor\%uliegen, wenigstens wem die Thiere von vorn gesehen wurden Wem ich meine Keichumg von Mikrococlides mit den Ingaben ïher die lage des Iuges bei Mikrocodon zusammenstelle, scheint dagegen die Lage des Augr's hei den beiden Formen recht verschieden. 
in eirönland an der Seite lag, als ich Mikvorodom mer dem Mikroskop beobachtete.

Den mastax betreffeud rinnert meine Abbildung recht viel an Grenacher's Figur bei der Seitenlage des Mikroeodon. Die Kirfer sind ja von den rerschiedenen Forschern. Welcha Mikrocorlon näher stuclirt haben ganz grundrerschieden dargestellt. Man brancht um diess einzusehen nur die Abbildungen, welche Howsox mol Wrower geben zu vergleichen. Der erstre zeichnot längliche rami mit kurzen, starken Kä̈hnen, die von einander recht entfernt stehen. Der letztere um nur eine Verschiclenheit hervorzuhehen zeichnet die rami hreit und ziemlich kur\% mit nahe stehenden feineren Zähnen. Meine Anffassmng des bau's des mastax wiurle betreflend das fulcrum Housox's Figur entsprechen. Dagegen möchte ich für die rami eler diejenige von Wrase als richtig anschen. Ein solches war nämlich das Bild, welehes jeh in Grönland bei einer zwar nicht sehr tiefdringenden Untersuchung des mastax rom Miliv-

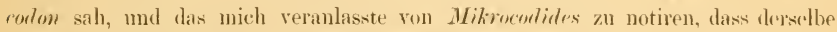
einen ähnlichen mastax wie Mitrocoulom besass.

Eine gewisse Ïhnlichkeit bietet auch rer Fuss dar, insoferu rine Kalye überwiegend ist und die eigentliche Fortsetzung des Fusses bildet.

Wemn ich auch diese Ähnlichkeiten gar nicht gering schätze, wäre ich demnoch wohl kaum vom bau dieser Formen anf die Iolee gekmmmen, dass sic vielleieht sogar identiseh sein könntem. Jjeser firdanke musste Finem alber einlallen, wenn man die lowegungsweise der bejdon Formen beobachtete. Iurb Mikrocrulides zeigt dieselbs leichte gleitende liewegung, welehe auch him durch das Spielen der ('ilien des cingulum hervorgerufen wird.

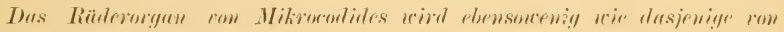

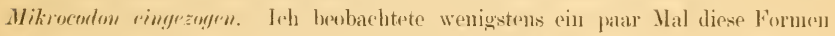
währent eines halhen Tages unaufhörlich und sah Mikroudirles heim Zusammenstosien mit anderen Thieren oder Joosblättern u. dgl. den weichen Kärper recht stark zusammenzichen, alere das Räßlerorgan wurle nicht eingezogen. Nur eimmal sah ich beim Kusat» von Alkohol eine Aulentung zu einer Einzichmug dieses (Organs. Dassolbe wurde indessen wioder ansgestreckt, whe ieh eime klare Anflissumg des Vorganges hekommen hatte.

Der Fuss wird immer steif und unbiegsam gehalten und ich sah denselben nie gehogen werden. Auch komte ich nicmals eincr bewegung der Zehen

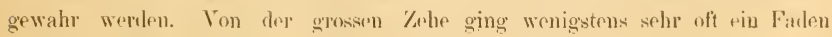


entweder zum Ctlase uler zu einem Ptlanzentheil, und auf dlesen stiitzte sich das Thier oder himg in demselben. Dagegen sah ich wohl kanm bej diesen grösseren Formen die für Mikrocodon so charakteristischen Werfungen.

1)en gs Ang. fand ich in demschlon sese ein kleineres läaderthier, das

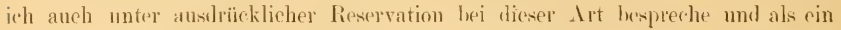
jungeres Stadium letrachte. \%uerst glaubte ich ein Mämnchen vor unir zu haben. fand aber bald, dass es nicht so war. Das Räderthier ist in Fig. 7 wiedergegeben. Die bewegungsweism und auch die schnellenden Bewegungen arinnern vollständig an Mikzocodon. Tom älteren Starlium zeigt freilich diese Form ziemlich bedentende Dhweichnngen. Ich muss sie indessen vorlänfig bejilo zusimmenfïhren. Die Kö̈r]erform ist fast gamz, dieselhe. Das Räilerorgan kam mir auch ganz gleich vor. Nur war der ('ilien tragende Rand rielleicht noch mehr ansugezogen und besass unten eine kleine Ansbuclitung nach hinten. Der trochus war etwas schwer zu sehen, weil diese Form nie ruhig war, schim mir aber etwas schwächer als hei der anderen Form. Etwas unter der Mitte ler. Vordertliche ragt ain sehr sehwacher Nundkegel hervor. Er ist anf der. Zeichmmg etwas zu gross geworlen. Mastax und Kiefer stimmen sehr gut mit dיu grësseren Individuen. Der Nagen ist hier durch eine leichte Einsehnürumg vom Darme getrennt, und beide sinl von grïnem Inhalte erfiillt. Das Auge liegt etwas mehr am hinteren Ende des Gehirns, zeight also dio für so viele Notommataden charakteristische Lage. [)er dorsale Taster sitzt auch ein wenig länger nach hinten. Die lateralen Taster sind nicht auf der Zeichmung ansgeführt. Ioh habe aher notirt, dass sie rine normale Lage latten. Die grösste Versthiedenheit zwischen diesen beiden Individuen bilden die Zehen, die hier tride ziemlich gleich grosis und ein wenig gebogen sind. Anch diese Form bowegte nieht ihre Zehen so, wie die Notommataden es zu thun pflegen. Sir wurken immer gestreckt gehalten und waren mit Drüsenfüilen befestigt. Das Thier stand still, glitt ganz sacht mmher um sich plötzlich ebenso wie Mikrocorlon ein weites stück zu werfen, wonach die gleitende Bewegung sogleich fortgesetzi wurde. I)as Thier war sehr lebluaft und gefrëssig. Ioh sah es immer von den Algenfäiden fressen.

Die Länge dos Körpers hetrug so Mik, diejonige des Fuswess 9 und dirjenige der Zehes anch !).

Ied, wïrde kaum trotz des grossen Ïhnlichkeit gewagt hateu beide diese

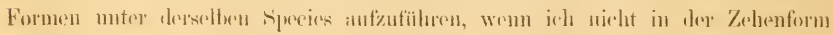


Zwischenstadien zwichen diesem kleinen und den grösseren Individnen geseluen hätte.

Wiirden spätere lintersuchmoren, wis es wohl wahrscheinlich ist, für diese kleine Form eine neur Art berechtigt zeigen, damm mus diesclbe immerhin in der Nähe von-der grösscren Form nud von Mikrocodon gestellt werden, denn unter den Notommataden kamn sie wegen der Form des Räderorgans kaum einen Jlatz finden. Irh kenne auch gas krine weibliche Notommatalen, die sich so bewegen mul die Zehen immer gestreckt halten.

Lm die Bederutung diestr Formen klarer stellen zu kïmnen wär es vielleicht nöthig aine bessere Kenntniss der Jugendstadion zn besitzon, als wir bis jetzt haben.

Anf die Ühoreinstimmmngen zwisehen Mikroudon und Mikrocodides halo ich vorher genug lingrzeigt. Hirs werds ich die Versehierlenheiten hervorheben.

Der hauptsächlichste Enterschied wird immer der Fuss bleiben, welcher bui Mikrocoton von zwei, quergestreifte Mnskelfasern enthaltend bestrht, und dic zusammen mit dor einzigen Zehe eine stachelförmige Bildumg: darstellen, während bei Mikrocodides zwei Zehen entwickelt sint, von deneu aber die eine grösser ist und die Fortsetzung des Fussgliedes bildet.

Enter den Illorienten, welehe mir lwkannt sind, findet sich kaum eino andire gut bekannte Form als Mikrocorlon, wolche meiner Art näher zu stehen scheint. L'nter den Lorienten befindet sich aine Form, die grewiss eine nicht

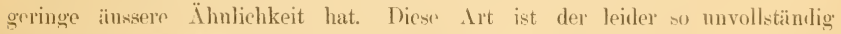
besehricheme strphanops chlona Gossk, welehe Art wohl auch in demselben IIasser, wo mein Mikrocodides vorkam, beobachtet, aber nicht studirt wurle. Ich halte es nicht ganz ummöglich, dass ieh bei dem hastigen Durehsurhen fincer Probe mit schwächerer Vergrösserung sogar diese Formen verwechsolt habon kamı. Fïr die zwei längere Zeit untersuchten 'Thiere ist diese Ammahme vollständig ansgesthlossen, denn ich lese in meinen Notizen, welehe ich hieriiber in (írönland niedergeschrieben, als ich dir Thiore unter dem Alikroskop hatte, von dem sinen: "Während der ganzen Keit, dir das Thier lehte, sah ieh es den Körper auf allen möglichen Weisen znsammenziehen uml biegen, aber niemals wah ieh eine Einziehung des Rüilerorgans" ete. Lnd rom anderen steht "- - - obgleich das Thier sich gan\% Heissig zusammenzag". The vortere

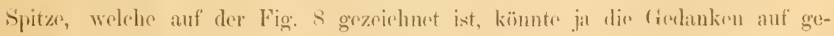


panzerte Formen führen. Es wäre aber falsch, demn diese Spitze konnte ibre Form ändern und trat zuweilen oher als eine stumpfe' Falte als wie cine seharfe harte Spitze hervor. Lie drei hinteren Lorne, dip Ausmändung des Darmes, die bei meiner Form so dentlichen Taster und die Bildung des Fusses verbieten ansserdem die Zusammenstellung der beiden Thiere.

Ich muss wohl auch mit einigen Worten die Stellung meiner Form zu dem von Gensox Thorpe beschriebenen Rhinops orbiculortiscus besprechen. In der Körperform und in der Ausbildung des Räderorgans sowie in Lage und Aussehen der Taster besteht eine grosse $̈$ hnnlichkeit, obgleich das cingulum bei Rh. orbiculodiseus sehr bedentend abweicht. Weitere Versohiedenheiten sind das Vorhandensein hei Rh. orbieulodisens von zwei Fnssgliedern, und von zwei gleich grossen Zehen und das Fehlen des Auges. Betreffend den mastax und die Ausbildung der imneren Organe sind dir Angaben über diese Form sowohl in Texte wie auf den Figmren so dürftig, dass eine Tergleichung dieser Theile kaum möglich ist ${ }^{1}$ ).

Es kamn wohl möglich sein, dass diese Arten nicht so weit von einander gestellt werden dïrfen, ich will aber jetzt, so lange der mastax von Rlinops orbienlodiseus unbekannt ist, kein [rtheil hierïber aussurechen. sovicl seheint mir jedoch sicher, dass diese letztgenannte Art wahscheinlich meiner Gattmng Mikrocodides eben so nahe oder nïher steht als der Gattung Rhinops.

Inh habe Mikrocodides zu der Familie Mikrocodida gefiihrt. Hierfür spricht selu entsehieden das Räderorgan, der mastax, die Körperform und zmm Theil auch der Fuss. Will man die biologische Ähnliehkeit in der Bewregung, in der Art die Zehen zn tragen und in den oben genannten Organen nicht die Versehiedeuheit in der Fussbildung anfwägen lassen, so muss für Mitirocortirtes eine besondere Familie in der Nähe der Mitroontide und Notommatade gegründet werden. Mit der letzteren Familie orler Familiengruppe zeigt ja Mitirocodides eine allgemeinc Übereinstimmung in der Lage des Auges, der Taster und im Grundplan der Fussbildung.

Ich will hier nor weiter bemerken, dass mir auch Mitivororlon näher mit den Notommatadenfamilien rerwandt seheint als init den lihizoten. Weber's

1) Gonson-Tyonpe, Y., New and Foreign Rotifera. Jomrn. of the Roy. Micr. Soc. 189I, s. 304, Pl. VII, Fig. 4 a mud 4 b. Jiese Arbeit wurde mir erst nach der Bearbeitung meiner Notizen über grönlündische Rotiferen bekant. 


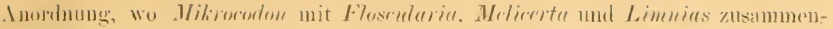
gestellt wird ${ }^{1}$ ), dïrfte wohl kaum als rine Vurbesserung der Itudson'sehen Eintheilumg betrachtet werden können. (ianz besonders diirfte die nene Galtumg Mikrocolides dagegen sprechen. Indessen wären für die systematik der Rotiferen $\ddot{b}$ berhaupt entwicklungsureschichtliche Studicn von nicht mur frïheren Eunbryoualstadien sehr wiehtig. Aber anch ohne diese Kenntniss kann man

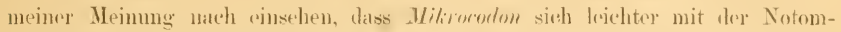
mataden-frmpe verkniphen lässt als z. B. dir so issolirt stehenden Philodineen, die Wrisen zwisehen Mikrocorlon und Hydatimu stellt.

Hier füge irh auch die Bemerkung zu, dass ich die Philorlinaden eher ror oder nateh den übrigern Riiderthieren stellen wärde mul nicht zwischen den Rhizot'n und den Ploimen. Trotz dieser Ansicht habe ieh jedoch oben Iludson's Aufstellung gefolgt.

e. Fam. Hydatinadæ.

IX. Hydatina Ehrbg.

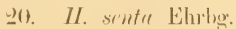

Hỵlatima senta Ehrhg l. «. s. 413, Tat. XLVII, Fig. II.

" Coln $\left.{ }^{2}\right)$ 1. c. s. 43(i, Taf. XXIII, Fig. 1.

" Blochmann 1. с. s. 10), Fig. 227.

$"$ Murkon 1. $\because$ Vol. II, s. !) I'l. XIT, Fig. I.

" I'late 1. (․ s. -2!, Taf. I. Fig. !)

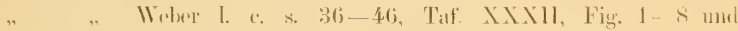
Taf. XXXIII, Fig. 1-5.

Dirses grosio in anderen untersuchten fregenden so gemeine Rïdorthier war in Grïnlaud nicht enowhulich. Nu einmal traf ich dasselloe an.

Jah fand es don 2!) Jumi in einer sehr kloinen l'fïtze, die an einer berewand latg, und Moose und kleinere Algen fïhrte. Nur wenige Fardenalgen kamen hier vor. Das Wasser war rein. sidmelzender selnnee lag in der Nähe, mul ein T'hril rom da entstehenden Watsier wurde zn diesor I'fïtze

1, 1. c. s. 61 .

2) (ons. F., Die Fortptlanzang der laderthiere. Zeitschr. f. w. Kool. Bd. VI1. 185ti. 
geführt. Ther war Ilydatina sehr gemein. Irh labe kein zwerites Räderthier in Grönland in solcher Menge geselnen. Die simne war diesen Tag so heiss, dass unsere Gesichter ron derselben stark rerbrannt wurden, obgleich oder vielleicht grade weil wir uns anf und neben grossen Schneemassen anfhielten.

Ich habe schon in meinem kleinen Reisobericht etwals hievïber gesprorhen, und da lie Frage aufgeworfen, of hier beschränkte Ausbreitung, oder die Nordgrenze des Thieres oder ein Zufall es gemacht haben mögen, dass ich kein zweites Mal im ganzen sommer Iydatima aufland, obgleich ich nacher so viele reine und schmutzige Wasseransammlungen untersucht habe. Freilich sind die kleinen Wasseransammlumgen in Grönland selten so schmutzig, so von übel riechenden verwesenden Thier- und Pflanzentheilen erfïllt wie manchmal in Europa. Ich will hier nicht unerwähnt lassen, dass auf diesem Inselehen jeden Herbst Nassen von Wallrossen "geschlachtet" werden, weshall, es möglich wäre, dass Krnochen-Theile herumgetragen werden, und dlass in einigen Pfützen auf diesem Inselchen mehr faules Wasser später im rommer vorkommen kamn. Der eigentliche schlachtplatz lag von dieser Pfïtze ziemlieh weit entfernt, und bei meinem Besuche waren in der Nähe der Hydutinu-

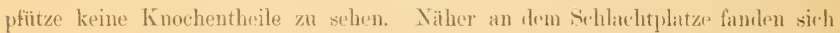
zwei Teiche, wo das Wasser sehr fanl war. Ich fand indessen Mrylatina in keiner imleren Wasseransammlung des Inselchens als in der vorher genannten. the kleine Insel lag in oder vor der Mündung des Nagsugtok's Nondre Strönfjorden) auf ungefïhr $67,30^{\prime \prime}$ n. Lir. mol $53,40^{\prime \prime}$ w. L.

Die Innahme Hydatina hätte sehon ihren Lebenseyklus für dieses Jihn beendet, als ich meine L'ntersuchnngen anfangen komnte, wäle ja in Europa ganz berechtigt, denn da tritt sie ja z. B. in der Gegend von Genive sehon im März und Ipril am häutigstesn aut, und in der Gegend von Rostock hat Tessin-13̈̈7zow sie im Mai 1885 sehn zahlreich angetroffen. Der letztrer sigt auch von diesem Raiderthiere: "Fs scheint üherhaupt nur im Frïhling häutign vorzukommen". In (irünland kamn jene Innahme kanm geltem, dem da ist es ja schneeschmelzmngsperiode noch in Ende Juni. Dieses Jahr legten die Grönländer in Agto - etwas nördlicher als die Nündumg des Nagsugtoks n. Br. $67^{\circ} 56^{\prime} 31^{\prime \prime}$, w. 1. $533^{\prime \prime} 37^{\prime} 15^{\prime \prime} 1$ ) erst 29 Juni ihre Pelzklevider ab. 
Deshall, wiirde man anch in manden T'tützen nech im Ende Juni und Anfang Juli noch Frühlingsthiere antreften kïnnen. Vielleicht grilt dies wenigner für die Gegend un Egedesminde, wo das Land so niedrig ist.

Putride Wasseransammlungen mit Eugleuenatigen (Organismen simel anch solten. Ich kam mich mur erimnern \%wei solelwe gesehen zn haben. Itie eine war auf Räfön, die ambere in Jakohshavn etwas südwestlich von dem llause

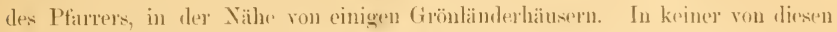
fand ich IIydation. In den in der Nïh der "Trankogericrne" gavegenen siompfen fand jeh weder Ilvalina noch ablerhaupt vicle lebende Wisen. Diese Gewässer waren sehr arm.

\section{f. Fam. Notommatadæ.}

\section{Hypopus n. g:}

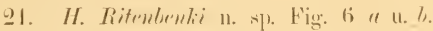

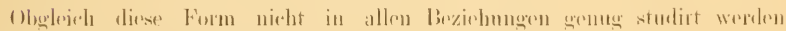

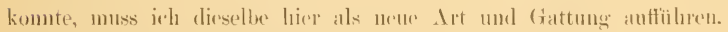

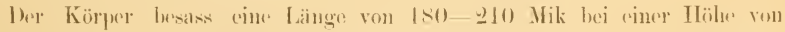

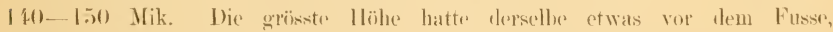
welcher nicht vom hinteren Fude, somblen von der Lintersoite des Körpers

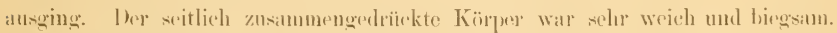
\%wei sejtliche läickenfalten liesson den wheren Theil des Rïickens fast wir

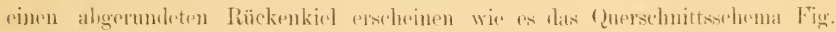
(j) b veranschaulichen soll.

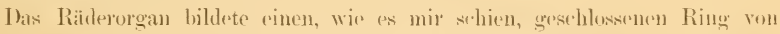

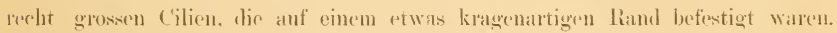
Das Crehirn trägt einen schr belentenden Kalkbentel, mol am vorderen Ende dessolben trat ein grosses. Auge deutlich hervor. Dis Kelon warn ziembich lang und spitz mit ein wenig angesehwollenen Batsaltheilen.

Vom mastax habe ieh nur motirt, dass desselbe selor dentich mol mogrwöhnlich spitz war mol ansserorelentlich schwarhe, zangenfömmige unci besass. Inch über die anderen imeren Oroane finde ich nur die bemerkung, dass der stark loraune Mageninhalt das meiste verbarg. 
In habe sellost ziemliels lang Zweifol gehegt, ob nicht diese Form mit

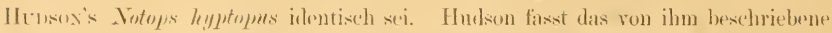
Rällerthier als mit Ehrenbergs Sotommuta hyptomms identiseh auf:

Vel. Enrfanerg 1. e. s. 4z6, Taf. L, Fig. VI.

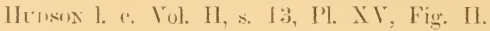

leh kann diese formen jetzt nicht als ielentisch ansehen, denn Iludsons Form ist hedentend grösser, als die mon mir motersmehte. Sie hatte eine zum Theil gepanzerte Cuticula, wogegen meine Form eine ganz wejehe Hant besass, so class die Form des Körpers recht stark verändert werden komnte. Die Körperform war anch melu abgerundet bei mener Art als bei Hursons. Nlle seine Figurn strllen die hintere (irenzlinie als winklig gegen the where mul untere abgesetzt dar. Die Zehen der Hudson'schen Form sind kürzer mul dicker, wogegen sie hei meiner lang und spitz waren (ith habe sie in meinen Notizen Metopicliefförmig genamnt).

Schliesslich finde ich den so dentlichen Kalkbentel gar nicht erwähnt, was mich allen die Iiten als verschieden anzusehen nöthigt. Dagegen müssen sie gewiss heide zn derselben Gattung geführt werden. Kaum darf jouloch

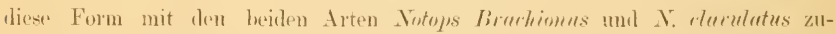
sammengefiihrt werlen. Diese beiken betzterens Arten besitzen eine roroma, die dem Hydatinatypus nabe kommt, einen mastax, dessen mallej knrz umi kräftig sind mit mehreren Zähnen an den fast querliegenden unci, wozn anch

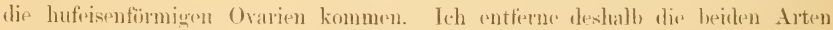

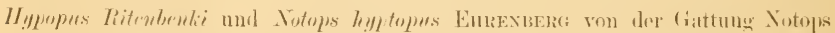

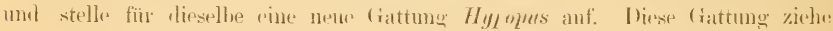
in lo von der liattmog Hydatiun otwas weiter hinweg und stelle sie, wiu ex Ehrenbergy mit seiner Art gemacht hatte, in der Nähe der Gattmos Notommata.

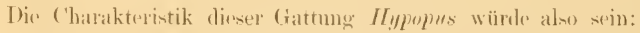

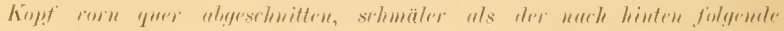

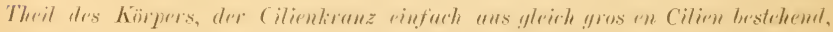

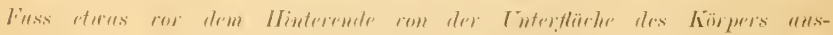

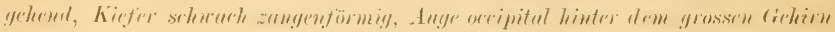
lingenel. 
Für die Berechtigung der Anfstellung dieser Giattung sprechen auch gewissermaasen Hunsosis Worte: "The third species Notops hyptopus ressembles N. elavulatus in the short foot and in the odd position in which it is placed; lunt differs widely from all the Mydutinater in the coroua and trophi. Feeble, however, as are its aftinities with the two other species of the genus, they are stronger than those it has with any other; so it has heen placed bere as the best makeshift that could he devised".

Es mag wohl sein dass diese Formen iblurall ziemlich isolirt steben werden, aber unter den Notommatalen tiudet man jedoch eine so verschiedenartige Organisation dass wohl auch einige Jerührungsunkte zwischen dahin gehörenden Formen und der Gattung Higwpus hervorgehoben werden können. Zweifolls stellt diese (iattumg Formen dar, welohs Notommata mit den (iattungen Sotops-IIydatima rerknüpfen. Die beiden Arten Hypopms Ritrulumki unal

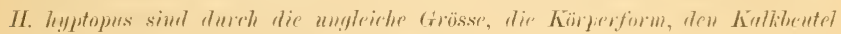
und die Form dre Zehen metreschieden. Obgleich ich nicht glaube, dass

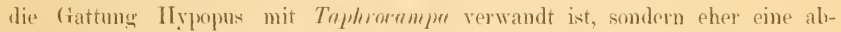
woichemle Form bildet, dic von Notommata oder Copens abgezweigt ist, lasser ich dieselbe hier als erste Gattung der Familie Notommatada stehen, weil sie zweifellos in derselhen Richtung wie Notops, deren andere Arten mir nicht durch Autopsie bekânnt sind, ansgebildet ist. Bei der Anfrechnmng der ïbrigen Notommataden folge ich wieder Hrusex, weil meine studien dieser sehwierigon Familie gar nicht auspohen $m$ m eine andere Infstellumg zu geben.

H. Ritruluenli; wurde den 3 September in einem Moortïmpel bei Ritenbenk grefundes, unl einige Exemplare wuden auch ant dem s'chiffe während dley ('rsten Tage der Rïickrcise unter Moosen, die von der quenamuten liasseransammlumg genommen waren, gesehen. Die Thiere hewegten sich ziemlich lehhaft mol sehwammon gern, wohei sie auf der seite lagen.

\section{Taphrocampa Gosse.}

\section{T. anmulosa Gosse.}

T. ammolosil Gosise in Hudkon 1. e. Vol. II, s. 16, PI. XVII, Fig. 12. 


\section{T. Leriuseni n. sis. ") Fig. 12 a 11. b.}

Die erste ron diesen Irten wurde in der Nïhe ron Egedesminde gesammelt mod flüchtig untersucht. Von der zweiten, wolche ich den obigren Namen gebs sah ich in Jakolsharn d. 24 Ang. ain Paar Individuen. Die Formen seheinen also in Grimland recht selten zu sein. Obgleich joh nur die oben ritirte selu schlechte Figur geben kamn. muss ich fiir diese Form eine eigene Art aufstellen. Torliegrende Form steht beinahe in der Mitte zwischen den ron (iossor aufgestellten drten $T$. ammlosn und $T$. Sammlersin.

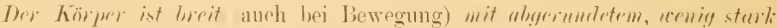

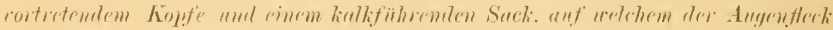
sitzt. Am Torderrande des Kopfes wurlen zwei kleinere nabe an einamler liegende Pigmentflecken heobachtet. Dir Cuticulu scrigt umgefähr elf cimamler. grnäherte Rimgfulten won denen zwei oder drei vor dem Angenflecke liegen. Die Zehen siml sehr lithz. etwas gehogen, oben und ror denselben befimdet sich rime lilrime Er-hrlmmg, die ein wenig gehogen ist. l)ieselbe kam mir eher als ein Inhang als wie eine lintere Fortsetzung des Körpers vor: Ton der ïhrigen Organisation habe ich nur notirt, dass Magen und Darm nicht getrennt waren, sondern eine in ihrer ganzen Länge fast gleich weite Röhre bildeten.

Die Bewegungen des Thieres waren srhr träge. Die (trösse wurde nicht gremeswen. Ith kamu nur sagen, dass es eines von den kleineren Rüderthieren war. Diese Form muss ja zn der Gattung Tefhrocumur gehören. und kamn jedoch weder mit $T$. ammulosa noch mit $T$. Sammeresier identisch sein. Tom dre

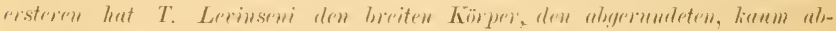

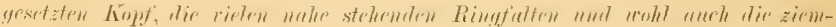

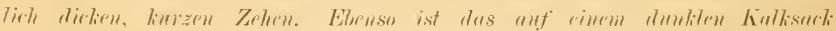

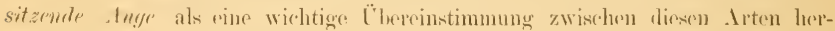
vorzulieben.

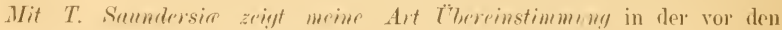
Kehen stehente Eirholung und in den zwoi vorderen Pigmenttlecken. Jodoch unss erwälnt werken, dass die zwo "globules", welelue (xosse nicht olıne Zweifol als Augen deutet, farblos waren. Indessen kam iels kanm bezeifoln, dass disse Bildungen einander entsprechen.

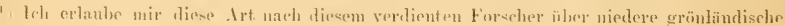
Thiere zu benemen. 
Wenngleich also $T$. Lerinseni Merkmale von den beiden frïher bekannten Irten hat, scheint sie mir dennoch der $T$. anmulosa etwas näher zn kommen. Aumerlung. In meinen Notizen ist noch eine in Egedesminde geseluene Form erwïhnt, die ich in diese Gattung stellen muss, obgleich die mamgelhatten Angaluen mir nicht ermögliehen näher anf dieselbe einzugehen.

\section{Pleurotrocha Ehrbg.}

Von dieser Gattung habe ich nur ziemliẹ selten in Gränland Reprïssntanten gersehen.

\section{T. sp.}

Yon einer Diglena-ähnlichen Form, die jedoch keine Angen hesass, fand ich in Siliswassertümpeh bei Egedesminde d. \& Ang. ringe Exemplare, welehe indessen nicht näher studirt werden komnten.

\section{T. sp. Fig. 9.}

Auh diese Art ist ungrnïgend untersucht worden. Ich habe nur dir mangellafte skizze Fig. 9. Disselbe erimnert nieht wenig an 17. yiblon Ehrhg '). Indessen ist diese Art selbst nicht gut bekannt, und Gosse ${ }^{2}$ ) führt nur mit 7weifol snine Form unter diesen Namen auf. Die Beschreibung ist ziemlich unvollständig. In meinen Notizen steht "Vorderende schräge algesehnitten, Zohen kurz, rundliche Kittdrïsen". Das Vorderende ist auf der Skizze heinahe quer abgeschnitten. Jedoch kamn bekanntlich das Aussehen des Vorderendes in verschiedenen stellungen recht ungleich sein. Von den ('ilien habe ieh niehts notirt. Ifieselben scheinen mir auf der Skizze stärker, als ich bei einer Pleurotrocha erwarten wiirde.

\section{P. auritu n. sp. Tab. II, Fig. 15.}

Obgleich anch diese skizze recht schlecht ist, ermöghieht sie jodoch einen Vergleich mit anderen Arten der Gattung, und dieser Vorgleich rrgibt als Rosultat, dass die Form bisher nirht bekamnt ist.

1) Eurenberg 1. c. s. 418, Taf. XLViI, Fig. IV.

2) Hunsus 1. c. Tol II, s. 20, I'l. XVIII, Fig. 5. 
Pl. aurita ist ein kleines um 100 Nlik. langes Räderthier, mit mehr oder weniger koniseher Körperform, ohne Ringfalten. Der Kopf ist kaum vom Körper abgesetzt, ist nicht sehü̈ge abgeschnitten, sondern ziemlich symmetrisch nach vorn ansgezogen, so dass er einen flachen abgestnmpften Kegel bildet. Jederseits trägt der Kopf eine kleine Erhebung. Der Fuss ist sehr kurz mit ziemlich langen geraden, spitzen Zehen. Vom Rüderorgan habe ich nichts notirt. Nach der Zeichmung müssen die Flimmerhaare sehr schwach gewesen scin, weil sie gar nicht gezeichnet sind. Der mastax lingt unter dem Gehirn und besitzt ungleich grosse mallei, die sehr schwache fast stiletförmige unci besitzen. Ihe Figur zeigt keine Einschnürung zwischen Magen und Darm.

Der Namen ist mit Rüeksicht anf die kegelfürmigen lateralen Erhebungen gegeben. Welche Bedeutumg haben diese? Ich wriss es nicht. Nur soviel, dass dieselben nieht den ohrenförnigen Schwimmorganen verschielener Notommatarten entsprechen, wage ich zu behaupten. Anch habe ich an denselben keine Tasthaare gesehen.

In seinen Bewegmigen erinnerte $P$. anvita wie viele Artem dieser Gattumg lebhaft an eine Diglena. Sie wurde d. 14 Ang. im Bodenselilamme eines ziemlich grossen Sees in der Nähe von Eggedesminle beobarhtet.

\section{P. marina n. sp. Tab. I, Fig. 13 a n. $b$.}

Fig. 13 a und $b$ stellen das Aussehen des gestreckten Thieres bei Bewegung (1 ) und stark zusammengezogen nach Zusatz von Kalihydrat (b) dar. Sie sincl olme Camera gezeichnet.

Anch bei dieser Art finde ich in der Körperform und in der weichen Besehaflenheit der Cutienla grosse $̈$ hnlichkeit mit einer Iniglena. Der Kärper ist ziemlich lang mu nach hinten gewöhnlich ${ }^{1}$ ) ein wenig höher als die vordere Hälfte. Der Konf ist dureh eine schwache Einschnirung alggesetzt und hat eine quere, ziemlich scharf abgeschnittene vordere Flïche. Über derselben sieht man einen gebogenen, hakenförmigen Fortsatz, der mir als Cnticularbildumg erschien. Dieser kam bei zusammengezogener Lage des Thieres fast vollstïndig verschwinden. Die Grösse dieser Bildung war anch recht versehieden bei versehiedenen Individuen. Dieselbe erimnert an ähnliche Bildnngen bei

1) Ich setze dies "gewöhnlich" hinzu mit Hinsicht auf die Verschiedenheiten, welche durch grösseren oder geringeren Mengen von Darminhalt verursacht werden können. 
einigen Loricaten, wo sie indessen ron einigen Sutoren als von Flimmerhatren gebilket anfgefasst werden. Ich glaube ïlorigens kaum, dass diese beiden Bildungen homolog sind, dem bei I\%. murina war der Fortsatz grösser, erimnerte fast an eine Faltenbildung. Die weiche Cuticula zeigt rinige nieht immer gleich deutliche Querfalten, Fig. 13 a. Der Fuss besteht aus cinem selten ausgestreckten (ilicde, welches zwei spitze, gebogen. Zehen trägt. I bis Zehen hahen angeschwollene Basaltheile und sind gewïhnlich nach unten geriehtet. Kittdriise, Excretionsblase und Gesehlechtsdrüse sind auf der Abbildung dargestellt und bicten nichts Eigenthümliches dar.

Die Nundöfmung, dureh welche dir Kiefer sehr oft hervorgestreckt werden, liegt ziemlich nahe dem unteren Rande der Vorderfläche des Kopfes. Von den Kiefern waren die langen, gebogenen mallei leicht zu sehen. Die unei sind einzihnig. Has fulcrum war kürzer als die manubria, und die rani schienen mir klein. Jedoch konnte ich sie nieht gut wehen. Wie ich den oesophagus, die. Magendrüsen, Magen und Darm sah, zeigt die Figur.

Dieses Räderthier hatte eine Länge von 150-180 Mik. Dasselbe kam im Meere vor und nicht nur in den kleinen Strandpfïtzen, welehe dureh die bedentenden schwankungen des Wasserstandes entstehen, sondern auch miter den bramen Fadenalgen welche auf weit hinaus im Neere mmbertreibenden Fueustheilen wachsen. Diese Fneusstiucke wurden z. B. bei Jakobshavn unter dicht liegenden Eisscherben eingesammelt, wo die Wassertemperatur natürlich sehr gering war. Sowohl bei Jakobshavn wie bei Egedesminde wurde diese Art mehrmals gesehen. Gewöhnlich kroch das Thier auf den Algenfäden, aber ich habe es anch schwimmend gesehen.

leh möchte glauben, dass unter den Formen, die ich als zu dieser Art gehörend notirt habe, noch eine zweite Art sich aussehciden lässt.

Ich will nicht merwähnt lassen, dass meine obenstehende Art eine ziemlich grosse Ähnlichkeit mit der Fureularia marinu Dujardin zerigt, welehe Art auch ron Gosse in England gefunden ist ${ }^{1}$ ). Es ist mir bisher nicht möglieh gewesen unter den Fadenalgen von mseren Neeresnfern mehr als ein Paar Diglene-iihnliche Räderthiere zu finden, weil ich keinen von den letzten beiden sommern zu llanse gewesen bin, und deshall, ist es mir sehwer eine wohl hegründete Ansicht in dieser Frage auszusprechen. Ich lasse die Formen

1) Hudsos 1. c. Vol. II, s. 41, Pl. XIX, Fig. 15. 
jetzt als verschiedene Iiten stehen, weil die Zehon anf den Abbildungen ziemlich versehieden sind, und weil ich für den Stirnfortsatz meiner Art keine Erklärung finde, wemn ich die Arten als ilentiseh auffasse. Beì Gousse's Art findet sich freilich eine "Antenna" l. c. Fig. 15 a, aber dieselbe scheint mir unmöglich dem hakenförmigen Fortsatz entsprechen zu können.

Dazu kommt noch, dass meine Zeichnung der Kiefern wenig mit Gosse's Fig. 15 b stimmt. Wenn ich diese Figur richtig rerstehe, ist die Zange ent $x$ der von den rami gebildet oder in eigenthümlicher Weise mit dem fulcrum zusammengewachsen, was meine Zeichnungen gar nicht andeuten.

Sollten indessen künftige Untersuchungen die Identität dieser beiden Irten anfweisen, so wird ja meine Art leicht verschwinden und als synonyme unter Dujardin's eingehen.

Diese. Gefahr scheint mir viel geringer als die andere, eine wirklich verschiedene Art unter einem alten ilr nicht zukommenden Namen anfzuführen.

Dann muss indessen diese Art Pleurotrorha marinu und nicht Furcularia mavina heissen, wenn überhaupt die Gattmg Pleurotrocha aufrecht gehalten werden soll. Vielleicht wäre es natürlicher die Gattung verschwinden zu lassen und die Arten derselben anf die Gattungen Diglenu und Furculuria zu vertheilen. Indessen wäre es wenigstens jetzt reeht schwer zu sagen, welche Arten zı der einen und welche zu der anderen Gattung gehören sollten. Wenn man aber mit Gosse Ehrexbers's Gattung Pleurotrocku bcibehält, muissen wohl auch die angenlosen Furcularien dahin geführt werden. Freilich seheint es mir sehr zweifethaft, ob Gosse's Frrenluriu ensiferu eine Furculuriu ist, und ganz sicber, dass die Furculuriu micropus ebensowohl eine eigene von Furculuriu getrennte Gattung bilden muss, wie Tephrocumpu ganz gewiss mit Recht aus der Gattung Notommutu ansgeschieden worden ist. Vielleicht konnte die letzt genannte Art sogar in die Gattung Tryhrocumpu übergeführt werden. Weil man jedoch in der Systematik der Rotiferen bisher grosses Gewicht auf das Vorhandensein oder Fehlen der Augen hat legen miissen, will ich jetzt keine solchen Veränderungen vornehmen, um so weniger da diese Formen mir bis jetzt nicht aus eigener Anschanung bekannt sind. Ich musste jedoch diese Frage hei der Besprechung der Furculariu murinu berülıren.

Ammerkuny. Betreffend die Benennung dicser augenlosen Formen besteht eine Versehiedenheit zwischen Hudson und Evrertu. Ehrenbers hatte für dieselben zwei Gattungen aufgestellt: Plecrotrochu und Theores. 
I) letztere Gattung umfasste jedoch bei ihm "solehe Arten, die mehr als drei Augen im Nacken gestellt und einen Gabelfuss führen" "). Er meinte also, lass die Arten der Gattung Theorus Augen besässen. Später haben verschiedene Autoren gezeigt, dass jene glänzenden Körner gar nicht Augen sein können, sondern eigenthümliche Einschlüsse in den Magendrüsen sind ${ }^{2}$ ) und meinen dann, dass die Gattungen Ileurotroche und Theorus (von ExrenTn zu Throre geändert) nicht länger getrennt werden dürfen, warum Exrenтн alle diese Formen Theoru nemen will, und Tessn-B̈̈tzow folgt ihm in dieser Nomenelatur. Mir scheint es selur klar dass diese Formen mit Ehrenberg's Name Theurotrorle genant werden müssen. Diese Gattung war durch das Fehlen der Augen charakterisirt. Für die Gattung Theotus gab EHrenberg dagegen das Vorhandensein pigmentloser Nackenaugen als Merkmal an. Seitdem nun dieses Merkmal weggefallen, muss auch der Name Theorus versehwinden, wenn die zu der so genamnten Gattung geführten augenlosen Arten zu derselben Gattung wie dic von Ehrenberg elun weyen des Frhlens der. Iugen zu seinem Genus Menotrocha geführten Räderthiere gestellt werden sollen.

lch finde es deshalb richriger den Namen I'enrotrochu beizubehalten wie IIunson es auch gethan hat.

Der letztgenannte Verfasser stellt indessen die Formen dieser Gattung vor der Gattung Notommatu. Nach Notommata folgen die Gattungen Copeus und Prorkes und arst dann Furcularia und Diglenu. Nach meiner oben angedentreten Insicht haben die Mearotrocha-Arten eher ihre nächsten Verwandten unter den Arten der beiden letzteren Gattungen als unter den NotommatuArten. Ich möchte diese Formen, wemn man sie auch in der Zukunft als eine besondere Gattung antführen wird, am liebsten zwischen Furculuriu und IViglena stedlen. läst man dic Gattung auf, müssen die Arten derselben hauptsäichlieh anf diese beiden Gattungen vertheilt werden.

\section{Notommata Gosse (nec. Ehrbg').}

Gewiss sehloss EmRenbercis (rattung Notomemate rine sehr heterogene sammlumg rin. Desshalb ist ateh diese Gattung von Honson \& (Bosse aufgelöst worklen, aber die imnige: Verwandtschaft dieser Formen maeht jedoch

1) Ehrexberg 1, c. $s$ 454 .

$\left.{ }^{2}\right)$ z. B. Trssix-Bützow 1. c. s. 146 und W. Mrsxe nach Hudsou 1. c. Supplement s 60. 
noch jetzt immer die Begrenzung dieser neutu Gattungen sehr sthwer. Besomblers bei der Ibarbeitung meiner Notizen über diese formen finde ich die Unvollständigkeit sehr gross. Und es muss anch nothwendig so sein, weil ich schr wenige Abbiłdungen von solehen Formen in Grönland zugänglich hatte, und sowohl Eckstein wie Blocmuns ïber diese noch immer so kritische Gattung nicht viel mittheilen. Teh muss deshall für manche Formen ein ef: zusetzen. Die notirte Irt crinnerte an diejenige, deren Namen ich anführe, ich kaun aber nicht versichern, dass sie auch in allen Einzelnheiten mit derselben ïbereinstimmte. Von den zu disser Gattung gehörigen Räderthieren sah ich auch selten auf cinmal mehrese Exemplare. Damn und wann wurden einzehe Individuen beobachtet.

Levinsen hat schon Notommata sj). angezeigt. Ich setze die Notiz hier, weiss aber natürhich nicht, ob die von ihn gesehene Form zu det Gattung Notommatu in dem hier angenommenen l'egriff gehörte.

28. N. cf. aurita Ehrbg.

N. anrita Ehrbg. l. c. s. 430, Tab. LII, Fig. III.

N. aurita Gosse 1. e. Vol. II, s. 21, Pl. XVII, Fig. 6.

? N. cf. saccigrea Ehrbg.

N. aaceigera Ehrbg l. e. s. 434 , Tab. L, Fig. VIII.

N. saccigera Gosse I. e. Vol. II, s. உ4), Pl. XVII, Fig. ㄴ.

Diesen beiden Arten nahe stehende Rïdesthiere wurden einige Male gesehen. Diejenige Form, welche ich mit $\mathrm{N}$. saceigera vergleiche hatte jedoch ein wenig geradere Kehen.

\section{9) '). N. of'. tardigrata Leydig.}

N. tardigrada Leydig l. e. s. 39, Taf. IV, Fig. 31.

Gusse glaubt diss diese Lerugh's Art mit DuJardin's och Cons's Limelia tornlosa identiseh ist. Nach der ziendich grossen Versehiedenheit der Abbildungen, welche von Leydig und Cohn gegeben worden sind, kann

1) Ifiese Arten sind zu wenig studiert und könnten wohl elen so gern alle drei ein Fragezeichen neben sich haben. Heine Notizen sind hier sehr unvollständig und wären nicht diese Formen fast überall so häufig, würde ich vielleicht die entsprechenden grönläudischen Formen ohne Nummer nur als N. sp. aufgefüht haben. 
ich mich dieser Auffassmng nicht anselıliessen. Ist sie indessen richtig, kann ich meine Form nieht mit Leydigs N. tarligrada vergleichen. Siolu (awse l. c. Supplement s. 22, PI. XXXIl, Fig. 90 (Copic von Cohu's Mblildung).

30. N. tardu n. sp. Tab. II, Fig. 16 " $, l, c$.

Diese seltene Art war von den anderen sehr leicht kenntlich dureh ihre grvingere Grösse und den dieken Körper. Ieh habe nur die mangellafte skizze Fig. 16. Der Kopf ist dureh cine ziemlieh tiofe Fulte seler deutlirh alygesetzt, ist mach rom rundlich mol zeigte simige medrige längsgehende leistenfïrmige Erhelmugrn, die mir etwas stärker cuticularisirt zu sein sehienen Fig. Iti $e$. I) Zehme waren dick und karz. Auf dem hinteren körpertheil traten zwoi Querfalten hervor. Einige sehr schwache Längsfalten waren aurh sichthar. Das Auge war sohr dentlich. Ot, ein Kalkbeutel da war oder nielit, habe ich nicht notirt. Dagegen habe ich angegeben, dass zwei deutlich hervortrotende angenähnliche Flecken, die nabe am Stirnmande sassen, beobachtort wurden. Vor diesen Flecken oder von der niichsten Umgebung derselben gingen einige längere Haare aus. Der Darmkanal bilkete cine rechteckige naeh hinten ein wenig schmälere Höhle, die keine spum einer Einschnïrung zwischen dem Magen und dem Darme zeigte.

Ich haloe kanm rin zweites so trïges Rä̈lerthier geselien. Dieser Form könnte mit $N$. brachyota oder Proales deripiens rerglichen werden, wem nieht diese seharfe Absetzung des Kopfes da wäre. Ganz sicher brsass diesolbe keine ohrenförmigen Ansluchtungen des Räderorgans. Mit der Trıłroc'rmpa anmulosa bietet sie auch Ïhnlichkeit dar, kann indessen wogen der Abwesenheit der bei dieser Form so ausserordentlieh seharf hervortretenden (Durefaltung nicht mit derselben identisch sein.

Wegen des Torkommens der vorkeren Pigmentfleeken bemorke ich, dass die Form unmöglich zu der Gattung Eosphor gehören konnte. Jie Flecken, dic Körperform und das ganze benchmen des Thieres erinnerten gar nicht an genamnte Gattung. Iaitte ich sicher notirt, dass dieses Räilerthier ein loelles Grhirn (ohne Kalksack) besïssese, wiirle ich dasselbe wohl zu der Gattung I'roules geführt halen. Diese beiden Gattungen sind indessen so ausserordentlich mahe verwandt, und die Verwandtschatt der Formen, welche die Gattung Proutes liklen, seheint mir gar nieht so besomlers gross, weshalb ich es vorziche die obigo Form jetzt unter den Namen Sotommata anfzufïhren. 
Ammorknuy. In meinen Notizen habe ich angegehen, dass ich bei einer N. tarda ähnliohen Form einen kurzen Rückenzapfen üler den Zehen sah. Bei der hier beschriebenen $\mathrm{N}$. tarda konnte aber, wie dir Profilansieht Fig. 16 b dentlieh zeigt, kein solcher beobachtet werden.

31. N. grë̈lamtica n. sp. Tab. II, Fig. 21 a, $е, f$, Tab. III, Fig. $21 b, c, \pi, y$.

Diese Art ist mit einigen Formen der Gattung Proules recht nahe verwandt. Weil ich aber diese Gattung nicht lür gut begrenzt halte - $P_{r}$. sorrlida und dreipiens düften mit $P_{r}$. giblu reeht wenig verwandt sem, wogegen die beiden erstgenamiten Arten wahrscheinlich sowohl meiner hier besehriebenen Form wie Not. forcipatn, brachyota und saccigera recht nahe stehen - nehme ich auch diese Art als eine Nutommate auf.

Der Körper ist Tanygezogen, die Haut sthr wrich und vollständig ohne Falten. Die Rïckinfläche füllt leicht gegen das Kopfende ab. Dirses ist schräge mol gellt ohne scharfe Grenze in die Cuterseite äher Fig. 21 b, r, g. Die Kopfhaut hat rine dorsale vorstehende Falte, die jedoch keine hakenförmige Verlängermng träigt. [nter dieser faltenförmigen Kante befindet sich eine Vertiefung, ans welcher kurze aluer starke Cilien ein wenig hervorragen Fig. 21 c, d. Man sieht eben die Spitzen jener Cilien, wemn man den Kopf von oben betrachtet Fig. 21 u. Unmittclbar unter der rimenförmigen Vertiefung sieht man eine ziemlich dicke Erhebung, die von vorn und unten gesehen fast quahlatisch erseheint Fig. 21 d, mol wie die Fig. 21 am besten zeigt, einen schmäleren Basaltheil besitzt. Luf dieser Stirnerhobung konnte ich keine Gilien und auch keine Tasthare sehen. l)agegen trat in der Mitte dersolben ein glänzendes Korn sehr deutlich hervor.

Seitlich von der eben geschilderten Erhebung liegen die sehr dutlirhen Wimproblen, welche längere (ihien tragen als der übrige Kopfrand. Disser obere Theil des Kopfendes ist ziemlich quer abgesehnitten. Der unter den Wimperohren kommende Theil fält dagegen sehr langsam ab und greht allmählich in die untere Kö̈rpertlïche über. Die Mundöflimng liegt nahe der Stelle, wrohe man sich als Grenzlinie zwischen dem Vorderende und der Enterseite vorstellen kann Fig. 21 \& mu. Writ nach hinten ron der Mumbäffum

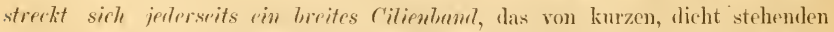
('ilien bestelot. (1) diese Cilienbänder so breit waren, dass sie auch die Mumb- 


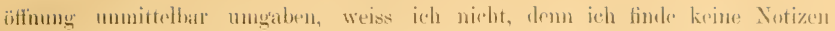
darïher, mul meine Figurskize zeigt nur ein loreites land an jeder serite. Fig. 21 l.

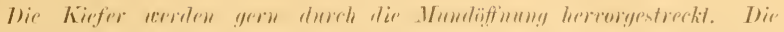

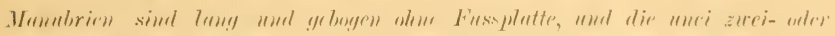
dreiz̈̈hmig.

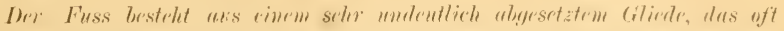

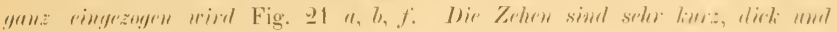

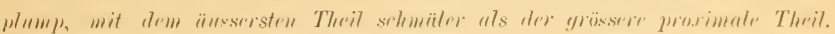

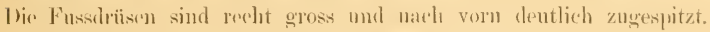

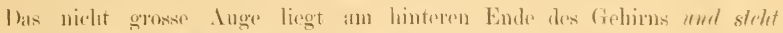

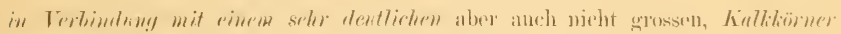

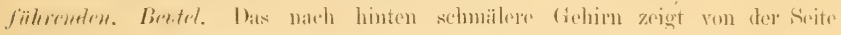

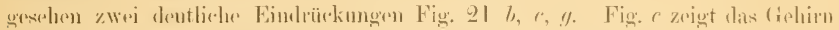

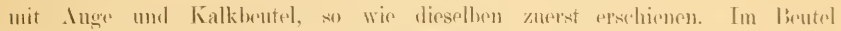

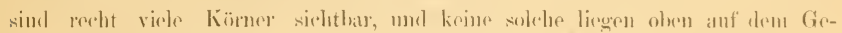

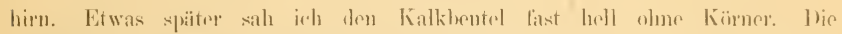
masten Kömos waren ausgerleückt mol lagen last wis in einem Ausführungs-

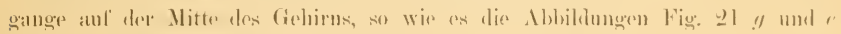

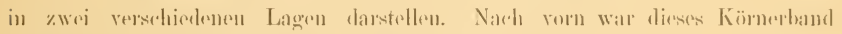
gegabelt.

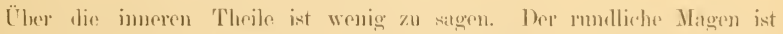

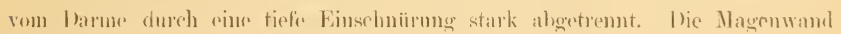

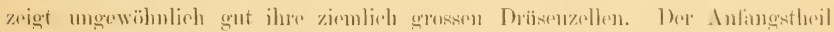

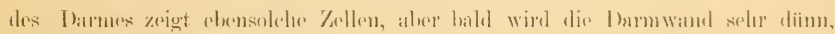

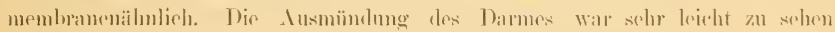

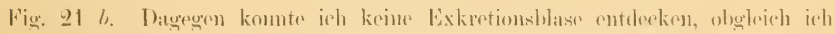

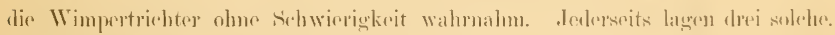

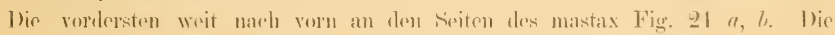

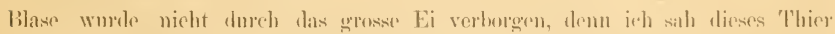

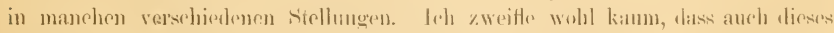
Räderthieg eine Blase besass, muss aber angebun. daks meine Notizen von mehreren Individuen sagen "Dic Blase umleutlich".

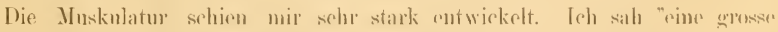

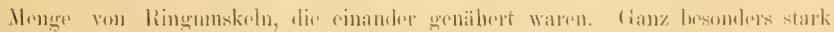


entwickelt waren sie in dor hinteren Körperhälfte. Aueh die ventralen Längsmuskeln schienen mir anffallend mächtig. Noch krättiges als bei dem abgebildeten Thiere waren die Mnskels bei einem anderen Exemplare, das in der Körperform eine geringe Abweichung zeigte. Bei demselben Thiere, das wic das abgeliblete ein grosses Ei trug. Waren die Magendriisen länglich und nach vorn zugespitzt. Der oesophagus hatte eine ovale, blasenförmige Erwejtermo und bei der Einmündung desselben in den Magen sah ich ein Büsehel von langen Cilien, die sieh weit hineiu ins Lumen des Magens streckten. Übrigens waren aueh die anderen (ilien fler Magenwand sehr leicht sichtbar, und der braume Inhalt des Magens und des Dames woule schmell berumgerollt.

Ilese Art, von weleher mehrere Exemplare beobachtet wurden, bewogte sich reeht lebhaft, gewöhnlich kriechend abor anch schwimment. Jedoch sah ieh um einmal ein Würmchen seine ohrenförmigen sihwimmorgane benutzen. Dirselben waren nicht gestiolt. Wie seloon frïher angedleutet, war dies Rüilerthier gefrïssig und streckte oft den mastax herror.

Die Länge war 1s(o_-200) Mik. Die Breite des abgedildeten Exemplares war bei 190 Mik. Länge um (i0 Mik. Die Länge der Zehen betrng um 9 Mik. Wurde bei Egedesminde d. I0 Aug. und bei Jakobshavn d. 27 Iug. gesehe'].

Diese Art steht in manehen Beziphmgen einigen T'orklesaten sehr nahe. Sie hat wie dieso Crattung mach Cousse's Diagnose "body genelally eylindric, or larviform" und "eiliated faer more or less prone", unterscheidet sich aber nicht wruig in anderen Derkmalen, demu zur Diagnose der Ciattung Proales gehört anch "In'ain elear; aurieles and tail wanting". Mit Pronles sordidu bieter diese Form recht grosses Ähnlichkeit dar. Dis Wimperolwen morken

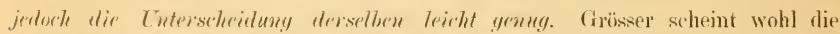
Verwandtschatt mit Notommate breckyotu, saccigere mol forripate, aber $N$.

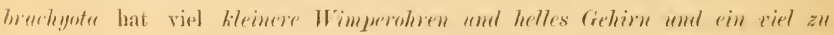

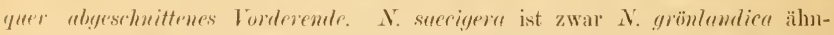
lichrr, aber dir Kärperform unterseheidet dieselben sehon deutlich gemug. Fine Vergleichung meiner Fig. 2I / mit Gosse's Fig. 2 a Pl. XVII lässt keinen Zweifel darüber dass vorliegende Arten versehieden sind. Dir Fimm der Zohen

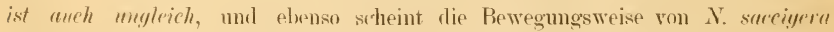
(ime andere zu suin. Gusse sagt l. c. Vol. II, s. 25: "The front is rounded, 
and an evolve two small hemisplierieal andeles, very observable, berause they are frecly protruled, even when the animal is not swimming, but pusling its way among the tangled alge . . . Both the form and mamers of this sjecjes strike the observer, at once, as unusual. It swims almost constantly; and athers the surface whon in fireslom". Ich babe oben ganz andere Angabon von meiner Art weliefert.

Noeh ähulicher shrint dir Art $N$. forcipute (Ehrenberg) Gosse, vom weleher Gosse an J'I. XVIJJ Fig. 1. 1 a mol I h Abbilelungen liefert, aber

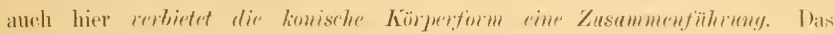
Räilerorgan kleidet bei $X$. forciperta mur den vorderen Thril der Enterfläche. Das (rehirn wirl "semi-opaque" gemamnt, mud es heisst weiter "an ample brain descents into the oeciput, whose pramidal tip. for a small space, is oceupied by a well defined gramulation of elear brown tissue, not white by reflected light and so not eretaceous; on the frontal cond of which is seated a broal,

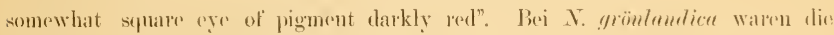
loicht rersehiebharen Kalkkörner sehr rentlich. Das Ange war auch kleiner. Die wichtigste $̈$ hnlichkeit zwischen diesen beiden Irten bilden die \%ehen, welche auch bei $\mathrm{N}$. forciputa plitzlieh zugropitzt werden. Aber anch die

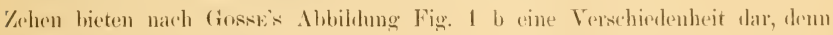
die versehmälerte spitze ist chen so lang wie der basaltheil, was bei den \%ehen ron $N$. grönlaulica nieht der Fall war.

Nachdem ich von N. forripute zu sprechen Veranlassung gehabt, kamn

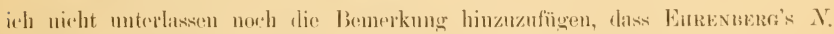

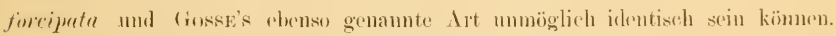
In Enrexbrat's Diagnose heisst (s: "Notommata corpore elomgato, parvo, pedis digitis longis, sippe decussatis, oeulo maximo" ${ }^{1}$ ). Emkexberc's Ablhildung ${ }^{2}$ ) seiner $\mathrm{N}$. forciputa zeigt auch eine andere Körperform, lange, schmale mod

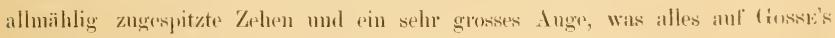
Abbiliung ganz amlers aussieht.

32. N. sp. Fig. 2บ " $, b, c$.

Aubh diese Form habe ich za kriner anderen lrïher beschriobenen fïhren kïmnen, finde indesiens sowohl die skizae wie die Notizen mugenïgend

1) Ehrenberg 1. c. s. 428.

$\left.{ }^{2}\right)$ 1. c. Taf. I.I, Fig V. 
fiir eine Namengelnmg und will also ohne dieselbe mit einem Nimen zu belegen eine kura lieschroibung geben. Ich fincle dieselbe am näthsten mit der vorigen von mir beschribenen Art vorwandt. Wie diese ist sie sackförmig, llümbäutig und besitzt einen sehr kurzen Fuss. Sie hatte dieselbe Länge wie meine vorige Irt, aber die Breite war viel geringer, 27 Mik, welehe Vuschiedenheit nicht allein ans versehiedenen Zuständen erklärt werelen kamn. J)ie Zehen hatten anch dieselbe Länge, 7 -y Mik. Sie zcigten nicht jene plötzhiche Thickenabualnme wie bei der rorigen Art, somelern wurden allmählig zugespritzt. Der Kopf war gewiss auch demjenigen der $\mathrm{N}$. qrönlandica ähnlich, jedoch wax sine (xpenze zwisehen dem Torderende und der Énterfläthe vied dentlicher horvortretend Fig. Qㄴ b. Las nackenstänlige Ange trägt hinter sich einen glcichen Kalkbeutel. [Her Magen war vom Darme nicht so deutlich ahgeschnürt. Teh komnts krine Einschniirung sehen. Die Drüscmzellen dess Magans komnten anch nicht dentlich gesehen werden. Thesonders muss ich

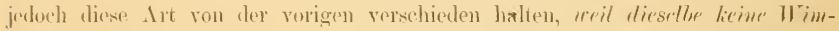
perolume lexass. Freilich wah ieh das Thier nicht sehwimmen. Bei der vorigen Art Wares indesen die Wimperohen anch in ringerogenem Zustande soln. dentlich. (tosse bemerkt von $\mathrm{N}$. brorhyota, dass die kloinen Vimperohren in

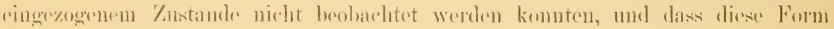

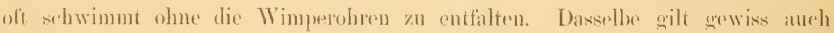
von anderen Notommataden, aber gewöhnlich habe ich die Wimperohren aneb

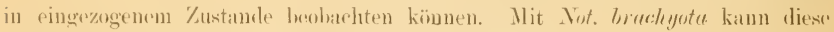
Art wegen des Vorkommons rines Kalkbentels niclet identiseh seiu.

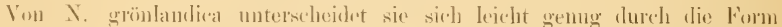

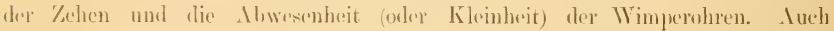
in der Lebensweise wich sie von $\mathrm{X}$. grönlemelien ab, wolche Art lebhalt war, währond dieso tommer träge kriorlenel geselen wurde.

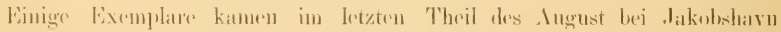
zour fieolachitung.

$$
\text { 3:3. N. reler n. sp. }
$$

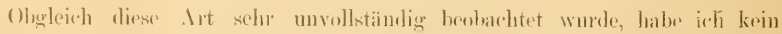
berkenken theselbe mit cinen Namen zu belegren, weil sie mir von den anderen so sitharl getremat sedicn. 


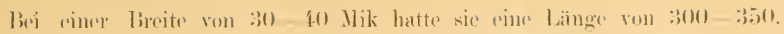

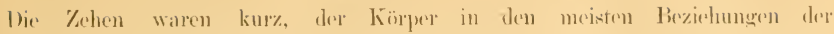

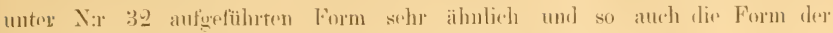
\%ehen. Das nackenstandige Inge besass keinen Kalkbentel.

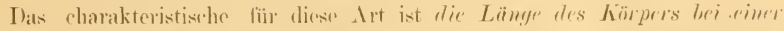

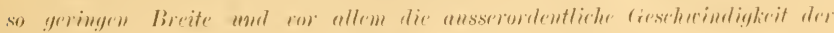

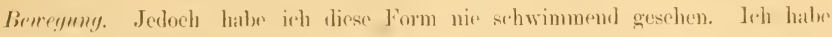
kamm bei irgend einem anderen häderthiese so sehnelle bewegungen beobarbot.

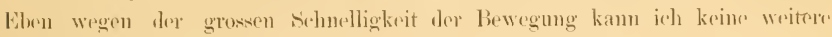
Anfklärmngen mittheilen, denn on war njeht möglieh dax Thier zwiseluen den

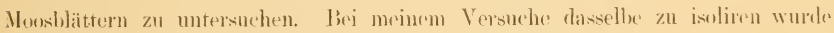
der Konptheil zerrissen. Der Kö̈pes war nämlichs sehr weich.

\%wri Individuen wurlen lei Jaknbshavn zusimmen mit der vorigen Art bisbachtet.

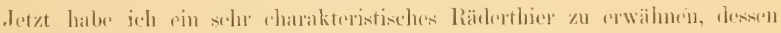

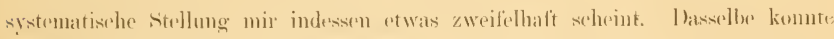

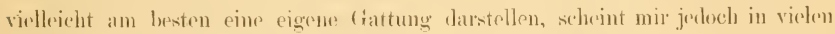

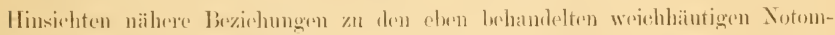
mataluten anlzuzeigen; und ich riche es deshalb ror datiselbe unter den Namen

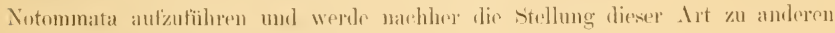
fribler bekamnten Irten besprechen.

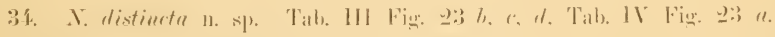

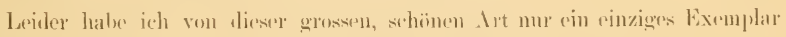

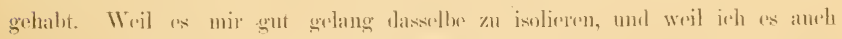

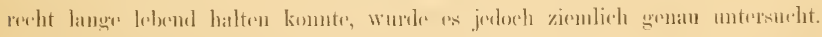

Der lange, breite Körpere sehmälert maeh den Enden an ab. Wie llant ist

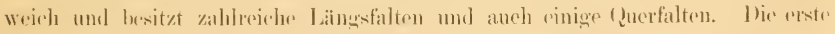
von diesen letzteren befand sich gleich hinter den 1 imperobren, die zweits

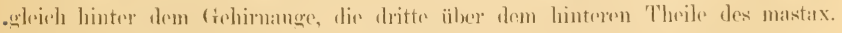

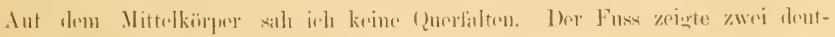
liehe ciliesler, die auch pin Längsfalte zoigtrn. Ihoselle war mu am ersten Fissgliede leirlit sichtbar. l'ei der Stullung, welche das Thier später cinmahm 


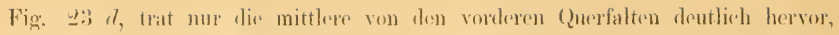

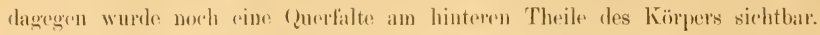

1)e Kopl ist nicht alogesetzt, das schräge aldallemde Vorderpude geht ungrefähr wio bei $\mathrm{N}$. grönlandica ohme Grenze in die Enterfläehe übes. Dus

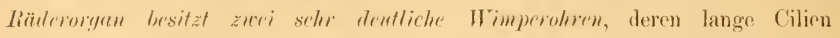
ans den in ringozogenem Zustande der limprohren grubenähnlichen Stellen dentlich herroragen. Ich muss indessen sehon hier hemerken, dass ieh diese Wimperohren nie bei diesem Thiere entfaltet sah. I'nmittellar vor denselben ist der Kopfrand ein wenig ringedriekt, hei " anf der Abbildung Fig. 2:3 a. Der vordere Stirmand st verlänft quep zwiselsen diesen beiden

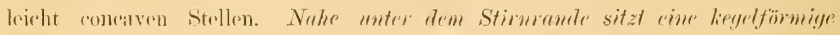
Erholum! stli, an teren sieiten ich verseliedene Male zwei kleinere silh, Fịg. I:3 ", b. Jener stirukegel kann ziemlich bedentend hervorgestreckt und wieder aingezugen werden. Derselbe schien mir nackt, ieh konnte weder Cilien noeh Tasthare an drmselben rnteeken. Ieh bramehe wohl kaum darauf hinzuweisen, dass dieser Kegel gar nicht mit den Faltenbildungen gleiehzustellen isk, welehe als Cinticularfortsïzo bei vorschiedenen Notommataden reeht oft heobachtet werden.

Wem man das Vorderende von vorm und unten betrachtet, erhält man

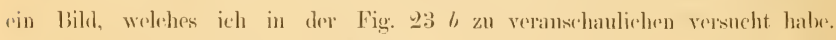
Man sielat da dis basis des Stimkegels von einer nierligen Erhebumg, dis: kurze ('ilien trägt, umgeben. Von den seitlichen Grenz'n-des Ringes wirh ane kurze (Cilienreilse ab, die mir auch äber die eingezogenen Wimprerohren

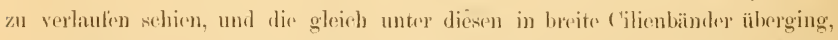
watehe sich weit nach linten von der Mundölthmng strexktrn. Die Mumbäflinng lag in einer rinnenförmigen Vertiefung. zwisehen den Cilienbändern. Wahseheinlich gingen die Cilienbänder ganz an die Seitenränder des Kopfes.

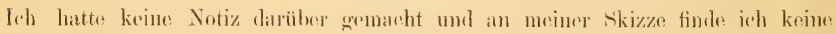
('ilien an diesent änsserston liändern gezeichnet, aber denke, dass ioh as mus

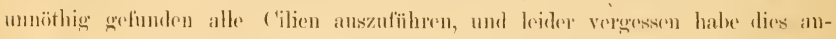
zmelenten. Von der Mundiffnung leitet rin kurzer rang zum schlumbopt. Die Kiefer waren ziemlich stark und noch dem forcipaten Typus gebaut, mel

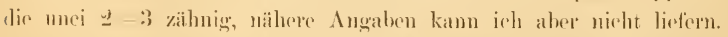

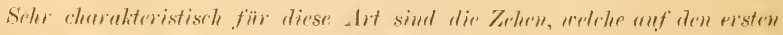

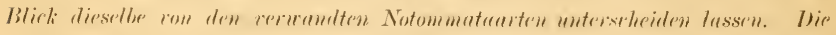

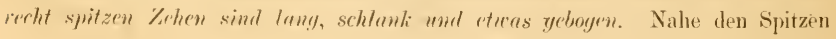


sass auf jeder Zehe ein kleiner gräuzender Knoten, welchen ich als zulällige Bildung rom erhärteten Sekrete der Fussolrüsen auffasse. Eben da glambte irh nämlich die Ansmïndungsstellen der Ausfïhrungsgänge der Drü̈se'n zu sehon.

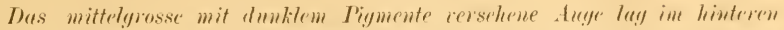

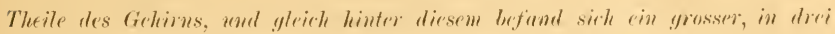

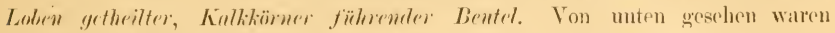
dis seitentheile des Bentels noch eimmal in drei kleinere loben getheilt, Fig. 2:) $c$. Aber ausser diesem l'ignentflecken, weleher dem normal aultretenden Auge der Notommataarten entrpurcht, funden sich bej dieser Art mebrere amdere sehr deutliche pigmentirte stellen. Das Pigment dieser Flecken war aber nieht wie dasjenige des Nackenauges dunkel violettroth sondern gelboth. Fiu soleder Flerli lug im Busultheile des Stimbergels Fig. 23 " und 23 b, zarei andro"

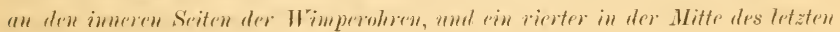

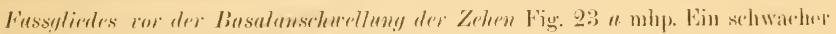
Flecken wurde aurh über dem mastax gesehen. Alle diese Flecken zagtru keine seharte Grenzen. Ieh sah keine hesondere Haare von ihmen ausgedurn.

Neben dem gelbrothen Flerken in der Mitte des letzten Fussghliedes lagn in jodem seritentheil desselben ciliedes ein kleiner, gliinzender, dunkelvioletter

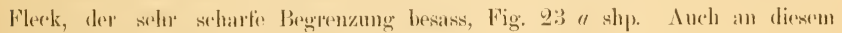
kleineren Fleck komnte ich gar keims Iarare entdecken.

Über die inmeren Organe theile ich mu das folgende mit. Viele Dinger

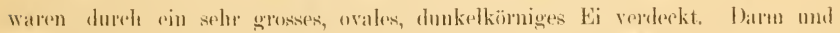
Magen waren dentlieh rom rinander abgesetyt. An der Magenwamd sall ioh sehe grosse Kellen (ieh habe in den Notizen sogar ron einer grossen Kahl

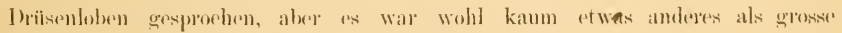

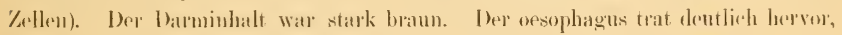
mol dio Magendrïsen sehirmen mir gestielt. Der Exerotionsappanat zeigte schr dentlich joderseits droi Wimpertrichter mit andfallend langen Flimmerzungen. Sie lagen alle drei im vorderen Körpertheil. Mäglielnerwaise waren einge hintere von den äbrigen bingeweiden verdeckt. Die Exoretionsblase bot niehts besomderess dar. Jis Fussdrüsen waren gross und wenigstons, wemu dej luss wie gewöhulich ofwas aingerogen war, seln dentlich lohirt.

Die: Länge des nicht gatn\% gestreckten Thieres war g:30 Mik. Die Breitewar fol) Mik. Dif Länge der Kolen hetrug 30 Mik. 
N. distimete worde bei Jakohshave il. 26 dug. gefunden. Das beobachtete Thierehen war nicht sely lohhalt, aber konnte anch nicht träge gramannt werden. Es war so hoeh, dass es nicht dureh Ilate gexen den lruck der J)eckglïser grashitzt werden komte, weshall, es sich erst frei bewegen komte, nachlem

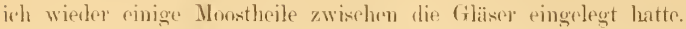

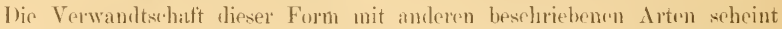
mir nicht so selır gross. Mit den in der änsseren Körperform etwas ähnlichen

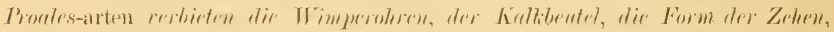

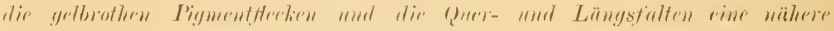

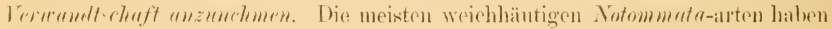

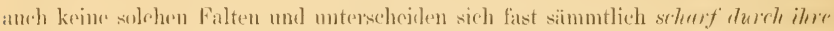
liurarn, dirlern Zehem. Netommetu ansutu besitzt zwar lange etwas gehogene Zehen,

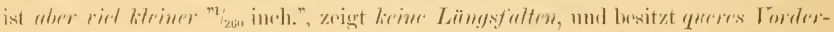

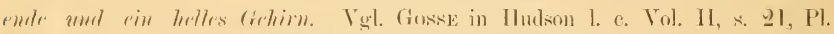
XVII, Fig. 3. Notommuti ryotopus, welehes Räilerthier cinen mätehtigen Kalk-

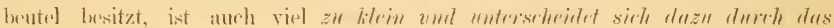

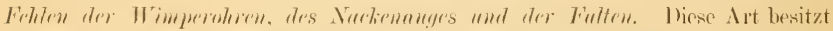

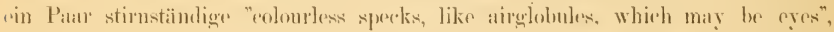

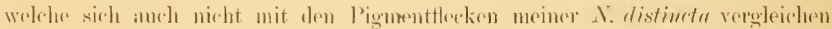

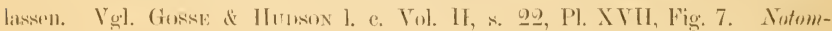

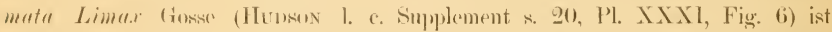

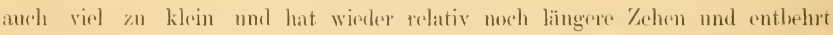

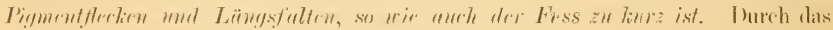

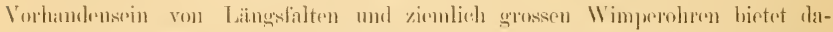

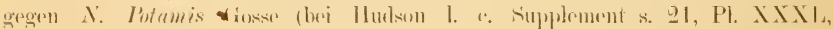

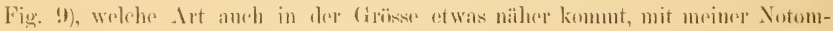
mata distineta grösisere C̈hnlichkerit dar. Die Untersehoilungsmerkmale sind

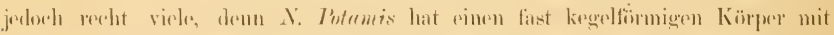

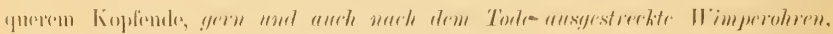

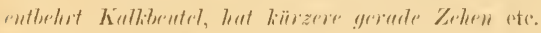

Mit den diten der Crattung Eosplowe muss auch diese Irt verglichen werden, weil jens Ciattung mehrere Pigmentflecken bexitzt. Diese haben jedech

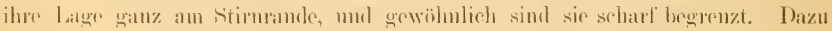

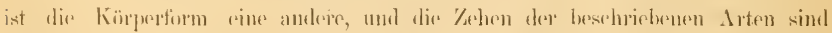

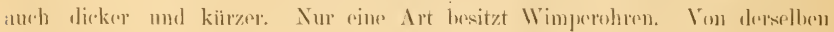


muterseheidet sich indessen .I. distiuctu anch dureh die Form des Kontes.

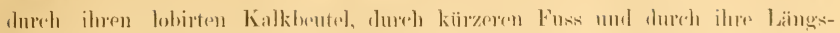
lilten.

llätte ich ein grössere Inzahl rom Exemplaren gesphen mul boi allen die Pigmentflecken kmotamt gefumelen, wiirde ich wohl anf dieselben, die

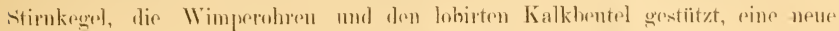

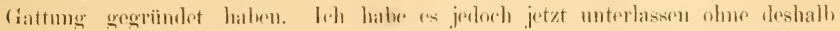

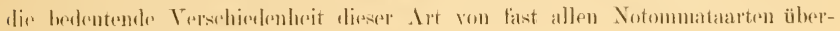
selion \%11 haben.

Diese Pigmentflecken selwinen mir an näelssten mit denjenigen bej

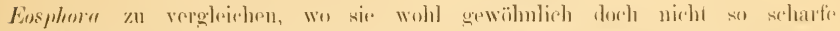

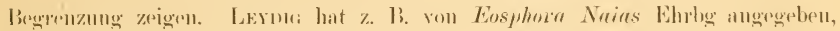
dass Ehrenbergx stimangen keine Angen sejen, weil die gelhrothen Flecken

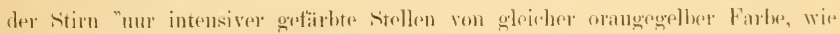

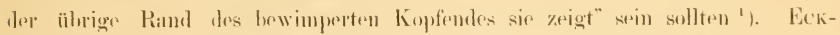

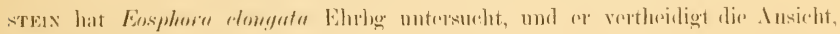

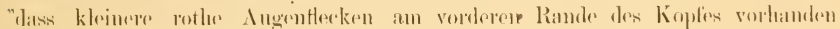
sind" 2). (rosse hesprielst anch diese frage und sigt "T lave no hrsitation in fromomoing them to be striefly amalogous, with what we all exes through-

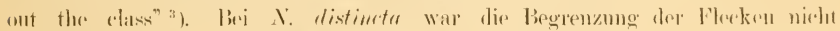

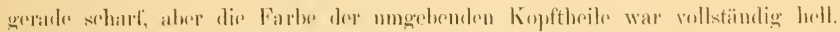

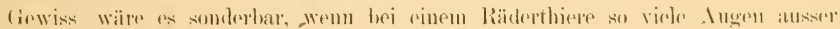

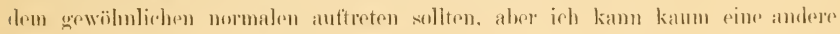

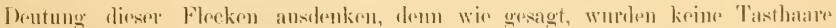

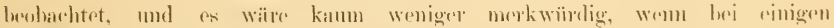

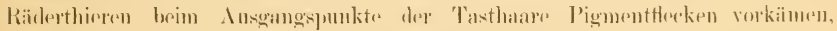

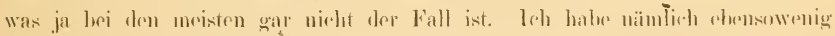

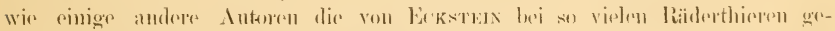

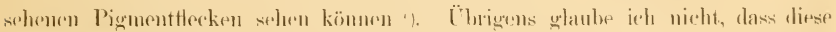

1. 1. r. s. fil.

3 1. r. s 367 .

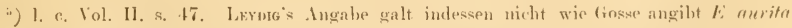

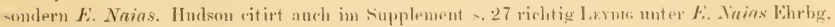

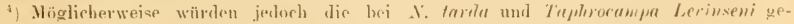

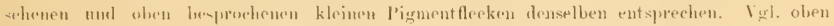
Sis $4 x$ und 5i).

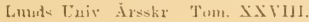


Ecksters's Pigmentflecken den grösseren gelbrothen bei $N$. distiwrtn entsprechen kïmen, sondern eher dass sie dersolben drt sind wir dir kleinem seitlirhen

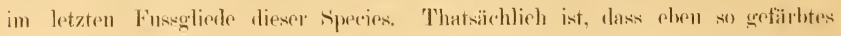
Pigment bei vielen Philodimu-arten in den normalen Angen lingt, währent bei anderen Individnen und Irten dunkelrothes oder violettrothes Pigment in den

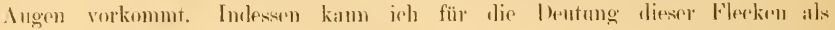

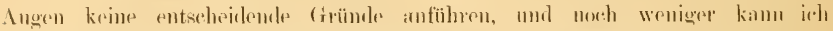

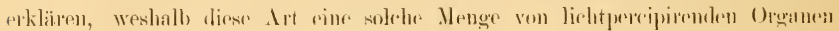
brauchen sollte.

\section{3.). N. Tompipes ก. sp. Fig. 20 a, l, c.}

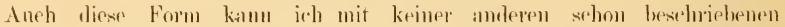

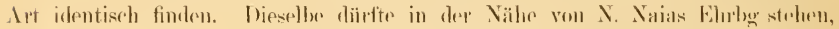
mul ieh glauhte sogar eine Zejt lang, dass sie zusammengeführi wrelen könutıu, aher genatirere Vergleidmugen hahen mieh besseres gelohrt.

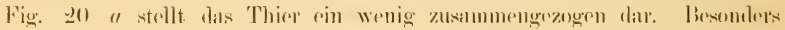

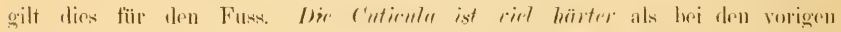
Formun, kam aber nicht gepanzert genamnt werden. Im stïrksten suhium mir

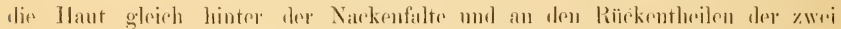

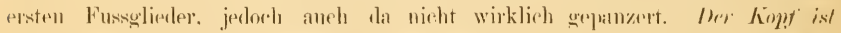

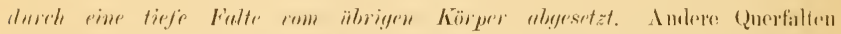

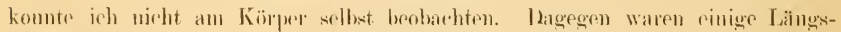

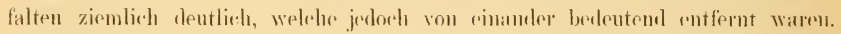
Die form des körpers ist vom olwen gesehen beinahe pektamgulär. Dep lass

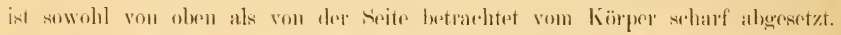

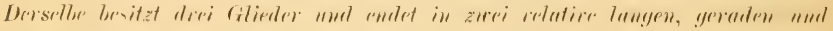

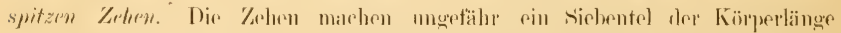

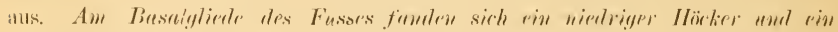

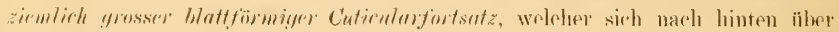

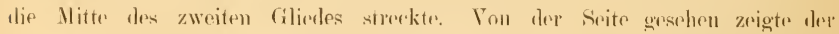
Fuss rine sehwach hegrortretende Linie, die wohl eine sehwarhe Falte angerdeutet haben mag.

Das Kopfende ist ziemlich quer ahgeschnitten, mo das ('ilienkleid streekte sich nieht weit nach hinten ant die Entertaiehe wie bei eingen vorher behandelten Arten dieser Gattung. Es. bildete anch keine Bainder an den sépen des 


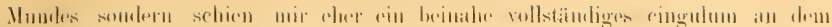

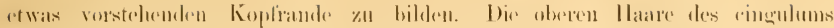

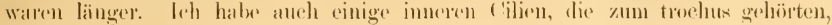

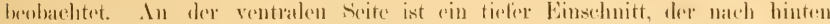

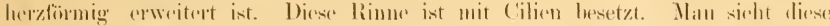

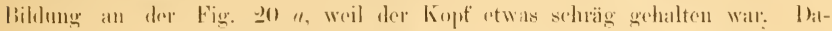

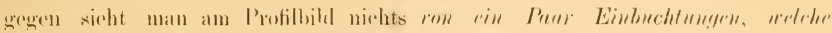

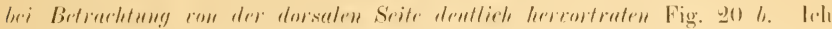

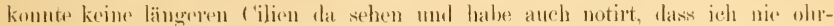

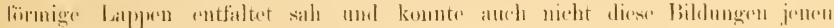

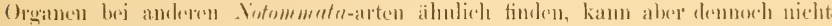
rerstehen, was diese tielien binhudhtungen sein sollten, wenn sif nicht Wimpreorame darstellten.

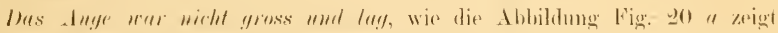

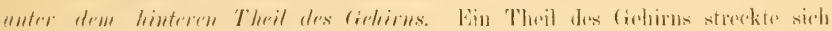
newh weiter mach hinten und war etwas dunkler gefärlst als das iibrige; nirht

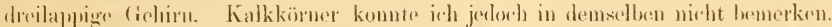

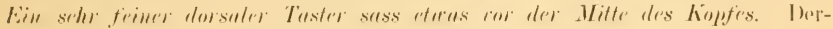

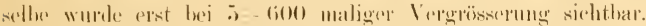

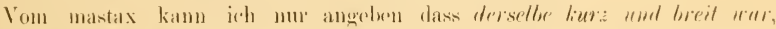

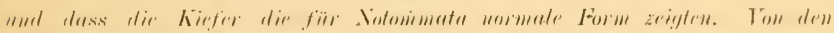

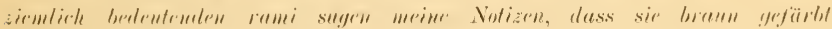
"thir"t.

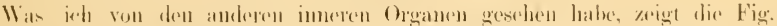

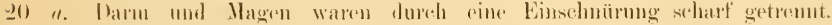

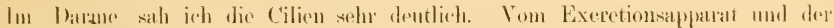

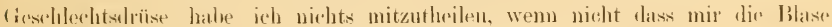
in gentiillen, erweiterten \%astaude megewïhnlich gross rorkam.

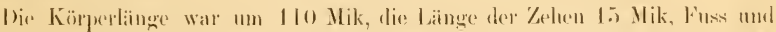

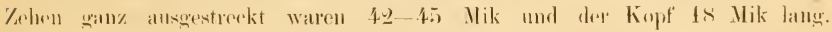

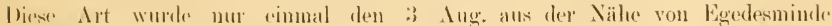
(r)hislten.

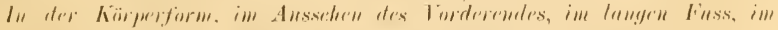

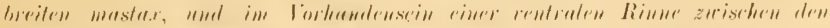

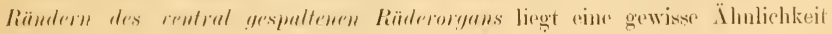


mit $X$. Neicts vor. Jedoch soll bei dieser Int die "eiliated face very long and oblique projecting far out from the ventral surface just below the mastax" sein, was hier nicht der Fall ist. Ëbrigens ist die Verschiedenheit in der Grösse so berleutend. dass irh es kaum nüthig finde die ïbrigen Merkmale hejvorzuhehen. Während meine Form II0 Mik war, ist die Länge des $N$. Naias nath Hunsox's Angabe ungefähr viemal so gross $\left(^{1}{ }_{\text {so }}\right.$ inch). IJir län-

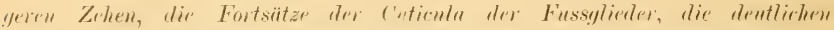

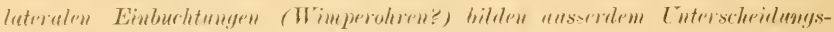
merlimale yrmug. Mit anderen besshripbenen Notommatu-auten scheint mir die Ahnlichkeit nicht so gross, dass eine Verwechslumg in Frage kommen kamm.

Num komme ich zu einer Abtheilumg der Gattung Notommata, wolche dis Arten unfassen, welehe sich Votommatu lacinulutu nähern. Ich kamn nicht glanben, dass es einer richtigen natiirliehen șistematik rutspricht sn divergente Formen in einer Gattumg zusammenzustellen wis die wurmähnlichen weichhäutigen Arten und diese, und deshalb wage idu für diese Formen eime nene Gattung aufzustellen, die ich jedoch corläufig nur als rine liuterguttum! inu Notommatu betraliten reill und nenne dieselbe

\section{(XIV). Notostemma $\mathrm{n}$ subgenus}

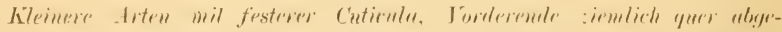

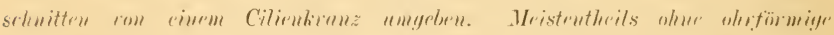

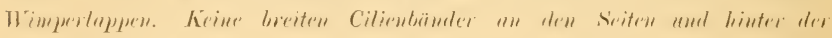

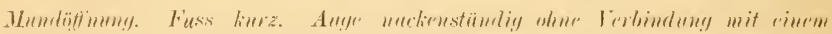
kirllibitel.

Ich lobe in frönland wenigstens drei zn dieser Gattung zu fïhlomsle frten

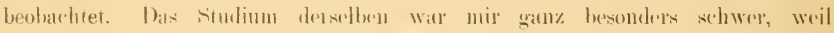
meine literatur hioriber fast gar nichts mittheilte. Ieh habe as atuch nawher

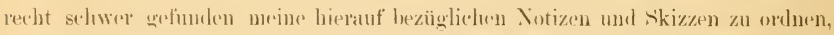
weil die Abbildmugen vom Notommutu larimulatu bei versebicalenen Antoren

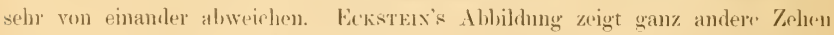

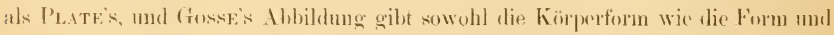

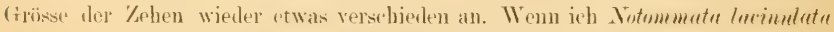
zu meiner (tattumg Votestemmn fïhre, beziehe ich mich besonders auf die

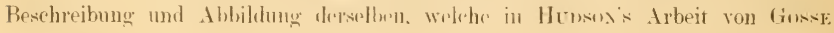




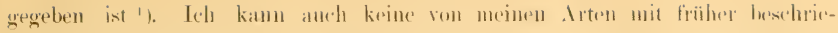

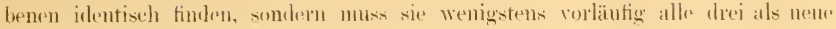
Arten anfïhren.

36. N. malivorephalu n. sp. Tab. III, Fig. I!I ", Tab. II, Fig. I!) h.

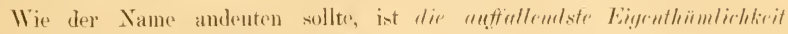

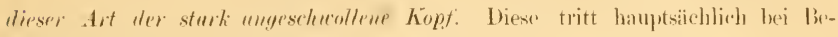
trachtumg von der seite hervor. Der Kojf ist nicht alugesetzt vom ïbrigrn Kürper. Der Körper ist kegelfürmig, mul der Fuss besitzt rin lintars. gr-

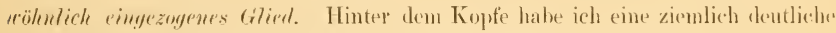
Falte wexehen, und nach Kalizusatz habe ich auch eine hintere (Querfalto beobachten kïnnen, welehe den Körper von Fussgliede tremute Fig. I!) b. Die

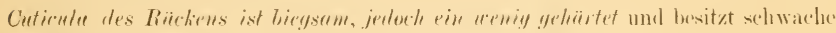

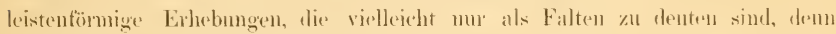
narh Kusatz rom Kali versehwimelen sie recht sehmell. \%wei seitlieler von dirsen Leisten lanfen von olen gexshen recht deutlich in kleind fextere spitzun

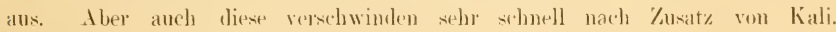

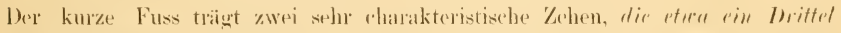

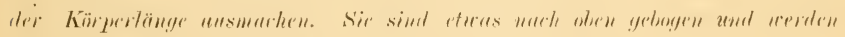

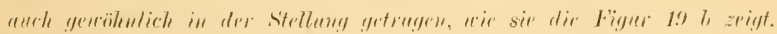

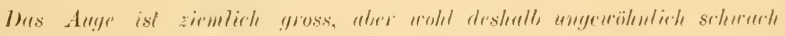

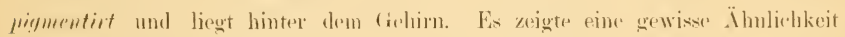

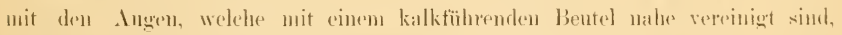

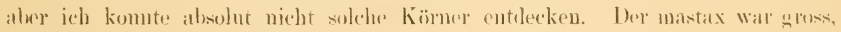
und ich gebe won demselhen, wetelere von der fïr die Familie typiselon form

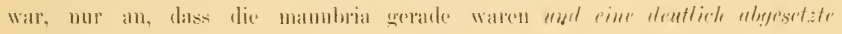
Finswlatte zeigtrul.

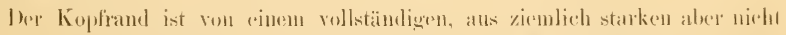

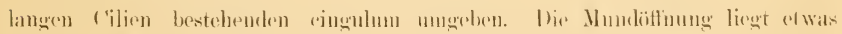

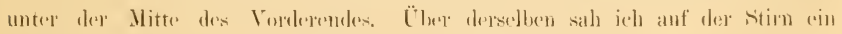
starkes liäsehel ron kuran, kröitigen ('ilien, die nicht su sehnell bewergt

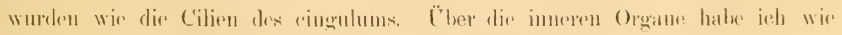
dic Figur zeigt keine Veranlassung atwas mitzutheilen. 


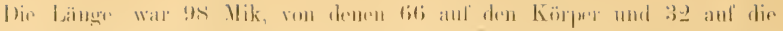

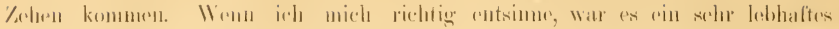
Thierehen.

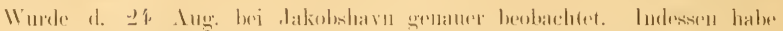

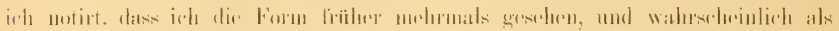
rime Inegendform andigefiast hattr.

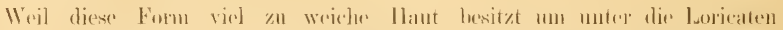

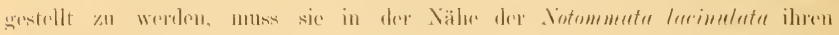
l'lat\% haben.

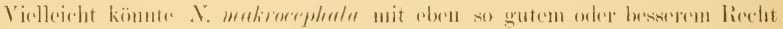
unter den Loricaten motergabracht werden; darou werde ich aber spaiterhin weiter sprerertien.

37. N. "uffinis 11. sp. lig. 17 a, 7.

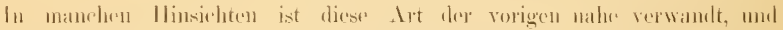

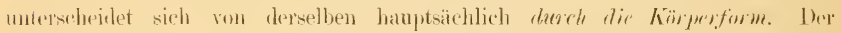
Konf ist nicht so grosis. Weshall, der Rë̈eken sowohl nach rom wie nach

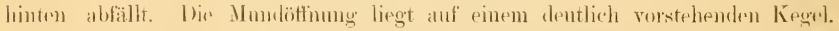

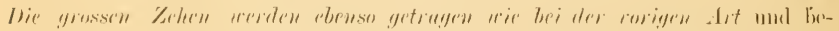

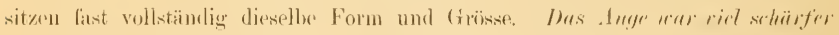

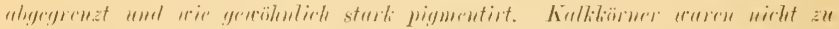
broburliten, obgleich das Gehim wie bei vielen Notommatalen eine hinter dem

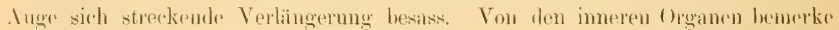

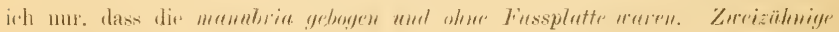

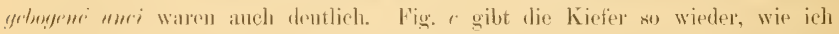

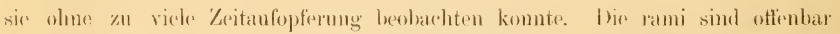
nicht deutlich gexohen, demn ich fasse die hinteren, queren Jinien als Iluskel-

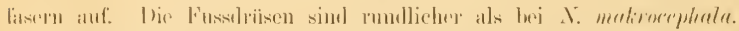

Kïrperlänge !n Mik, von demen 30 : unf die \%ehen kamen.

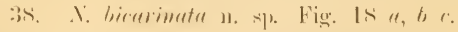

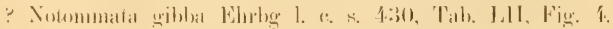

? Proules gribha trosise 1. e. Vol. 11, s. :37.

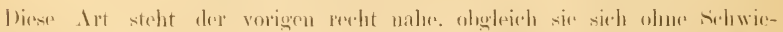

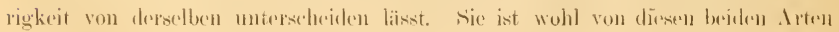




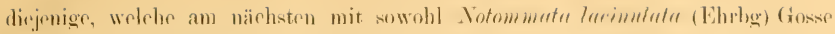

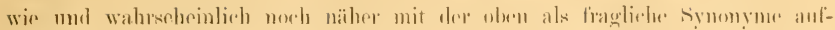
gefiilntenl Ibomles gilly verwamlt ist.

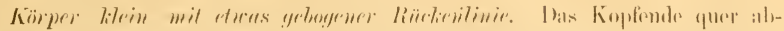

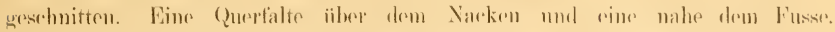

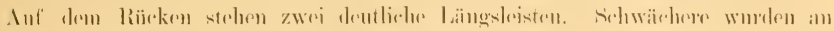

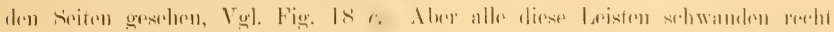

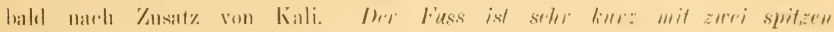
Zelien.

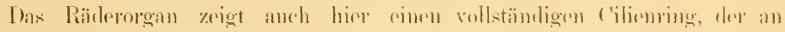

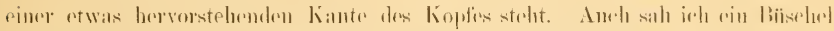

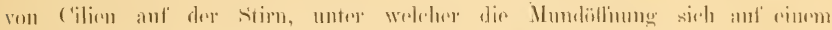

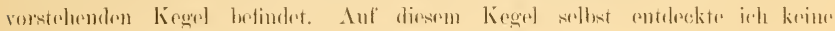
('ilinill.

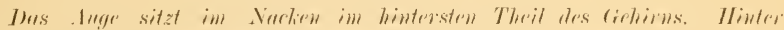

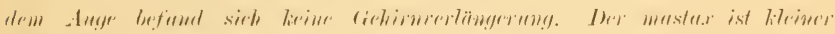

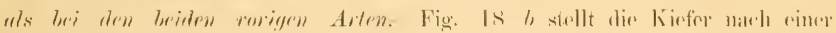

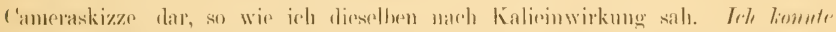

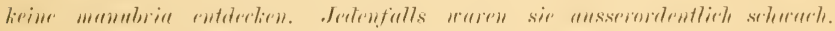

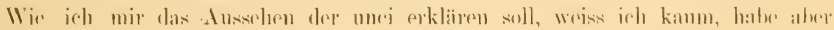

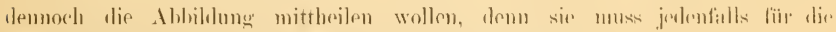

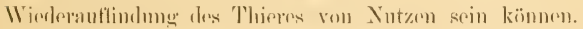

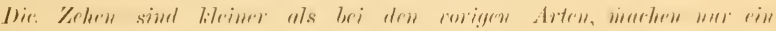

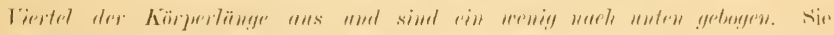

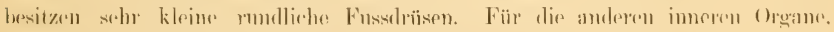

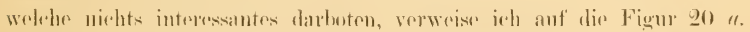

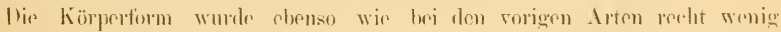
geähdert. Der Kopf mit dem Raiderorgane und der Fuss wurlen eingerogem,

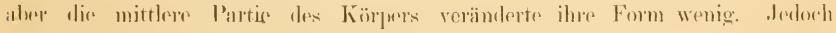

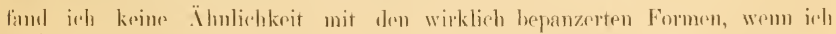
auch zugeben muss, dass dinse Art ebenso wie dir vorigen einen gewissm

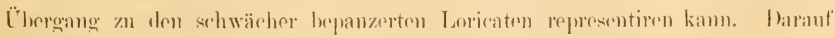
will ioh aber nieht hier rimgehen, denn solehe schwäher bepanzerte Formen

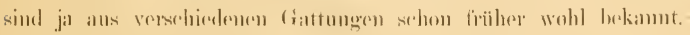


Kärperlänge eines ansgewarlsenes Thieres mit einem grossen Eir is Mik.

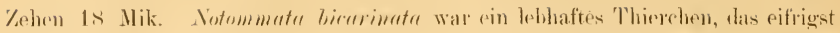

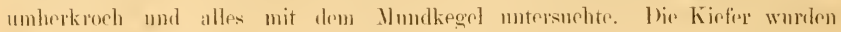
anch nicht sulten ausgestreckt. Dis kijechemele Bewegung war nicht selur

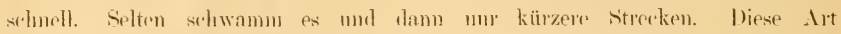

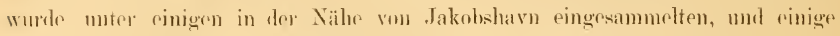

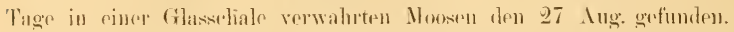

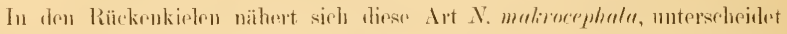

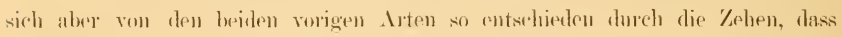

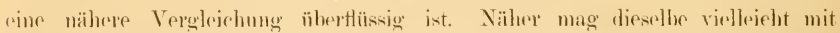

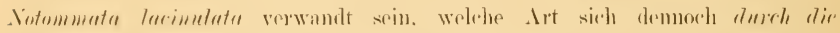

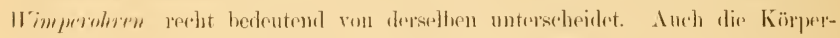
lorm und dis trophi verbieten das Zasammenfüluren dieser Formen.

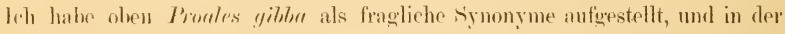
That bosteht auch eine nicht goringe Ïhnliehknit zwischen aliesen Thiepen.

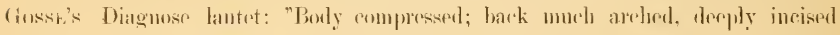
above the stent foot; toes slemder, pointed, slightly deourved" was ja nieht so

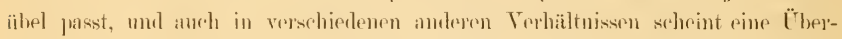
rimstimmung zu bestehen. Als Pegrimblung fiis meinen Namen zeige irlı anf

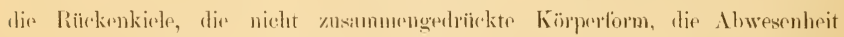
der ïbre die stirn vorstehenden "semiovate plate" und anf die stäkeren Bepanzermeg meiner dot hin. Gosse spricht nämlieh nicht von einer Pepanzerung,

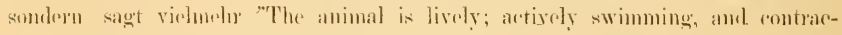

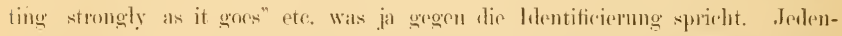

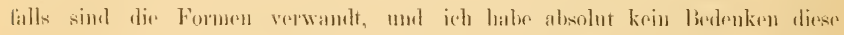

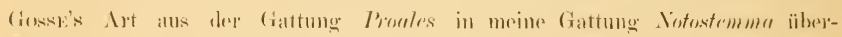

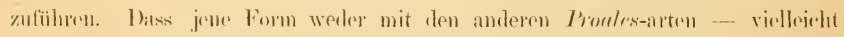

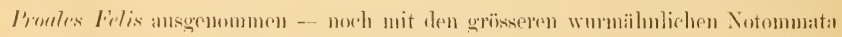
den in derselben Gattmog zusammensteben darf, scherint mir genügend ans der Körperform hervorzugehen. Gosor wirft selhst die Flage anf, ob sie nicht luesser mit Notommatu lucimulutu zusammonzustellen wäle. Weil die Gattumg Notostrmmu niclst rigentlich hepanzerte Formen umfasit, kann ich selbstrerstämllich kein

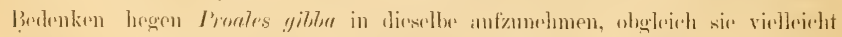

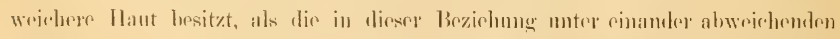

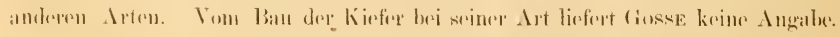


Wweitellos steht die (inttung Notostemme der (rattung' Votommata aum nïchsten. In der Körperform kommen die zu derselben gestiihrten drten auch rinigen Fureularien recht nahe.

In der Literatur halx joh hauptsichlich zwei andere Gattungen gefunden, die hier etwas besprorehen werden müssen. Ilie eine ist rlie Gattung Hiaschiza

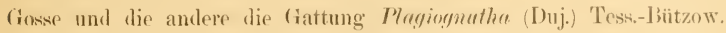

Die Arten der ersteren Gattung wurden ron Goss erst s]rit gefunden. In Hunsox's grosser Arbeit schreilot er: "This well markwd group, now ronsisting of seven speeios, was wholly manspected a fex months ago". Zu den sichen da beschriehenen drten hat derselbe, kurz nachlor noeh fïinf andere getegt. Die Diagnose der frattung ist "Body compressed, the dorsal half of the trunk inclosed in a "arapaee, which is split medially; one eye present, usually cervical; trophi virgate, not distinguishable from those of Fureularia; toes long, blade-like, fureate" ${ }^{1}$ ). Gosse stellt seine Gattung Druschizen in dic Familic Salpinade, zusammen mit den Gattungen Salpime, Diplu.e und I)iplwis. Nach der Anflassung, wolehe ich von den Arten meiner Gattung Notostrmma erhielt, waren sie wohl mit etwas erhärteter Hant versehen aber gar nicht gepanzert, mul ich kamn nieht glauben, dass ich die beiden Theile des Riuckenschildes ïbersehen hahen kamn. Übordies verschwand beim \%usatz von Kali diese Ilaut sehr schnell. Ich bezweifle deshalb gar nicht, dass diose Formen zu weiche Hant besassen um wirkliehe Lorieaten zu sein. Dir Körperform wurdo melur geändert als bei liurella und Mastigocerca Rattus. Indessem habe ich, wie ich anch an anderen Stellen ansgesprochen, die Ansicht, dass dic gepanzerten and mogepanzerten Formen nicht immer wegen dieser Versehirdenlueit zu versehiedenen, Familien gefuihert werden dürfen. Tichneler halte ich eine syste-

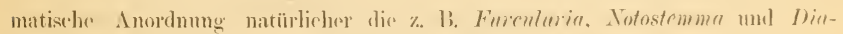
schiza in eine Familie zusammentïlurt und auf diese grabuelle Versehiedenloeit der Festigkeit der Hant kein so grosises fiewioht legt. Unter den von Gross besehriehenen Diaschize-arten halte irh keine mit irgend einer meiner obigen Arten identiseh, wemu ich anch ammehmen kömnte, dass Gosse diuse formen als gepanzort anfgefasst häite, oder dass ich das Vorhandensein dieses rigenthümlichen Panzers ïhersehen. Es wäre nicht unmöglich, dass durch kiinltiger Entersuchumgen diese beiden Gattungen rereinigt werden kïmuen. Sie werden dam geviss nicht $7 . n$ den Loricaten geführt werden.

1) Htudson ('. T. 1. c. Vinl. II, \&. 77.

Lunds Enis. Aroskr. Tom. XXYII. 
Ms ich meine Gattung Notostemma anfstellte und die Charakteristik der Arten schrieb, wasste ich norb nieht, dass Tessix-Bützow gewissermanssen dasselbe Berlïrfinis erfahren fiir diese kleineren mit relative foster cuticula versehenen, meh" oder weniger kegelförmigen Arten cine eigene Gattung zu bililen.

Derselbe hat Drmarmx's Gattung Playiogmuller anfoenommen and die Charakteristik derselben sehr grändert (1. c. s. 149). DuJARus führte zu dor so genannten Gattung eime Menge sehr heterogener Thiere, welche or hanjtsäehlich deshalb zusammenstellt, weil sie durch die Form ihres Kiefer von allen anderen Fureularien uetrennt sein sollten "). "Machoires à bumches parallides tourníps dn même coté et reourbées vers le bord cilié, aree une tige rentrale (Fulermu) droite, tres lomgue, élargie à ma base". N'eiter ist der Kö̈rjer "oblong courbí et convexe d'un coté, on en eornet obliquement tromqué en avant, at terminé en arrière par une quene phus on moins distinete portant deux stylets", mul die Thiere bexitzen "mo ou denx points ronges oruliformes". Iney

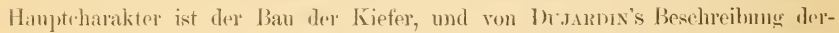
selben sagt (iosse, welcher ja unter allen Forsehern diese Organe am genanesten stmelirt lat: "This description is so vague, that it might embrace a multitule of willy remote spepies and semera, while it does not at all indicate the true pecoliarity of the organs it protesses to define" ${ }^{2}$ ). Dusarmx lat anch zu

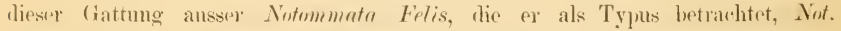
lerimulule und Distemmin setigerum und vorsehlagsweise Notommeta Tigris, Iniglena catellina (Diglema larnstris?) uml eine Art, welche er als Notommatu hyptopus Ehrbg auflassen will, die aber, wie mir scheint, viel eher eine ('olurnsArt soin diurfte, führen wollen.

ITem ieh von der ('lanaktristik der Kiefer und von den zwei AngenHecken absele, so könnte diese Charakteristik recht gut auf meine Notostrmmu-arten passen. Tessix-B̈̈тzom hat schon eine Menge rom diesen Di:JARun's Jiten ansgeschirelen und gibt seiner Gattmng die folgende Diagnose: "Gicstalt länglich oder keilförmig. Fnss mit zwei bauchwärts gekrïmmten, nirht sohr langen Zehen. auf der Oberseite nit vier Borsten. Ein Inge im Narken". Von diesen Charakteren passt nicht auf meine Formen, dass der

\footnotetext{
1) Marms, F. Historie Naturelle des Zoophytes ets. Paris 1841, s 65:1

2) finser. l'. H On the mandueatory organs ete., 8, 432.
} 


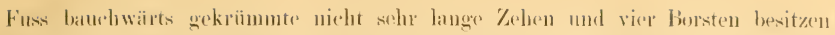
woll. Leh halte diese Merkmale fïr weniger wichtig und fïlure in meiner fiattmong Sotostemma formen zusammen, die sich in dieser Hinsicht verschieden ver-

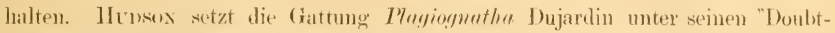

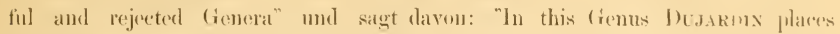
togetlere Not. larimulata, Distemma setigerum. Rattulus tigris, Dightena atellina, Noteps Ilyptopus ete. on aceount of a sujposed similarity in their trophi (l. ". silpplement s. (60).

leh bezweifle dmehaus nieht, dass Tessis-Bï rzow's und meine Arten zu derselben Gattung geführt werden dürfen, wemn sie nieht alle in biusehiz"l dadureh Platz finden können, dass die Diagnose dieser Gattmug bedentenul "rweitert wird, kam aber nach dor so nngleichon Lmfassung und Charakteri-

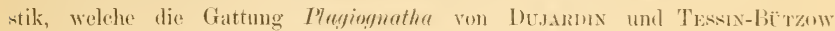
erhalten hat, und weil die l)iagnose des letzteren gar nicht anf meine Artem

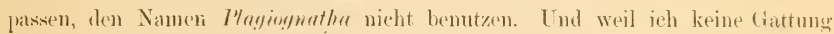
finde, wo meine Arten olne Kwang untergebracht werken komiten, muss ich

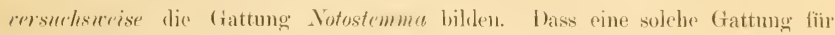
kleinere Notommataïhnliche Formen in rinem natürdichen system der Räder-

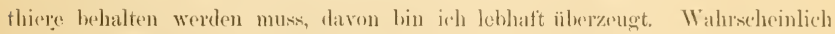
muss auch eine andere entsprechende (rattung fïr in gleicher Weise organisirte Fureularien aufgestellt werden.

\section{Monommata Bartsch.}

3!). 17. longiset" (Ehrbg) Bartseh Fig. 14 a. l.

Vorticella longiseta (). F. Müller I. (. s. 295, Tab. XIII, Fig. 4), I0.

Notommata lomgiseta Ehrbg. 1. (. s. 43.), Taf. LIII, Fig. 11.

Notommata lomgiseta [erty l. e. s. :3s.

Nonommata longiseta Bartsch l. c. s. 41.

Monommata longiseta Evferth I. e. s. 110.

Notommata longiseta Eckstein I. c. s. 3(i.j.

Nonommata longiseta Blochmamn l. c. s. 10:3.

Fureularia longiseta Fosse 1. e. Vol. 1I, s. 46, P]. XVIII, Fig. I6.

Monommata longiseta Tessin-Bützow 1. c. s. 151. 
Diese leicht kenntliche lrt wurde in der späteren Hälfte des Monats August ziemlich allgemein. Ich sah sie wohl in den meisten, Moosrasen führenden Wiaseransammlungen, welehe ich in der Gegend von Jakobshavn mintersuhte. Walnscheinlich babe ich sic auch rorher eimmal in Egedesminde gesehen. In meinen da genachten Notizen steht nämlich: Eine Notommata mit ausserordentlich langen Zehen. Über die Verwandtschaften dieser Form ist lie Auffassung, der Autoren recht verschieden. Ich werde deshalb, nachdem ich einen Anszug aus meinen Beobachtungen über den Bau dipsos Thierchens mitgetheilt, einen Versuch machen meine Ansieht, dass B.skTscu mit Reeht für liese Art eine eigene Gattung anfgestellt hat, zu begrïnden.

Ieh habe bej keinem anderen Rialerthiere den Körper so weich gesehen. Die Form des Körpers ist ganz unglaublich veränderlich. Man würde kanm glauben, dass amoh dir weichste Rotiferencuticula so bedentende Formverändenungen relauben kïmnte. Es ist fast wie bei riner l'lanarie, die Kontraktionen geben aber vie] schneller. Die gewöhnliche Form beim Kriechen zeigt meine Fig. 14 o.

Das querabgeschnittene Kopfende trägt am Rande ein cingulum, ron welchem sich in der ventralen Mittellinie einige Cilin abzweigen und sich "twas nach oben ansbreiten olne jedoch die Mundölinung zu errejehen. Anf der Stirn steht in der Mitte pin Bäsehe] ron recht kräftigen ('ilien, und von demselhen schien mir auch en Band von kïrzeren Cilien nach unten zu gehen mol his an den Mund zu reichen. In den Seiten und gleich unter der Mund̈̈ffinumg sah ich keine Cilien.

Ich sah deutlich einen dorsalen Taster, ïber das Vorhandensein von seitlichen Tastern wurle ich abej nicht ganz sicher. Wenn sie da waren muissten sip weit narh linten gelegen sein. Gusse sagt: "Ther is a prominent angle on the oceiput, which may indicate a protrusile antema, hut I have not seen it exserted". leh kann kaum glauben, dass dieser Taster pingezogrn werden kann. Eher mörhte ich ammehmen, dass er nach vorn nieder gelegt werden kamm, balte ws jedoch wahrscheinlicher, dass dorsellhe wegen seiner Kleinheit auch in "ausgestrecktem" oder anfstehemdem Zustande leicht genug ïbersehen werden kaum.

Magen und Darm waren sehr scharf getremut und die Wäude sehr dick, was besonders ron den in der Nähe der Einschnürung gelegenen Theilen dersplben galt. Die Magendrïsen waren gewöhnlich gar nicht sichtbar, Nur 
einmal sah ieh die kloim Inschwellumg am vorderen Theilo des Magens, welehe auf der Abbildung mit $d r$ bezeichnet ist. (tusse salgt "the courtractile resicle is very large". und so habe ich sie anch gesehen und gezeichmot. Vom Exeretionsapparate sah ich mu einen Wimpertrichter, der voru nehru dem mastax lag, und ein kleines. hinteres Stïek des einen Längskanals.

Die grönländischen Exemplares scheinen kürzere Zehen zu haben als dic europäischen, dem bei fast allen Verfassern finde ich die Ingabe dass dis

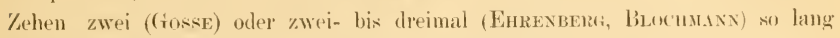
wis der Könper sein sollen. Bei mehreren Exemplaren habe irh deshalb dic frösse der Zehen mit der Körperlänge verglichen und fand ohne Ausmahme die kleine Zehe gleich lang wie ler Körper und die grössere beinahr anderthalh mal so lang. Eine Messung, die als typiseh angegeben worden kamn, gat):

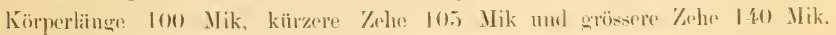

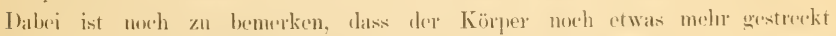
worden konnte: Die Kehen werken gewöhnlich mohr oder weniger gebogen gretragen. The kleine ist öfter gerade als dic grosise.

Hie grrösste Eigenthümlichkeit jener Zehen sind die cuengestreiften Muskel-

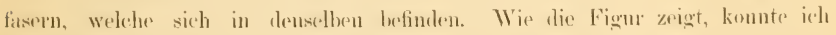
in jerler Zehe zwej relativ starke Fasern heobarehten. welehe von der Golenkstelle der Zehen am Fusse allogehen und sieh sohem im proximalen l)rittel oder Viertel ansetzen. Die eine von diexen Nuskeln war konstant kïrzer als die andire.

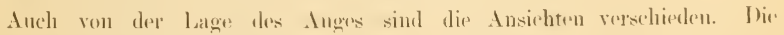

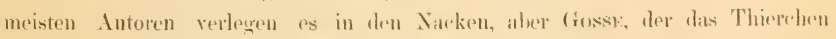
ron vier verselienlenen stellen in siblliwhen bingland untersudet hat, sact indessen: "A great brain rarries an opanpe terminal mass at its point. The frent, viewed dorsally, has the outline of a law rone with a single minute red

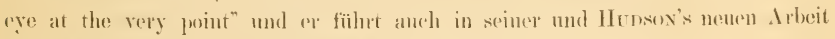
diese Art zu dor Gattung Fureuluriu.

Ieh hale dagegen an meiner Skizz. und in meinen Notizen nur ein im

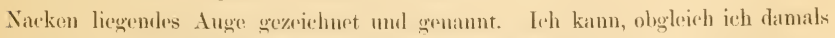

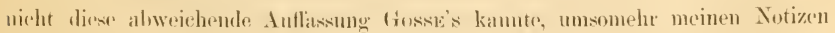
in dieser Frage Vertranen sebenken, weil ich notirt habe, datss ieh bei einigen Individuen (vielleicht allen, das steht aber nicht anshriicklich) an den reitentheilen des Gehirns eigenthümliche, nicht kleine gelbrothe Flecken beobachtote. 
was wohl wahrseherinlinh macht, dass ich atreh den rothen frontalen Fleeken

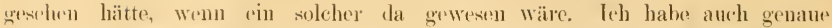
Notizen ïber das Räderorgan gemacht und eine skizze über das Kopfende von vorn gesehen verfertigt, mol dabei mïsste irh ohne jerlen Zweilel ein frontal strhendes Inge benerkt haben. Es seheint mir anch moglanblich, dass ioh den feinen dorsalen Taster gesehen hätte aber nicht das frontale Arege. Wreil die Sische für die Verwandtwhatt dieser Art sehr wichtig ist. hathe ich diese Verhältmisse angeführt, welche meiner Meinung nach für die Richtigkeit meiner Beolachtung sprechen. Diese angenommene frontale Lage des Auges hat wohl fiusse veranlasst diese Art in die fattung Furcularin aufaundmmen. Wenn jederh das Inge nackenständig ist, so fällt wohl der Hauptgrund dieser Iuflassung. Jie Bewegungsart ist so eigenartig, dass sie anch nieht gern für eine nähere Verwanditsehaft mit Furculuria als mit Votommetu sprechen kann. Momommatr longiseta sehwimmt sehr gut, schmell oder langsam. Oft genug sieht man sic cine Zehe nach jeder seite in entgegengesetzten Richtungen strecken, oder sie stelzt fast gespensterähnlich anf ihren langen \%ehen hinwog, welche sie auch in anderer Weise zu blitzschnellen Verändermgen der Beweg'mussichtung und zu recht belentenden spriungen benutzt. Ith glaube, dass die Gattung Monommete mit sowohl Notommate wie anch mit Fureulariu recht nahe verwandt ist, mol werde deshalb keine Worte daran spenden anseinanderzusetzen, weleher der beiden sie näher steht. So ansserorlentlieh nahe kommt mir nämlich diese Verwandtschaft nicht vor, und ich kann mich nur wnmlern, dass Gosse, machdem BARтsch eine eigene Gattung für diese Form grogrindet latte ${ }^{1}$ ), dieselbe wierler zu einer anderen Gattung fïhrte. Auch Frkstein, der aber diese Form nicht aus eigener Inschammg kamte, führte sir noch einmal als Sotommutu lomgiset anf. W' Wm auch die Länge dev \%ehen fiir die Begriindung einer Gattmg mgenïgend sein mag, möchte ich grauben, dass neben diesem Merkmal das Vorhandensein von Mhskelfasern in den Zehen einen besseren Grund für die Anfstellung einer Gattung abgibt, als sich tïr recht viele andere von allen Antoren erkannten Rotiferengattungen anfiihren lässt. BakTsen hatte indessen seine Gattung Momommatu so bestimnt, datss sie nicht lango in dem Begritte beibehalten wordon kounte.

1 Sichon
Sippe bilden". 
Zu der neu aufgestellten Gattme führt er nimlich noben der oben luebandelten Form auch Notommuta Tigris Ehrlog, eine Art, deren Platz und Benemung anch, wie wir später sphen werden, bei den rerschiedenen Virfiksern sehr abwechselnd gewesen.

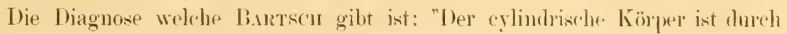
eins zum Theil erhärtemle C'utienla bederkt und geht in zwei lange Fusspitzen ans. Ein Nackenauge". Die gowöhnliche Kürperform der M. longiseta ist nicht so schr einem ('ylinkler älnlich. Wenigstens haben dann die mejsten Notommataden ebenso gut rinen cylindrischen Körper. Bei INimrllı Tigr is ist die Cuticula wirklich theilweise erhärtet, bei $M$. lougiseta ist, wie ich schon obru angegeben habe, der Körper sehr weich '). Die Form und Besehaffenheit der Zehen ist bei den beiden Arten, welche Bantscu in seine Gattung anfuahm, so verschieden wie mu möglich. 1)asselbe gilt auch in Folge dessen fiir alic Bewegung und Lebensweise. Dass Bartscn sis zusammengestellt hat, kamm wohl nur daraus erklärt werden, dass or $M$. lougisetu nicht aus cigener Inschaumg gekamnt zu haben scheint. BaRTscn führte seine neus fiattung m

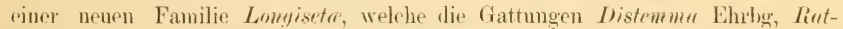

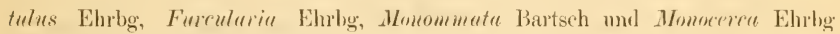
umschloss. Später hat er noch andore Gattungen - Dimorharis? Triverthru, Mastigocrece und Polyartha - in diese Familie eingeführt, wie ich aus einer Arbeit Hunsox's ${ }^{2}$ ) entuehme, demn die Arbeit Rotatoria Ilungaria ist mir nicht zogängig gewesen, Evrertu gibt der entsprechenden Familie den

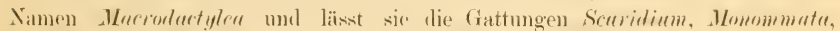

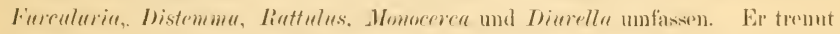

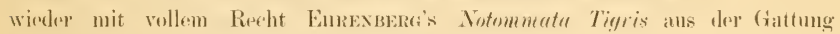
Monommata aus und führt sie. wir mil scheint auch vollkommen richtig, als

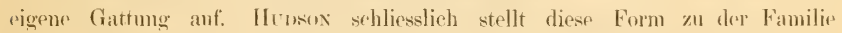
Notommatada, mod Gosse nimmt sie, wie oben dargestedlt worde, in die (rittumg: Finrulario auf:

1) Diese Thatsache ist schon von O. F. Mitukr hervorgehohen. Seine beiden Figuren stellen das Thier in sehr verschiedenen Contractionszuständen dar.

2) IItnos, ('. T., An Attempt to reclassify the Rotifers. Quarterl. Journ. of Microsc. sience, Vol. XXIV. New Series. 1884, s. 335, und Lexckart's Berieht in Arehiv für Yaturgesch. 1878. Bk, II, s. 679, wo indessen mu die nenen Arten angeführt werden. [bitse Bartsu's Arbeit ist ausserdem ungatriseh geschriehen, 
Die Formen, mit welchen Mnmommate in Auftreten und Bewegungsweise vielleicht die grösste Ïhulichkeit besitzt, dürften die Scaridien sein, alıe irh kann nicht glauben, dass sie auch morphologiseh die nächst rerwandten sind, dem Scuridium hat lang ansgezogenen Fuss, in welehem die quergestroiften Muskolfasern sich befimlen, umd ich möchte auch glauben, dase Vommmutı in der Familie Notommatarla stehen soll. Die weiche Hant, die Körperform, songar das Räulerorgan, die Form der Kiefer und die Lage des Auges findet man dal ganz wie bej dieser Art. Dagegen fincle ich die Ausbildumg der Zehen bei den Gattungen Mastigorren (unt Momorerea), Reutulus und Dinrella ganz verschieden. Sie sind ja mehr ofler weniger stachelförmig, stark euticularisirt, wogegen dif Zehen der Monommata sehr liegsam mul mit Muskelfasern versoben sind. Eine besonders nahe Verwandtschaft zwischen Momommatı und jenen mehr oder minder gepanzerten Formen kann ich nicht annehmen, wenn ich anch, wie öfter angerlentet, zu cler Meinung neige, dass die Bejanzrung keine so grosse Kluft zwischen die Gattungen legen sollte, wie sie in riclen systemen gethan.

Auhany. Als ich die Bearbeitung meines in Grönland anfgezeichneten Notizen machte, war mir die in die obige symonymenliste jetzt eingesetzte gename Arbeit von T'Essix-Bï:Tzow leides nieht zug̈inglieb. mul ieh habe darum oben auf dieselbe nicht Rïeksicht nehmen kömnen, will aber hier ein Paar Bemerkungen zufïgen. Er behält Erfertu's Familic Macruluetylon und

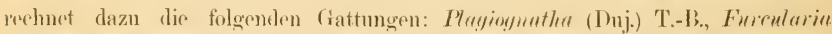
Ehrlog, Momommata Bartseh, Aconthenluctylus T.-Is, umd Srarielium Ehrbg. Zu der von ihm aufgestellten Gattumg Acantloulactylus werden die Gattmogen

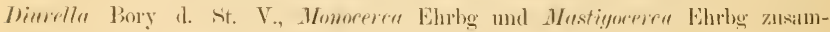
mengeschlagen. Weil ieh sehon oben Eyforth's ähnliche Auflassung hropurben lube, brauche ich nicht weiter hier darauf einzugehen.

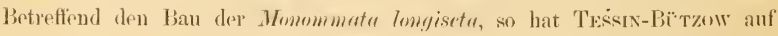
seiner Abbildumg den dorsalen Taster gezeichnet. Er bat auch die lateralen 'Taster gesehen, mol sie liegen weit nach hinten, mgefailu dal, wo ich sie auch zu sehen geglaubt babe. Anf seiner Zeichmung sehe ieh aurh nieht die an den anderron Figmen targestellten Magendriäsen. Vom Ange sagt ar: "Dats Auge ist nicht ein einfaches Ange, wie es his jetzt immer beschriebren wourle, somdern der eigentlirbe, längliche Pigmentfleck liegt in dem vordenen

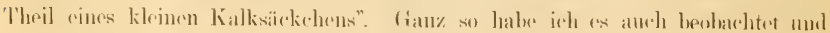


gezeichnet. Von einem frontalen Auge wird nichts gesagt, unil ich kann mich also auch auf seine Bcobachtung gegen Gosse berufen.

In zwei anderen lieziehungen muss ich dagegen abweichende Beobachtumgen vorlegen. Tessix-liärzow gibt als (iattungs-merkmal unter anderen an: "Cuticula mit parallelen Längsfurchen". Von solehen als eonstanton Bildungen finde ieh in meinen Notizen nichts angegehen mol sehe diesolhen ebensowenig an Tessin-liëtzou's Zeichnung wie an meiuer vigenen. Auf der Figur stellt Tessin-Pützow es so dar, als gingen die Muskelfasion in den Zehen bis an dic spitzen. Ich habe es ganz ander's geschen, wie es auch meine Figur zeigt, uml ich glaube anch die Wirkmmg der Nuskeln würle sehwer verstänllich sein, wemn die Zeichnung Tessus-Bïrzow's darin riehtig wäre. Ich habe rleser Frage genane Aufnerksamkeit gowidmet und habe mur im oberen Theile der Zehen Muskolfasern gesehen. Es wäre ja möglieh, dass kloinere Muskelfasern, welche sich länger nach aussen streckton, mir entgangen sind, abor ich kann auch das nicht glauben. Die plötzlichen $T$ mwerfungen der Brwegungsrichtung scheinen mir nur möglich, falls sich die Muskelfasern, welehe dicse Bewegung veranlassen, nahe dem Gelenke der Zohen ansetzen. Grehen sie bis an die Spitze, würde wohl bei deren Contraktion eher eine biegung orler Zusammenziehung der Zehen eintreffen.

Weil ieh Momommata wenigstens eben so nahe mit Notommata wie mit Fmreularia verwandt halte, lasse ich hier einige andere, wohl anch mit Notommata nabe verwandte (iattungen folgen. Wenn ich dieselben zwisehen Momommotre und Furularia stelle, will ich jedoch nicht damit andeuten, dass sir nïher mit Furedurin als mit Notommate verwandt sein sollten.

\section{Copeus Gosse.}

40. (! cambatus Collins. Fig. $25 a, b, r, d$.

Copens caudatus Gosse 1. е. Vol. II, s. 32, Pl. XVI, Fig. 5.

Von dieser so gut kemutlichen Art habe ich bei Egedesminde einige Exemplare gefunden. Früher ist er, so viel ich weiss, nur von ein paar Stellen in Englanul bekannt. Die zwei ersten, welche genauer untersucht wurlen, silmunelte ich den 14. Juli mit Mossen und Algen in einem Moortümpel anf Rüfön, und später silh ich einge andere Exemplare aus derselben Gegent. Ieh habe 
diese Art nieht in Jakohshavn oder Ritonhenk gesehen. Sie gehörte z.n den seltenen Formen. Wegen der ständigen Bewegungen war dies Thierchen sehr schwer zu beobachten, und weil os schon ziemlieh spät Abends war, konnte ich nicht die Intersuehung so genau ansfïhren, wie ich gewünseht häitte. As ich später einige Exemplare unter das Mikroskop, lekam, war jch mit anderen Arbeiten besehäftigt. Ich habe alse keine mit f'amera gemachte Skizze mitzutheilen. Folgender kurzer Auszug meines Notizbuchs mag vielleieht nichts desto weniger hier Platz finden.

Das gemessene Thier war 160 Mik lang. Die Körperhant war sehr weich, Falten waren kaum siehtbar. Einige Inteutungen kamen jedoch vor. Das Halsstïck ist lang und nieht wenig sehmäler als sowohl der Kopf wie der weiter nach hinten folgende Theil des Kö̈pers. Einige dorsale Cilien des Räderorgans waren dentlich länger als die seitlichen. Der dorsale Taster hatte rine eingedrückte Spitze, sah fast wie ein Ilandschuhfinger ans. Ich sehe vieht ein, warum der hintere, lnmbare Taster als der wirkliche Sehwanz des Kürpers betrachtet werden soll, wenn der vordere mor als ein Inhang angesehen wird. Es ist ja ebrn charakteristisch für diese frattung, dass an verschiedrnen Stellen des Köppers Tasteranhänge ausgebildet werden. Gosse hat auf der spitze des "angular prominence" eine "rather short seta" gesehen, und seine Zeichmung Fig. is stellt ein kurzes nach unten starkes Haar dar. Ich hahe drei Ilaare gesehen, von denen das eine kürzer war, wie meine Zeichmmgen es aurh darstellen. In meinen Notizen steht es "drei Iaare oder vielleieht Haarbüschel".

Der Fuss schien mir zwei wirklich abgesetzte Glieder zu besitzen, von d'men das letztere eine schwacho Andentung einer wiederholten filiedermo zeigte. Eis kann wohl sein, dass hier wirklich drei gleichwerthige Glieder vorkamen. Die Zehen zeigten anch etwas vor der Mitte eine sthwache Querlinie. Es war indessen keine wirkliche (relenkbildung, denn ich sah niemals eine Bewegung des Endstiicks auf dem Basaltheil. Der lange oesophagus schien mir fadenfein, dennoch sah ich in seinem lumen sehr dentlich die Bewegung dor Cilien. Ehenso im Magen, der sehr scharf vom Darme abgesetzt war. Der vortere Theil des Darms bildete einen ebensoldhen ovalen Körper wie der Magen. Das hintere Stäck des Tharmes war wieler fadenfein, und sein lumen trat mur deutlich hervor, wemn eine Frealmasse zum After gefülust wurle. 
Ich sab seler deutlich die lateralen Taster, welche weder bei Coubixs noeh bei Gosse rrwähnt sind. Dieselben lagen mgefähr aul der Grenze zwischen dem zweiten und dem letzten Drittel des Körpers. Die Tasthaare, relehe sehr fein waren, sassen nicht an einer Verlängermng des Körpers, wie an den zwei anderen Tastern. Solehe kleine laterale Taster scheinen auch bei

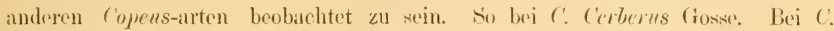
puchyurus Gosse sind die Tasterfortsïtze sehr klein, sollen aber merkwürdigerweise nach Gosse setæ entbehren.

tumerkuny. Ich halte es nicht unwalurseheinlich, dass C: ('erberus aueh von mir geschen ist. Iel habe ja unter den Notommataden von Formen gesproehen, bei denen ich einen kleines Fortsatz über dem Fuss gesehen.

\section{Proales Gosse.}

\section{Ir. sp.}

Ich habe Formen qusehen, die Proales sordida nud $\mathrm{I}$ : alecipirns sehr nahe kommen, habe aber keine genanere Aufzeichnungen mol gehe deshalb nieht näher hieranf ein. Ich habe schon friiher hervorgeboben, dass ich äber die Existenzherentigung dieser fattung Zweifel hege, und dass ieh die Begrenzung derselben nicht natürlich finde. Es wäre nicht ganz unmöglich, dass diese Formen mit Lnrecht ihre Nummern erhalten haben, und dass sie schon unter Notommata angeführt sein könnten. Deshalb gebe ich ihnen anch nur (ine Nimmer.

\section{Diops n. g:}

4.). D. murima n. sp. Fig. $27 a, b, c, d, e, f, g$.

Auch diese Form macht mir Schwierigkest. Viellejelat könnte sie als rine Furcularia oder I Higlene anfzufassen sein. Aber ganz genan stimmt sie mit keiner von diesen beiden Gattungen, unel ieh lasse sie deshalb, bis ieh unsere Meeresrotatorien nïher zu motersueben Gelegenbeit finde, als nene Form gehen.

Eine ziemlich langgestreckte Form, deren sowohl Quer- wie DorsiventralDurchmesser recht bedeutend ist, Figg. $27 u$ und $27 y$. Dus Vorderende ist 
quer abgeschuitten und trïgt einen pripherischen r'ilimring, dessen arsule Ciliene um mächtigsten siverl. In de's ventralen Srite lief cin mediuler Einschnitt, wodurch eine dit Rimue grbildet worre, und wexigstens an den lï̈ndern der Rimne wurden. Citien gesehen. Auf dem inneren Theil des hopfendes wroden einige liürzere cilien beobuchtet, welche mir als zwei geyon rinander stehende hullmondförmige bämder schienen, die sich con der Stinn gryen die ventrule Rime strecliten. Ob sic diese anch erreichten, vermorhte ich nicht zu entscheidey.

Die Rückenflüche ist stürker gewölbt als rlie ventrale, aber auch die letztere ist sehr oft etwas konvex. Gewöhnlich war der Körper am höelssten an oder grleich hinter der Mitte und fiel nach vorn allmählich, nach hinten aber recht schnell ab. Die Hout ist weich und zeigt meistentheils zueci rondere auf rlem Hulstheil liegende schunche Fulten. Die Körperform wird durch Contraktionen ziemlich stark geändert.

Der Fuss ist ziemlich lung und besteht aus anei Gliederu, von denen das letztere länger ist. Zwei ziemlich dicke, spitze Zchen sind wie grewöhnlich bei den Notonmataden vorhanden. Eine Eigenthïmlichkeit ist dagegen, rluss die Zehen ycuöhnlich sturk eingezogen sinel, so wie es die Fig. $27 c$ darstellt. Im Fusse gingen auch deutliche Muskelfasern neben den langen Fusidrüsen. Meistentheils zeigen die Zehen einen ventralen geraden und einen dorsalen etwas gebogenen Rand.

Ich habe anf der Figur einen dorsalen Taster gezeichnet. Mehrmals glanbte ich einen solehen an diesem Platze zu sehen, aber ich komte ihn nic länger als einen Augenblick fest halten.

Dus Auge wur stimständig wie bei versehiolenen Fureularien, war aber nicht eiufach, sondern bestand bei allen vom mir untersueliten Inelividurn aus zwei zusammengelagerten, seharf gegen rinambr abgegrenzten Irigmontfleclien. Das Pigment war dunkelviolett. Obgleich das Ange gar nicht gross ist, tritt die Doppeltheit desselben sehon bei geringer oder mittelstarker Vergrösserung hervor. Sehr deutlich sicht man die zwei Pigmentflecken nach Zusatz vou Kalihydrat.

Der mastax ist nicht sehr stark und besitzt, wenn ich dic Verhältnisse richtig anffasste, gebogene oft éin wenig unsymmetrisehe manubria, an denen ziemlich starke dreizähnige unci vorhanden sind. Mugergen wer es mir bei 
mrhmals conenerten Uutersuchumgen rench nach Kalizusatz rollstänelig unmöylirle rin fulcrum sichtbar an machen.

An einigen Exemplaren konnte ich ummöglich eine Einschniirung zwisehen dem Darme und dem Magen beobachten, aber dennoch waren sie lejeht unterseheidbar, deun der Mageninhalt wie die Magenwände waren bräinlich, wogegen Iarminhalt und Darmwände hyalin waren. Ich sah keine Cilien an der Magen- und Darmwand. Der Inhalt wurde während der langen Beobachtungszoit nicht in Bewegung gesehen. Andere Exemplare zeigten eine leichtr. Einschnürung. Bei den meisten von mir untersuchten Exemplaren waren die langrestreckten Magendrüsen mit lobru versehen. Die Exkretionsblase war grosis. In anderen Beziehungen boten dic inneren Orgme nichts Eigenthïmliches dar.

Die Lïnge war bei einigen gemessenen Exemplaren $180-200$ Mik. Genau lässt sie sich kaum angeben, weil der Fuss fast immer mehr oder weniger eingezogen wird, sobald das Thier ruhig steht oder lingt. Ich habu schon oben angefüht, dass anch die Zehen in das Fussglied deutlieh eingezogen sint. Das Thier zeigt nicht selten eine schwache brämnliche Farbe, krieeht gewöhnlieh und ist sehr lebhaft. Es kam indessen anch ganz gut sehwimmen.

Diops marina kam bei Egerlesminde in den letzten Tagen de's Monats Juli schr allgemein ror und wurde auch im Angust gesehen, aber nicht so zahlreich. Anch bei Jakobshavn ist sie beobachtet worden. vie liebte am meisten die kleinen Strandpfützen, wo auch meine Plemotrorhn marimu zuerst bemerkt wurde, aber ganz wie diese wurle sie auch an sehwimmenden von kleineren Pheophyceen bewaehsenen Fucuszweigen gefunden. siu scheint zum grossen Theil von Diatomeen zu lohen. In den Exkrementen sall ich nämlich bedoutende Mengen davon.

Für diese Gattung ist das charakteristisehe: Ein doppeltes, stirnstrimliges Aluge, mestar olme fulcrum. In übrigen Beziehungen besitzt die (iattumg die gewöhnlichen Eigenschaften der. Notommataden und kommt wohl Furenlaria am näehsten. Weil aber das Auge von zwei Flecken hestrht, kömnto es auch möglichrweise zwej getremnten entsprechen, und damn würde die Gattung Diglene in Frage kommen. Jedoch ist die Körperform bei den meisten Higlenen rine andere.

Ton bisher besehriehenen Formen sind es eigentlieh drei Arten, welehe zu viner Vergleichung anffordern nämlich: Furcularien Boltomi Gosse l. c. Vol. 


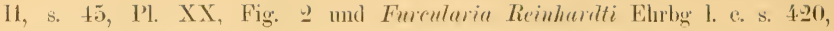
T'af. XLVTII, Fig. IV.

Gosse hat selbst Zwoifel gehegt, ob nieht seine $F$. Boltomi mit Enren3ERc's hier angeführten Art identisch sein könnte, findet aber, dass die crstere

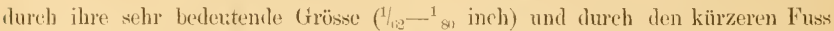
(ein Viertel der Körperlänge, bei $F$. Reinhardti die IJäfte), durch ein kleines Auge unel dureh ihr Torkommen in süsscm Wasser "in a pool in the heart of England" vou derselben genügend untersehieden ist.

Meine Dinjs marima zeigt in einigen von den angeführten Merkmalen Übereinstimmung mit $F$. Boltoni, unterseheilet sich aher dureh geringere Grösse mud durch die Beschaffenheit der Kiefer. Ton diesen sagt Gosse "the mallei being slight and feeble, while the incus is strongly developed with wide, glassy, areherl rami produced into long deeurved points", und bildet auch ein fulcum ab. Das Profilbild Fig. 2 i stellt auch eine recht versehiedene Kieferform dar. Jas Kopfende ist sehräge mu bietet das Aussehen vieler Diglenen dar. Diese Formen sind deshalb wahrscheinlich sehr verschiesten.

Furcularia Roinhuralti Ehrhg bietet vielleicht noch grössere Schwierigkeiten dar. Die Kö̈pergrösse ist fast dieselbe. Jas Ange wird gross genamnt, ist aber nieht so gezeichnet. Der mastax seheint atuch das fulerum zu entbehren. Aber das Ausschen der unei seheint mir rine filentität unmöglielı zu machen. Der Fuss ist auch als ungegliedert gezeichnet, und IItoson vermuthet, dass diese Art mit fosse's Notommate Thendora l. c. Sinppl., s. 21 vejwandt oder sogar identisch ist. Mit der Abbilung jener Form 1. e. Pl. XXXI, Fig. 8 " und 7, bietet meine Diops murinu ganz sicher sehr geringe Ïhnlichkeit dar. Der schmale fast Momostyla-ähnliche Fuss lässt an eine Identität dieser beielen Arten gar nicht denken. Von beiden Arten dürfte anch das doppelte Auge ein unterscheidendes Nerkmal ansmachen. Furularia Rombarlti ist eine marine Form, die nirht nur an Sertulurior und Coryne gefunden worden ist, sondern die anch ganz wie meine llops murina anch an losgrerissenen Funuweigen beobachtet worden ist. v. Fucнwaub hat diese Form später bei Reval gesehen, wo sie "selur hänfig im Seewasser" war. Die mil nicht ganz

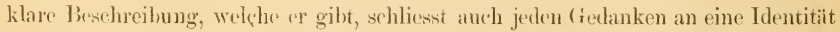
ans, weshalb ich seine Worte wiedergebe. "T)er Körper" selbst ist im ausgedibuntem Zustande sehmal, aber sehr lang und verlängert sich noeh mehr dureh Ansschieben, wio ein Fermohr, gleich dem Fusse, der in emem eylin- 


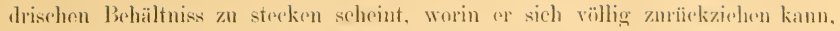
während das Behältniss sellst nach innen tritt mul singezogen wirl" '). Achmal kamn der Körper von Thiogs marina niomals genannt werden.

leh musste den obigen Vergheich anstellen. weil (ss doch möghleh wïre, dass die früheren Verfasser kein Gewicht auf das doppolte Ange gelecgrt hätten.

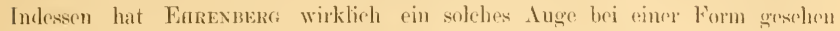
und alogebililet, mod diese Form, die anch marin ist, mol die selihissish wohl die grösste Ïhnlichkeit mit meiner. I)iops marina darbictet, ist Distemmon marimm Ehrhg 1. e. s. 450), Taf. LVI, Fig. IV. Lie loiagnose derselben lautet: "Corpore ovato-conioo, ocellis pubris valde approximatis, peedo longo digitis validis longitudine pedis".

Lic Grösse ist $1 / 12$ Linie, was ja so ziemlich der Grösse meiner Art ent-

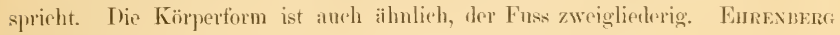
sagt weiter: "Vielleicht wïre sie zn der Gattmog Notommate zo stellen, allein iels wïrle geneigter sein sir als Typms eines Sulogenms von Distrmme anfzustellen, da das Ange offenbar doppelt ist. Das Gemus J Jistemma rerfiele damu in das Subgenus Lierntrum, Stachelzahn, und Euclesmu, Bündolzalın gerade wie Notommata in Labionlon und Ctenodon. Bemerkt muss werden, dass die Augen nicht hinter dem Schluudkopfe sondern vor demselben, aber doelı hinter drm Räderwerke liegen. Bei vielen Notommatis ist es aber cbuso, mol viclleicht war auch die frühere Insicht bei Rattulus richtigor - - _ - ".

Weiter spricht er die Ansicht ans, dass diese Art mit Miillers im Merereswasser gefundenen Torticellu sureollate ilentisch sei, was aber nicht zu rntscheirlen ist.

ILuson bespricht kmrz diese Form (J. c. Suppl. s. 32) und findet wie

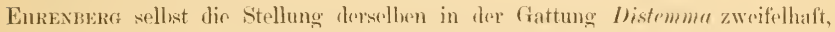
demn rindeed it resembles the rest of the genus in only one point, viz. in having two eerrical eyes". Iluoson glaubt weiter, dass Ehrenbergs Zeichmung

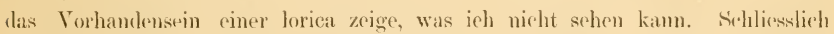
sagt Hunson "It is obvious that this Rotiforom must be more earefully olserved, in orier that its proper position ma be assigned to it".

1) v. Ercmwato, E., Zweiter Nachtrag zur Infusorienkunde Russlands. liull. d. la sor. - Imp. des Naturalistes de Moseon, Année 1849, n:r 1, s. fin The Behandlung der liaklerthiere fäingt an s. 526 an. 
Das Auge ist auf Ehrenbergs Figur etwas grösscr gezeichnet, als ich es gesehen habe, und zeigt auch eine andere Form. Ieh weiss alcer nieht, ob ex diese Theile genau darzustellen beabsichtigt hat. loh wïrle kaum zweifoln, diese Formen zusammenzuführen, wemn nicht dieses Narlien-auge wäre. Eurenbers bemerkt gewiss ausdrïeklich, dass es ror dem mastax lingt, aber er setzt hinzu, dass so aneh bei manchen echten Notommatis der Fall ist, und zejehnet das Auge vom Vordereme recht weit entfernt. Der mastax zeigt gewiss anch grosse Ähnlichkeit in der Form. Fünf Zïhne habs ieh jedoch nicht gesehen. Ehrenberg hat rin fulcrum gesehen, was bei meiner Form nicht entrleckt werden konnte.

Es wïre anch eigenthümlieh, wenn diese Art in der Ostsee und an den Küsten von Grönland allgemein wäre und nicht an der englisehen Küister vorkïme. Man kömnte dafür anfiihren, dass das Ostseewasser dem grönländisehen Strandwasser etwas ähnlicher wäre, weil an letzterer Stelle so gewaltige Eismassen ins Meer transportirt werken. Das scheint aber sehr geringe Wirkung zu haben, demn sogar bei Jakobshavn, wo einer von den allergrössten "Isfjorde" ausmündet, ist die Zusammensetzung des Wassers nur wonig versehiclen von derjenigen des Atlantisehen Oceans. Bei Jakobshavn nahm HAmмR in Oktober und November 1879 viele Proben, und der Salzgehalt war gewöhnlieh $11 \mathrm{~m} 3,33 \%$, Minimum 3,24 \% Maximum $3,46 \%$ Ja, in der Mitte der Miindung des [sfjords fand or im März einen Salzgehalt von 3,21 "1/ ${ }^{1}$ ). Man kömnte einwenden, dass diese Maasse im Winter genommen worden sind. Das hat aber selır wenig zu bedeuten, denn Jexsen fand z. B. bei Kangek, N. Br. 68 $07^{\prime}$, IV. L. 53" $14^{\prime}$ im Ang. 3,44\%. Sogar weit hinein im Nagsugtok fand er hei N. Br. $67^{\circ} 52^{\prime}$ und W. L. $5\left(0^{\prime \prime} 19^{\prime}\right.$ (1. 31 Juli noeh $3,12 \%$ die $\mathbf{l}$. 11:ten und 14:ten Juli näher der Mündung dieses Fjords genommenen Proben zeigten noeh hïheren Salzuphalt, und dis Proben, welehe den 30:sten Mai bei Natarnivinguak N. Pr. $67^{\circ} 09^{\prime}$ IV. L. $53^{\prime \prime} 49^{\prime}$ an der Mündung des Isortok untersueht wurlen, zeigten auch ziemlich hohen Salzgehalt, nämlieh meistentheils üher 3 " $\%$. Von 15 Proben hatten 10 höheren salzgehalt als $3 \%$ eine abop niedriger, nur 1,22\%. liese Probe war um $11 \mathrm{U}$. Naehts genommen. In'n vorigen Tag war der Salzgehalt geringer, aber um 11 U. N. höher, 3,13 ${ }^{\circ}{ }^{2}$ ).

1) II ммкк, R. R. J., Indersögelser ved Jikkohshavns Isfjord ete. 1. c. s. 39 u. fi.

2) J Jaske, J. A. I)., Istron. (H). efe. 1. c. s. 205 11. ff. 
Von den gesammten mir bekannten Observationen geht es gewiss herror, dass der Salzgehalt des Wassers in den langen Fjorden geringer als im offenen IIrere und anch geringer im sommer als im Winter ist, alber alle zeigen sio auch, dass das Meereswasser nahe an der Kiiste ungefaihr diesethe Zusammensetzung wie dasjenige der Nordsee hat. Es wäre ïbrigens sehr merkwïrlig, wenn eine geringe Versehiedenheit im Salzgehalt eine Art von der englisehen Küiste vertreiben sollte, dem die Räderthiere scheinen gegen eine solehe Verschiedenheit wenig empfindlich zu sin. Von 34 Arten, die im Mrece vorkommen, sind nicht weniger als die llälfte auch in sïssem Wasser gefunden ${ }^{1}$ ).

Dass bei meiner Form keine loriea vorkam, zeigten die energischen ('untraktionen des Körpers.

Ich habe mir Algen von unseren Küsten sehicken laswen und darin wohl einige Räderthiere gefunden aber weder Erresmera's Di temma murimm noch meine Jiops marima. Indessen ist das Material bisher schlecht gewesem, wril irh es nicht selbst habe rinsammeln kömmen.

Unter solehen Umstïnden muss ich jetzt nach meiner Art nova sjucies setzen. Fïr die Anfstellung einer neuen Gattung meine ich kaum weitre Criinde anzuführen zu brauchen. Dass mejne Art gar nichts mit l)istemmu

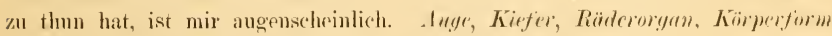
umel Zehen spreflen alle dagryen, mul viel besserer steht es auch nicht mit der Übereinstimmung zwischen den Gattungen Diglena und J Diops. Furenlarin steht zwal noch zurück, hat aber nur sin einfaches Stimangr mul wirit wohl mach eines Rovision auch in Räderorgan, Körperform und Zehen fast elven so grosse Abweichung zeigen. Ich lasse indessen meine Gattumg in der Nähe von Fincularin stehen.

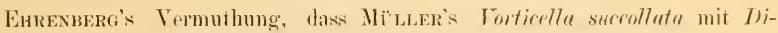

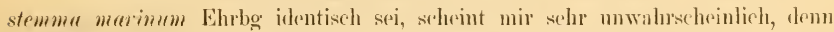
diese M̈̈llek's Form hatte sowohl vordere wir hintere Syitzen. lliese sind an allen Abbiłdmgen mit Ansmahme der merkwiirdigen Fig. 12 dentlich zu sehren, und diese stellt wohl ein beschärligtes Thier dar ${ }^{2}$ ). Nareh den Abbildumgen zu urtheilen seheint os mir möglid, dass MëLlwe's Fom gepanzert war, und in der Nähe ron Salpina (oder Momura) ilnen Platz haben soll.

1) Hunsox, C. T., The presidents adress. Journ. of Roy Micr. Soc. 1889, s. 176.

$\left.{ }^{2}\right)$ Múller, (O. F. l. c. s. 28!, Tab. Xl, Fig. $8-12$.

Lunds Univ. Ărsskr. Tom, XXVIII. 


\section{Furcularia Ehrbg.}

Manchmal habe ich in Grönland Furcularien gesehen, hatte aber dennoch nie Gelegenheit sie genaner zu untersuchen. Zu den häufigeren Rüderthieren komnten sie jedoch nicht gerechnet werlen. Auch war meine Literatur betreflend diese Gattung besonders arm. Aus meinen Notizen geht hervor, dass ich wenigstens drei Arten beobarhtet labe, ron denen die zwoi sich mit schon beschriebenen vergleichen lassen. Dis dritte scheint jedoch nicht früher bekannt zu sein.

\section{F. $r f$. graritis Ehrbg.}

F. gracilis Ehrhg I. e. s. 421, Taf. XLVIII, Fig. TI.

F. gracilis Eckstein 1. (. s. 374, Fig. 43.

F. gracilis Blochmam l. с. s. 102, Fig. 239.

F. gracilis Gosse 1. r. Tol. II, s. 42, Pl. XIX, Fig. 14.

Eine kleine, kaum 100 Mik lange Furcularia, welehe divergirende Zehen und sehr kurzen Fuss zeigte, glaube ich mit dieser Art vergleichen zu können. Die Übereinstimmmng ist recht gut, nur hahe ich sie als fast fusslos notirt. Sie wurle in August im Bodensehlamme nahe dem Uffer eines ziemlich grossen Sees in der regend ron Egedesminde gesammelt.

\section{F. of. giblua Ehrbg. Fig. $96 a, b$.}

F. gibln Ehrbg l. e. s. 420, Taf. XLTIII, Fig. III.

F. gibla Eckstein 1. c. s. 37 4.

F. gibla blechmann l. e. s. 102.

F. gibba (iosse 1. c. Tol. II, s. 43, Pl. XIX, Fig. 13.

Ich habe gewiss diese Art gesehen, halte es jedoch nicht unwahrscheinlich, dass ieh in meinen Sotizen zwri Formen unter diesen Namen zusammengeführt habe. Die leiden Formen trugen lange, aufwärts gebogene Zehen. Ecksters sagt in seiner Cattumgsliagnose "/ohen lang gekrümmt", und deshalb fand ich es zuläissig anzunelımen, dass solche Zehen bei Furenlaria normal seien, ologleich es hei Blochmann von gibba hiess: "Fuss kurz mit zwei langen geraden Zehen - - - ". Bei einer Form habe ich die Länge der Zehen als 60) Mik notirt, bei einer anderen sehr älnnlichen habe ich dagegen ungefähr dieselhe Totallänge 170-180 Mik angeführt, die Länge der Zehen war aber 90 Mik. 
Von dieser letzteren bekan ich zufälligerwejse eine sehy gute Ansicht der Kiefer und gebe meine Zeichnungsskizze hier wieder, weil diesolhe, wenn anch die Kiefer etwas verzerrt waren, eine hedentende $̈$ hnnlichkeit mit Grosses Abbildung dieser Organe bei Furculariu giblua zeigt; rgl. Fig. 1:3 l, der angeführten Arbeit. Sowohl mambria wie fulerum sind sehr ähulich. Nur tritt der Fuss des letzteren nicht deutlich hervor, was vielleicht eine Folge der Lage dieses Theils sein kömnte.

Bei der einen von den beiden unter dieser Nummer angeführten Formen

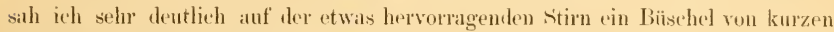
sich träge bewrencenten Cilien.

Ich habe diese Formen nur lïr Jakohshavon notirt, aber erinnere ganz dentlich, lass solehe anch bei Egedesminde mehrmals ïler das Gesichtsfeld Zogen.

\subsection{F: sp.}

Eine kleine Irt mit seharf ahgesptztem Fusse, kürzeren, dickeren Zohen, die nieht aufwiirts gekrïmmt waren, wurde d. 26; Aug. bei Jakolshavn benbachtet.

\section{Eosphora Ehrbg.}

46. E. cf. Naius Ehrlog. Fig. 29! " und l.

E. Naias lihrlgg 1. e. s. 451, Tat:. LVI, Fig. VII.

$" \quad$ Leytlig 1. e. s. 40, Tif. III, Fig. „2).

$" \quad$ " Hudson simplement s. 27, Pl. XXXIII, Fig. @.

Zwei Mal habe ich bei Exedesminde einige Exemplare dieser fiattung gesehen, welehe wahlselemlieh nieht alle ganz übercinstimmend waren. Sijäter habe ich in Jakolsharn den y:3 Ingust ein Riesenexemplar eines zu dieser Gattung gohörenden Thieres geschen. Sic sind indessen alle nicht recht geniu mntersucht worden, und das in Jakobshavn greschene Thier trug cin ausserordentlich grosses, sehr dickrchaliges $\mathrm{Fi}$, welches die fiestalt desselben ziemlich stark verïuderte. Die anderen Individuen zeigten die rharakteristisehe roktanguläre Kö̈rperform. Fig. „2! " zoigt das Rïiderorgan eines der in Egedesminte gefumlenen Thire, von oben gesehen. lipi demselben Thier sah ich ausser einem sehr dunklen Nackenange zwei kleinere in deutlichen Fort- 
sitzen des Kopframdes liegende gelbrothe Flecken, was ja sehr gnt mit der Ibbilelung LeYpre's übereinstimmt. Etwas näher der Mittellinie lagen in fast derselben Ilöhe wie die Augenerhebungen zwei viel kleinere Fortsätze stf, welehe an ibren spitzen Tasthaare trugen, die sich nicht bewegten. Dieselben waren ungewölnlich dentlich, weshalb es mir sehr unwahrseheinlich workommt, dass sic vom einem so alsserordentlich scharfen Boobachter wie LEYorg sollten ibershen worlen sein. Diese Thatsache macht mich in meiner Bestimmung dieser Form ein wenig unsicher.

In Fig. 2!) 7, habe ich den vorderen Theil der 1)igestionsröhre desselben Thieres dargestellt. Der viejeckige mastax mit kräftigen nicht näher mutersuchten Kiefern trat sehr deutlich hervor. Der ocsophagus dieses Thieres war sehr weit und zeigte gleich hinter der Mitte eine ovale Ansehwellumg. Vicllicht war diese nm eine zufällige Bildung, obgleich sie da blieb; so lange ich das Thier beobachten konnte. Der Nagen war kaum vom Darme abgosetzt, somdern der Darmkanal hatte fast dasselbe Aussehen, wie es Eckstrin in sciner Fig. 30 bei $E$. elomgute darstellt. Auch darin fand sich eine Übereinstimmung vor, dass auf dem erweiterten Theil des Dinmkanals sehr urosse: Zellen gelegen waren. Sie lagen fast ringtörmig nm die Erweiterung (den Migen). loh fasste sie damals mit Eckstem als besondere Inrïsonbildungen auf, aber es kamm wohl möglich sein, dass sie nur grössere Wandzellen Waron '). ther Inbalt des Magens war hyalin, die Wände aber stark bram. Jie Magemeliisen waten auch weisslich oder hyalin. Zwischen den Magendrüsen

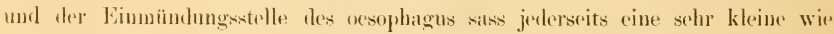
grestielte Zelle, die anch in Verbindumg mit dem lumen des Magens zu stehen schien. Man kënnte vielleicht diese Bildungen als Zellen der Körperflüssigkeit - Blutzellen — die zufälligerweise festgewachsen waren, aulfassen wollen ${ }^{2}$ ). Intessen shejnt mir die symmetrisehe Lage gegen eine solche Erklärung zu sprechen. Anch babe ich nichts Ihuliches bei anderen Rotiferen gesehen.

1) Vgl, ubrigens Eckstux 1. c. s. 415, Zicharias, 0. Über Fortpflanzung und Fintwicklung von liotifer culyaris Z. f, w. Z. Bd. XLI 1884, s. 231, Zeliski 1. c, s. 115 und llupsos 1. e. Suppl. s. 32 bei Triophlithalmus.

2) Dass Blutzellen wirklich bei Räderthieren vorkommen bestätigt Zвusкı in seiner schönen Arbcit: Studien über Räderthiere III. Zur Entwicklungsgeschichte etẽ. Z. f. w. Z. Bd. LIII 1891, \& 25 . 
Die Exeretionsgefixse waren stark entwickelt, und jedes trug fiün Wimpertriebter nebst eimigen mehr wer weniger zusammengeknäuclten drüsigen Verzweigungen. Die starke Muskulatur un seh dentlich queryestreift.

Ziemlich mahe dem Hinterende des Körpers sass jederseits ein lateraler Taster.

\section{E. sp.}

Einige Eosphoren zeigten in verschiedenen Hinsichten Mbweichungen. Ich habe aber zu wenig notirt un darauf näher einzugehen. Djo Stirnatlgen welche wohl so gross wie das Nackenamge waren, sassen nicht in Erhebumgen, solche wurden nicht gesehen. Vielleicht sassen sie sogar ein wenig hinter dem Rande. Davon habe ieh aber niehts notirt. Nur eine skizze zeigt dieses Verhältniss. Bei diesem Thiere war der ()arm deutlich vom Magen abgesetzt. Der oesophagus war schmal und kejne kleine Drïsenbildungen wurden beobarhtet. Las Thier batte in Magen grosse Kiefer von einem zur Familie Philodinarle gehörigen Thier. Ins Raiderorgan war ziemlich schwach. Die Zehen waren lang aber nicht ganz so lang wie der Fuss.

\section{Dirlena Ehrbg.}

Lavises batte Diglene sp. beobachtet.

Nicht wenge Diglenen kamen mir zu Gesielst, waren aber immel vereinzelt und komnten besonders in Infang des sommers niclit näher beriirksichtignt werken. Nach meinen Notizen lassen sie sich mit dru folgenden vergleichen').

48. I) forciputa Ehrlig.

I). forcipata Ehrhg l. c. s. 143, Taf. LV, Fig. 1.

" $\quad$ Blochmann l. e. s. 102.

$" \quad$ Gosse 1. e. Vol. II, s. 50, Tab. XIX, Fig. 2.

Egerlesminde d. 10 August.

1) Sie müssen indessen als ziemlich selten angeselten werden, denn ich habe wohl nur 5 oder 6 Individuen gesehen. 
49. I). ct. catellina Ehrbg.

D. catellina Ehrbg l. c. s, 444, Taf. LV, Fig. III.

$" \quad$ (rosse 1. e. Vol, II, s. 53, Pl. XIX, Fig. 10.

$" \quad$ Weber l. e. s. 46, Pl. XXXIV, Fig. 1-6.

Eine kleinere Diglena, die ich mit dieser Form zusammenstelle, wurde pinige Male Hüchtig gesehen.

\section{5). D.? matums n. sj.}

Diese Form wurde anch schr flüchtig untersurht. Sie kam wahrscheinlich in zwei Exrmplaren anf emem Objektträger zusammen mit versohiedenen anderen interessanten Formen vor. [ch sah sie während meiner Arbeit mit diesen mehrmals, als ich aber nach einigen Stunden fertig war dieselbe zur näheren Untersuchung vorzmuchmen, komnte sie nicht wierlergefunden werden. Indessen habe ich kein bedonken für dieselbe eins rigene Art anfzustellen. Es war beinahe das autfallomdste Räderthier was ich jemals gessehen habe. Es wu rölligy hyulin und fast noch durhschrimender als die von mir gresehenen Mämnchen, mit denen sic anch in des kegelfärmigen Körperform grosse Älnlichkeit darbut. Indessen war sie ein mit Darmkanal und mastax versehenes Weibehen. Das ansser der bewegung so sehr charakteristische war ein hreitev

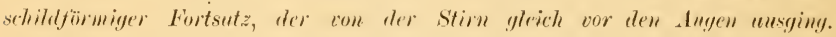
Jiene Bildung hatte keine $\mathrm{Thmlichkeit}$ mit aten bei so vielen anderen Diglenen vorkommenden hakenartigen Koptfortsätzen. Hiese letzteren sehen von oben oder unten betrahtet entwoler wie ein kleiner hakenförmiger Fortsatz aus, valer werden sic kanm benerkt. Im Profilbild sind sie dentlich hakenförmig wogegen dieser Fortsatz bei $I$. nuturs von oben geseben plattenförmig war und wenigstens dic halbe Breite des Kopfes besass. Thiese dünne sicheibe mag ihnen wohl mophologisede entsprechen sieht abex ganz anders aus. Die zrei

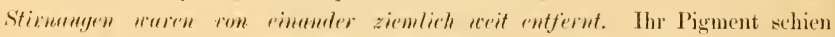
mir intensiv sohwar\%, so dass die kleinen Angen sehr scharf hervortraten. An

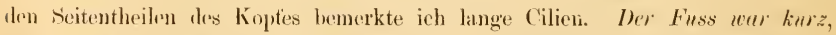
die Zeleen degregen lemy, gerade und spitz. Der mastax wurde nicht hervorgesshoben und die Kiefer aurh nicht ausgestreckt. Ich glaube gewiss dass eine nähere Untersuchung zur Aufistellung einer neuen Gattung fïr diese Form geleitet haben würke. Nach meiner obertlächlichen Besichtigung kann ich 
dieselbe jetzt nicht ganz ohne Berlenken als neue Art anfiihren. So unvollkommen meine diesbezügliche Notiz auch ist, bio ich nicht desto weniger ganz. gewiss, dass dieses Thierchen, wenn jemand dasselbe wieder antrift, sogleirh wieder erkannt werden muss.

Als eine Notommatade mit zwei Stirnangen konnte sie ja nur mit lliglena verglichen werden, aber die Körperform dieser Gattung hatte sic gar nicht uml anch nieht die Bewegungsweise. Eine Diglena kriecht ja raseh umlerr, zicht iluren weichen Körper oft zusammen und streckt die Kiofor horvor.

Jiglena? jotans wurde nur sehwimmend gesehen. Sic schwamm eine Strecke umher, dann hielt sie plötzlich still, ohne dass ich sie jemals was berühren oder ampacken sah, obgleich sowohl andere Thiere wir Algen mul Monsenblätter mit auf dem Oljektträger waren. Sie stand dann eine Weile ganz luhig gespensterähnlich, fast wie nachsinnend still, und nach einigen Minuten fuhr sie wieder blitzehnell nach einem anderen Rande des Gesichtsfoldes oder der fenchten Kammer fort um da vieder zu pausiren. Nahrung sah ieh sit gar nicht weder suchen noch eimmelmmen.

Es wïre nicht absolut ummöglich, dass diese Form einen Panzer hesass, dem so weit ich erinnern kamn, sah ich sie sich niemals zusammenziehen. Aber die. Verwandtschaftsbeziehungen wairen mir in solchem Falle wenigstens ebenso mnklar, als wem ich dieselbe als eine mit Diglene verwandte Form auffasse.

Indessen spricht der kegelförmige, geringelte Körper kanm dafür. Ieh kemme auch keine Loricatengattung, welche ohne Zwang diese Form einräumen könnte. Der Kö̈rper ging ganz allmählig ohne Spur von Absïzen in den Fuss und dieser in die Zehen über.

Ich habe nur ein oder zwei Exemplare gesehen, in Jakobsharn d. 27 Aug. Die Länge schätzte ich zu ungefähr 100 Mik. (Sie wurde nicht genan gemessem.)

Vom Namen geleitet glaubte ich in EHrenberg's Itigloma frontulis vielleicht eime ähnliche Form zu hahen, aber diese zeigt eine ganz andere Form des Körpers und des Rïderorgans. Eurenberg schlägt für dieselbe den Nimen Rhimoglena vor '). Wemn meine Art wiedergefunden wird, und, wie ich rer-

1) Ehrenrerg, C. G. Über die neuerlich bei Berlin vorgekommenen Formen des orgauischen Lebens. Berichte über die zur Bek. geeign. Verh. d. K. Preuss, Ak. d. Wissensch. zu Berlin 1853 , s. 193. 
muthe, zu den Hlorieaten und zur Fanilie Notommatada gefuhrt werden kann, diirfte dieselloe passend $K$ lypeoglena heissen kïnnen.

(XXII). Arthroglena n. subgenus. Fig. $30 a, b$, c.

\section{A. Lütleni n. sp.}

Die Abbildung Fig: 30 zeigt eines von den sebünsten Räderthieren, die ich his jetzt geschen habe, von welehem ich leiser auch nur ein einziges Individumm gehabt habe. Ich kenne selbst zu wenig. wie gross die Variation unter den Räderthieren sein kamn $n$ men Werth dieser Charaktere ganz sieher beurtheilen zu können. In der Literatur sind mir auch wenige Angahen hierüber bekannt. Bei keiner anderen Diglena habe ieh die Charaktere gefunden, welehe diese Art auszeichneten, und muss sie deshalb als neue Art anführen. Die wesentliehen Eigenthümlichkeiten, welche mich sogar zur Aufstellung einer neuen Untergattung von Diglena genöthigt haben, sind das Fehlen von Augen unul die grgliresterten Zehen.

Die Körperform, welehe die Figur recht genau wiedergibt, ist diejenige einer Diglenu und hat nicht geringe $\ddot{A}$ hnlichkeit mit derjenigen einer $D$. forci; atu. Nicht selten war der Körper etwas melır gestreckt. Der Rücken ist schuarh gewölht, wogrgen dir Gienzlinir des Bauches fast gerale verläuft. Die vordere Kopftläche ist gewöhnlich nur wenig von der Bauchfläehe abgesetzt, jedoch mehr als bei $I$. gramlis und $D$. forrizatu, wehche in anderen Beziehungen die nächststehenden sind. Bei Zurückziehungen des Kopfes trat indessen jene Grenze riel sehärfer hervor, Fig. 30 b. Hir Haut ist sehr wrich und zeigt einige leichte Falten, drei vordere md zwei hintere, deren Lage genügend aus der Figur hervorgehen dürfte. Dir Rïrlituluut sotzt sich am

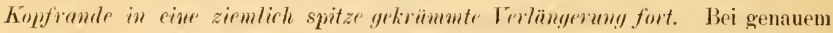
Nachseben wurde immer über jenem Haken ein kleinerer mudlicher Fortsatz all beobachtet. Der Fuss bestrht aus rimem drutlichen Grliede. Auf dem Rürken dieses Crliedes schien eine kleine leistenförmige Erhebung zu laufen, welche nach hiuten in einer kleinen spitze endigte. Diese Eirhebung war wohl ain wenig fester als die übrige Haut. Der Fuss trägt zwei lange, selumale schwurh yelogene Zalken, welehe einen grossen deutliehen Grelenkkopf besitzen. Inam folgt ein langes fust in dw yanzen Länge gleich dickes Basalstürk, mul enllich das schwach gekrämmete Endylied, welches durch ein deutliches Cirlenk abgesetzt ist, 
umal aler stumpl als spitz gmamut wrolen muss. Dir bei Digl. farripata vorkommenele proximale Verdirkmng der \%elen findet sich hier nieht.

Das Räilerorgan und die vorilere Kopftlïche sind in der Fig. 30 b, von

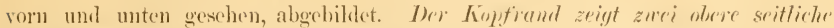

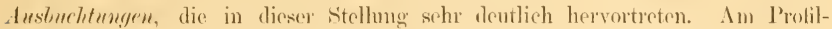
bild Fig. 30 " simd sie nicht so bedentent. Die daselhst stehemulen Ramdeilien simd kürzer als dirjenigen, wolehe am Kopfrande nach oben und nach unten von diesen Ansbuchtumgen ihren Jlatz haben. Ther dem Stimbulen befoud sirh

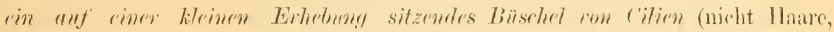

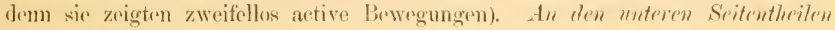

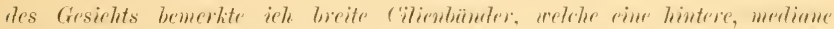
zum Mumel grhende. Eimsenkung begnenzten. Wahrselecinlich war aurh dieso liinne von C'ilien beklejelet.

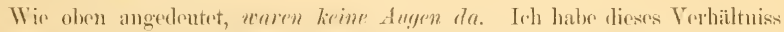

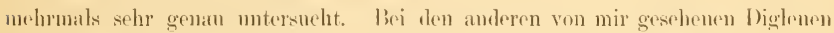
waren wohl die Augen klein, aber sio traten demnoch sehr seharl hervor:

Etwas hinter dem Gehirn wurde während dee ersten Stumben der Porobachtung ein kleiner wie es mir sehien blasenförmiger Kärper gesehen, der vielleicht dem bei so vielen anderen Notommataden so oft vorkommenden Kalk-

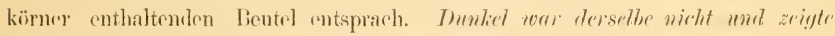

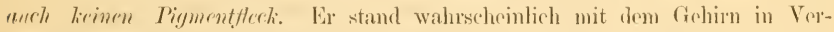
bindung. Anf meiner skizz war indessen keine solehe Terbindung ringe-

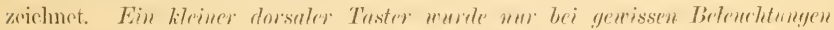

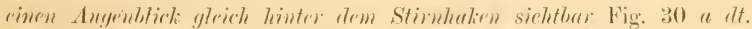

Die immeren Organe butretfend finds ich mur das folgende erwïhnenswerth. Der ziemlich grosse mastax lag ein stïek vom Vorderende ontfernt, und sehlosis ganz leicht sichtbare aber sehwouter Kiefor ein. Sie waren denirni-

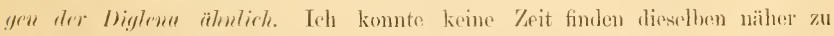
mntersuchen, somblern konservirte das Thier und bewahte os in rilyecrin ant. Nbur nach meiner Heimkehr ist es mir nicht möglich gewesen dir Kiefor dentlieh zu machen. Das Kalihydrat hat mir dabei keine llitio gerleistet '). Vom orsophagus habe ieh niehts notirt. Der Iarmkanal zeigte gar

1) Dasselbe ist leider anch bei einigen anderen Thieren der Fall gewesen. Freilich dituerte die Inflewalurung nicht so kurge \%eit (2-3) Monate), aber ich kam keinen (irumd fimlen, weshath die Untersuchung nicht uachlier gut gelingen sollte.

Lumls Univ. Arsikr. Tom. Xxvill. 
keine Grenze zwisehen Darm und Magen. Die ITand des vorderen Theils war sehr dick. Die Dicke nahm nach hinten allmählig ah, und das letztr Stück des Darmes zeigte sine ungewöhulieh dïnne Wandung. Die Magendrüsen waren klein. Die Gesehlechtselrüse war lang und zeigte eine vordere hellerr Abtheilung; in weleher grosse, helle, blasenförmige lierne sichthar waren. In hinteren Theile lag ein grosses, dunkleres Ei, das sehr diimnschalig war mul jedem Drucke nachgab. Die Form desselben war eben deshalh sohr verschiorlen, jo nachdem die Exkretionshlase gefüllt oder vor kurzem entleert war. Ansier der Blase bemerkte ich nur eimen vorderen unter dem mastax liegenden Wimpertrichter und ein vorderes Stüek des einen Exkretionsgefässes, wie auch dir Figur zeigt.

Im Fussgliede lagen zwei mulliche I) rïsen, von denen Fortsetzungen in die Zehen ausgingen. Weil die Zehenbasen so stark angeschwollen waren, ungefähr wie hei Monommata, suchte ich besonders eifrig nach Muskeln in donselhen, komnte aber keine finden. Eine sehr starke Muskulatur war im Körpes entwiekelt, und ganz besonders waren die starken Ringmuskeln des Kopftheiles auttallend.

Ich beobachtete diese Form d. 25 Aug. unter Moosen aus einer Wasseransammlung nahe bei Jakobslavn. Anfangs war sie sehr lebhaft, kroeh ohue Riuhe moher unel zog jeden Angenblick iluen Kopf stark zurïek. Beim

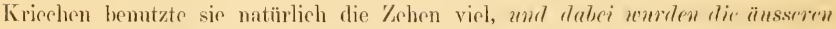
Gtieder der Zelem stark bewegt. Ieh sah diesolben sehr oft iollhommen senkrecht gegen das Basalstück strhen. Nur selten sehwamm sie kleinere Streeken. Moin Thier lehte nach der Isolinung eine Nacht über unter dem Deckgläschen mul war anch den zweiten Vormittag noch sehr munter. Eine gewisse Verändermong war dennoch eingetreten. Die Blase arbeitete langsam und sehr mmegolmässig, nul die Fussdrüsen wie aurh andere Organe waren viol kïrniger geworden. Während des ersten Tages sah irh das Thier nicht die Kiefer bewegen, aher am zweiten Tage nahm ich einige Kanbewegumgen wahr, wohej der mastax nach vorn geführt wurle.

Jic Länge des Thieres war um 230 Mik. Dis Zehen waren sin wenig lïnger als 50 Mik.

Irh habe zwei Mal hei Rïderthiren z. B. Copens equlatus eine selowach

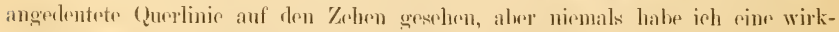


liche Gelenkbildung gefumblen, und ich hatbe anch katum in der Literatur etwas derartigess angeführt gefunden,

Bei einigen zur Gattung Diglena geführten Formen findern sich krine Augen, weshalb dieser Charakter gewiss nicht wiehtig genug ist um eine nene (iattumg anfzustellen. Zasammen mit den geglierlerten Zehen finde ich jodvel dieses Merkmal wiehtig gentg mm these Form in der alten (iattung Diglenn rine Untergattung bilden zu lassen. Dass die augenlosen Dighenen wohl zum Theil wenigstens in die Gattung Ilenrotroche iibergefiihnt werelen nü̈sisen, wemn dise letztere Gattung bestehen soll, habe ich ïbrigens sehon friihrer hervorgehoben. Es ist kaum meht berechtigt um der Körperform Willen ührigens versehiedenartige Formen zur Gattmog Diglene zu fülnren, als es frïher richtigr war alle Formen, die ein Nackenauge besassen, in die Gattung Notommate linein zu zwingen.

Arthroglenu unterseheidet sich von den näher verwanclten Diglenen auch in

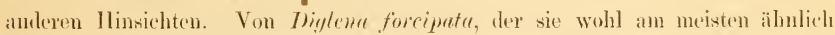
ist, weieht sic durch geringere Grösse, längere, geratere Zehen ab, sowie and dadurch class die Cilienbänder sich nicht so weit nach hinten strecken wie bei dieser Art. Anch ist die ventrale Begrenzumg des Fesichts viel schärfor. Diglene grumlis ist viel grösser und hat geradere, scharf zugerpitzte Zehen. Diglene gibber, von weleher Gosise nur ein Exemplar, das nieht ganz lebhalt war, untersmehen komnte, unterseheidet sich durch ledeutendere Girösse umil dureh eime eigenthünliche panzerartige In̈ille, welehe sich ïher den Rïeken stark crhobt, und weiter dureh gekrïmmte Zehen. Von den Zehen dieser Art sagt der. oben citirte Verfasser: "On each toe at about one-fourth of its length, there is an abrupt deerease of diameter on its superior edge, with the alyearance of a joint; and a delicate line crosses each near its point ${ }^{1}$ ). Diese übrigrens so wohl getrennte Irt würte sich also möglicherweise in der Beschaffenheit der \%ehen meiner fithoglene ctwas nähern. Indessen sohoint mir die äuscere

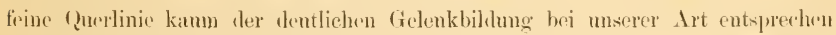
zu kömnen. Es lässt sich aber nicht entscheiden, dem Gosse hat das Thior nicht kriechen gesehen. Es war sehon dureh das Ansreissen des mastax so heschädignt, dass es weder sehwimmen noch kriechen kounte, "thongh it con-

1) Die Länge der Zehen kann ich kaum vergleichen, denn die Figur und der Text stimmen schlecht. Nach dem Texte wären die Zehen ungefäh doppeit so lang 100 Mik. Der Korper aber 255. Inf der Zeichnumg sieht es aber ganz anders aus. 
stantly contorted its body, and threw about its toes" I). Freilich mörchte wohl bei diesen Beweghungen eine wirkliche Gelenkbildung an den Zehen sieh deutlich merkbar gemaeht haben. Iuch in ciner anderen Beziehung scheint eine gewisse Ütrereinstimmung zu bestehen. Ingen werden nicht genannt, sind anch auf der Zeichnung nicht angegeben, aber offenbar hat Gosse dem negativen Rirsultat seiner Untersuchung, weil das Thier beschädigt und vorne etwas zusammengezogen war, kein grösseres Gewicht znerkennen wollen. Ith habe bei dieser Vergleichung nichts vom mastax gesproehen, weil muine Angaben zu alleremeiss und zu umbestimmt sind. Er schien mir jedoch nach dem allgeneinen Diglenentypus gobant, aber gewis's weder mit demjenigen der I). forripatu noch mit alenjenigen der $D$. grandis ganz ïbereinzustimmen. Von dem mastax

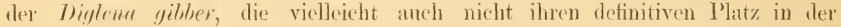
Gattung J bigleue finden kamn, hat Gosse auch keine Angaben geliefert.

Arthroplenu biulleni ist zur Ehre des Herrn Prof. S F. Lëtкen in Kopenhagen, benannt, dem ich es verdanken kam, dass diese Fieise mir anfgetragen wurde, und der mir auch bei der literaturanschaffung für diese Arbeit freunllichst llialfe geleistet hat.

\section{Distemma Ehrbg.}

\section{D. dubire n. sp. Fig. 31.}

Eine sehr kleine Form, welehe einen von den letzten 'Taugen meines Aufenthaltes in Egedesminde gefunden wurle, dürfte am besten hier ihren Platz finden. Sie wurde im Borlenschlamme eines sees nalse am Ifere grenommen.

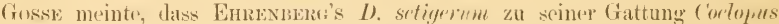
gehören muss. Diese Gattumg ist dadureh ansgezelehnet, dass der Fuss angesehwollen und im hintersten Theil des Kärpers eingeschlessen mol dass die vine Yohe cine breite Platte ist, auf weleher die andere in verschiedener Bhene liegt, und dazu haben alle untersuchten Siten dre Gattung Coelogme ein Ange, dats im hinteren Theile des (tehirns sitzt ${ }^{2}$ ). Jie zweïugige, aines mastax entbehrende Irt (: mimutus Gosse kaun nämlich kaum mit liecht liordor gestellt werlen, und frosse selbst bryeichnet anch dieselbe als rine speeies

1) 1. c. Vol. H, s. 49, Pl. XIX, Fig. 7.

$\left.{ }^{2}\right)$ lch nehme keine liücksicht auf die Art "tenuin,", bei welcher Gosse gar uichts von einem Ange sagt. Giosse 1. c. Vol. 11, s, 67-70. 
incertar sedis. Um so unwahrsehemlicher int es, dass dieser Art zu der Gattang Coelopus gehört, da dieser Antor nicht hat entscheiden können, ob die Zehen und der Fuss nach dem Typus dieser Gattung gebaut waren. In der Gattung

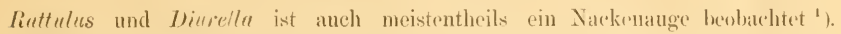
Es wird immer sehwer worden zu sagen, ob diese ein wenige gropanzerten diten bexiser unter die Lorieaten als moter die Illoricaten zu stellen sind, und deshall, lasse ieh bis weiter diese Art in der Gattung Jistemmen stehen. loh habe dieses Thier viel zu obertlïchlich beobarhtet um darauf lin irerenel cinc Voränderung in der Nomenklatur vornehmen zu dïrfens.

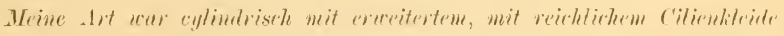

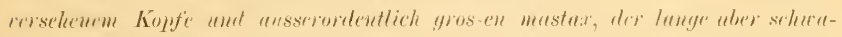

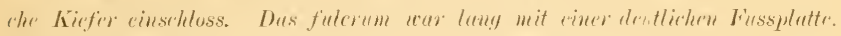
\%wri kloine aher sehr scharf hervortretende Nackenaugen waren zus sehen, leren Pignent tief schwarz ersehien. Von den Zehen habe ixll nur angengeben,

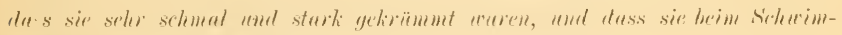
men merh unten hinefen. Das Thier sehwamm sehr schnell.

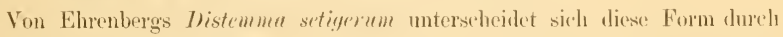
den seitlich erweiterten Kojt, grösseren mastax und das schwarze Angenpigment. Emandera hebt sogar in deg Diagnose semer Art das rothe Iugenjigment hervor.

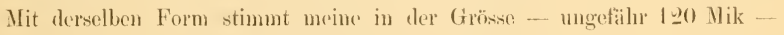
iiberein.

Ich hatte keine Veranlassung die Kehen näher zu betrachten, und deshall,

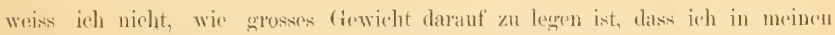
Sotizen von zwei Zehen spreehe. Ciewiss fasste ich es so anf, als ob zwei symmetrische horstenähuliehe Kehen existirten und meinte, dass allf der Figur

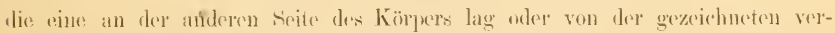
drekt wall. Wemn nun die nach moten hängenden Kehen vines schwimmenden coclopens leicht die Vorstellung hervorrufen könmen, dass zwei symmetrische nach dom gewöhnliehen Tyjus gratalteten Zehen vorhanden sind, damn ist es wohl denkhar, dass ich mich getänseht haben kann, demn moine Lutorsubhung musste ja so sehomell als möglich beendet werden. Ich hathe nieht notiut, oh jeh ain oder mehreare Individuen gesehen habe. Jodenfalls arer des Thire selur selten.

1) Bei R. culyplus ist kein Auge gesehen. 


\section{Unterordnung Loricata.}

\section{g. Fam. Acanthodactylidæ (- Rattulidæ Hudson \& Gosse) ${ }^{1}$.}

- XXIV. MFastigocerca Gosse (nec. Ehrbg).

Emrenbers: hatte eine Gattumg mit diesen Namen für seine Irt curimutu aufgestellt, und andere verwandte Arten fübrte er späiter zu einer newen Giattung Monocrece, währemel er Anfangs alle zusammengeführt latte. In seiner grossen Arlonit sagt er unter der Gattung Wrestigocerea: "Die nahe Verwandtachaft mit Momoerce Ruttus liess anch mich beide Formen lange verwechseln, allein ich halte jetzt, seit 1830 , beide generiseh unel selbst der Familie nach versehieden" ${ }^{2}$ ). Er fülurt nämlich die (tattung Monocerea zu seiner Familie Iyclatinaa, die Gattung Mestigneeren aber zur Familie Enchlunilote. Gosse sehlägt diese beicle Gattungen wieder zusammen, und ich folge ihm darin, weil diess Irten sowohl in der Körperform wie in anderen Zügen des baus übereinstimmen, und weil chen dic Gittung Monocerce, deren Arten in schr ungleichen Frate gepanzert sind, mir die ziemlich geringe systematisehe bedeutung eines stiarkeren oder geringeren Bepanzerang der Cuticula darzulegen selurint.

\section{M. Rettus (Ehrbg) Gosse.}

Trichoda liattus 0. F. Müller I. e. s. 205, Pl. XXIX, s. 6.

Monocerea Rattus Elubge 1. r. s. foz, Tab. XLVIII, Fig. V'll.

Monocereat Rattus Blochmann l. c. s. 103.

Nastigocerca Rattus (iosse 1. e. Vol. II, s. 63.

Aeanthorlactylus Rattus Tessin-Hïtzow l. e. s. 15 ti.

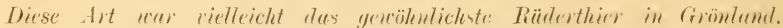
hasselbe und cinige Phibdinarlen kamen in den meisten (iewäissern vor, und es war gleich gewölmblich in ten Gegenden ron Egedesminde, Jakobslatrn und Ritenbenk. Es war so gewöhulich, dass ich solu oft viele Individuen in einem Troplien Wasser arhalten konnte. Indessen muss bemerkt werlen, dass ich

1) Den Grund, weshalb ich den Namen verandert habe, findet der Leser unter der Gattung Diurcllu.

$\left.{ }^{2}\right)$ Ehrenberg 1. c. s. 460. 


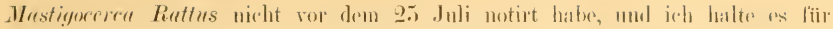
absolut mumöglieh, dass ieh dieselbe ähersehen hahen kimun.

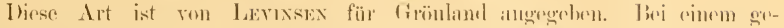

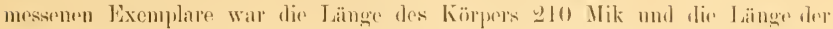

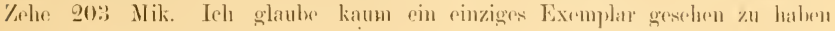
bei welchem der Stachel ammerkungswerth länger als der Körper war:

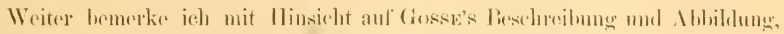

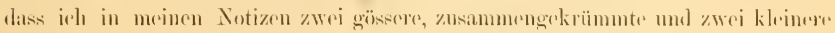
Nobenstacheln als dentich sichtbar bezichonet hales.

\section{M. cf. Lophlö̈ssa Gossn: Fig. 32.}

M. Lophoessil Gosse 1. e. Vol. II, s. (60, Pl. 20, Fig. 10.

the Form, welche irh hier anführe, fasste ioh in firinland un als cine

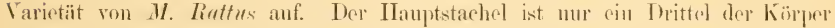
länge (bei M. Loyhoüssa zwei Drittel). Damn kommt an dex einen Sieite desselben Hanptstachels riner, der kaum die balbe Länge des grösscren bositzt, una an dessen ätsserer Seite war noch ein kleinerer, ein wonig gekrïmmter, nur mit Schwierigkeit sichtbar. An der anderen Serite des glossen Sitarhels war ganz deutlieh rin Stachel zol sehen. Der mastax war viol kï̈zer als gerwöhnlirh. Rüekenkiel seht niedrig, kaum vorhanden. Jhas Auge war kloin. Jir Wimperzungen waren ungewöhnlich lang; weit nach vorn wurden droi solelıe geschen und eine vierte in der Nähe der lilase. Irh sehe recht wohl ein, dass diese Form anch ron $M$. Lophö̈ so abweicht, wollte sie incksen nicht merwälunt lassen. Fs ist hauptsïchlich der so kloine mastax, der mich velamlasst laat, dieselben zusammenzufïhren. Derselbe ist an meiner \%eiehmung moch viel kürzer als an Gesse's Figur. Nögliellerweise und sogar wahlseheinlich sollte diese Form eine eigene neue Art hilden. Das hive lespuru-

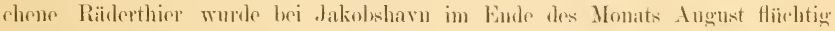
untersuclit. Loh kamn deshalb nieht sagen, ob es selten oder grwöhnlich war. Das arsteres seheint mir wahrseheinlich.

55. M. Diromis (Jhrleg) (rosse. Fig. 41).

Monocerea bicornis Ehrlgg l. c. s. 42:3, Tab. Xl, VIII, Fig. VIII.

Monoeren biontonis likochmamn l. e. s. I0:3.

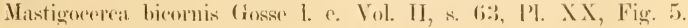


Eine in frönland viel seltenere Form als M. Rattus. Ich habe sie nur

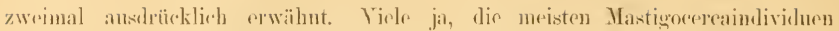
liess ieh selbstrerständlich eqehen ohne sie näher anzusehen. Das orste Mal, als ich M. hieornis antraf, war 1. 19 Juli. Ioll gebe einige Maasse eines yomessemen Exemplares an:

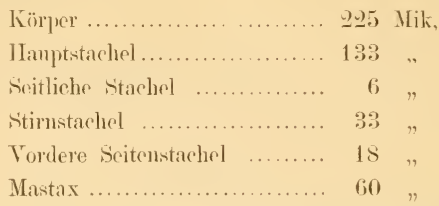

Iels glaubte ganz bestimmt an der Basis des Hauptstachels zwei kleinew stacheln zu sehen. Meine Inflassung war natürlich von den Wort enin Blucll-

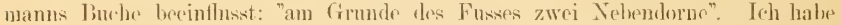
sie indessen an ciner Zeichmmgrskizze ansgeführt, unl ich sollte moinen, lass sis anch an Gosse's Figur angulentet sind, obgleich derselbe sagt: "The toe, is slightly swollen at its hase, but I canuot detect any substyle though Ehrenbers speake of them".

XXV. Diurella (Bory d. S:t Vinc.) Eyferth.

56. Diurella tigris Bory d. S:t Vine. nach Ehrenberg.

Triehoda Tigris Müller 1. e. s. 206, Tab. XXIX, Fig. \&.

Notummata tigris Ehrhg 1. (. s. 431, Taf. LIII, Fig. I.

Diurella stylota Eyferth 1. c. s. 108 .

Jimrolla tigris Eckistein 1. e. s. 376 , Fig. 21.

Diturella tigris Plate 1. с. s. 5(), Fig. 13, 14.

Jiurella tigris lihchmam l. c. s. 103.

Ratulus tigris Gosse ${ }^{1}$ ) 1. e. Vol. 1I, s. 65, Pl. XX, Fig. 1:3.

Acanthodactylus tigris Tessin-Bützow 1. c. s. 153, Fig. 13.

Ielı kam hier nicht (rosse's Nomenklatur folgen. J)ie ('harakteristik,

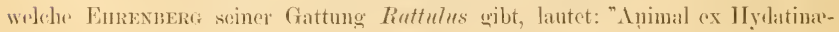

1) (ii)SEE setzt bei dieser einzigen Art MïLuz als Nimengeher, obgleich derselle mit chenso vielen lecht bei einer ganzen lieihe von den Ehrenhergschen Arten stehen könnte. fch tinde sogar Müllers Figur nicht so besonders genau auf Jinrellı tigris passend. 
orum familia, oenlis duobus frontalibus, pede simplicites styliformi, cirris pinnulisve earens". Gosse charakterisirt seine Gattung Ruftulus mit den Worten: "Body cylindric, eurved; loriea smooth, (usually) without a ridge; toes two deemved, symmetrie" und in der Ilagnose der Familie Rattulida heisst es dazu - - " "ye single, eervieal". Es muss damn gewiss brstannen weeken, wem mam nach iler so charakterisirten Gattung Ruttulus Ehrenberg als Autor gesetzt findet mol das oline jede liemerkung. Unter seiner Gattung Coolopus sagt Cosse: "It is possible, that Ehronbergs Ruttulus lunaris may represent my ('. poserllus ete. But the absenee of any detailul diagnosis, in his text, leaves it loubtful; while his assigning of two eyes to his species is against the identification".

Es soheint indessen als wäre Emrenbers's liattulus lamaris nicht so

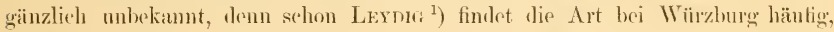

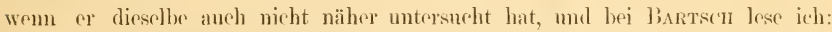
"Ruttulus E. Körper eylindrisch, kurz, gebogen an beiden Enden abgerundet. Zwei Stimangen; Fuss einfach horstenfömig. R. lumais E. lle einzige von Ehrenberg aufgestelle Art kam mir ziemlich hänfig zn Gesicht. Wic PerTr, der das Thier sohr häufig gefunden, bemerkte _ _ _ " ${ }^{2}$ ). Wril also mehrere Verfasser głauben Ehrenberg's urspringliehes Thier geschen zu haben, kann ich nicht eine solehe Verïndernng der Perlentung des Namens berechtigt ansehen. Wenn nicht der Fuss horstenförmig sein sollte, könnte möglicherweise diese Form sogar Distemma nahe stehen, dem die Stirnaugen sitzen hier nicht so wong vom Stimrande entfernt. Enrexbers will sie indessen nicht "wie frïher Nackenaugen nennen, weil sie vor dem Schlundkopfe liegen" ${ }^{3}$ ).

Übrhaupt diirfte es ausserdem hesonders die Rotiferen und Infusorien betreffend sohr sehwer sein zu behaupten, dass ein 'Thic von einem Verfasser nicht richtig anfgefasst worken ist, weil es noch nicht wieder gefunden worken ist. Ehe man wagen kamn eine solche Behauptung auszuspreehen,

1) Z. f. w. Z. Bd. VI etc. s. 20.

2) Viele andere Verzeichnisse nehmen auch diese Art auf, und, was mir schwer begreiflich ist, IIudson sotzt selbst Rathlus lunaris (ohme Pemerkung) als eines von den häufigeren Raiderthieren. Hudsos, C. T. The presidents adress. Journ. of lioy. Micr Soe. London 188!, s. 171. Diese Arbeit ist mir erst lange uach der Abfassung des Textes zunginglich geworden.

3) Ehrhg l: e.

Lunds Univ. Ărsskr. Tom. XXVIII. 
mïssen wenigstens sehr genaue und dureh vicle Jahre lortgesetzte Entersuchungen an derselben ()it angestellt worden sein.

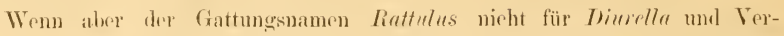
wancite passt, sn genört vielleieht der wirkliche Reutfulus kaum zn derselloen

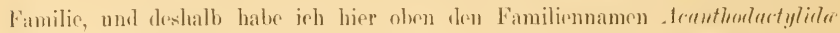
lountzt ohue damit etwas anderes sagen zu wollen, als dass der Namen Rattulila in dieser Bedeutung wenigstens noch nieht verwendbar ist. Dor Emfassung der Familie ist ganz diesclbe wie Hursox's und Gosse's.

Tessix-Bï тzow hat die Gatmugen Mestigocered und Dimpelle zu einer Gattumg, Aranthodactylus, zusammengeführt, und dafïr kïnnou gewiss versehiedent (iriumle hervorgezogen werden. Ich habe jedoch diese Thiere zu wenig beobarhtet, um in einer solchen Frage zwischen einem so erfahrenen forscher wie finsse und Tessix-Bützow urtheilen zn kïnnen und folge deshall Gusse.

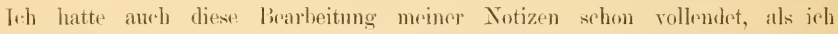
Trasix-lï тzow's Arbeit kenmen lernte, und habe jetzt keine Zeit nicht absolut nothwondige Veränderungen vorzmehmen. Nur habe ich den Familiemnamen, den ich sehr passend fand, nach seinem Gattungsmamen gebildet und gergen den anderen vou mir früher angewendeten Namen vertanseht und auch soinen Namen in die Synonymonliste eingefiihrt.

Jinella tigris wurde wie die Mastigorerea leuttus im späteren Theile des hommers reeht gewöhnlich. In Egerlesminde sals ieh sic viel seltener als in Jakohshavm. Ith kamn Ecksters's Angabe, dass die Zehen bei der Pasis gertrenut sind, mit ihren feinen spitzen aber zusammenliegen, bestätigen. Übrigens zeight eben diese Art sehr bedeutende Variationen in der Länge der \%elen.

\section{Dimella of. Rettulus Eylierth.}

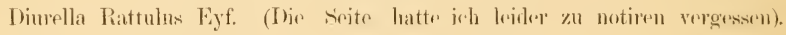
Diurella Rattulns Erkstrin 1. r. s. 3776, Fig. 20).

Wird von (rosse 1. e. Vol. II, s. 67 hesperochen.

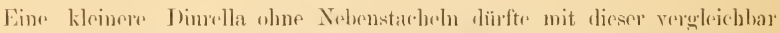
sein, oder es kämnte möglicherweise rine forlopuss-ant soin. Sie warle nicht näher mitersucbt. 


\section{h. Fam. Dinocharidæ.}

\section{Dinocharis Ehrbg.}

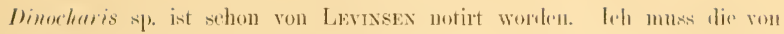
mir gesshenen Formen als zwei drten anfüluren.

5ั. 1). tritectis Ehrlog.

D. tetratis Ehrby 1. e.s. 473, Taf. I.IX, Fig. II.

1). tetractis Iludson 1. e. Vol. II, s. 72, Pl. XXI, Fig. ㄴ.

Bei sowohl Egredesminde wie Jakobshavn kam eine Form vor, die lichrer gefiiht werden muss, weil sie keinen Dorn zwischen den beiden \%ehen besass.

\section{5!). 1). intermetin n. sp. Fig: 33 $九, l$.}

Teh finde in der Literatur niehts von einer interessinten Form, erwillut, die gewissermassen die sonst so versehiedenen Arten /). Collinsii (iosse unut

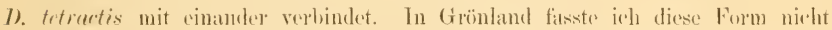

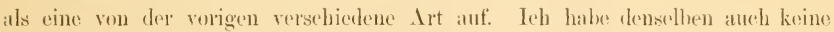

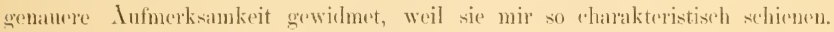
Indessen babe ich rin in Glyeerin anfbewahtes, komserviertes Exomplar mit nach Ilanse geführt, nach wolehem die Keichnmmgen theilweise ansgefülnt simd, und das anch netren meinen in Grönland rerfassten Notizen der folgenden [arstellung zu Grunde liegt.

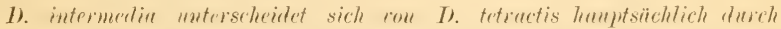

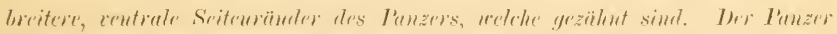

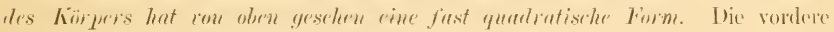

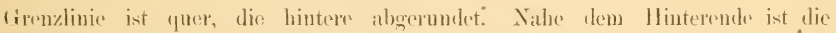

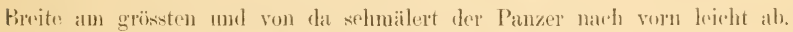

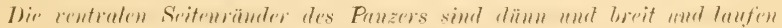

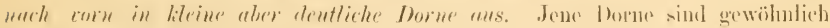
ctwits nach innen gokriimmt. Von den Zähnen der seitenränder sind einige grö̈ser und andere kleiner. Darin scheint aber keine liegelmässigkeit vor-

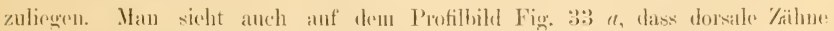

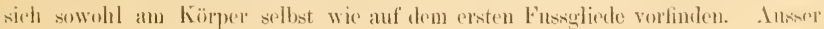


dem finclen sich sehr kleine spitzen an den Feldern des Panzers. Grosse Rïckenzacken, so wie sie bei $I)$. Collinsii zn piner bestimmten Auzalil auftreten, sind nieht vorhanden. Im lian des Fusses und der Zehen stimmt I). intermedia mit 7 . tetractis vollständig ïberein. Nur sind, wie aben genannt, am Rückentheil des arsten Gliedes bei I). intermedia einige kleinere Zarkin ansgebildet, die dann und wamn so gross werden kïmnen, datss sic beinalie ohne Grenze in die grösseren auch bei 1 ). tetractis vorhandenen Fortsiitze iibergehen.

Die Zehen sind lang, etwas gebogen und mit zugeschärften Endspitzen versehen. Sie stehen gewöhnlich etwas von einander ab. Auge, mastax und Lebensweise boten, so viel ich weiss, nichts Eigenartiges dar.

Aneh betreffend diese Form tritt die Frage hervor, ob sie nicht eher als cine Varietait von Dimocharis tetractis wie als eine selbstständige Lit anfanfissen sei. U'm das zn entseheiden wäre es nöthig gewesen über die grönländisehen 1). tetractis ansgedehntere und genancre beobachtungen amzustellen, als ich es komnte, da meine Zeit so beschränkt war.

Das Interesse, welches diese Form unter dieser Voraussetzung darbieten wörde, wäre gar nicht geringer, als wenn sie als cine eigene Art anfzuführen wäre, wie es hier geschehen ist, dem sic wïrde auch in diesem Falle dic angeführten beiden Arton ebensogut verbinden.

D. intermotia stimmt mit I). Collinsii hauptsiehlich in den gezähnten verbreiterten Seitenrändern des Panzers ïberein. Die Bezahnumg variurt jeeloch viel mehr als bei collinsii. Das sieht man indessen deutlieh genteg auf der Abhillmme Fig. 33 l.

Dic vorderen bedentenderen Dorne der seitemränder seheinen weder bei $I$. tetractis noch bei $D$. Collinsii vorhanden zu sein.

Aurh in der Körperform seheint jerloch 7 . intermedia sich recht bedentend von $D$. tetructis zu unterseheiden "). Sowohl Gosse's Abhildnug wie seime Worte geben eine andere Vorstellung vom Insselien des Panzers. In Texte liest man "the trunk vieuwed dorsally has a somewhat triangular ontline, the apex of the triangle being towarls the foot, and is shorter in proportion to the foot and toes than it is in the former specios". 1)ererste Passus dieses

1. Ich zeige indessen hier besonders darauf hin, dass ich für die Vergleichung der Körperform dieser beiden Arten, nur das konservierte mit eingezogrenem Kopfe versehene Thierchen, wrlches die Abbildung darstellt, berücksichtigren konute 
Gitat's stimmt gat nieht mit meinen Notizen umel këmnte möghieluerwoise eincu grësserer Linterschied zwisehen den bejiden Mrten ansmachen, als ieh angenommen habe.

Indessen habe ieh jetzt auch keine Mëglichkeit eine grössere Menge der emropiischen 1). tetractis zu untersmehen um die bedentmeg dieser Versehiedenhait richtig schätzen zu kömnen. In Grönland hate ich nicht besonders daranf geaehtet.

Ein gemessenes Thice zeigte folgende Maasse:

Länge des Panzers (ausser dem Kopftheil)....... š - 90) Mik,

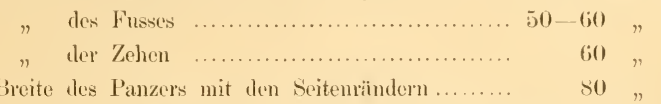

Die Dinoeharisarten worken mehrmals bei Egerlesmincle gesehen. Ith kam ats oben dargelegren Gründen nielst angehen, welehe von den beilen hier behandelten Arten die gewöhnlichere war.

\section{Scaridium Ehrbg.}

60. Se. Lomgicautum Ehrbeg.

Trichoda longicanda (). F. Näller 1. c. s. 216, Tah. XXXl, Fig. s- I0. Searilium longicaudum Ehrbg 1. e. s. 4.40, Taf. LIV, Fig. I.

$"$ longieamila Eckstein 1. «. s. :37:3, Fig. 4.

" longicaudatum Bibehmam 1. c. s. 107.

$"$ longicaudum Gosse 1. e. Vol. II, ж. 7:), Pl. XXI, Fig. 5.

Nath meiner Erfahrung gehört diest Form in frö̈nland zu den seltenem

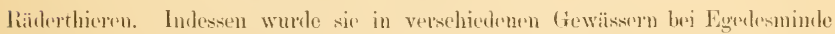

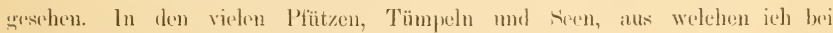
Jakobshavn Proben untersuchte, kam diese Irt nie vor:

[He latraten Taster sald ich sehr deutlich gleich hinter der Körjermitte. Über die streitfinge, ob der rothe Flecken am mastax ein Auge ist oder nieht, habe ieh koine entseherdende Jeobuelstungen gemacht. Weil dor Flecken mit dem mastax bewegrt wird, hat ja Plate die Ansicht ansegesprochen, dass cel nur ein statk rothbrauner Theil des chitinösen Kaugeriests sei. Lels spreche ameh in meinen Notizen ron dem stark rothbramen Flecken auf dem mastax. 
Hudsos mel Gusse wollen indesisen nach genauen Lintersuchungen dieses Organ als ein wirkliches duge deuten. Gosse sagt: "The most remarkable peeuliarity of the speries is the anomalous character of the eye, - a linge flattened capsule with aimson pigment not quite filling it, permanently attached to the surfice of the mastax, and apparently not commecterl, as usual, with the oecipital brain, which however, presses upon it from above and behind".

Nach dieser Aussage Gosse's, welche eine genaue Untersuchung voraussetzt, kann ich natürlich meiner oberflichlichen Untersuchung geringes (tewirht zuerkemmen. Ilenson ghaubt auch, dass bei $S c$. emlactylotum das Gehirn sich sehr weit mach unten streekt, so dass es direkt auf dem mastax zu liegen kommt.

Die länge eines gemessencn Thieres:

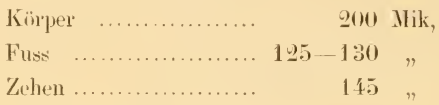

61.? Sc. lomgic. $f$. maculatum n. f.

Bei Ritrnbenk sih ich einmal einige Indivishen riner searidiumform, welche sehr rigenthïmliche lellgelbe Fle ken im Kople besasen. Solche Flevken batte ieh bei den anderen soaridien nicht bemerkt. Jch habe anch bei keinem

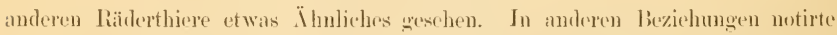
ich von dieser Form bei meiner sehr Hüchtigen Lutersuchumen nichts Bemerkenswerthes, obgleich ieh grlaube, dass auch der Fuss einige Versehiedenheiten aufzeigte.

\section{Stephanops Ehrbg.}

Lavisex hat Stephomops lemellaris für Grönland angegeben.

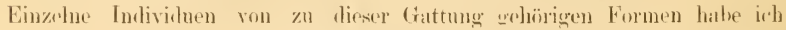
ziemlich oft in Proben ans den fiewïssern von den fregremen mm sowohl

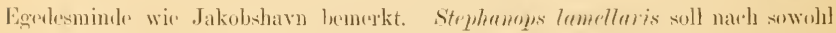

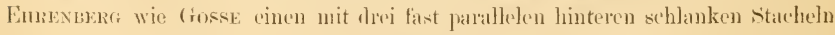
rersehenen P'anzer besitzen. Solche stacheln, wie die Ablihlungen dieser Inturen darstellen, sah ich niemals an grönländicehen stephanopsarten, was ich um so sicherer angohen kann, da ixh gleich nach meiner Riiekkehr hier in Lund rinen Strphrmops lemellaris untersucher, und sogleich diese hinteren stacheln sehs 


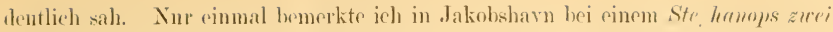
kleine stumpfo Fortsät\%e am Hinterende des Panzers, die jerlech ummöglieh

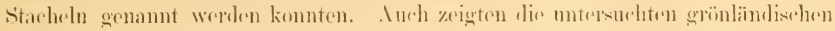

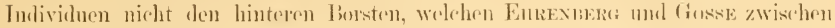

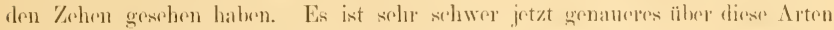

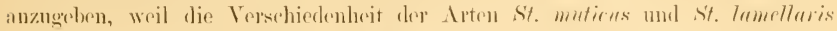

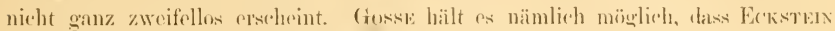
in seiner Ahbildumg beide Arten zusammengeführt hat, und setzt sogar zu: "I confess I have haul suspieions that these are hut one spueies. I have haul speremens in my live-hox of what sermed lamellaris, with the throe ramblal spines elear enough; yet in a few minutes I conla find only spreimans of mutiens, with no spines at all to be disermenl, to my great bewilderment. It sermel as if the spines conld at will disappear, but I ranmot ronjecture how. This has happened repeatedly: Exerpt the greater developenent of the neek, there is little she to diseriminate the twoo". Thehr lange habe ioh bisher nielet diese Thiere beobachten kïmmen, hale aber etwas solehes gar nicht hemerkt, und betrachte sie deshall, wie auch fioss: selbst, bis auf weiteres als gut

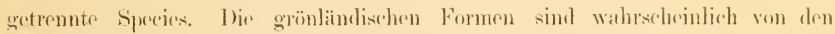
europäischen etwas verschieden. Indessen führe ieh siv zum Thril unter denselben Namein auf.

\section{St. ef. Iomellaris Ehrhg.}

Brachionus lamellaris O. F. Miiller l. c. s. 340, Tah. XIVII, Fig. \&-11. Stephanops lamellaris Ehrbg 1. c. s. 47s, Taf. LIX, Fig. 13.

" lamellaris Eckstein 1. 1. s. 394.

, lamellaris Blochmann 1. e. s. 10s.

" lamellaris Gosso 1. e. Vul. 11, s. 75, I'l. XXI, Fig. 7.

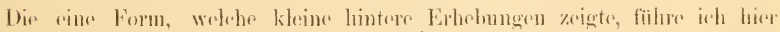

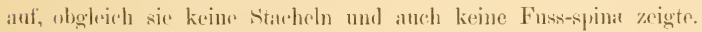

\section{(i3. St. grönlandiens n. sp. Fig. 41.}

Ich wïrde diese Form als st. rf. mutirus anfueführt haben, weil sie die

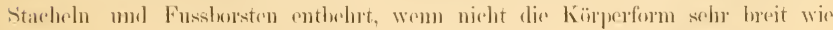
bei lamelleris uewesen wäre, und weil der Kïrper bei vorliegonder Form gar

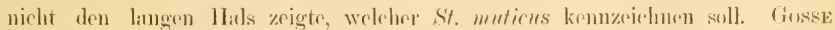


gibt diesem IIaks eine bedeutende ringfürmige Ansehwellung. Auf Ecksteıx's Abliklung ist der Kopf dagegen dureh eine tiefo Einschnürumg vom Kü̈rper abgesetzt. Kinines vom hejilen passt auf die von mir gesehenen Exemplare. Ineh war die Körperform nicht dieselbe wio anf deu Mbbildungen von St. muticus hei den genannten Antoren. Gosse seheint hauptsäehlich auf die Nackenanschwollunge (rewieht zu legen, und dann kamn jeh nieht meine Form ads mit der seinigen identisch auflassen. Fine solehe Ansehwellumg habe ioh bisher bei keinem Stephanops gesehen. Ich habe nicht notirt, wie oft die eine oder andere ron den obigen Formen beobachtet wurde.

Die Länge eines gemessenen in Glyerin aufbewahten Exemplares war lis Mik und die grösste Breite war 66 Mik.

Nach der Ablildung hei Eckstem ist hei St. mutirus die Länge drei und ein halb Mal die Breite. Tei Gosse enthält sie aber die Breite fünf und ein halb Mal.

Nach einer mir erst lange nach der Abfassung des Textes dieser Arbeit bekannt gewordenen Notiz in Jommal of Roy. Mikr Soe. $1890 \mathrm{~s}$. 44 soll IV. B. Tures in ler mir nicht zugängigen seienee-Gossip 1s89 s. 179-81 stwas über eine Irt St. intrmedius mitgetheilt haben, dic er zwisehen den beiden Arten lamellaris und mutiens stellt, obgleich er os noeb besser hält alle drei zn einer Art zu vereinigen. Viellejeht kam diese Art, von der ieh nichts weiter kenne, meiner mahe kommen.

\section{St. Chlona Gosse.}

? Stephanops (hlaena Gosse 1. e. Vol. II, s. 76, Pl. XXI, Fig. 9.

Unter diesen Namen führe ich einige Thiere auf, die ich in derselben Wasseransammlung, wo Mitivocorlides rorkam, beobachtete, dir aber lejder wenig genau untersucht wurden. Indessen scheinen mir meine Notizen die Zusammenstellung dieser Form mit Gosse's Strphanops Chlana nieht mur zu erlanben somdern sogar zu fordern. So lange ieh dis Thiere lebend zugänglich hatte, habe ich geriuges Gewicht auf die Vorschiedenheiten gelogt, die sich zwisehen dieser Form und Mikrorortides vorfanden '). Aber nachler finde jeb die Keichnungsskizzen so abweichend, dass sie gewiss sebr versehietene Thiere darstellen mïssen.

i) Deshalb kann ich anch bei flüchtiger Betrachtung dieser Formen sie verwechselt halsen. Eine solche Verwechshng ist dagegen bei den skizzirten Formen kaum dénkbar. 
Diese Form zeigte eine (querlinie gleich hinter den hinteren Spitzen, und diese Linie muss die Grenzlinie des Panzers dargestellt haben. Eine kleine spitze sass dorsal fast rechtwinklig gegen die Zehe. Leider uahmen in den Tagen andere Besehüftigungen und speziell meine Arbeit mit Mikrocodiles meine Zeit so stark in Anspruch, dass ich der etwas unvollstïndigen Besehreilung Gosse's nichts zufügen kamn. Ich kamn deshalb um diese Art hier anführen um die Aufmerksamkeit späterer Forsehor auf dieselbe hinzulenkisn.

Wenn ich aber diese Form mit Gosse's zusammenstellen kann, so geschieht es gewiss nur unter der Voraussetzung, dass sitrphromps chlomu keine stephumops-Art sein kam, und ich glaube auch kaum, dass jemand. der einen Blick auf Gosse's angeführte Abliklung wirft, es möglich finden kamn diese Art

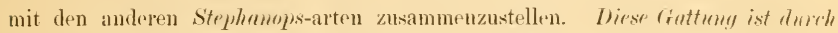

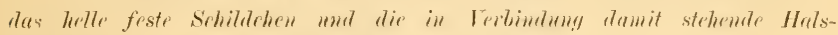

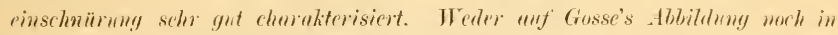

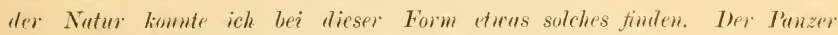
schrint auch ziemlich abweichemel ron demienigen der anderen, whenso die einfache Zehe. Dazu hat St. Cleleme nur ein Auge, woyegen die amberen diten dirser Guttumy, welche Amyen besitzen, zwei solvhe holorn. Augen können woh] bei einigen Arten solcher Gattungen fehlen, die meistentheils Augen führen, aber kaum weiss ich ein Beispiel, dass man in dieselbe Gattung Arten mit pimem und mit zuei weit getrennten Augen zusammenführt.

Würde cliese Art in der Gattung Stephomops ihren natïrlichen Platz funden, so müssen z. B. I liaschiza und Furcularia, Salpinal und Diplax, Colurus und Monura, Brachiomms und Notens; Ameraen und Notholea wieder zusammengestellt werden. Wir kennen his jetzt wahrscheinlich nur den geringsten Theil sogar der enropaischen Rüderthiere, und es kann wohl deshalb kein Berlenken erweeken eine Gattung aufzustellen, wo rorläufig nur eine Art hinzustellen ist. Übrigens hat schon fosse unter den aus zwei verschiedenen Loealitäten stammenden von ihn untersuehten Exemplaren so bedentende Abweichungen gefunden. lass er fragt, ol, nicht zwei, Arten vorliegen.

Die Art St. cimatus, welche Gosse den St. Chloma mit den anderen normaler gebauten Stephamops-arten verknüpfen lässt, zoigt ja schon nach MïLLER's Abbildung sehr dentlich sowohl dir sehirmartigre Platte wir auch die Hakeinsthniirung. 
Weil ich indessen die vorliegende Form in der Natur zu wenig beohachtet Inabe, lasse ich sie his weiter in der Gattung Steplanops verbleiben, bin aber ganz ïberzengt, dass sie bald als selbstständige Gattung im Systeme der Räilerthiere stehen muss.

\section{i. Fam. Salpinadæ.}

\section{Salpina Ehrbg.}

65. S. cf. mucomota Ehrlog. Tab. IV, Fig. 34 a, b.

Brachionus mueronatus O. F. Müller l. c. s. 349, Tab. XLIX, Fig. 8-9. Salpina inueronata Ehrbg l. e. s. 4tig, 'Taf. LVIII, Fig. IV'.

? " $"$ Eckstein 1. c. s. 380, Fig. 18.

",$\quad$ Blochmann l. e. s. 107.

$"$ (tosse 1. c. Vol. II, s. 83, Pl. XXII, Fig. 1.

In den meisten Gewässern Grönlands war eine Salpina sehr häufig mol nach BLochuaxis Beschreibung der Salpima muromatr fasste ich dieselhe als fine soiche auf. Sie trat auch oft ziemlich massenhaft in den Grefissen anf, in welchen die eingresammelten Mooszweige ete. anfbewahrt wurlen. Iuh habe nur ein Paar Mal solche Formen gemauer untersucht, habe aber niemals bej den anderen nur Hïchtig gesehenen Individuen Verschiedenheiten bemerkt. Wemn ich also nur eine Salpina-art notirt habe, können nichts destoweniger sehr wohl auch andere Formen derselben Gattung reeht gewöhnlich sein.

Etwas weicht jedoch meine Abbildung der grönländischen Form von den Abhildungen Ehrenbera's mol Gosse's ab, demn auf diesen sehe ich eimen vicl sehärfer hervortretenden lumbaren stachel. Ehenso wird dadurch die hintere Grenzlinie des Panzers zwisehen den lumbaren und alvinen Stacheln mehr bogenformig, wogegen ich an meiner Abbildung eine fast gerarle Grenzlinie grezeiehnet habe. Weil indessen die allgememe $̈$ hnlichkeit sehr gross ist, und weil ich nachher unter den nach Hanse geführten in spiritus aufhewahren Mooszweigen wonigstens die Panzer dieser Art zu finden hoffen kann, lasse jels jetzt die grönländisehe Form unter diesen Namen gehen. Das Vorderente zejgt wie hei der gewölnlichen S. mucronato zwei fast gleich grosse Dorne an jeder soite und zwischen denselben eine zirmlich gerarle firenz- 
linie. Eine Vertohiedenheit finde ich dagegen darin. dass bei dor grönländischen Form auf dem vorderen Theile des Panzers grössere Zacken orler Ilöcker vorkamen als auf dem grösseren hiuteren Theil desselben. Wix Eunexumac heixst es "loriea sulitilissime seabra" und bej Gosse finde ich im Texte keine Mittheilung über die kleinen Körner des Panzers, aher seine Fig. I l zeigt kleine Erbehungen des Panzers, die überall glejeh gross sind und ïberall lïnger von einander entfernt sind, als ich es leobachtet habe.

Bej Ecksters lese jeh dagegen freilich: "Der Vorderrand des Panzers hat rinen breiten Imsehlag, der mit kleinen Zacken und Ilöckern besotzt ist, während der übrige Panzer fein gekörnelt erscheint" und die Angabe passt sebr gut zu meiner Salpina, aber die Abbildung Eckstesx's scheint mir kaum eine Zusammenstellung unserer Formen zu erlauben. Ebensowenig kaun ich glauben, dass seine, Enrexneks's und Gosse's Salpina mucronata dieselle Irt darstellen. Der lumbare stachel seiner salpinaart ist viel länger als die alvinen. Ansserdem ist er gerade, mol so seheint anch die Grenzlinie des Panzis zwischen dem lumbaren und den alvinen stachelı.

Es könnte deshalb vielleieht möglich sein, dass die grönländische sialpina eine verschiedene Art oder Varietiit darstellte.

Die Jänge eines gemessenen Panzers betrug 165 Mik.

\section{k. Fam. Euchlanidæ.}

\section{Euchlanis Ehrbg.}

(i6. E. dilutata Ehrbg.

Brachionns Bractea O. F. Niiller 1. e. s. 343, Tah. XLIX, Fig. (5-7 '). Euchlanis dilatata Ehrbg 1. c. s. 463, Taf. LVIII, Fig. II.

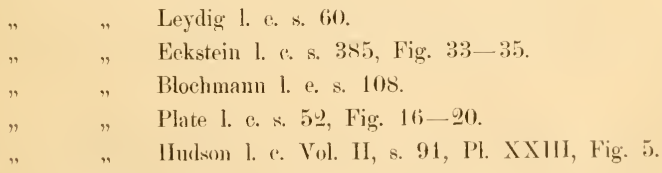

1) Diese Abbildung passt sehr gut auf diese Art, nur weiss ich nicht sicher. was die beiden "unciunłæ binæ distantes" bezeichnen könen. Kam man anmehmen dass dieselben nur die seitlichen Ränder des Fussausschnittes im Panzer bezeichnen? 


\section{7.? E. macrura Ehrbg.}

Euchlanis macrura Ehrbg 1. c. s. 463, Taf. LVIII, Fig. I. Hudson 1. c. Vol. II, s. 91, Pl. XXIII, Fig. 6.

Ich habe bei N:r 67 ein Fragezeiehen gesetzt, weil es mir sehr wahrseheinlich vorkommt, dass diese Arten nicht getrennt werden dürfen, weil, wie Hunson bemerkt, diese Merkmale einer bedentenden Variation unterworfen sind.

Die in Grönland gewöhnlichste Form hatte viel längere \%ehen, als Ecksteıx auf seiner Abbildung dargestellt hat. Einmal beobachtete ich bei Jakolshavn eine kleinere Form, die auch relativ kürzere Zehen besass. Im Vorhandensein von setæ kamn kaum ein Merkmal liegen, dem erstens sieht man bei einem Individuum eine Weile die setæ, mol dann kann man sie nicht länger entderken, zweitens variiren hei den mit setæ versehenen Individuen die anderen Nerkmale nicht wenig;, und drittens kamn man bei unstreitig zu derselben Art gehörenden Individuen, trotz langer und wiederholten Beobachtung nicht bei allen die setre aufweisen. Prite hat schon die Aufmerksamkeit hieranf gerichtet, indem er nicht die Art $E$. unisetatu Leydig als eine von den anderen rerschiedene Irt betrachten will.

In einem nicht mmichtigen Pnnkte ist die Autfassung des Bans dieser Thiere verschieden: Plate sagt: "Rücken- und Bauchschild haben die gleiche Form, nur dass das erstere breiter und gewölbter ist als das letztere". Ecksters sagt: "Während der Rückenschild Hach ist, ist das Bauchstück in der Mitte gewölbt, so dass dadırch Raum für die Leibeshöhle gewonnen wird". Ich habe auch mehrmals in (irönland die Lage des Thieres so aufgefasst, als ob es auf einem flacheren Rückensehild lag, will aber hierauf kein Gewicht legen, da ich nicht absichtlich darüber besondere Beobachtungen anstellte.

Ich habe weder die von Eckstein genannten Pigmentflecken an den Basen der Zehen noch die Nebenaugenflecken sehen können.

Ein gemessenes Exemplar hatte eine Länge ron 200 Mik ausser den Zehen, welche 60 Mik maassen. Grösste Breite des Panzers 125130 Mik.

Die Euchlanisformen, welche ich unter den ohigen Namen anfgeführt habe, waren nie häufig, aber hiv und da wurden einzelne Individuen von den ersten Tagen des Juli an bei sowohl Egedesminde als Jakobshavn notirt. 
6s. E. triquetre Ehorbg.

Euchlanis triquetra Ehrbg l. c. s. 46I, Taf. LVII, Fig. VIII.

Hlochmann l. c. s. 108, Fig. 247.

Hudson l. c. Vol. II, s. 91, Pl. XXIll, Fig. 4.

Diese schöne Art war viel seltener als die vorigen. Sie wurde nicht hei Egedesminde gesehen. Nur bei Jakohshavn babe ich sie cinige Male notirt. Sollte das möglicherweise darin spinen Grund haben, dass ich meine Untersuchminen in Jakobshavn später vornahm?

\section{Fam. Cathypnadæ.}

\section{Cathypna Gosse.}

\section{9. (. sp. Tab. V, Fig. :3}

Es ist besehämend diesem Räderthiere nicht ganz sicher einen Nanıen geben zu können, denn dasselbe gehört zu den allergewöhnlichsten Rotiferen Grönlands. Ieh hoffe aber diesen Mangel später ahhelfen zn können. Ak Entschuldigung mag gelten, dass ich in meiner literatur keine Form fand, mit der ich dasselbe näher vergleichen konnte. Ja, ich komnte sogar nicht die (rattung finden, denn ich wollte dies Thierchen nicht gern zu der frattung Euchlanis führen, weil es in der Lebensweise eher einer Monostyla ähnlich war. Weil das Thierchen fast überall so gewöhnlich war, wurde die grenanere Untersnchung von Tag zu Tag versehoben, so dass es schliesslich zu spät wurde. Aus dem Gedächtnisse und nach meinen oberflächlichen Notizen kann ich nur das Folgende mittheilen. Die Abbildmg stellt eimen alten zerrissenen Panzer eines schon lange todten Thieres dar. welehes ich der vier darin liegenden Eier wegen ein Mal skizzirte. Weil ich keine andere Zeichnung habe, theile ich jetzt diese mit, obgleich sie gar nicht für eine Publieation beabsichtigt war.

Das Thier schien mir trotz des deutlichen Panzers die form des Körpers ein wenig rerändern zu können, wenigstens habe ich dieses von einigen Individuen angegeben. Von anderen sagen meine Notizen, dass solehe Veränderungen nieht gesehen wurden. Der Panzer ist ziemlich hoch und hat ron oben gesehen eine etwas längliche ovale Form, und zeigte einige, meist längslanfende Leisten, die jedoch nicht längere Strecken verfolgt werden konnten. Zwischen 
diesen Leisten schienen mir grubenartige Einsenkungen vorzukommen. Die langen Zehen zeigten sehr deutlieh gekrümmte Klauen.

Weil Eckstein für seine (iattung Distyla einen deprimirten Panzer angibt '), kam jeh nicht das Thier dahin führen, obgleich dasselbe eine nicht so geringe Ähnlichkeit mit (rosse's Abbildung seiner Distyla Afexilis zeigt ${ }^{2}$ ). So lang war jedoch der Panzer nicht, und die Leisten desselben gingen, so viel ich erimnern kann, nicht ganz vom einen Ende bis zum anderen. Vou anderen mir bekannten Abbildungen konnte nur die Abbildung 5 auf derselben Tafel XXIV in Gosse's Arbeit hier in Betracht kommen. Aber zu derjenigen Art, C'athypu sulcuta, gehörte die grönländische Form gewiss anch nicht.

\section{Monostyla Ehrbg.}

Zwei Arten von dieser Gattung sind ganz sicher beobachtet worden, und es ist wahrsebeinlich, dass ich noch ein paar andere flürhtig gesehen habe. Sie waren gewöhnlich, sogar sehr gewöhnlich, und konnten wenigstens in den Gefïssen, weiche mit schwimmenden Iooszweigen einige Tage in meinem Zimmer gestanden, zusammen mit der vorigen und Salpina mueronata ziemlich massenhaft auftreten, so dass viele in einer mikroskopischen Probe vorkamen. Gosse und anch andere Verfarser sehen in dem langen hinteren stachel eine Zehe. Nur bei Momostyla Lordii Gosse äussert dieser Verfasser einen Zweifel, ob nieht nur der äısserste bei dieser Art scharf abgesetzte Theil einer Zehe entspreche. Ich kann mich der Anffassung, nach welcher der ganze Stachel eine Zehe wäre, nicht ansehliessen, weil jeh bei den von mir näher untersuchten Thieren immer leicht eine Gliederung des Stachels habe sehen können. Ich betrachte nur las äusserste Glied als eine Zehe.

70. M. Quemuersterlti n. sp. ${ }^{3}$ ). Tab. VI, Fig. 39.

Diese Art steht Momostyla lumaris Ehrbg sehr nahe, ist jedoch von derselben durch die Beschaffenheit des Fusses scharf unterschieden. Derselbe läuft

1) Eckstein 1. c. s. 383 .

${ }^{2}$ Gosse 1. c. Pl. XX1T, Fig 7.

${ }^{3}$ Da ich diese Art nach meinem verehrten lehrer Herrn Prof. A. W. Quesserstedt benenne. erlaube ich mir ihm hiermit meinen besonderen Dank zu sagen, weil er durch seiu Entgegenkommen bei der Anordnung meiner Dienstpflichten am zool. Institute mir diese Reise möglich machte, wie er mir anch später sowohl wie früher in vielen Beziehungen Beistand geleistet hat. 
bei $M$. lunaris in eine grössere Sipize aus, an deren Basaltheile zwei kleinere sitzen. Der Fuss rom M. Quemmatedti setzt sich dagegen solw allmählig in

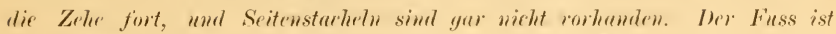
selur dentlich yeglimdert. In fast allen anderen Beziehungen stimmt diese Art mit M. Immuris ïberein. Der Panzer ist hoch und breit. Der mastax ist sehr gross, und das Anssehen bei eingezogenem Kopfe ist ganz dasselbe. Ich habe indessen mit Ecksteiv's Abbildung neben mir den Fuss so genan untersucht, dass ich meinen Notizen diese Frage betreftend volles Vertranen sehenken kann. Einmal habe ich von einer Hüchtig gesehenen Monostylaform notirt, dass der Fuss mehr plötzlich in die Zehe ïberging. Es wäre deshalb möglich, dass ich anch die verwandte $\boldsymbol{M}$. lumaris gesehen habe. Diesen allgemeinen Thieren konnte ich natürlich nur dann und wann nähere Aufmerksamkeit widmen.

Die Länge eines gemessemen Thieres war 168 Mik ansser dem Fussstachel, weleher eine Länge ron bs Mik besass.

\section{M. ef. ronmutu Ehrbg.}

Trichorla cornuta O. F. Mïller l. c. s. 20s, Tab. XXX, Fig. 1-3.

Monostyla cornuta Ehrbg l. e. s. 459, Taf. LVII, Fig. IV.

$\begin{array}{ll}" & \text { Eckstein 1. e. s. 382, Fig. } 50 . \\ " & \quad \text { Blochmann 1. e. s. } 107 . \\ " \quad & \quad \text { Gosse 1. e. Vol. II, s. 98, Pl. XXV, Fig. } 1 .\end{array}$

Diese anch gewöhnliche Form war weniger hoch und breit und hatte den Panzer nach rorn abschmälernd. Der Fuss zoigte auch keine plötzliehe l)ickenabmahme. Er war etwas kürzer als bei der vorigen Art. I)ic Abbildung Ehrenberc's wïrde wohl besser als Gosse's zu den von mir mntersuchten Exemplaren passen.

\section{m. Fam. Coluridæ.}

\section{Colurus Ehrbg.}

Levines hat Colmins sp. angegebell.

72. C. Inrimatus Ehrbg.

Brachioms uncinatus O. F. Müller l. c. s. 350, Tab. L, Fig. 9-11. Colurus uncinatus kholog l. «. s. 475, Taf. LIX, Fig. VI. 
Colums uncinatus Eekstein l. c. s. 378 , Fig. 45 \& 46.

Blochmann ]. e. s. 107, Fig. 243.

Gosse l. c. Vol. II, s. 103.

Jiese kleine Art wurde anch in vielen Gewässern beobachtet. In der Grösse, nnd in der Form des IIinterendes des Panzers kamen sicher bei einigen C'oluren Verschiedenheiten vor, welehe Abweichungen jedoch nicht so beständig waren, dass ich sie fïr Artenunterscheidung benutzen konnte. Gosse hat eine ganze Menge von Colurus-arten aufgestellt und sagt ron C. mrinatus: "It is usually of mimte dimensions and though wilely spread, rather rare". Ieh glaube jedoch, dass alle von mir etwas nähel untersuchten Colurus-individuen zu des Art umcinatus geführt werden müssen, denn ich wilmete dieser Art nicht geringe Zeit. Möglich wäre, dass auch (. oltusus gesehen worden ist.

Ieh habe C. uncinatus für die (iegenden ron Egerlesminde, Jakobshavn und Ritenbenk notilt.

\section{Monura Ehrbg.}

73. M. Amblytelus (Gosse). Fig. $35 a, b$.

Colurus Amblytelus Gosse 1. r. Vol. II, s. 104, Pl. XXVI, Fig. 5.

Ich finde so grosse Übereinstimmung zwischen ılem hier abgebildeten Thiere und Gosse's C. Amblytrlus, dass ich sie als identisch annelmmen muss. Gosse behält "mainly in deference to the great Prussian zoologist" die (iattung Monura, obgleich dieselbe sich von (blurus mur durch die pinfache Zehe unterscheirlet. Obgleich er diese beide Gattungen als so nahe verwandt betrachtet, stellt er dennoch die Gattung Metopidir zwischen dieselben. Ich kann ihm darin ebensowenig folgen wie in der Begrenzung der Gattungen Colurus und Monura. Ich würde es gar nicht umrichtig lalten die Gattung Momro ganz weglallen zu lassen. Läisst man aber dieselbe bestehen, muss selhstverständlich anch die obige Art in die Gattung Momere und nicht in die Gattung Colurus gestellt werden.

Ich sah im proximalen Theil der Zehe eine Jinie, die wohl eine Andentung der Grenzlinie zwischen den beiden verwachsenen Zehen darstellte. Weiter nach der spitze zu komnte ich dieselbe nicht gewalur werden.

Was ich von der inneren Organisation beobachtete, zeigt die Abbildung: Der Magen war sehr deutlich vom Darme abgesetzt unl hatte einen stark braumen Inlalt. 
Dieses Räderthier kam im Mrere ror und gan\% wie die beiden anderen vorher besprochenen Meeres-rotiferen wurle es sowohl in strandpfützen wie auf woiter hinaus auf dem Meere treibenden bewachsenen Fucuszweigen gefunden.

Eine grössere Coluride, welche ich aus dem Bodenschlamme eines grösscren Soes hei Egedesminde holte, schien mir dieser im Mecre gofundenen Art sehr ähnlich. Ich wage jedoch nicht sicher zn behanpten, dass sie identisch waren. Irh hatte für diese Formen lieine Literatur, und es ist also sehr möglinh, dass diese süisswasserform wirklich eine andre Art z. B. Colurus caudutus oder eine verwandte gewesen, denn meine kurze Keit erlaubte mir nicht mohrere Exemplare von derselben zu sammeln und genaue Zeichnungen zu machen. Ieh war nämlich eben in den Tagen im liegriffir von Egedesminde abzureisen. Gosse sagt von M. Amblytelus: "This species seems exelusively marino", mol aus dieser Aussage würde ja olme weiteres folgen, dass das eben genamnte Thier nieht $z$ derselben dit gehören konnte.

M. Amblytelus war seltener als die anderen von mir im Meepe an dep grrönländischen Kräste beobaehteten Räderthierarten.

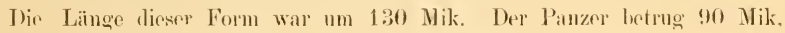
die \%ohe 95 Mik.

\section{Metopidia Ehrbg.}

Aurh diese Gattung war reiehlich vertecten und einige tahin gehörende Formen wurden besonders in .Jakobshavn sehr oft gesehen mol traten anch in gröiscrer Anzahl auf. Die Jiestimmmo ist hanptsärlylich nach moiner Rï̈ckkelı ansurefiihrt.

74. M. (cf.) Lepardella Ehrhg. Fig. 37 a, b.

Motopidia Lepadella Ehrbo l. e. s. 477, Taf. LIX, Fig. X.

(tosse 1. e. Tol. II, s. 106, Pl. XXV, Fig. 6.

Diese an den meisten Orten so gewölmbiche Art mar in Grïmlamd selfon. leh sah diesolbe nur in Jakobshavn, und auch da war sie nur von wenigen Individuen vertreten. Der Panzer derselben war nach hinten nicht so stark verjüngt, wio es Gosse's Abbildung darstellt. Embexnere's Figur passt viel besser auf diese Thiere. Weil ich die Kö̈perform auf Squamrlla oldongre 
linweisend fand, suchte ich genau nach einem zweiten Paar Augen, nul kaun

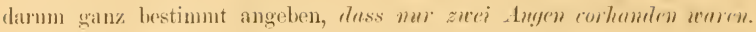

\section{M. solida Gosse.}

Metopidia solidus fiosse l. a. Vol. II, s. 106, Pl. XXV, Fig. 11.

Fine growse Form, wolche fast cirkelrunden Panzer mit rinem breiten durehseheinenden Rand besass. Auf meiner Ibbildung ist der Panzer fast noch punter als auf Gosse's.

Diese Art war sowohl bei Egedesminde wie bei Jakobshasn in vielen frewitsselun und in meinen klemen dipuatengelässen sehr allgemein, viel gerwöhnlicher als die vorige. Auch bei Ritenhenk wurde sie gesehen.

\section{I. affimis n. sp. Fig. 42.}

Fine mit der vorigen sohe nahe verwandte Art, dir ich jestorh als von

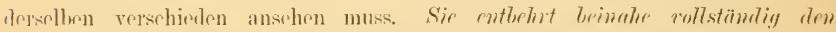

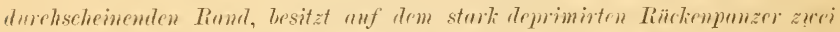

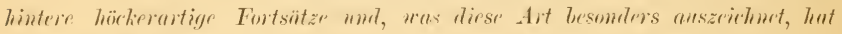

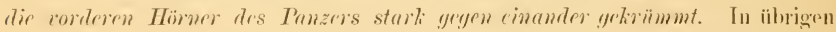

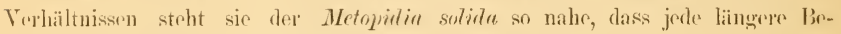
sehrrilung übertlïssig ist.

Die Grösse ist etwas geringer als dicjenige der vorigen Art.

17. "ffinis wurli Anfang hiptember in wenigen Exemplaren in einer lisergpfiit\% in der Nähe von Ritenhenk gefunden.

\section{M. acuminutu Ehrbg.}

Metopiclia areuminata Ehrbeg I. c. s. 477, Taf. LIX, Fig. XI.

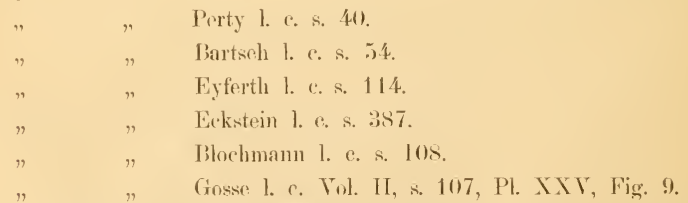

länes von den allergewöhnliehstend der Ritiderthieren Grönlands. Fie cinzige Abwejehung von den in der Litratur befindlichen Besschreihungen dieser Art. welche ich bemerken komnte, war, dass die hintere spitze ctwas kleiner war 


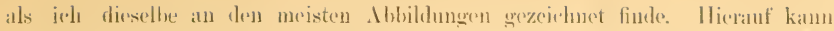
ich jerlorh nicht cine Irtiverschicalenhert begründen.

Eigrnthümlich seheint es mir, dass diese Form so gewiihnlich in firinland war, denn in Europa scheint sie gar nicht so häufig zu sein. Ennkxmat batte nur ain Exemplar, in Berlin 1832, gefunden, als cr secelss bahre spätre. seine grosse Arbeit ausgah. Wewss: reshet sie erst in seinem dritten Ver-

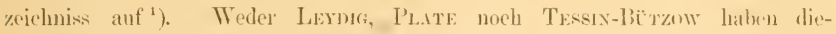
selbe in ihren Verzeichnissen aufrenommen. Perty hat sie bei burn aber mur in einzelnen Individuen gefunden. DarTsen sagt von dieser Art niebst ob dieselhe gewähnlich odes selten war. Wenn dic Arton allgumoin Wilrum, pflegt er jedoch dieses anzugeben. Evrketn sagt von derselben "nieht häufich".

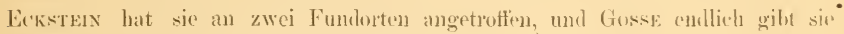
für drei stellen an, setzt aber hinzu "rer'y searee".

Ich würde kaum eine Wasseransammlung in Grönland nennen kömnen, wo jeh nicht wahrscheinlich diese. Irt gesehen habe. Natiurlich halde ieh nirht olt ïber ejn so häufiges Thier qrenanere Untersuchungen angentellt oder beson-

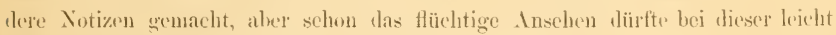
kenntlichen lit für eine sichere liestimmung genügen.

\section{Tร. M. triptera Ehrbg.}

Metopiclia triptera Ehrbg l. e. s. 47s, Taf. LIX, Fig. XII.

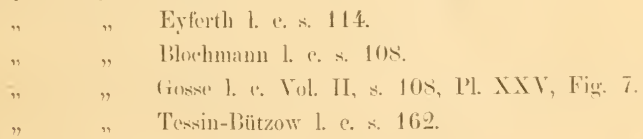

biese mole leichter kenntliche kleine set war viel seltener als $M$. solicle

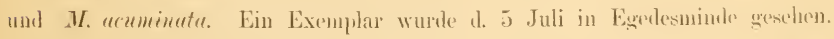
Spaiter wurde sie wäluenel moines langen Aufenthalts daselbst nieht cin rinziges Mal wierler angetroffen. Ende August fand ieh sie in Jakohsharm wienler, und daselbst wurde sie während meines Anfenthalts in melureren Wasseransammlungen und in reeht vielen Exemplaren beobachtot. Es seleint mir deslaall, wahrseheinlich, dass anch diese Irt in cirönland häufiger als in Eurnja

1) Weisse, J. F. Drittes Verzeichniss etc. V. 1847. s. 39. 
auftritt. Ieh setze hier nur hinzu, dass diese Art in Wersse's ') erstem Verzeichniss erwähnt worden ist, und dass Gusse dieselbe "rare" nennt.

In Ritenbenk wurde sic nicht wahrgenommen, aber unter einigen Mooszweigen, die da gesammelt waren und während der Rückreise in einer bedeckten Glasschale aufbewahrt wurden, habe ich sie nach meiner Räickkehr boobachtet.

Anmerkinng. Es fällt mir sehwer zu glauben, dass die so gewöhnliche Metopidia lractea Gosse (Squemella bracted Ehrbg) nicht in Grönland allgemein wäre. I'h habe sie aber nieht notirt. Vier Angen habe iel ganz sicher bei keinem einzigen näher untersuchten Thiere gefunlen. Dir einzige Irt, mit welcher sie verwechselt werden konnte, ist ja M. acumimata; ielı will deshatb austrücklich erwähnen, dass ieh viele Exemplare dieser Art genau besichtigt habe und eben so deutlich die kleine hintere Panzerspitze bei allen geschen, wic ith bei keinem vier Augen habe bemerken können. Es wäre darum ein eigenthünlicher Zufall, wem $M$. bractea unter den anteren nur ganz flüchtig gesehenen häufiger vorkommen sollte. Teh will anch hier bemerken, dass ich kein augenloses Metopidtu-ähnliches läaderthier gesehen labe, welches mit der sogenannten Lepadella oxulis Ehrbg zusammengestellt werden könnte.

\section{n. Fam. Pterodinadæ.}

\section{Pterodina Ehrbg.}

79. It'. ef. alliptica Ehrbg (nee Gosse ${ }^{2}$ ). Fig. 36 ", t, r.

Pterorlina alliptica Ehrbg 1. c. s. 117, Taf. LIV, Fig. V.

Blochmann l. c. s. 108 .

Diese Art wurde Ende des Monats August in Jakohsharn mohrmals gesehen, aber nur unter den ans einem Teiche stammenden Noosen und mur in ainzelnen Exemplaren. Ich habe mit keinem anderen Räderthie' so viele

1) Ich bemerke dies, besonders weil Ecksturv in seiner gewöhulich so vollstiundigen Litteraturangabe für diese Art W Ersse nicht eitirt hat. I ch habe meistentheils nicht W Ersse's Arbeit in den Synonymenlisten mitgenommen, weil sie mu eine Infzählung enthailt, und weil ich sie nur ziemlich flüchtig auf der licrliner libliotlıck benutzt habe und bei meinen Notizen nicht dic seite angeführt liabe.

$\left.{ }^{2}\right)$ Gosse hat jedoch seine znerst 1 t. elliptica genaunte Form jetzt als 1 t. truncuta aufgeführt 1. c Vol. II, s. 115. 
Miihe grolabt. Wenigstens droimal hatte ich Thiere ansgestedit und glieklieh isolirt, aber wurde immere gestört, musste andere l)ingo vornehmen, und die isolirten Thiere gingen alle vertoren. Ich habe cine skizze gemacht und theile ateh einige Notizen mit.

Ich sals diese Art nicht, als ieh in Ritenbenk Proben ans einigen Gewässern untersuehte, habe abe' nachher unter den schon frïhor erwähnten nach IIause gefühten Moosen, welche in Ritenbenk gesammelt waren, eine I'terodina beobachtet. Dieselbe stimmt indessen nicdit ganz mit meinen in Jakobshavn mntersuchten Pterodinen überein. sic war breiter und kam der I't. I'atina näher. These Thiere könnten allerdings hier in Lund hineingekommen sein, demn die Glasplatte, welche ïber dem Gefäss lag, wurle ja damn und wann anfgehoben, und I'terortina I'atina kommt hier in Lund häufig vor und wurde unter nöthigen Vorsichtsmatasseweln gleichzeitig untersucht. Ich halte jedoch diese Annahme für seher unwahrseheinlieh, da sie nu mit Staul, hätte hineinkonmen kïnnen und meine (iefïsice nie anstrockneten. Auch draussen war es ja im Herbste so feneht, dass ain Herumführen durels den IVind für diese Art ziemlich sicher ausgeschlossen war.

Es scheint mir nieht sicher, dass 1 't. elliptice und I't. Putima gut getrennte Arten sind, und deshall, führe ich die beiden Formen unter vinen Namen an, welcher besser auf die in Grönland sellost untersuehtem Exemplare passt. PLATE glaubt abenfalls, dass die beiden Formen nicht versehiedene Irten bilikn. Er hat sowohl dio Körperform wie die anderen von Einkisere angeführten Merkmale variirend gefunden. In Grönland sah ieh jedoeh niemals so rundliche Thiere wie die später hior untersnchten I't. Patina, und hier in Iamd ist It. Intimu nath meinen bisherigen Entersuchungen zu urtheilon eonstant fast ivirkelruml.

Wann man meine Abbildung einer von der Seite geschenen grönländischen I'terodiue mit llowsen's entsprechender Abbildung einer in derselben Lage befindlichen It. I'ntima vergloieht, tritt eino recht bedentende Verschiedenheit hervor, indem IJunsox's Figur 11 b cine bedentende dünne hintere Partic zeigt, wozu ich auf meiner skizze nichts linteprechendes finden kann. Ineh mein ideales (Enersehnitsbild ist llensox's Abbildung 11 e wenig ähnlieh. Die dünnon membranartigen Ränder simb viel breiter an den Iludson'selren Abbildungen. 
Das in seitlicher Lage abgebildete Thier war mit seiner Fusspitze befestigt,

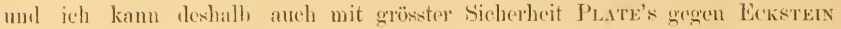
atusugesproclene Angalie, dass die Pterodinen ihren Fuss in derselben Weise wic andere Räderthiore, bonutzen bestatigen. Es wundert mich, dass hieriber verschiedene Meinumgen existiren kïmnen, denn ich beobachtete gar nicht selten, dass rine I'terouliun sich ziemulich lange anf demselben Platz mit dem Fusste festhiclt und den Körper nach rersehiedenen Seiten streckte. Der Fuss war damn nicht ganz ausgestreckt und die in seiner spitze befindlichen starken Cilien waren auch ringezogen. Dor Fuss war immer nur mit rinem Theile des Ramiles befestigt.

\section{o. Fam. Brachionidæ.}

\section{Brachionus Ehrbg:}

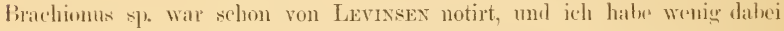
zuzufïgren. Nur das mörhte irl, bemerken, dass diese Irten in firönland selten waren. Tch habe nur zwei rersehiedene Arten notirt.

80. Br. ef. Balieri Ehrbg:

Brachionus Bakeri Ehrbg 1. c. s. 514, Tat. LXIV, Fig. I.

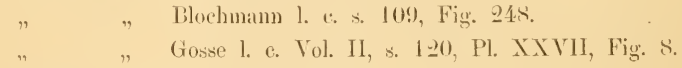

Nur einmal sah ieh in Egedesminde eine ziemlich kleine Form, die sehr flüchtig hesichtigt werden komnte, und die ich mit der obigen Art vergleiche. In Jakobshaven sah ich keinen zu dieser Irt gehörenden Brachiouns. Weil ieh so wenig von liesem Thier geselıen habe, wollte ich keine ansfülnlichere Synomymenliste mittheilen.

\section{sl. Bi.: sp.}

Dats ansserordentlich schmell seliwimnende Räderthier, welchen ich hior cinige Worte widme, wurke in vielen Exemplaren in Jakobshavn geselen, aber die Zeit wure mir schliesslich für die immer dureh andere Arbeiten von cinem Tage zo dem andern verseholuene nähere Untersuchung zu kurz. Nach meiner läickkely hale ich dasselbe in dem nach Ilause mitgeführten Material bis jetzt nielet auffimlen kömmen. 


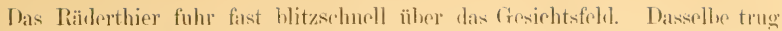
cimen glänzenden, whashellen, durchseheinenden Panzer, wolelere, so viol irh reinnere, fast rechteckig war und melurere (wenigstens drei jeclerseits) langer hintere

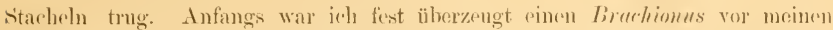
Angen $7 \mathrm{n}$ haben. Eimmal sah ich ein Exemplan otwas nïher an und gericht

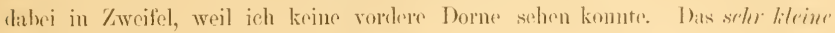
'Thier trug ein oder mehrere Eier mit sieh herum.

Ich kenne keine Ibbildung einer bireliomusart, welehe mir diesem Thirare rocht ähnlich erseheint. Fs war fast einer Tolyosthioa ähnlicher, aher war gepanzert und mit rom Hintremde ansgehenden Stacheln verselere. (iamz

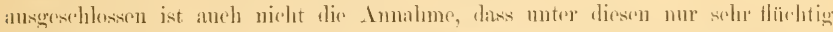

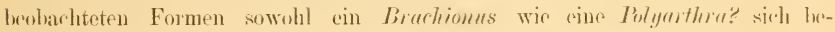
fanclen.

Näheres kanm inh jetzt nieht angeben. Ieh hatte Mooszwerger u. 1. gel.

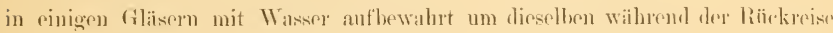

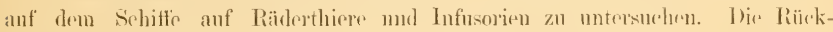
reise war aber sohr stürmisch, so) dass man gewöhnlich grosse Mülıe luatte um seinen eigenen Körper auf dem eingenommenen Platze fest halten zu kömmen, mul alle Gegenstände, die nicht fest waren, ziemlich schmell anf dem lioklen mmher geworfen wmelen. Obgleich ieh num mein Mikroskop nareh der anf ('hallenger gebrauchten Methode mit einer Feder befestigen komute, zaigte: es sich vollkommen unmöglieh unter diessen Verhültnissen lebende Rärlerthiere auszusuchen und genauer zu beshatehten. Präparate komte jeh dagegen freiliel fiir kiirza Augenblicke recht gut betrachtem. Nun hatte ich bereshnet hesondors diese s. g. Brachiomusart wie anch eingor andere in Grönland nicht gemmy untersurhte, gepanzerte Arten auf der Rückreise volstïndiger zul studieren.

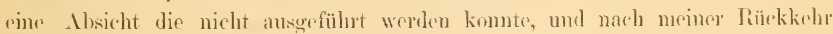
war dieses Material so faul gewordrun, dass ich es leider sebou in Koprenlangenu wogwarf olue zu bedenken, dass dic Panzer wohl wahsehoinlich democh lü̈ten gefunden werden kömnen. Hoflintlich werde jeh später diese Art in meinem sipiritusmaterial anfsuchen kïmmen. Ioh theile das obige mu dowall

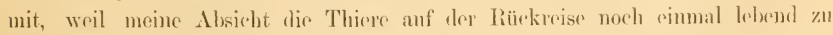

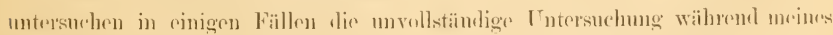

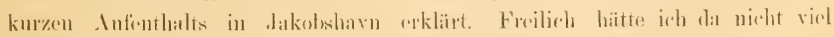


mehr erreichen kïmnen, drnn ich sass fast den ganzen Tag an meinem Mlikroskin').

\section{p. Fam. Anuræadæ.}

Ammrtiung: Ieh schalte anch hier die von DE Gutrxe und Richand angeführten Amron cochlearis frosse und An. longispina Killicott ein. Vgl. oben s. 13.

\section{Notholca Gosse.}

\section{se. Notholed ambigua n. s]. Tab. IV, Fì. 24 ", b.}

Gosse brielıt diese Gattung aus Ehrensere's Gattung Ammote aus und fïhrt zu dersellon die Arten, deren Panzer sechs vordere Dorne und longitudinale Furehen and Leisten besitzen. Auch gibt er als Gattmosmerkmal "no hind spines" an. Jedoch ist der Panzer "sometimes produed behind". Meine hier angefiihrte Art seheint Merkmale der heiden Gattungen zu rereiuen. Jedoeh sebeint sie mir den Notholeu-arten näher zu kommen. Diese Gattungen scheinen mir auch sehr nahe verwandt zu sein.

Auch diese Form ist ungeniigend beobachtet worden. Ein Exemplar wurke sehon d. 25. Juli beobachtet. Ieh hatte damals noch die Hoftinung andere zu finden und konnte es übrigens im Augenblick anch ans anderen Grïnden nicht so eingehend wie wïnschenswerth untersuchen. Ieh habe jekloch in der ganzen Zeit kein zweites Amman- oder Notholen-individum gesoluen. Trotz der mangelhaften Untersuchung und der unvollständigen Skizze seheint sie mir dennoch eharakteristisch genug um die Aufstellung einer nenen Art: zu rechtfertigen.

Diese fusslose Form zeigt einen etwas bräunlichen Panzer, der vorne sechs Dorne trägt, von denen die medianen des Riickens an längsten erseheinen. Diese sowohl wie die oberen, sejtlichen sind dünn, stachel- oder stäbchenfürmig. Die unteren sind dagegen breiter. Der mediane Einschnitt zwisehen den beiden dorsalen Stachehn ist viel tiefer als derjenige zwischen den dorsalen einersoits und den oberen seitlichen anderseits. Norh hinten läuft der Rë̈rorn in einen

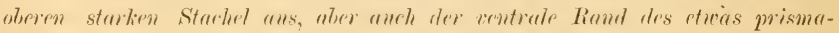

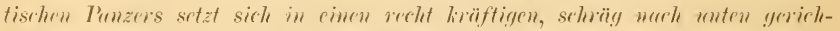
treten, liürzerem Strehel fint.

C̈ber die skulptur des Panzers sind leider meine Notizen unvollständig.

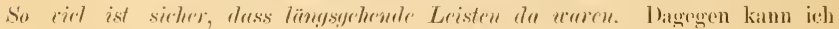


nicht sicher angeben, ob dieselben ohne jerts Luterbrechung rom vorderen Ende bis zum hinteren hinzogen, oder ob sie an einigen stellen zustummentielen.

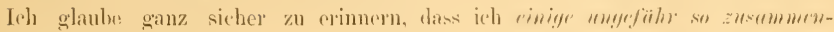

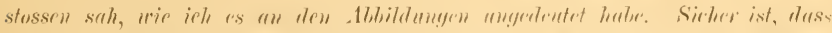

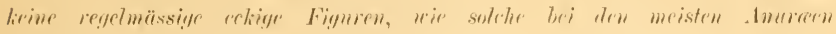
iorlommen, de weren.

Dagegen sollte ieh glauben, dass die Leisten upresse Öhnlichkerit mit den-

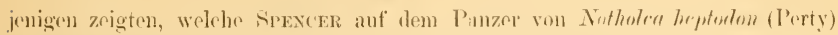
IIudsen zeichnet. Nur waren dir Teisten in viel grö̈sserer \%ahl vorlamben. Ehensowenig kam ieh sagen, ob der I'anzop aus rinem riuzigen "box-like"

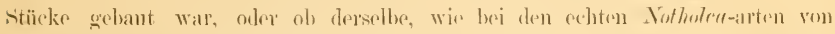

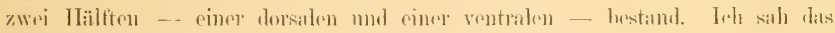
'Thior nicht in Bewegung.

Die Länge des l'anzer's ..................... 17\%) Mik,

Der hintere lumbare Stachel 16.20,

Dic meslianen vorrlerens Stacheln

. In ilner merlianen srite............... (2)

An der äussoren Sirito $10-12$,

Die oleren seitliehen Starheln. $11)$,

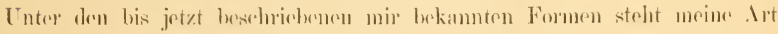

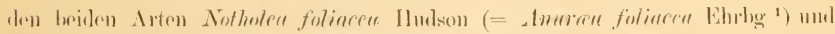

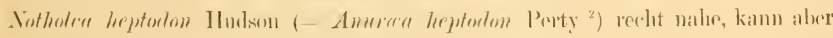

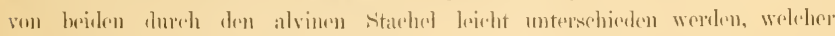

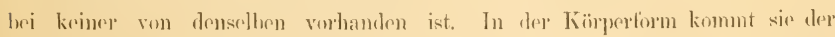

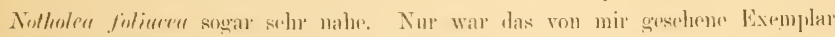

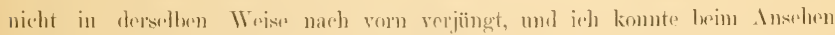
vou oben nur vier stacheln auf ein Mal sehen. Von den Lefisten habe ich

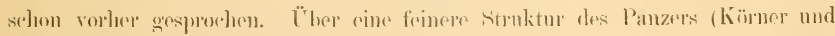
(lyl.) halus ich nichts notirt.

1) Ehrenerg, 1. c. s. 507, Taf. Lxil, Fig. X.

Huns: 1. с. Suppl. s. .) 6 , 1'1. XXXTY, Fig. 35

1':kry 1. c. s. 45, Taf. II, Fig. 4.

IItusen 1. e. Suppl. s. 56, P1. XXX11. Fig. 34. 


\section{Über einige in Grönland beobachtete Rotiferenmännchen nebst einigen Bemerkungen über die Männchen und die Wintereier der Räderthiere.}

Einige Male habe ich wïluend meiner Arbeiten mit der Famna der sïssen few:isser in Grönland Rotiferemmämnehen bobachtet und gobe hier eine etwas ansführliehere Mittheilung dariblee, wril diese Thatsache, dass Mämmehen and in Cirönland vorkommen, mir mit Rä̈ksicht anf rersehiestene eben in neneren Irbeitem dargelegte Beolachtumgen num Ansichten busonders interessant mud gewissermaassen anch wichtig erseheint. Nur ein einziges von diesen Männwhen komnte ieh etwas niiher untersuehen.

Ich führe dlasselbe zn dor Gattung Furmlaria und lasse hier eine so eingrhende beschreibung. wie die etwas lüekenhalten Beobalchtmoen es erlanbun, bilgen, weil, soviel ieh weiss, kein Furculariamänuchen bisher beohachtet mul heschlupieben worden ist Fig. 28 "Tab. V stellt dasselbe in starker Vergrösserung dax: In den Abbilkungen Fig. $28, a$ und 28 b wind die ('ontonren bei viel

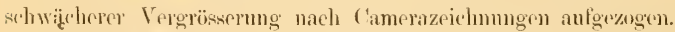

1)isses Nämohen ist sehr langgestreckt. Es wurde erst gemessen als es sich ein wenig znsammengezogen hatte und zeigte demnoch nieht weniger als 110 Mik Lïnge. leh sehäitzte dieselbe anfangs zu gegen loo Mik, was ja für ein Rotiforommämuchen eine recht grosse Länge ist. S'ehr dentlich traten ainige limgfalten hervor. Ich habe an zwei von meinen Abbildungen sechs lingfalten gezeiehnet. Aul der Fig. 28 b sind nur fünl zu sehen, was wohl durele eine Lungenanigkeit beim Zeiehnen entstanden ist. Meine Notizen geben nimulieh anch die Zahl der Ringfalten zn sechs an. Die zwischen zwei lablten

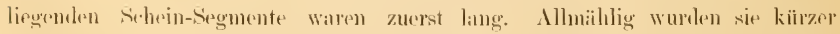
und kürzer. Die Dicke des conischen Kö̈pers nimmt nach hinten rasch abce 


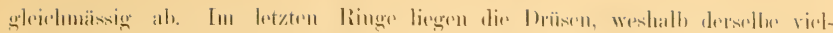

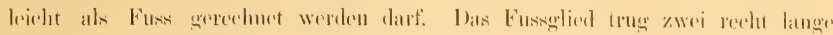

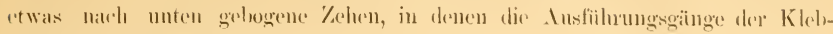
drïisen sichthar waren.

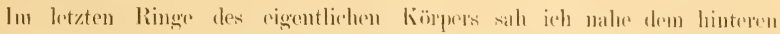

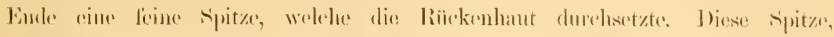

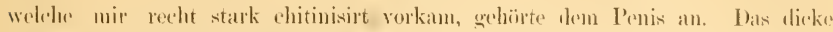

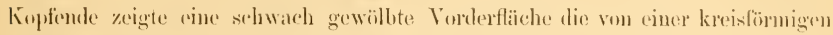

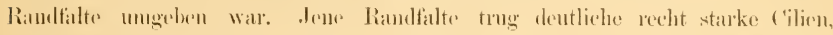

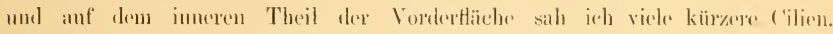

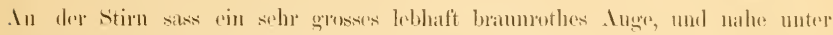

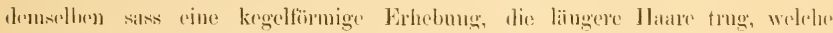
ich nieht in selbständiger Bewrogung sals.

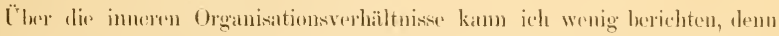

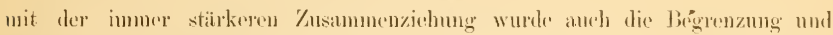
struetur der Oromane weniger deutlieh. Die Längsmuskukatme war antfallend dentlich mol kiäftig. Nahe der Mitte lagen im Inneren des Känjers drei

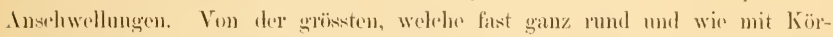

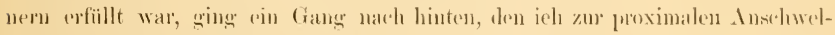
lung des P'enis verfolgen komnte. Jene körnerfïhrende Anschwellung mus demmach matürlich als dey Testis gerlentet werden. Naeh oben und hinten vom diesere lage rin valer blasenförmiger Kö̈rper, in welehem sich eine Matsis statrk

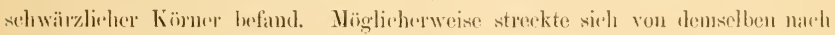

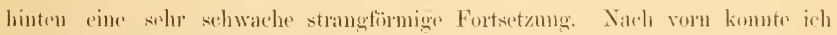

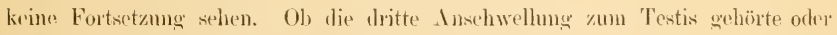
eine andere berkentung hatte, weiss ieh nieht. Ehensowenig wurde mir dio

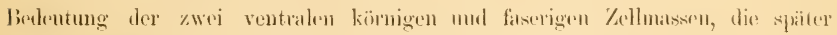

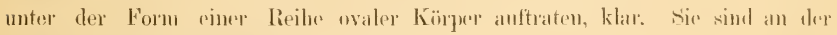
Figur mit einem Fragrzeichen versehen.

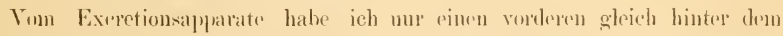

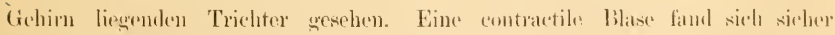

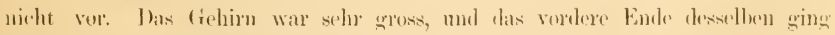
laxt mmittellar an den stimkegel mul das Iuge.

Der Penis war berlentend lang mit einer seloarfon Spritze. Lie ('hitinisirumg desselben streckte sieh anch reeht weit aul den basaltheil des Prnis hin. 


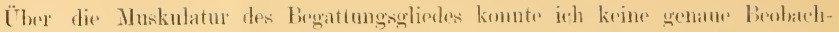
tungen anstellen, denn die schrmmpfung trat nath der vorgenummenen Isolimmgr sehr bald ein '). Frïher, so lange das Thier unter Mooshlaittern frei herumkriechen komnte, war es sehr munter mel leblaft. Es bewegte sieh sehr sehmoll aber fast nur kriechend. Nit dem Vorelerende untersurelite es selor genau

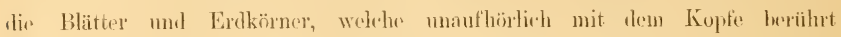
wurlen. Sein ganzes Benehmen. ähnelte roht viel dem suchen eines Jaydhundes. Hätte ich nicht den mastax und lin Darmkanal vollständig vermisst,

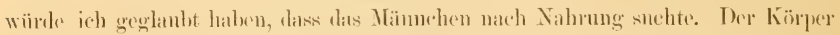
war sehr biegsam, aler wurke beim kionhen ziemlich wenig contrahirt.

Eine merkwärdige Frscheinung war, dass, seitdem ich das Thier cinige Stuncen anf rincm Ohjektträges gehaht hatts, die Zehen beim Zusatz einer sehr sehwachen Kalilïsung ganz versehwamdsu. Der ïbrige Körper schien gar

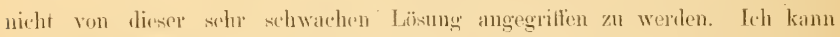
mir diese Thatsarhe uur dachureh erkläres, dass die Zehen viel weniger cutienlarisint waren. Ich habe nir etwas .̈hnliches bei anderen Räiderthieren gesehen. Die hiegsame gefaltete llant schliesst nämlich jeden Gedanken an eime bepanzerung von vorn herein vollstïndien aus.

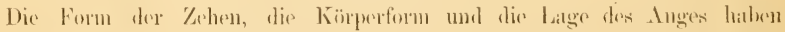

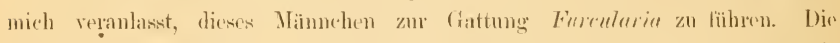
Körperform ist derjenigen vieler Totommatalen soler ähnlich, und dies gilt auch von der Form der Zehen. Conter den Notomuatalen kommt rin Stirn:

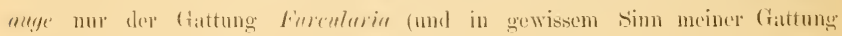
l)iojss) zu.

Wem ich dieses Mämmehen mit den amberen bisher beobachteten Mämunen vergleiche, finde ich dic Kürperform sohr limggezogen und anch die Grösse ziemlich bedentend. Elxense sheint es mir, als wäe lie starke Chitinisirung des Jenis rechn mogewähnlich. Dieselbe wäre freilich zn erwarten, wenn P's.ATE's Angaben richtig umel allgemein gïltig wären, nach welehen bei Hyrlatimn das Mäunchen bej der liegattung die Matut des Weibehens an einer heliebigen stelle durchbohrt. Bei Hydatiua lässt Plate diese lumehbohrung dureh die spitzen stäbchenförmigren К̈̈̈рer geschehun, welche derselbe wie vor ilm larmu:

1) Es wäre ja auch möglich, dass die Lebenszeit des Männchens schon vorüber war. Die Männchen der Rotiferen sollen bekanntlich sehr kurze Zeit leben - einige Stunden his 3 Tage. 


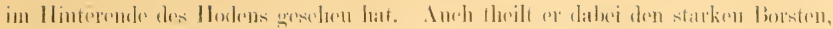

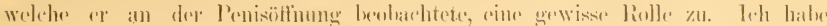

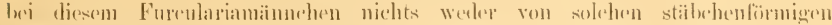

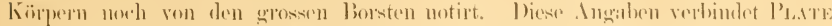

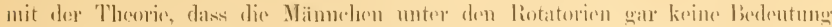

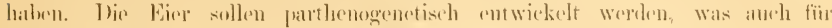

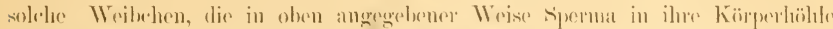

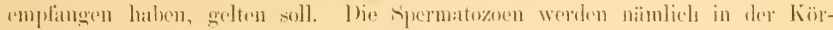

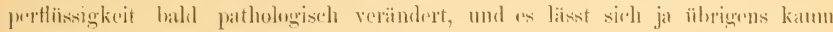
versteben, wie die spermatozoen von der Kärperlöhle zu den Eiern kommen sollten. Anch die damals angenommene Ahwesenheit von Riehtungskörjern'

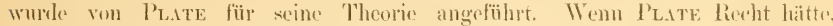
so wïrle man anch amnehmen kömnen, dass bei virlen Rotiferen dic Männ.hen,

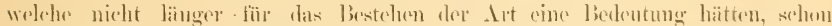
g:anz vertilgt wäress. Folglich wäre der Grund dazu, dass so wenige Mämnelun bisher gefimden sind, darin zu suchen, dass dieselben bei verschiedenen Arten ïberbant nieht länger ansgrbildet werden. Immerhin spricht gegen P'LATE's

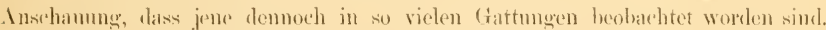

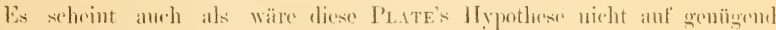

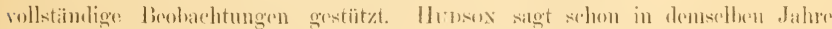

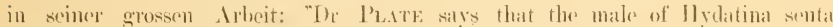
gieres the fomale, anywhere, with its penis. He admits that he has never secen the organ within the female's hody, amel that he never conlel lind any aperture alter the apparent penctration; but sugerests that the eilia of the penis make very minute punetures in the skin, and that the rod-like sjermatozea find their way thromgh these. Such hypothesis searesly repuires serious notiee; but I may mention that Mr lisigruwele, Mr Gosste, Mr lloun and mysell have all seen coitus take place, in various Rotifera, at the doaca" ${ }^{2}$ ). (rosite hatre

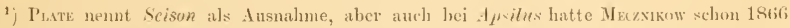
Richtumgskörper gesehen.

2) Hubses, 1. c. Vol. I1, \&. 83. Tgl. mein olen gelicfertes Iieferat der. Plate'schen An-

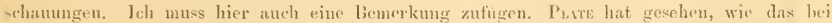
der legattumg durch die durchbolnte llant eingefuilurte sperma sich zuweilen um die gebildete Hautöflumg in einem klumpen anhäuft. - Plate 1. c, s. 38.

lch kam nicht sehen dass Burguтwen, pine doacale liegattung wirklich beobachtet hat. Er hat seine Jerolochtungen bei geringer Vergröscerung gemacht und sagt z. 13. "- - - 


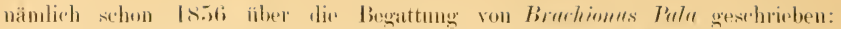
"- _ame I listinetly salw the thick genis presented to the cluatea and for a moment inserted about half its own length; then it was instantly drawn

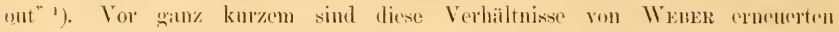

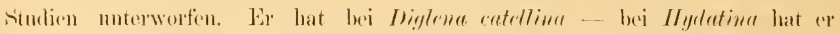

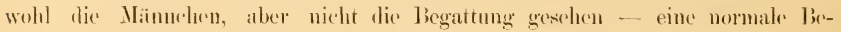

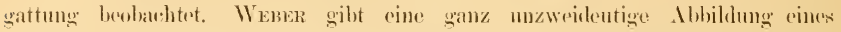
Pärchens in copmlas, wo man den Penis tief in die Cloake des Weibehrns eingedrumgen sicht. Er hat viele Mämmehen gohabt mol immer ist lice Be-

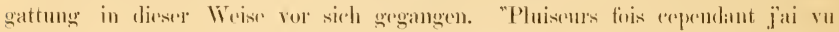

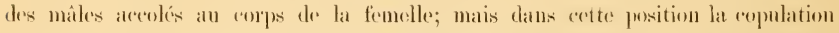
ne s'effectne pats. J'ai observé le mome fait chez Ilyclatina. La copulation

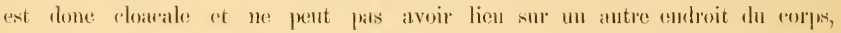

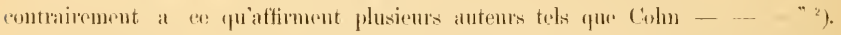

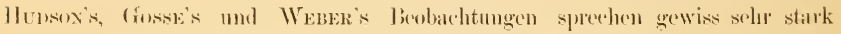
gegen die oben angeföihrte Inuahme Platés. Aber diese Verfasser luaben

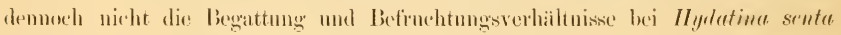
untersurht.

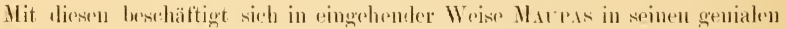

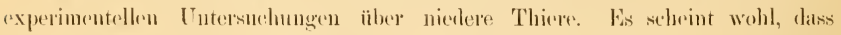

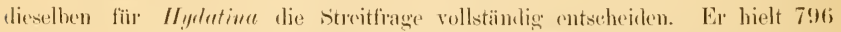

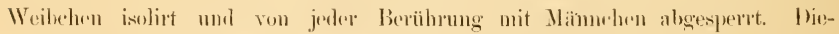

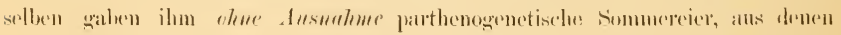

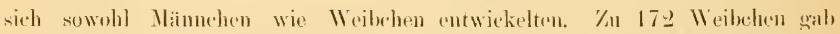

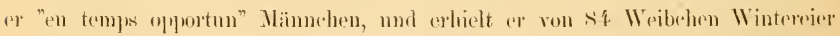
und vou ss Weibehen parthenogenetisehe Eier. Er hat mohrmals gefunden, datso

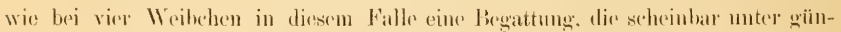
stigen Cmatänlen vor sich ging, resultatlos blieb. Dio Weibrhen müssen nämlich

attache his sperm tube to its side and remain so attached lifty sconds". Auch von den anderen Manmehen sagt er immer "attache to". Siche bingurwsus gleich muten citirte Arixit s. 156 \& 157.

1) Cinsse P. Il. (Hu the dioecions character of the liotifera. Comm. by. Th. licll. Ihil. Trans, of the lioy. Soce of London. Vol. (XI,VII, s. 313. Was lier citirte s. 317. Wer dufsatz wurke im März und $\Lambda_{\text {pril }} 1856$ in der society gelesen.

2) W EIBER 1. e. s. 53. 
schr jumg sein. Er glaubt, dass die günstigste Keit lïr die Begattumg ron der ersten bis an die sechste stunde naeh dem Auskriechen ans dem Ei fïllt. bei den Weibehen, welehe schon Eier zu legen angefangen habru, bleibt eime brgattung immer lesultatlos ').

In einer anderen Lntersuchungsseric experimentirte Maras mit seg jungen Hydatinen. Er liess :342 sieh begatten und eontrolierte, dasis wirkliell rine Begattung eintrat. Er bekan von 252 (- 7 4 \% $\%$ Wintereies und rou $90\left(=260_{0}\right)$ parthenogenetische, wribliche Eier (- weibliche fommereicr). Die anderen 480 Wejhehen, die Sohwestern dop vorigen Serie, hielt ar von du Mäunchen ahgespert und bekam rom denselloen $36 \mathrm{f}$ mämuliehe fommereies

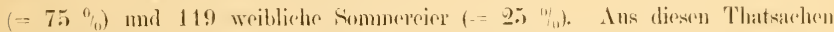

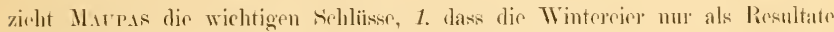
riner bolruehtung entstehen, \&. dass dis Befruchtumg nur auf soleles lísime, die, parthenogenetisch entwickelt, Mämmelon gegelsen hätten, rinwirken; in Folger. derselben werden sio zu Wintereiern umgehildet, und 3. dass aber diejenigen Kósme,

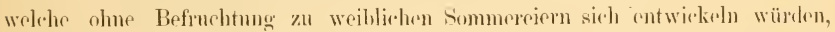
keim Einwirkmog durels die Befruehtumg empfangen. Dieselben sind alsu fiir liefruclitumg nicht empfönglich $\left.{ }^{2}\right)$.

Yon der Befiuchtomg selbst sagt Matpas: "Les petits mâles s'areomplent en se fixant par leur penis sur un point guelongue du corps des limulles dont ils perforent la paroi extéricure pour injeeter leur sperme. Plusious mâles quelquefois eim à six peuvent doms s'aecompler simultanément aver mo finolle. Liaeenuplement dure un peus moins d'ume mimute. I'n seul aceouple-

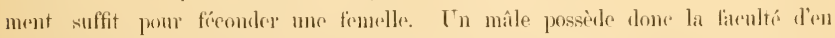

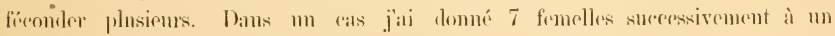

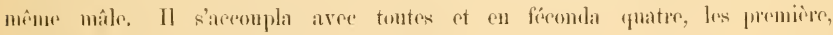
denxiime, troisieme et sixime" s).

Matpas bestätigt demmachl den entgegensotzten Vermuthungen von llimsox mol Wemse zam Trot\% die von c'ms und Peate golieferten Amgaben ïber, wie

1) Marpis, M. Sur la multiplieation ef la fécondation de l'Myglatina senta lihrog. Note

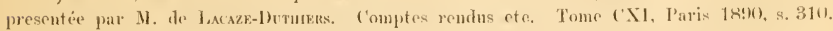

$\left.{ }^{2}\right)$ Maupss, M. Sur la fécondation de l'Hydatima senta Ehrlig. Note transmise par M. de Lacaze-[nтнеиs. $11 \mathrm{~m}$ 18!0). s. 505.

3) Matras, M. 1. c. s. 312. Verschiedene von diesen Thatsachen waren schon von PLAtE mitgetheilt. 
dic Begattung bej Hyrlutima zogeht, zeigt aber, dass die Männehen absolut koin Luxusartikel, sondern mmmgängliels nöthig sind, insofern ohme Hegattung' keino Wintereier entstehen kömmen '). Wir kommen also zu der alten Cons'sehen Anflassmng dieser Frage zurïek, wem nämlich dir ans den Verhältnissen bei IIydatina gezogenen tohlüise verallgemeinert werlen dïrten.

Wemn disse Resultate Mavpas richtig sind, so wirl anch das Suchen nach Mämehon in den Gattumgen, wo sie nicht gefunden sind, wiohtig. Damn kamm ich mir auch lrichter crkläıen, dass dic Nännehen sugar ganz nothwendig in Grönland anftreten müssen, wo die Natur gewiss nicht viel anf Luxns verwenden kamn.

Es seheint wohl, als uh es narh diesem vielen Beobarlitungen von Maupas

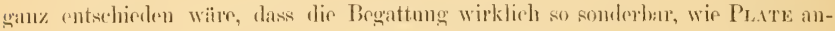

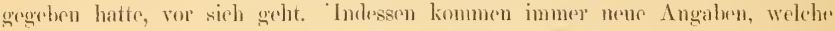
dis Sache moln mol mehr verwickelt marhen. Ehonso bestimmt wie diese Angaben von Plate und Moupse lanten, lautet nämlieh anch eine writere Anuabe von llumson, wo er, indem el soinen friiher geïusserten \%weifel an

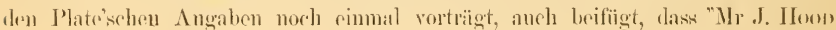

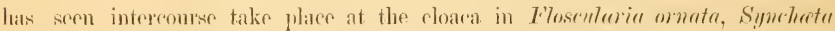

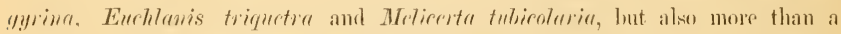

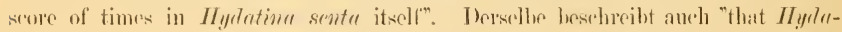
lime semfe eopulates while elinging with her foot to some eonfervoul filament",

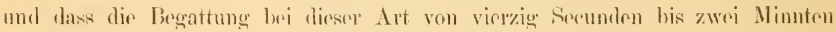
daucit $\left.{ }^{2}\right)$.

Betreftend die Art des Begattmo kamo natiirlich das olen beseluriebene

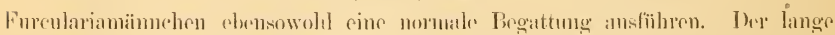

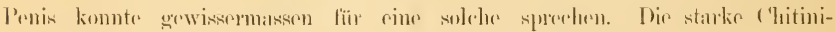
sirumg hätte dam wohl nur die Bedeutung dem Penis dir nöthige Sitritheit zul geben.

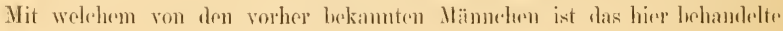
Mämmehen näher zu vergleichen?

1) Vielleicht kömmen jedoch aneh hier nene Kxperimente erforderlich sein, dem PLatk's Angahe "auch die Wintereier entstehen parthenogenetisch, wie Versuchsthiere, die aberhampt nie mit Mämmehen zusanmengeknmmen wareu, gegeigt hahen" stelıt noch immer uuerklärt da.

2) Hubsox, ('. T. The presidents adress on some looulful lonits in the Natmal llistory of the liotifera. Journ. of lioy. Mierose. Aoc. London 1 s:11, s. 6. Diese Ahlandlung ist mir erst lange nach der Ahassung des Trxtes bekannt geworden. 
Von den mehr als 450 Arten der Räderthiere kennt man wahrseheinlich kaum die Männchen von 50 Arten. Ausser von de'n so selı abweichenden Seisoniden und Trochospherva ${ }^{1}$ ) sind dic Mämmchen rom folgenden Gattungen genaner bekannt: Flosculuia, Lacimmlaria, Apsilus, Conochilus, Asplunchna, Mydatimu, Proules (= Mertwigin Phate), Iniglemu, Euchlunis, Bruchiomns und Peclation ${ }^{2}$ ).

1) Die Seisoniden sind von Grobe entdeekt und von Giavs und PLATE näher untersucht worden.

Cusus, C. Über die Organisation und die systematisehe Stellung der Giattung Scison (ir. Festschr. der k. k, zool. bot. Gesellsch. Wien 1876.

Dersclle. Zur Kenntniss der Organisation von Scison. Zool. Anzeiger 3 Jahrg. 1880.

Die auch an Nebalien im Neapler Golfe vorkommende Gattung Proscism beselireilst PLATE eingehend in seiner Arbeit "Über cinige ectoparasitische liotatorien des Golfes von Ncapel". Mitth. aus der zool. Station zu Neapel, Bd. VII, 1887, s. 234, Taf. 8. [as Mänuchen der Trochosphera ist ganz neulich in Brisbane gefunden. Gonson-Tnonp, V. New and Foreign Rotifera etc. 1. c. s. 301.

${ }^{2}$ ) Diese sind ausser in Hudson's (und Gosse's) grossem Werke in den folgenden von mir benutzten Arbeiten beschrieben:

Brigutwell, Some aceount of a dioccions Rotifer, allied to the genus Notommata of Eurenberg. Ann. und Mag. of the nat. hist. II ser. n:o 9, London 1848, s. 151. Asplanchna.

Datrmpite, J. Description of an infusory animalcule allied to the genus Notommata of Ehrenberg hitherto undescribed. Phil. Transact. of Roy. Soc. of London 1849, s. 331. Asplamilina.

Gusse, P. II. On the dioecious char. ete. Brartionus Pala, mbens, ampliecros, Batieri, Doreas, Mialleri und angularis, Sacculus, l'olyarthra platyptera und ? Synehata tremulu.

Lexing, F. Über den Bau etc. Z. f. w. Z., Bd. VI, 1854. Notommata (Asplanshina) Sicliolili.

Dirsclbe. Über 11ydatinu sentu. Mïllers Archiv für Anat. u. Physiol. Jahrg. 1857, Iierlin, s, 404.

Conv, F. Die Fortpflanzung der Räderthiere. Z. f. w. Z. Bd. VII, 1856, s. 431. Ilyelatina, Braclidinus areolaris.

Drrsclbe. Bemerkungen über Räderthiere. Ibm Bd. IX, 1858, s, 284. Euchlunis.

Dersclbe. liemerkungen ïber Räderthiere III. Ihm Bd. XII, 1863, s. I97. Notommute purasitu ( = Proales Gosse = Hertwigia Plate), Comochitus, Brarliumus.

Местмкож, E. Apsilus lentiformis, ein Räderthier. Z. f. w. Z. Bd. XV1. 1866, s. 346, Taf. XIX.

II:dson, C. T. On Asplanchina Ebticshomi n. sp. Jonrn. of the Roy. Micr. Soc. of London, (1kt. 1883, Ser. 11, Vol. III, Part. 2, s. 621, London 1883. Siehe besonders 8. 1i26.

Prate. 1. e. 1885. Conothitus, Polyarthere, Triarflera, Asplenelena, Proules ( Iertwigin Plate), Hydatina, Brachionus.

Eypertit. 1. c. Digtena.

Werer. 1. c. 1889. Hydatina, Diglena und Bruenionus.

Lunds Univ, Ărsskr. Tom. XxviI. 
Über die Organisation des Männehens von Notops Bruchiomus gibt IIusson einige kurze Notizen und gibt auch eine Abbildung des Männchens von Symchate oblonga. Gosse hat ausser einigen näher untersuchten von den oben angeführten auch andere flüchtig gesehen, weshalb vielleicht auch die nur mit Zweifel angeführte Zugehörigkeit diescr Männchen zu den angegebenen Arten noch nicht genügend sicher gestellt ist. Diese sind Melicerta (IIndson), Limnias, Mitrocodon, Succulus und Metopidia. Plate erwähnt die Mämnehen von Triurthare nnd Anuraa sehr kurz und MrLne gibt eine Abbildung und einige Notizen über das Männchen von Meurotrocha mustela Milne $\left.{ }^{1}\right)$. Im Tageblatte der Leipziger Naturforscherversammlung liest man: "In Ganzen hat Prof. Stein die Männehen der Gattungen Asplanchna, Mydatina, Brachiomus, Synchata, Polyarthra, Notommata, Eosplura, Monorerca, Monostyla, Colurus, Metopidia, Euchlunis, Salpinu kennen gelernt" 2). Leiler scheint er nichts Ausführliches über diese Männchen veröffentlicht zu haben, und man kennt deshalb weder die Organisation dieser nur von ihm angeführten Männehen noch die Gründe, auf welche er dieselben zu den respectiven Gattungen geführt hat. Unter den zu Hunsox's Familie Notommatadxe gerechncten Gattungen scheinen deshalb bisher nur von Miglena und Proules Männehen angegeben zu sein. Vielleicht gehörten auch zu derselben Familie die von Stein mit den Namen Notommata und Eosphora belegten Männehen ${ }^{3}$ ).

So viel ieh es beurtheilen kamn, ähnelt das Fureulariamännchen am näehsten dem von MiLNe beschriebenen Mämnchen von Plcurotrocka mustelu, nähert sich aber auch recht viel dem von Wreser genauest gesehilderten Männehen ron Diglenu cutellinu. Proules parasitu ist ja durch den Parasitismus so ungestaltet, dass es nicht auffallend ist, dass zwisehen ihm und dem Fureulariamännehen geringe $̈$ Änlichkeit besteht. Das Männchen ron Diglena besitzt

1) Mrune, W. Description of a new Rotiferon, Male and Female. Proceedings of the Philosophical Society of Glasgow 1884-1885, Vol. XVI, 1885, s. 188. Plate V. Das Männchen, Fig. 7.

$\left.{ }^{2}\right)$ Diese Mittheilung wird in Ecкsтеix-ZnLinkıs Literaturverzeichniss anfgefuhrt unter dem Titel: Stern, Rotatoria. Tageblatt der Leipziger Naturforscherversammlung 1872, s. 140. Ich habe diese wie verschiedene andere mir hier nicht zugängliche Arbeiten in der königl. Bibliothek zu Berlin benutzen kümen, wofür ich mir hier meinen Dauk auszusprechen erlaube.

$\left.{ }^{3}\right)$ Für Eosphora ist das sicherer als für Notommata, denn diese Gattung umfasst ja bei älteren Antoren viele jetzt nicht länger zu derselben Familie gehörende Gattungen z. B. Asplanchna, Notops und Diurella. 
anch einen langen ehitinisirten Penis, und ebensowenig wie bei Diglenat kamen bei meinem Fureulariamänneheṇ Hate oder Cilien an der Penisspitze ror. Eine Verschiedenheit liegt darin, dass der Penis sich bei Diglena catellina wie bei den meisten anderen Männchen bis an den Testis streckt, wogegen bei dem Furculariamännchen ein reeht langes vas deferens vorhanden war.

Eine andere wichtige Übereinstimmung zwisehen diesen Formen besteht in dem Fehlen der Exkretionsblase. Weber will sogar darin einen allgemeinen Charakter der Mänuchen sehen. Fr sagt bei der Behandlung des Hydutinumännchens: "Cohn, Leydig, Daday, Hudson dessinent dans leurs planehes d'IIydatina senta mâle une vessie contractile: ils l'ont vue aree les yeux de la foi! ou bien ils ont pris pour la vessie une des grosses glandes prostatiques, qui se trouvent sur les eotés du penis ${ }^{1}$ ). Ich habe nichts von solehen Drüsen notirt, aber sie waren vielleicht schon versehwunden, als ich die stäkeren Linsen beutzen konnte. WEBE々 lat bei Diglenu grössere Zell- und Körnermassen als Rieste des Thigestionsapparates gedeutet. Vielleicht könnten die auf meiner Figur gezeichnoten ventral liegenden Körnermassen einem mastax und einem vorderen Theile des Digestionsalpparates entsprechen. Indessen lag die wohl abgegrenzte Blase, welehe die dunkle Kürnermasse enthielt weit davon, mehr dorsal.

Leider ist MuLne's Mittheilung iber Peurotrocha sehr kurz. In der Körperform scheint sich sehr grosse Ïlnlichkeit vorzufinden. Jenes Männehen besitzt auch Hautfalten. Die wiehtigste Ïbereinstimmung seheint darin zu liegen, dass auch bei dem Ileurotrochu-mämmchen "there is the indication of a tube running up towarls the vessel with the spermatozoa", und die Röhre musste ja dem vas deferens bei meinem Furculuriu-männehen entsprechen. Als T'estis fasst er ein "vessel" auf, das "was seen to contain bacterium-looking bodies, which kept vibrating for a short time after death". Aus der Figur VII kinn ich keine Vorstellung über das Aussehen dieses Testis bekommen. Die Iä̈nge dieses Mämnehens war anch berlentend, ungefahr 140 Mik. ILvison lührt Minde's Art als Diglenu mustela anf.

Ich kamn nicht erinnern während der früheren Zeit des Sommers ein Männchen gesehen zu haben, obgleich ich mich die ganze Zeit mit Rotiferen beschäftigte, und den rorkommenden, wemn sie mir nicht schou bekannt waren,

1) Ich setze hier jetzt nachträglich zu, dass WEBER's Verallgemeinerung sehr scharf zu rüickgewiesen wird. Journ. of Roy. Microse. Soc. London 1889, s. 60. 
immer wenigstens eine kmze orientierende Untersuchung widmete. Dageg en habe ich noch später ein oder wahrscheinlich zwei zu anderen Arteu gehörende Männehen gesehen. Das eine wurde in Ritenbenk den 4:ten September gesehen Ieh habe dasselbe zu der revidirten Gattung Notommata Gosse geführt. Dieses Mänuchen hatte grosse änssere Ähnlichkeit mit dem Furenlariamännchen. Der Körper war kegelförmig, die Haut weich und gefaltet, die Zehen etwas kürzer und das Auge nackenständig. Auch will ich mich entsinnen, dass dieses Mämnchen viel mehr schwamm als das Furculario-männehen. Ich glaubte auch, lass ieh von der erwähnten Art auf demselben Objecträger zwei Männchen auf einmal hatte, habe aber darüber nichts ganz Sicheres notirt. Die schlechte Belenchtung in der Sehiffskajüte und der geringe Raum, der mir zur Verfügung stand, machten eine nähere Untersuchung der inneren Organisation eines so besehwerlichen Gegenstandes ummöglich, aber ich kamn kaum zweifeh, dass meine Bestimmung richtig war. C'opeus ist ja dureh die tastertragenden Fortsätze untersehieden, und den Proales-arten war das Mämmchen auch nieht ähmlich. Eine gepanzerte Form kommt wohl nicht in Frage. Die bekannten Männelıen von Loricaten, welche nicht gepanzert sind, haben doch mehr oder minder die Form des Weibehens. Bei Euchlanis und wenigstens einigen Brachionus-arten ist auch ein schwacher Panzer da. Das Bild, welebes Hudson von eincm Salyina-männehen gibt, scheint anch einen Panzer zu zeigen '). Es gibt - so denke ich wenigstens - keine gepanzerte Form, lie ein langes, kegelförmiges mit gefalteter Haut versehenes Mämnchen besitzen könnte. Dass es mir unter den genannten Umständen nieht gelang das winzige Männehen zu isoliren, brauche ich wohl kaum zu bemerken oder zu entsehuldigen.

Ich habe schliesslich hier ein drittes Thierehen zu erwähnen, vvelchess ich in Jakobsharn in einer Probe, wo noch viele andere interessante Räderthiere gefunden wurden, beobachtete, das ich auch recht lange und wiederholt ansah, aber doeh nicht näher untersuchen komte, weil dasselbe beim Isolierungsversuche verloren ging.

Es war das kleine Thierchen, von welehem in Fig. 43 Tab. VI eine sehr schnell hingeworfene Contourskizze wiedergegeben ist. Die Länge, welehe nicht genau gemessen wmile, schätzte ich zu ungefähr 50 Mik. Die llant

1) Hodsox, An Attempt to re-classify the Rotifers. Quarterl. Journ. of Microse. Sei. Vol. XXIV. New Series, s. 352. Diese Figur 15; ist copirt nach nur E. C. Bousfield. 
zeigte besonders im hinter'n Theile des Körpers eine Andeutung zu sehwachen Querfalten. Iängsfalten wurden nicht gesehen. Aueh besaiss jenes Würmehen keine Zehen. Das Räderorgan hatte sehr grosse Cilien nut komnte in eine vordere rohrartige Verlängerung des Kärler's eingestülpt werden. Hinter dem Rädlerorgane traten zwei relative grosse Augen deutlich hervor, die von einander ziemlieh weit entfernt waren. Das llinterende war lang, allubihlig verjiingt und ziemlich stmmpf. Ich glaube dasselbe als einen P'enis deuten zu dürfen.

Über die imnere Organisation blieb meine Untersmehmng des oben erwaihnten Unglücks wegen selbstverständlieh sehr mangelhaft. Nmr das Fehlen des mastax konnte ich sieher stellen. Anch sah ich keinen Verdammgskanal, aber die immeren Theile wurden mir überhanjt nicht deutlich, dem nur für einen Augeriblick komnte ich stärkere Systeme gebranchen. Ob ein T'estis wirklich da war, weiss ieh also nicht sicher.

bei der sehr schnellen Bewegung, welehe passend raupenartig genannt werden kamn, fixirte das Thierchen sich mit dem Hinterende. Fis kroch besonder's gern an einem kleinen Erdkorn, das mit unter das Dovkgüäsehen hineingekommen war, wnrle aber auch schwimmend gresehon.

Die Bewegungsweise und die Angenstellung gaben mir grleich den Gedankon ein, dass ich ein Philodinamännehen vor mir hatte, aber gewiss wage ich kam dirse Meinung hier auszmsprechen, demn das Räderorgan dieser Gattung besitzt ja eine ganz andere Form. Später habe ich an ein Floseulariamännchen gedacht, glaube aber, dass ein soleles sich in anderer Weise bewegt. Jir geringe Grösse hat mich auch an Rhizotenjmge dinken latssen. Im meistru bin ieh jetoch geneigt das Thierchen als ein Mämnchen anzusehen, gebe aber. gern zn, dass die Deutung etwas msicher ist.

Vielleicht kam Jemand Anderer mit mmfassenterer Erfahrung anf diesem Gebiete leicht genug diesen Thierchen seinen riehtigen Platz anweisen. Wie die vorigen, mzweifelhaften Männchen wmole auch dieses Encle Angust beobachtet.

Wemm Maupas' Untersuchungen mod Sehlüsse richtig sinel, maeh welehen die Befruchtmo für die Entwicklung der IIintereier nothwendig ist, versteht man anch reeht wohl, dass einerseits die Männehen in Grönlamel vorkommen müssen, uml dass sie andererseits vorzugsweise in Ilerbst anftreten sollen. Dor hommer ist sehr kurz und die Keit, $\mathrm{i}_{11}$ der sich gewöhnlieh Waser in den I'fützen befindet, 
soll noch viel kürzer sein, und im Winter ist ja alles Wasser gefroren. Nur die tiefen Seen balten unter der dicken Eisdecke etwas Wasser, aber da kömmen kaum andere als pelagisehe Rotiferen überwintern. Weisse hat nämlich die Vermuthung ausgesprochen, dass die meisten Infusorien und Rotiferen aneh im Winter unter dem Eise fortleben $\left.{ }^{1}\right)$. Freilich ist seine Beweisführung nicht besonders scharf.

Er hatte sich von dem Teiche im Jussukowschen Garten eine Bouteille voll Wasser verschafft, als der Teich nur so eben von seiner Eisdecke befreit war, und als noeh keine Spur von Vegetation zu entdecken war. Bei einer achttägigen Untersuchung dieses Wassers erkamnte er 51 Arten von Infusorien und Rotatorien. Die letzteren waren nur von den überall vorkommenden Callidina eleyans und Rotifer rulyeris vertreten. Diese Arten konnten ja zum grossen Theil während der Absehmelzung der Eisdecke durch die Frühlingsisonne erweckt worden sein, wenn sie auch nicht zum Theil während der Untersuchung hineingekommen waren.

Viel beweiskräftiger sind die Beobachtmigen und Schlüsse, welche in einigen Arbeiten von Імноғ hierüber enthalten sind. Er hat in versehiedenen seen Thiere unter einer dieken Eisdecke gefunden. Dasselbe Resultat haben auch andere Autoren z. B. Forel und Noruquist erhalten. Aus diesen Untersuchungen hält Imuor die Folgerung wahrseheinlich, dass es sogar den Thieren günstig ist, dass die Seen frühzeitig zufrieren ${ }^{2}$ ).

Dem mag nun sein wie ihm wolle, sicher ist, dass in Grönland kann in den allermeisten Fällen eine solche Überwinterung frei lebender Formen absolut keine Bedentung für das Bestehen der Art bis zur nächsten Lebensperioxle haben, denn die oben angreführten Beobachtungen betreffen alle socn, welche nur eine Eisdecke bekommen, die meisten hier von mir in Grönland notirten Räderthiere wurden aber alle in seichten, ganz sicher in Winter bis zum Boden gefrorenen Tümpeln, Pfützen und dgl, gefunden. Sollen die ausgewachsenen Thiere in Grönland überwintern, so müssen sie also dias lange Einfrieren gut ẗberleben. Das mag wohl in einzehnen Fällen vor sich gehen, dürfte aber auch nicht grosse Bedeutung haben, da ich während meiner ersten

1) Wersse, J. F. Drittes Verzeichniss Petersburger Infusorien. Bull. math. phys. d. l'Ac. d. S:t Petersbourg, 1Bd. V, 1847, s. 39.

${ }^{2}$ ) Weil ich nicht hier näher auf diese Frage eingehen kann, gebe ich die Titel der Arbeiten nur in dem Litératurverzeichniss im Schlusse der Arbeit an. 
Beobachtungszeit relative wenige Formen sals. Die Production soleher Fies, welche gewöhnlich lange rulen, und starke Kälto aushalten kïnnem, ist gewiss eine für die mikroskopischen Lebenstormen Grönlands nothwendige IBerlingung, und ich habe auch eine nicht geringe Zahl von Fiern, die ich als IVintereier von Rotiferen deutete gesehen. Beim Studium dieser Frage war es mir jedoch besonders peinlich, dass ich nicht vorher grössere Erfahrung anf diesen Gebiet besass.

Grosse diekschalige Eier sah ich auch in einigen Rotiferen. Áo sah ich in einer grossen Eosphora ein ausserordentlich grosses diekschaliges Fi, das noch nur mit einem Rande an der Geschlechtsdrüse befostigt war. Inas Ei war so hartschälig, rlass die eneroisehen Contrartionen dis kräftigen 'Thieres kaum die Form derselben zu verändern vermochtem. Auch das grosse bi woluhes ieh in dem ron mir Notommate distiucte genannten Thiere beobachtete, derute ich, trotzdem es noch etwas veränderlich war, als ein Winterei. Leider habe ich nicht Zeit gehabt ïber diese biologisehe Frage viele Notizon zu machen, aber so viel geht indessen aus moinen Notizen hervor, dass ich wir die Männehen auch die Wintereier vorzugsweise geunen das Ende des sommers beobachtete. Ich will mich auch entsimnen, dass ich einmal trïher mehrere solehe bei Räderthieren sah, die aus einem sehr seichten Toiche auf der Insel Räfïn geholt waren. Es war zwar im Juli aber dieser sciehte Teich war rben im Pegriff vollstïndig auszutrocknen. Ieh neige deshall, zu der Auflassung dass die Männehen und die Wintereier vorzugsueise gegen das Ende einer Lebensperiode der Lebensformen, welehe eine gewisse Localität bevölkeru, entstehen. Es wäre demmach weder so sehr der Frühling noch der Ilerbst oder der Ilochsommer, welehe in besonderen Grade bevorzugt wären, sondern für die Ausbildung der Männehen sind die für jede Localität herrschenden Verhältnisse bestimmend. Es ist ja in manchen Fäillen vollständig unmöglich zu sagen, welehe Trsachen die Lebenszeit pines Infusionsthieres oder Räilerthieres bestimmen. Die allbekannte Thatsache, dass in cinem (refïss, wo den eimen Tag ein Thierehen massenhaft auftritt, bahl nachher vielleicht kein einziges solches entdeckt werlen kann, zeigt ja daranf hin, dass grewisse uns nicht wahrnehmbare Veränderungen des Wassers oder der anderen Lebensformen desselben anf die sonst so lebenszïhen Rïderthiere sehnell und stark einwirken. Wir kïmen keine Veränderung der Lebensverhältnisse beobachten, aber vielleicht haben die Thierchen eine Einwirkung gelitten, vielleicht ist eben die Ent- 
wicklung von Männchen und Wintereiern eine Folge soleher für uns noch nicht bemerklaren Veränderungen. Wenn also eine Art wïhrend eines Jahres melurere Lebensperioden hat, weil z. B. die Pfütz", wo sie rorkommt, mehrmals anstrocknet und wieder durelı Regen gefüllt wird und dgl., kann es sehr wohl vorkommen, lass Männchen in verschiedenen Monaten gefunden werden aber dennoch immer gegen das Ende einer Lebensperiode derjeniger Colonien, welche disse Wasseransammlung bewohnen. Natürlich können andere Umstinde als Austrocknen dieselbe Folge haben z. B. eine geringe Veränderung der Zusammensetzung des Wassers, oder der Vegetation.

Über dic Zeit, wo die Nännchen entwickelt werlen, besteht eine eigenthïmliche Unsicherheit in der Literatur. Prate sagt ${ }^{2}$ ) "Es ist eine vir] verbreitete aber ganz unbegründete und irrige Ansicht, dass die Mïnnchen der Rotatorien im Frühjahr mol Herbst besonders zahlreich auftreten. Sie kommen ebenso häufig mitten im Sommer wie in den ersten Tagen des April und Ende Oktober vor". Nach ihm hängt das Auftreten der Männchen nur diavon ab, dass eine Art gut gedeilit und in grossen Mengen an einer Stelle anftritt. Diese Annahme stimmt nicht recht gut mit meiner gewiss geringen Erfahrung, denn ich wïsste nicht eine Fureularia anzugeben, die in demjenigen Teiche, wo ich dieses Männchen fand zahlreieh vorkam, und ebensowenig war eine Notommata in Ritenbenk um diese Zeit hänfig. Das gewöhnlichste aber doch seltene nahe stehende Räderthier war wohl meine Art Hypopus Ritenbenki, und zu derselben gehörte gewiss nicht jenes lange kegelförmige Männchen, welehes ich in Ritenbenk sah. Hunsox's lange und reiche Erfahrung lïsst ihm die Sache zweifelhaft erscheinen. Er fragt sehr bescheiden: "_ _ and why do they appear only for a short time during the year" ${ }^{2}$ ).

WeBer der letzte Verfasser, der etwas Ausführliches über diese Frage veröffentlicht hat sagt hierüber in seiner "partie genérale" ebenso bestimmt wie Plate: "Les mois les plus propices pour la recherche des mâles sont arril, mai, juin, et juillet; a arès eette époque, ils déviennent extraordinairement rares". Von Floscularia campamlata Dobie fand er gegen Ende Juni ein Männchen. Von Hydutina sammelte er einige Mämehen im $\Lambda$ pril und den ersten Mai, "on trouve en moyenne un ì deux mâłes sur 100 femelles". Die Männehen von Diglence catellina wurden im März und April und ein Männchen von

1) Plate 1. c. s. 113.

$\left.{ }^{2}\right)$ IIunsos 1. c. Vol. I, s. 11. 
Brarhiomus mrolaris im Mïrz gefundm. Im allgemeinen Theil wirl als die Zeit, in weleher Brachiomus-mämnehen anftreten, Juni und Juli gesetzt.

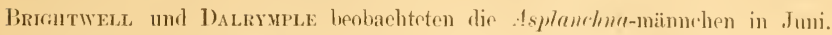
Sie geben an, dass gewöhnlich anch die Lebensperiode der Weibehen kum wark. Ans Gowse's wichtiger Arbeit iiber "the diereious character etc:" nehme ich die folgenden Angaben. Die Nämmehen wurden in folgenden Nonaten lreobuhtet.

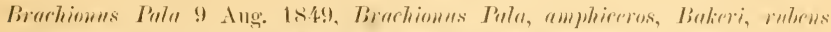

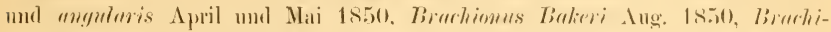

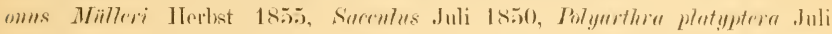

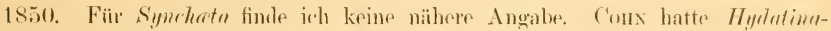

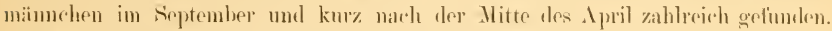

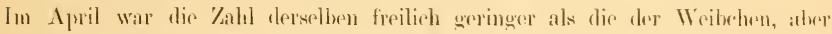
er land doeh in jedem Tropfen mehrepe. Vom Ende April an wiren die Weiluchen spärlieher aber doch immerhin niclit selten anzutreflem, von den Männchen komnte er aber kaum ein einziges Exemplar auffinden. In kude

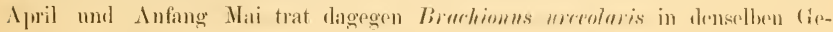

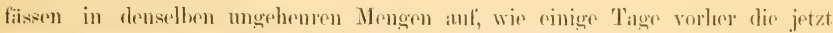

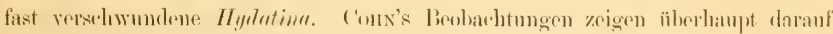
hin, dass dir Mämehen in gewissen Perioulon anftreten.

Nanche von diesen Angaben sagen nicht viel, weil man keine mähere Anskunft darïber, oh die Weibchen anch in ameleren Momaten dessellocu

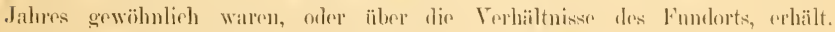
Indessen scheinen die meisten Autoren eine lostimmte Zeit für das Auftreten der Vänndhen anzmohmen. Ilierïher sind gewiss die Cutersuehungen katum angefangen. Noch rerwickelter wird diese Frage, weil man die nemesten Resultate von Manpas' experimentellen Intersuchungen beyïcksichtigen muss.

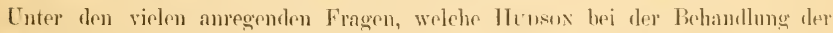
Mämonchen aufwirft ist auch diese: "and is the appearance (of the males) due to external causes, or are they the incritable completion of a eycle of repro-

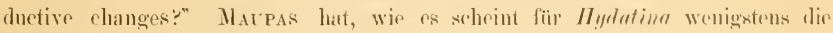
Frage sebon heantwortet, er hat sich nach Wunsehe mainnliche oder weibliche

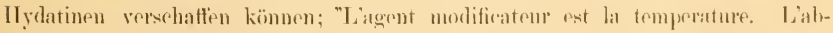

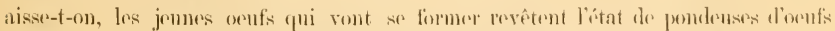

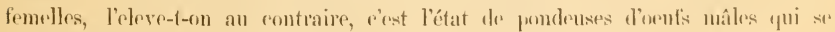
développent". 
Ton 104 Eiern entwickelten sich bei $\div 26-28^{\circ}$ C. $97 \%$ ponteuses mâles und $3{ }^{\circ}$ pondeuses femelles. Ton 110 Fiern bei $+14-15^{\circ}$ C. $24{ }_{0}^{0}$ pond. mâles und $76^{\circ}{ }^{\circ}$ prond. fomelles. Yon 118 Fiern derselben Mütter wie die vorigen entwickelten sich dagegen bei $+26-28$ C. $81 \%$ jont. mâtes und $19 \%$ pond. femelles. Bei einigen Versuchen mit der höheren Tempratur erhielt ex sogar $100 \%$ pond. mâles ${ }^{1}$ ).

Cons hatte, wie aus den obigen Mittheilungen hervorgeht, in allen seinen Arbeiten über Räderthicre die Ansicht verfochten, dass die Wintereier wahrscheinlich das Resultat der Befruchtnng waren, PLAte's Experimente zeigten ihm nach seiner Anffassung, dass die Befonchtung ganz hedentungslos wäre, und dass dic Wintereier ebensowohl von unbefruchteten Weibehen gelegt sein kïnuten. Maupas hat endlich Resultate mitgetheilt, die zu zeigen scheinen, dass die Wintereier nur von einem befruchteten Weibehen gelegt werden. Dieses Resultat seheint mir schon a priori wahrscheinlich, demn irgend eime Berlentmng müssen doch die Männchen haben, und die Beobachtmongen aller Antoren zeigen ja, dass männliche Eiep und weibliche Sommereier von unbefruchteten Weibehen gelegt werden kïnnen. I amn steht ja nichts Anderes zurüek, wofür die Männchen Bedentung besitzen können als für die Ansliklung der Wintereier. Alwer auch diese Annahme hat viclleicht nicht so allgemeine Gültigkeit, demn nicht nor die oben angeführte Angabe PLATE's spricht dafür, dass anch Wintereier von solehen Weibehen gelngt werden kömnen, die mit keinen Männchen zusammen gekommen waren. BALBAAs batte schon vor längerer Zeit mitgetheilt, dass ein Weibehen von Notommatn Wermerkii zuerst Sommereier und daun, gegen das Ende des Lebens, Wintereier legt. IJusos meint deshalb in einer ganz neuen Publication ${ }^{2}$ ), dass die Wintereier wahrseheinlich nicht das Resultat einer befruchtung sind, "lont that the ephippial egg is the termination of that budkling proeess, by which virgin females proiluee virgin females through many generations, and that it is resorted to when the vigour of the ovary begin to fail, so that a single germ is no longer able to produce a living animal". 1)iese IIjothese scheint ja schon jetzt durch Matpas' Exprerimente wenigstens für Mydatima nicht annehmbar, und ich verstehe, wenn dieselhe richtig wäre,

1) Marpas, M. Sur le déterminisme de la sexualité chez lHỵdatina senta. Comptes rendus etc. Tome (XIII, 14 Sept. 91, s. 388. Paris 1891.

2) Hctoss, ('. T. The presidents adress on some Doubtful ete. l. c. s 10 \& 11. 
nieht, wie man so oft bei vielen Weibchen anf ain Mal solche Wintereier oder, wie Hunson sie correcter nemen will, ephippiale Fier antreflen sollte, ader warum, wie amch Ilunsos anmimmt, die Mämnchen periodiseh auftreten sollten. (Ob) wirklich die Wintereier eine grössere Kahl von Eizellen enthalten, ist wohl kaum bisher entschieden und hat wohl nicht grosse liedentung, demn bei den meisten, wenn nicht bei allen Rotiferen soll ja vom lie eine Masse Nahrmeg ans den ein syncytium bildenden Dotterzellen anfgenommen werden. Die Eizelle sclbst schnürt sich ja von dem ein syncytium bildenden Keimstocke ab, und weil keine Zellengrenzen da zu entdecken sind, lässt sich schwer entscheiden, ob rine oder viele Zellen darin eingehen. Ich labe diese Arbeit von Hudson crst nach Fertigstellmng meiner Ahhandhung kemen gelernt, wollte seine Ansicht jerloch wegen der hohen Antorität, welche ihm ant diesem Geliete mit grösstem Rerhte zuerkamnt werden muss, nieht übergehen somelern schalte sie hier ein '). Doch finde ich ïbrigens diese Hubsox's Hypothese schon durch PLate's Experimente beinahe wiederlegt. Dem, wem das Iblegen der ephippialen Eier die Folge einer solehen Ermattung oder eines solehen Verbrauchs des Ovarimns wäre, damn würde es schwer erklärbar sein, wie ein Weibehen so viole ephippiale Eier legen kamn. theine in der Tabelle (s. 43) anfgenommenen Thiere A, B, C, 1), die nur Wintereicr erzengt haben, legten resp. 12, 6, 5

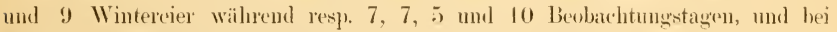
Matpas' Experimenten wurde eine noch grössere Inzahl solcher Fier gelegt. B.sbasis Beobachtmengen sind auch nicht so bestimmt, wie man aus IIubson's 1)arstellumg glauben könnte. Erstens sollte die Befruchtung wohl sehr früh, wrum die Weibchen noch frei leben, vor sich gehen, und dass Bataisn keine Mämmchen gesehen lat, dürfte deshalb leicht erklärlich sein. Etwas grössere Bedeutung hat gewiss die 'Thatsache, dass er auch keine mämnliche Eier gesohen hat, aber auch das ist nicht so wunderbar, wem man bedenkt, wie selten Weibehen mit mämlieher 'Tracht bei anderen beobachteten Formen sind. Zweitens zicht Babbian seine Schlussfolgermo, daks ein Weibchen sowohl Sommerejer wie Wintereicr legt aus der Beobachtmo, dass beide zusammen in einer Gallenanschwellung liegen kömen, während "sauf de rares exceptions" nur cin

1) Es war nieht gerade leicht eine passende Stelle für die Einschaltung zu finden. Für eine unfussendere I'marbeitung habe ich jetzt keine Zeit.

$\left.{ }^{2}\right)$ B.ußuxi, M. Observations sur le Notommate de Werneck etc. Amales d. sci. nat. VI Serie Zool. Tome VII. Paris 1878. Art, n:o 2. Vorzugsweise ss. 22-28. 
pinziges Räderthier in diesen fiallen sitzt, und gewiss branchen wir riel genauere Angalren über dic Jläutigkeit dieser Ausnalmen, ehe wir ans der oben mitgetheilten Thatsacho einen solehen gegen zablreiche Beobarhtungen und Experimente: anderer Verfasser streitenden sichluss ziehen können. Freilich sind diese Publachtungen hei anderen Irten gematht, abej ich kamn nicht gern glauben, dass für die Bildung einer Art Eier bei versthedenen, übrigens so nabe verwandten Räderthieren versehiolene fiesetze gelten kömnen. Gern gelse irh democh zn, dass dis Balbiani'schen Beobathtungen gegen eine zn schuelle Verallgemeinerung der aus den Experimenten an Myrlatima gezogenen sedoliisse

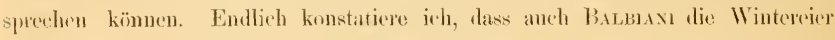
erst gegen den Schluss der Beobachtmogszeit gesehen hat.

Tnd weil mun die Cohn'sehe Intfissumg von der Bedentung der Männchen wenigstens bei eingen Räderthieren breehtigt war, seheint es mir auch wahrseheinlieher zu werden, dass die Angabe, welehe er und ander über das Iuftreten dar Mämnehen in einer gewissen Periode liefern, richtig ist. Nur muss man dabej immer erimnern, dass diese nicht nur von der Jahreszeiten abhängig ist, somdern ebenso viel mud vielleicht moch vied mehs von der beschaftenheit der Wasseransanmlungen, wo die häderthice leben, und von den Vorhältuissen der anderen in denselben vorkommenden lebenden Wesen, sowohl der Thiere wie der Pflanzen.

Mavess' [ntersuchungen seheinen es jedoeh wohl wahischeinlich zu machen, dass die Mämneben in den heisieren Monaten anftreten, und wir haben ebon gestehen, dass eine ambere Ansicht isemlich allgemein angenommen ist. Im Fröhling kams es vielleicht erklärlich sein, temn die T'ïmpel und kleinesen Wasseransammlungen werden gewiss wärmer, je kleiner sie sind, und je näher inren Austrocknen sie sich befinden. Für das Auftreten der Männehen im Ilerbste kam von allgemeinem standpunkte nichts gesagt werlen, denn an vielen (Jitens sind die Ilerbste troeken mod warm so z. b. September sehr oft hier in süid-schweden, und wenn auch das nieht der Fall ist, wird democh die Zusammensetzung des thierischen und ptanzlichen Lebens der 'Tämpel seln' geäudert.

Ich habe auch die Maupas'schen Tntersuchumgen aus einem anderen (irumble angeführt. Die für das llrvorbringen der Mämnchen günstigo 'T'rnsperatur bei Myglatimu war höher als $15^{\circ}$ C. (Maupss' Experinente wurden bei +26 2s" ( $\quad$ angestellt). Eino kn bohe Temperatur dürften Gewässer in 
Grönland kaum je erhalten. Dic (tewässer, in denen ieh dir ohen erwähnten Mämohen fand, hatten wenigstons nieht wähend 14 Tagen eino höhere Temperatur als : I 2y gehabt, und ziemlich sicher war die Temperatur dorsillen im ganzen sommer nicht höher gewesen. Während meines Aufenthalts in Jakobshavn famb ich diese höhrese Temperatur des Wassers nur cin par Mittagsstumden eines Tages in eingen von der somne stark belenchteten kleinen Gewässern. Die anderen Tage zejoten cine Temperatur des Wassers von

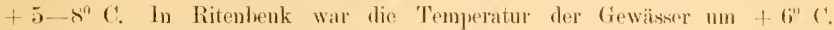
Nur die 'Temperatur des obersten Wasserlagers, so ticf' wie das Termoncter einsank, wurle gemessen. Die unteren Lager waren nicht wenig kühler. Iuch da, wo ich meine Gefässe, die aber hier nie lange mit dersellene Probo stehen blieben, verwahrte, war die Temperatur ziemlich konstant um $L \& "$. In dem Zimmer, wo ich arbeitete, wurde sie trotz 3-4. Mal täglich wiederholtem Einheizen gewönlich $11 m+10-12$ (14).

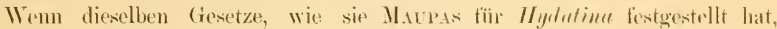
auclı lïr andere Räderthicre geltem, so mïssten sich diese Riderthirmänmehen in Grönland dennoch bei einer relative sehr niedrigen 'Temperatur antwickeln. Vine etwas erhöhte Temperatur kanm wohl in guten Jahıen auch Infang Juli in den einex vollständigen Iustrocknung nahe stehenden grönlämlisehen fiewässeru grtumlen werden, aber gewiss nicht höher als -i 14".

Nun treten ja zum grossen Theil dieselfen Räderthiere in Grönland wio

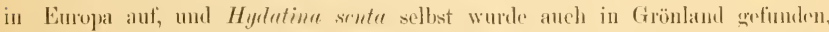

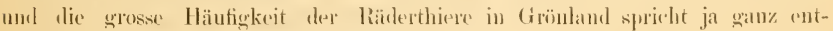
schirelen dafür, dass dir äusseren liedingumgen daselbst den liädertliseren gïustig siml. Die lange dauerule kalte Zeit fordert nothwendig vorzüghiohe Einrichtungen fïr das C̈herwintern, und hiertïr sind wohl ganz besonders die "phippialen Ëier geeignet. (Obgleich ich also keine ahgesshlossene Intersurhungsreihe ïber die biologisehen Verhältnisse der grönländisehen Räuderthere habe geben kömnen, scheint mir jedoch das wenige, das ieh über grörmändische Rotiferenmännchen mittheilen kann, eben mit den neueren lixsultaten dex Forsehung zusammengestellt rin gewisses Interesse beanspruchen zu dïrfen. 


\section{Vergleichungen mit anderen Faunengebieten und Schlussbemerkungen.}

l) oben erwähnten und besehriebenen Räderthiere balse ich in den grönlïndischen dewïssern gesammelt während der Zeit, welehe ich mich in firönland bef:unl, und weldhr zum grössten Theil auf diese Arbeit geopfert wurde. Dass in vielen Füllen mein Urtheil über die Bestimmung einer Form unsicher geworden ist, mag die Schwierigkeit solehe Stulien ohne Zugang zu reicherel literatur anzustellen entsehuldigen, weil die an Ort und Stelle gemachten Notizen jir kn\% und die Skizzen grob sein mussten. Ohne eingehendere Literatur verstand ich nicht überall, wo es nöthig gewesen wäre, die wiehtigen Verhältuisse nud Merkmale zu berüeksiehtigen. Ieh habe meine Notizen eingehend mit den wichtigeren Arbeiten der Literatur verglichen, nnd meistentheils labe ich die gesehenen Formen mit einer schon bekanten Form wenigstens vergleichen kömnen. Ich habe mich anch bemülıt bei den Arten, wo ich die Bestimmum zweifelhaft finde, dasselbe hervorzuheben. Wenn einige von den Arten, welehe ich als neu aufgeführt habe, schon früher besehrielsen sein sollten, habe ich unr die Eutschuldigmng, dass ieh dieses meinen Notizen und der nir zugännglichen Literatur nicht sicher entnehmen konnte, und ich halte es ans allen Gesichtspunkten besser eine neue, später leicht rerschwindende Lrt eine Zcit in der Wissenschaft mitzuschleppen als zu risikiren unrichtige Verlreitungsgrenzen für alte Arten zu bekommen. Von diesen zwei Ühelständen seheint mir der erstere geringer.

Ich habe einige Nale nene Arten beschrieben, obgleich ich von denjenigen Formen nur ein einziges Individum gesehen habe. Ich habe es dennoch ohne Bedenken gethan, weil in der Literatur eine solehe Masse von Räder- 
thierarten auf ein einziges gesehenes Exemplar begründet sind. So hahen Einesmerg und Gosse, die wohl anf diesem Gebiete bisher dic unfassendsten Artenkemintisse besessen haben, cine ganze Anzahl Arten nach einzelnen

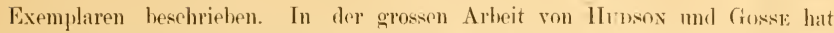
der letztere von nieht weniger als beinahe dreissig nenen Arten und vier ne'ul'n Gattungen nur ein einziges Exemplar mtersuchen kömnen. Lis wäre natïrlich besser, wenn ieh mohreve gesehen hätte, aber vor die Wahl gestellt die Form entweder nicht zu erwälmen, ihr nur eine Nummer zn geben oder einen Namen beizufügen. habe ich das letztere nach gutem Beispicle ameh deshalb gewilhlt, weil dadurch eine I iskussion in der Literatur viel leichter wird. In den Fällen, wo ich zweifelte, ob eine neue Art bereshtigt war, habe ich es immer anselrüeklich betont mol manchmal anch dieselbe mit einem ef. zu dieser anderen nahe verwandten $\Lambda$ rt geführt. Dass man auf solehen Reisen immer die gefundenen Formen, welehe nicht konservirt werden kümnen, vollständig durchforschen sollte. wäre eine Forderung, die ohne weiteres an ihrer Umü̈glichkeit stranden wïrle. Das Konservieren von mikroskopischen Thieren fordert fast eben so grosse Keitverwendung wie eine Untersuchung und hatte bisher übrigens in den meisten Fällen nicht für systematische Studien branchbaren Erfolg.

Bei einem genancren Studium der Räderthiere merkt man anch pecht bald, dass die gründliche, gewissenhafte Bestimmung, welehe man nach dem ersten gesehenen Exemplare, vornahm, fast immer richtig war, und nur schr selten findet man, dass später gefundene Exemplare zu einer geänderten Auffassung leiten, wemn sie auch sellstrerständlich in manchen Peziehungen die Kemntnisse vertiefon.

Ich habe aneh rinige Gattumgen anfoestellt. Das ist clren betreffend liaderthiere eine schwere Saehe, weil die bestehenden Gattumgen von so sehr ungleiehem Werth sincl. Es gibt kanm eine andere Abtheilung des Thicreichs, wo die wiehtige Vorschrift "('hararter non dabit genus sed genus characterem" in der jetzigen Periode schwerer durchzuführen ist. Versehiedene Verfasser und besonders Gosse haben für die Familie Notommatadie zum Theil kleinere und natïrliehere Gattumgen anfgestellt jedoch die beiden Gattungen Fureularia und Diglena fast unverändert stehen lassen. Wegen der Schwierigkeit der Sache selhst kann ich wohl deshall, nicht hoffen immer richtig geurtheilt zu haben, aber 
es kam mir vor, dass die Formen. für welche ich neue Gattungen anfgestellt habe, nicht mit Recht in eine andere Gattung gestellt werden odex ihren Platz da länger behalten komnten.

Jetzt will ich einige allgemeine Betrachtungen zufügen. Teh wïnsche hier theils auf den Reichthum der grönlänlischen Rotiferenfanna hinzuwrisen theils auch auf einige Eigenthimlichkeiten dieser Fauna, so wie icl: diesellhe kemmen gelernt habe, im Vergleieh mit derjenigen anderer Gegenden Anfmerksamkeit zu wecken.

Ehe ich zu diesem Vergleich schreite, betone ich, dass in der von mir oben angebenen Zahl von grönlänlisehen Rotiferen sehr wenige pelagische Arten eingehen. Ieh konnte wenige solehe sammeln, und auch diese sind bisher mgenïgent untersucht worden. Weil einige solche - comochilus, Ammara, Asplaurlua. Triarthra — schon in grönläindischen Seen gefmulen worden sind, ist es wohl wahrseheinlich, dass noeh andere pelagische Arten in Grönland vorkommen. Inum nimmt nämlich in einer neulich veröffentlichten Arbeit nieht weniger als 30 (29 Arten und 1 Varietät) ${ }^{1}$ ) Rotatorien als wirkliche Mitglieder der pelagischen Fauna der Süsswasserbecken anf.

Wem ich mir anch vorstelle, dass unter den von mir angefiihrten Notommataden die eine oder die andere nicht ganz zweifellos unter dem aufgrefïhrten Namen steht, musis ich dennoeh glauben, dass dif Zulh der yeselemen Arten micht zu hool ist, dem es sind ausser den mit Nummern bezeirhueten noeh

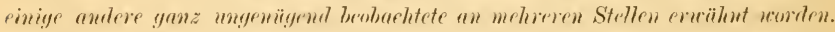
Die Zahl ale rom miv brobarhteten Avten kam also mit grö̈ster Sicherheit

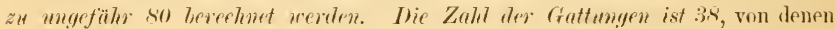
ja die Gattungen Hypopms, Mikrocolides, Diops, Notostemma und Arthorglena neu sind. Weil diese Gattmegen zum Theil schon früher bekannte Arten enthalten, setze ich bei dieser Vergleichung die Kalıl der Ctattungen zu 35 und bemerke dazu noch, dass einige von den anderen Gattungen von Gosse aufgestellt sind, mol deshalb zum Theil in den Ehrenherg'schen Collectivgattungen

1) Diese Zahl nehme ich aus einer nenlich und wïhrend des Druckes dieser Abhandlung veröffentlichten Arbeit dieses Verfassers. Immp, O. E. Die pelagische Fauna der Süsswasserbecken. Biol. Centralb]att 18\%2. N:r 6. Auch Zochonk hat in zwei, sehr interessanten Arbeiten "Faunistischen Studien an Gebirgsseen" einige pelagische Rotiferen genannt. 
enthalten waren '). So waren in Ehrenberg's Notommate die hier als Tuphrocampu, Hypopus (\%. Th. = Notops (xosse), Notommuta, Notostemma, Proules, Monommuta und Copeus aufgeführten Gattungen enthalten. Natürlich kam man nieht voraussetzen, dass ich in tieser kurzen Zeit, wo ieh auch amdere Beschïftigungen zu besorgen hatte, mehr als eine geringe Zahl dieser Formen sah. Diese sehon a priori so gut als selbstklare Anssage gewinnt vollständige (rowisiheit durch die Thatsache, dass ich auch in der letzten Zeit meines Aufenthaltes in Grönland beinahe eben so oft wie in der früheren und fast jeden Tag n'ur Formen sah. Es war nicht Mangel an nenen Formen mur an meinen Kenntnissen und meiner Zeit, weleher verursachte, dass ich nicht noch vich andere interessante Formen anfïhren kann.

Es wäre wohl deshalb kaum riehtig meine Ausbente während einer kurzen Reise mit den Resultaten derjengen Forseher zu vergleiehen, wolehe wiv Eamenbert und Ilunsen \& Gosse oder Ilood ${ }^{2}$ ) jahrelang mol in versehiedenem ungleichartigen Gegenden den Rotatorien ihre unter giunstigen änsieren Umstïnden vorgentmmenen studien gewidmet haben, sondern muss meine Anshente unit derjenigen der Forseher, welehe in kürzerer Zeit eine Gengend untersucht haben, vergliehen werden.

leh werde hier einen kurzen Auszug ter wiehtigeren solehen Arbeiten geben.

Wesse gibt in den Jahren 1845, 47, 48, 49, 50 und 51 Verzeichnisse iiber die Petersburger Infusorien und Nachlesen dazu, welehe zusammen 10:3 Arten und 4: Gattumyen von Räderthieren enthalten. Von den letzteren

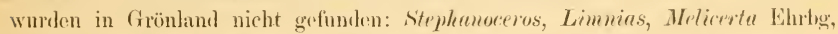
Orcistes, I'ty!gura, Mastigoreren Ehrbg, Ruttulus? ${ }^{3}$ ), Lepatella?, Squamella?, Noteus, I'olyartha, Triophthalmus, Cycloglena?, Otoglenu?, Synehata, Actimurus nind Momolulis?.

Perty gibt 1852 in seiner zusammenfassenden drbeit anch rin $V^{r}$ erzeichniss der von ihm während relative sehr lange fortgesetzten Studien in der

1) Bei den nachfolgenden Vergleichungen nehme ich auch Rincksicht anf die von liabol gesammelten Gattungen, Asplanchua, Triartha und Anuraa, welche ich aus ohen dargelegten Gründen nicht gefunden habe.

$\left.{ }^{2}\right)$ J. Hood's List of Rotifera found within a liadins of twenty Miles romd Dundee. Scott. Natural. (3) Vol. 1 s. 20-25, 2 s 71 -81, nimmt nicht weniger als 224 . Irten auf.

$\left.{ }^{3}\right)$ Mit einen Fragezeichen bezeichne ich die (iattungen welche entweder sehr ungenügend bekannt sind oder jetzt eingezogen und zu anderen fiattungen gefuhrt werden.

Lunds Univ. Ărsskr. Tom. XXVIII. 
Srhwejz beobachteten Rüderthiere. Er nemnt 9s Arten und 38 Gattungen. Von den letzteren umfasst Notommata noch die Gattungen Asplunclua, Dimellı, Momommata und Hypopus. Von diesein Gattungen, welche Pertr in der Schweiz vertreten fand, sind in Grönland nicht notirt: Ascomoryha, Symehota, Ruttulus?, Triophthalmus, Lepudella?, Notogomia '), Squamella?, Aetimurus, Notens, Polychetus, Limmias, Mclicerta Ehrbg und Stephanoceros. Die Gattung Theorns nenne ich nicht, weil dieselbe der Gattung Plewotrocha entspricht. Polyehatres vergleicht Hudson mit Dinochrovis Collinsii und hält es sogar nicht ganz unmöglich, dass sie identiseh seien.

LEYDic gibt in seiner früher angeführten für die Kenntniss des morphologisehen Baues dieser Thiere wichtigen ja, gewiss grundlegenden Arbeit eine Anfzählung der von ihm in der Umgegend von Würzburg beobachteten Formen und nennt 53 Arten und 28 Gattumgen. Tnter diesen Gattmogen befinden sich folgende, welche ich nicht in Grönland vertreten gefunden habe: Mrticertı Ehrbg (Leyng trennt nämlich mit EHrenberg diese Gattung von Tubicolaria), Mustigocerce ${ }^{2}$ ), Rattulus?, Symchata, Polyartha, Ascomorpha, Noteus und Lepailella?.

Tóтu gibt 1861 eine Aufzählung der Rotatorien der Umgebung von Pest-Ofen ${ }^{3}$ ). Nur 23 Arten werden genamnt. Von nicht in Frönland vertretenen Gattumgen finden sich in sciner Aufzählung: Actimurus, Lindia (wohl eine Art von der jetzigen Gattung Notommata), Asplanelua (als Notommuta Sielolelii von Тóтн aufgeführt), Melicerta Ehrbg, Stephanoceros, Leparlella? und Noteus.

Bartscir studierte 1870 die Rotatorienfauna der Gegend von Tübingen, und findet seine "Bemühung über alles Erwarten belohnt, denn mehr als 50 Arten, darmter einige neue bereichern die hiesige Fauna". Genan angegeben sind es 5s Arten und 28 Gattungen ${ }^{4}$ ), welehe er in seiner Arbeit anfzählt. Von den Gattungen wurden in Grönland nicht boobachtet: Melicevtu Ehrbg, Synchate, Rattulus?, Actiunus, Leparlella, Squamella mol Ascomorpha. erscheint.

1) Eine nach Perty nicht wieder gefundene frattung die aber sehr charakteristisch

${ }^{2}$ Leynig und Wersse führen die Gattungen Mastignerera und Monocera als getremnt anf.

3) Тóтн, A. Rotatorien und Daphnien etc. s, 183.

4) Barrscul führt wie früher angegeben Dinrella Tigris zu seiner (tattung Mommmata. 
Eckstern untersuchte in Laufo pines sommers die Rotiferen der nüheren und fermeren Utmgegend Giessens und gibt davon in seiner oft citirten ansgezcichneten Abhandlung, welche auch wälırend meiner Rotiferenstudien in Grönland meine Hauptquelle war, sehr'genaue Angaben.

Die Zahl der gefundemen Arten ist 50 mud der Gattmugen 27. Dabei muss indessen bemerkt werden, dass die in dieser Zalıl mitgerechneten früluer ron derselben (iegend bekannten Lacinularia socialis und Apsilus lentiformis nicht in Jahre 1\$82, wo EckstEıs seine Untersuchungen ausführte, gefonden werden konnten.

Nicht in Grönland beobachtet sind von seinen Gattungen aussel den beiden eben genamnten nur Actimurus, Triophthulmus, Squamella? und Notens.

Platł behandelt in seinen auch schon mehrmals angeführten Beitrïgen zur Naturgesehichte der Rotatorien Formen, die er vorzugsweise in der Gegend von Bomn und Bremen gesammelt hat. Nur wenige Arten hat er in Jena genonmen. Weil es seheint, als ob er weniges fiewicht auf die Bustimmung • der Arten gelegt lätte, gebe ieh nur die Zahl seiner Gattungen an. Er nemnt s6 Gattungen. Von diesen habe ich nieht in Grönland Lacinularia, Actimurus, Iolyuthru, Hevturgin (Gosse fühut diese Form als synonyme für I'roudes prerasita anf), Synchota, Rhinops, Pomplholyx und Notens beobachtet. Disis macht nieht weniger als ein Inittel der von jhm angeführten Gattungen.

Tessin-Bützow widmete im Jahre 1884 einige Monate (August bis Infang November, dem Studium der Rotiferenfauna in der Umgegend von Rostock und fand 49 Arten. Die Zahl seiner Gattmgen ist 24, wobej indesien bemerkt werden muss, einerseits dass seine Gattung Acanthoductylus die bei versehiedenen Antoren als getremete Gattungen aufgefïhrten Diurella, Mustigncercu und Monocerce umfasst, und anderseits, dass seine I'lugiognuthu-arten wohl bei vielen anderen Autoren unter Notommata stelen. Von scinen (iattungen dürfen deshalb nur Actimurus und Syuchatı als nicht grönländiseh genannt werden.

Obgleich nicht viel in diesem Zusammenhange von WenEk's smmmariseher Angabe geholt werden kamn, will ich demnoeh erwihnen, dass dieser Forscher beiläutig erwähnt, dass er in der Nähe von Gencve "pendant une sente saison" wenigstens 150 Arten und Varietäten hat bestimmen kömmen. Er sprieht atueh deshalb das Urtheil aus, dass diese Gegend reich an Rotiferen ist, und findet die Ursache hierzu in der grossen Menge Tiimpel, die unter sehr versehiedenen "posi- 
tions climatériques" gelegen sind. Da indessen weder die Gattungen noch die Arten m itgetheilt werden, so kamn ich von dieser allgemeinen Angalse nur sehr geringen Nutzen für eine Vergleichung ziehen.

Ein wichtiges Vergleichungsmaterial bildet Gosse's erstes Verzeichniss über in England vorkommende Räderthiere ${ }^{1}$ ). Dasselbe gibt die von ihm während dreier Jahre bobachteten Arten an. Sie sind jedoch zum aller grössten Theil in der Nähe von London gefunden. Die Zahl der Arten ist 103 und die der Gattungen 35. Mustigocerca ist noch von Monocercu getrennt, dagegen ist Proales noch nicht aus Notommata ansgebrochen. Von diesen Gattungen wah ich die unten aufgezählten nicht in Grönland. Succulus, Occistes, Meyglotrochı, Stephanoceros, Limnias, Melicerta Elrbg, Synchota, Polyusthra, (Mastigncerca), Diplax, Noteus und Pomplolyx: Die englische Rotiferenfauna bictet ja ein besonderes Interesse dar, insofern dieselbe ja Grönland relutive nahe liegt und wohl auch in einer relutive leichter Verbindung mit der grönländischen Fauna stehen dürfte.

Weiter bietet diese Gosse's Arbeit eine gewisse Gelegenheit dar eine Vergleichung der Resultate einer ersten Arbeit mit den Resultaten der späteren genaueren Durehforschung anzustellen.

Jetzt kemnt man von den Britischen Inseln - zum grossen Theil Dank dem Fleiss desselben Forschers - ungefähr dreihundert Arten, und denuoch fand Gosse während dreier Jahre nur ein Drittel dieser Zahl. Es kommt mir vor, als könnte man aus dieser Thatsache einen ziemlich unerwarteten Schluss betreffend den wirkliehen Reichthum der grönländischen Fauna, ziehen.

Wenn wir die verschiedenen Verzeichnisse mit einander vergleiehen, treten auch einige charakteristische Züge der grönländischen Fama, so wie ich dieselbe zusammengesetzt gefunden hale, hervor. Fis sind wohl kaum einige orler wenigutens sehr wenige da vorkommende Gattungen, die etwas charakteristischess darbieten. Aber $\mathrm{nm}$ so mehr fällt das Fehlen einiger von den in den meisten Listen stehonden Gattungen ins Auge. Solehe Gattungen sind Strphanoceros, Melicerte (s]). ringens), Limnius, Lucimularie, Actinurus und Synclerta. Die Gattung Polyarthru würde ich wohl auch hier setzen, wie ich dieselbe kurz vorher mehrmals bei den Vergleichungen genamnt habe, aber

1) Gosse, P. II. A Catalogue of Rotifera found in Britain: with descriptions of five new Genera and thirty-two new Species. Anuals and Magazine of Natural History Vol. VIII, II Serjes, London 1851, s. 197. 
ich bin nicht ganz sicher, ob nicht unter den als Bruchionus sp. hier oben zusammengesehlagenen Rotiferen, die fast blitzschnell, nicht gerado selten über das Gesiehtsfeld sehwammen, sich auch Exemplare dieser Gattung befanden. leh erinnere nämlich recht wohl mehrmals Eindrücke bekommen zn haben, die recht wohl der Abbildung' 5 b Pl. XIII im Hunson's Buebe entsprechen. Ich würde sie sogar ohne Bedenken als Polyarthro platyptera anffïhren, wenu nieht eine Notiz von Dornen am hinteren Rande der loriea spräche, und wenn nicht, so viel ich sah, diese Dorne unbeweglieh waren oder besser, weil ich nie diese Anhänge sich bewegen sah. Dennoch neige ich dazu unter diesen Formen neben einer Brachiomus-Art anch eine Polyarthra einzuschaltun. Wenigstens wage ieh nicht ohne jede Reservation das Fehlen dieser Form als ein atszeichnendes Merkmal für die grönländisehe Rotiferenfauna hervorzuhaben.

Als für dieselbe bemerkenswerthe Eigenthiimlichkeiten muss ich dagegen gewiss die Seltenheit der Brachiomus- und Anura-arten anfïhren. Von den in tast allen Gegenden reichlich gefundenen Anuraen sah ieh nur ein einziges Exemplar, dasjenige, welehes ich zu der Gattung Notholec als $N$. ambigun geführt habe. Nur in Tessin-liaitzows Verzeichniss fehlt dirse Gattung. (rosse hat in seinem ersten Verzeichniss nicht weniger als 7 Arten, PERTy hat fi, Bartsch 3 oder 4 Arten, Eekstein nur 1, Plate sagt mehrere und Honson sehliesslieh nennt Amuran aculeate und Notholen striata unter den :30 wohlbekannten Rotiteren, "die er als in wenigstens fünf von acht von ihm l'rüh'p" genannten Ländern Enropas (Britain, France, North and South Germumy. Denmark, Switzerland, Hungary and Russia) vorkommend zusamm('ngestellt hat ${ }^{1}$ ).

Anch Brachiomus muss ats in Grönland relative schr seltem angegerben werden und vor allen Dingen muss hervorgehohen werden, dass num ein paar Arten notirt wurden. Auch das Fehlen von Notens ist wichtig genug. In allen Verzciohmissen ist Brachiomus vertreten und in den meisten mit mehreren Artun, die ausdrükklich als sehr häufig angegreben werden. Auch Notens ist von den meisten Untersuchern einer Geogend notirt warden.

Dass ieh nur an einer Loralitait IIydutima sah, kann wohl trotz der grensern Verbreitung dieser Art nicht so wichtig sein, weil rliesetbe wio friiher besprochen ja vielleicht vorzugsweise eine Frühlingsform ist.

') Ich erinnere jedoch lier noch eimmal dass liabot Anmor longispina und fmura rochlcuris in zwei Seen gesammelt hatte. 
Unter fehlenden Arten hebe ich weiter Mastigocercu curinutu hervor. Diese Gattung war ja übrigens mit drei Arten vertreten, vou denen $M$. Rattus (Monocerca Ehrbg) sehr gewöhnlieh war. Aneh die Abwesenheit von Actimurus hebe ich nochmals hervor. Derselbe ist ausser in fast allen Gegenden Europas, in Indien, in Australien und wohl auch in Amerika gefunden.

Das Fehlen dieser Arten und Gattungen fällt leicht genng in die Angen, viel schwerer ist os dagegen einige in Grönland vorkommende gewissermaassen leitende Arten oder Gattungen anzugeben. Frei lebende nicht parasitisehe oder symbiotische Callidinen scheinen in Grönland relative allgemeiner zu sein. Mikrocorlon wurle in sowohl der Umgegend von Egedesminde wie in derjenigen von Jakobshavn beobachtet, md nach unseren bisherigen Kenntnissen zu beurtheilen diurte derselbe in vielen Gegenden Europas ziemlich selten sein. Mikrocotides ist ja bisher $n \mathrm{~m}$ in Grönland gefunden und war auch da sehr selten.

Ebenso scheinen mir Iypropus Ritenbenlii (mit Notommata oder Notops Hyptopus nahe verwandt), Copens cuudatus und Diops murina erwähnenswerth zu sein. Bisher nur grönländiseh ist anch Arthroglema. Stephanops (hlanu ist auch in Europa bisher in wenigen Gegenden notirt werden. Setze ich weiter hinzu, dass Mctopnelia acuminata häufig war, so dürften dic wichtigssten, mehr oder minder eigenthümlichen Züge der Rotiferenfauna Grönlands hervorgezogen worden sein. Es kann vielleicht zugefügt werden, dass dic Versehiedenheit betreffend die Loricata viel geringer als betreffend die Rhizota und tie Ploima illoricata erseheint.

In thiergeographischer Hinsicht können ja die Rotiferen wenig Interessantes darbieten. Sie können ja durch den Wind herumgeführt und von den Wasservögeln mitgeschleppt werden, und deshalb gibt es ja kaum Grenzen fïr dic Verbreitung derselben. Es ist anch eine grosse Menge von diesen grönländischen Formen, die sehon jetzt nicht nur in Europa sondern anch im subtropischen Austratien und Indien gefunden sind. Die Gattungen Flosculariu, Conochilus, Philorlima, Rotifer, Asplanchma, Notommata, Copens, Monommata, Diglena, Mastigocera, Dinocharis, Scaridimm, Euchlanis, Cathyma, Momostyla, Colurms, Metopidia, Pterolina, Brachiomins und Amurea sind auch anstraliseh.

Und in einigen Teichen in oder bei Calcutta hat H. II. Andersson Räderthiere gesimmolt und liefert einige Notizen von den Arten, welche er zu sehon bekamnten Gattungen führen konnte. Diese Arten sind 46. I)ie Zahl der 
Gattungen ist 28, und ron diesen sind sohr wenige oder nur Malicerte (ringras), Limmias, Cephalosiphon, Oeristes, Megalotiocha, Actimus und Notrus nach meinen Beobachtungen nicht auch in Grönland vertreten. Iilentisehe Arten sind nicht gerade sehr viele, Floscularia ormatu und enmpanulata, Róotifer mulgaris, Monommata longjiseta, Diglena forripata, Diunella tignis, Scarialium

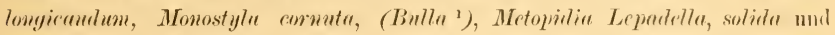
triptera, and Brachiomes Balieri oder 12 (13) von $4\left(;{ }^{2}\right)$. Weil aber dis indischen Formen alle aus einem sehr besehränkten Gobiete geholt sind, dïrften die angeführten Arten wahrscheinlieh ein noch unvollständigeres Bild der Fauna dieser Gegend geben als meine gewiss sehr lïckenhaften Anfzojehnungen von Grönland liefern. Deshalh kann man kamm schon jetzt diese Unonlejchlieit für eine Sehlussfolgerung benutzen. Ich bemerke demnoch, dass AnDERsson ausser diesen Formen noch andere, für dic er eigene Gattmngen aufzustellen nöthig' hielt, welche er aber noch weiter studieren wollte, gefunden hatte, mol woldhe also die Verschiedenheit zwisehen der indisehen und grönländischen Rotiferenfamna wahrscheinlich noch mehr vergrössern.

Wenn also die Rotiferen, soviel man bisher kennt, fast kosmoprolitisuh sind, kann man auch nicht grosse Hoffnung hegen entseheiden zu kïnnen, ob dir grönländische Rotiferenfauna mrsprünglich amerikanisch oder emropäisch ist. Tm etwas darïber aussprechen zu künnen, kennen wir sowohl die grönländischen wic die amerikanischen mul vielleicht anch die emropäischen Rotiferen vir] zu wrnig. So viel kennen wir sicher genug, dass die meisten amerikanisehen Formon mit emropäisehen ilentisch sind, und deshalb lohnt es nieht die Mühe hier zwiseluen ler amerikanischen und der grönländischen Rotiferenfamna eine genancre Vurgleichung anzustellen.

Wenn Hooker und Waruing eine ganze Menge von höheren Pflanzon in Crönland während der Eiszeit gelebt haben lassen, mo wenn NAтunıst dieselbe Mögliehkeit für wenigstens einige wenige I)utzend Arten annimmt, kömnte es ja aueh möglich sein, dass ein grösserer Theil der Rotifurenfamma Grönlands sehon vor der Eiszeit sich in Grönland befand und also nicht spëter

3) Ich halte es gar nicht unwahrseheinlich, dass auch Monostyla Bulla unter den von mir in Grönland gesehenen Monostylen vorkam.

2) Andersson, H. 11. Notes on Indian Rotifer's. Journal of the Asiatic Society of Bengal. Vol. LVIII, Part. II, N:o IV, Calcutta 1889, s. 345. 
aufs neue cingefühst zu werden brauchte. Näher darauf einzugehen geben mir die bisjetzt vorliegenden Thatsachen keine Veranlassung.

Die grönländische Rotiferenfauna bestätigt demnach die schon a priori wahrseheinliche Annahme von der ausserordentlich weiten Verbreitung der Gattungen und Arten der Räderthiere. Eine besondere Eigenthümlichkeit ist jedoch insofern zu bemerken als die Rhizoten, wenn wir Floscularia ausnehmen, in Grönland selten sind oder gar nicht vorkommen. Tubicolnvin (= Melicertu Tubicoleria Hudson) wurde nur in einem Teiche und anch da selten gefunden. Ebenso wurde Conochilus von mir nur in einem see gefunden ${ }^{1}$ ), aber vicle Scen wurden auch nicht untersucht. In fast allen Ländern Europas, in Australien, Indien und Nord-Amerika aber nicht in Grönland sind die festsitzenden Melicertu ringens, Oecistes, Limmias, Lacinuluia (nicht in Indien gefunden) und Stcphanoceros (nicht in Australien und Indien gefunden) notirt. Weshall, fohlen sie oder sind selten in Grönland? Es könnte sehr gut darauf beruhen, lass sie nicht durch den Wind verbreitet werden, und dass immerhin relative wenige Vögel, welche die Süsswusser anderer Gegenden besuchen nach Grönland zichen. Ebenso ist der Schiffsverkehr zwisehen Grönland und anderen Hafen anch relative sehr gering. Die Erklärung dieser Thatsache könnte aber anch in den für die Pflanzen, unter und auf denen jene Räderthiere vorzugsweise vorkommen, weniger günstigen Bedingungen in den grönländischen Gewässern liegen. Die höhere, phanerogame Vegetation ist ja in denselben reeht arm, das Wasser in den grösseren Wasseransammlungen sehr kühl etc.

Wenn also die grönländisehen Rotiferen zum grössten Theil das schon vorher wahrscheinliche bestätigen, muss es jedoeh Erstaunen weeken, dass cine solche Menge dieser. Thiere unter so harten Lebensverhältnissen das Leben fristen können. Die geringe Zahl anderer Land- und Süsswasserbewohner ist ja seit lange bẹannt genug, und ich habe sehon vorher in meinem kurzen Bericht als das vielleicht schlagendste Beispiel auf die geringe Zahl der Käfer hingewiesen. Die Zahl der yesummten grömlämlischen Coleopteren ist ungefäh 21. Vielleicht erreichen die Dipteren und Lepidopteren eine anch relative ein wenig höhere Zahl, aber überall steht jedoch die Anzahl der grönländischen Formen gegen diejenige der nordischen Länder in Europa ausserordentlich

1) Raвот hatte ihn wahrscheintich in demselben See genommen. In dem anderen sipe wo dieser lieisende fischte, in Tasersuak, wurde Conorhilus nicht gefunden. 
zurück. Fs liegt zimblich grosse (invissheit ror, dass die angegebenen Kahlen niclit sfe sehr viel zo nierdrig sind.

Es fragt sich dann, wir es möglich ist, dass so viele liotiferem da gare

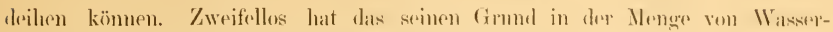

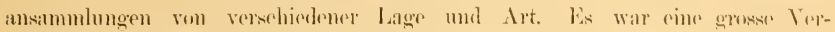

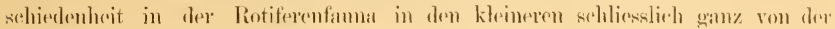

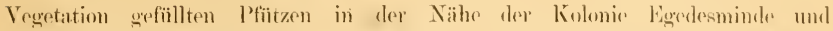

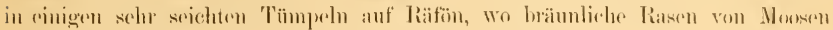

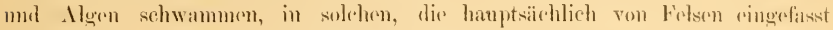

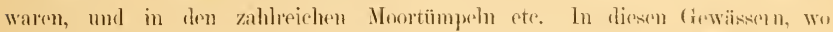

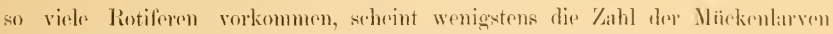

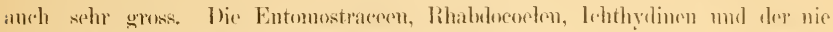

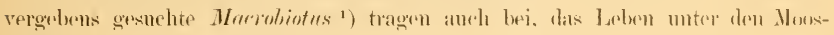
blätern in rinem Wassertroptom gamz rege zn marhen.

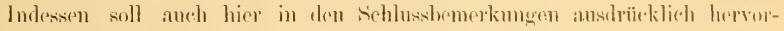
geloblen werden, dass die Zahl dor Rotiforen mur insofern gress ist, dass man fast immer einge fimlot, und dass die Kahl dor Arten ganz guress ist. Die

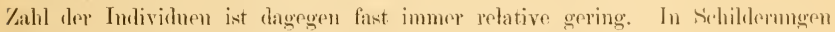
son dem Vorkommen der Räilerthiere in Enropa wird oft ron rahmatigen

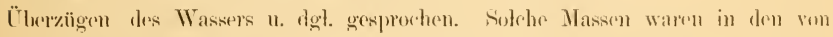
mir lesuchten fregenden Grïnlands nie zu sehen, und die allermessten Formen

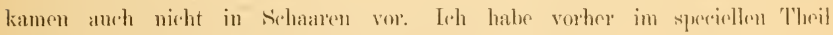
immer angegeben, ob eine Art peichlich vorkam oder selten war, weil das mir atus thiergeographischem Gesichtspunkte beinahe whenso wiehtig wie das Vorkommen einer Art erseheint. Die fast ïberall gewöhnlichen fattumgen waren in (irön-

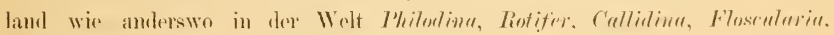

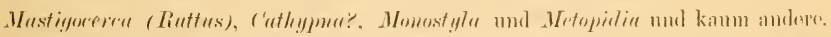
folurus war in den meisten Gewässern vorlanderi aher fast immer selten. Die glosise Gattung Notommata war wohl in beimahe jeder Wasseransammlumg vertreten, aber ich weiss keine Irt zu nomen, die vorzugswoise läufig wals.

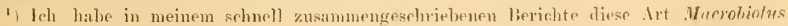
of. Srkulzii genannt. Ich kounte nämlich bei den untersuchten lixemplaren keiu Angen

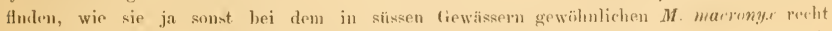

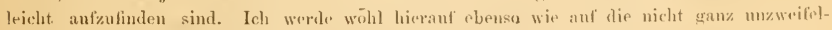
hafte Angabe äber das hänfige lorkonmen einer Mydrorkm anderswo wieder zurbekkommen. Ich habe wegen eincr lieise von dem berichte kein. l'orrectur gesehen. 
Sind die hier zusammengestellten Resultate allgemein giiltig? Die Frage kamn matiolich noch nicht heantwortet werden. Vielleicht sind die Räderthiere in wïmeren Sommorn viol häntiger. Vielleicht schwinden aber damn die frowïsser so sehnell bei oter nach der sichneeschmelzung hin, dass die Entwirklung der Formen in kleineren Tümpehn fast ausbleiben kam. In den länger nach innen zwiselen des tiof ins Land eindringenden Fjorden gelegenen Theilen diüfte wahrseheinlich die Fauna noch reicher soin. Ina ist ja tie Vegetation viel reicher, und in den tiefen gegen die kalten Winde gut gesehützton Thälern soll ja sine ielative hohe.Temperatur vorkommen. Allenfall

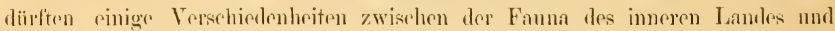
der kïaste bestohen. In besleutenden Theilen des Tamoles ist das pisfreie Kïstrnlanel inmerhin breit gemug um klimatisehe L'ngleiehheiten z.u verursachen. Vielleicht hieten anch die sïdlicheren Theile des Landes etwas gïnstigere T'erhäilnisise dar.

Übrall, wo bisher die Rotiforenfanma genaner untersucht worten, sind neur Arten gefunden, mul Gusse besehrieb lsst nach der Teröftentliehmug der grossen Hunson'sehen Arbeit, wo re sehom eine ansehnliche Menge nener Arten beschrieben latte, nicht weniger ak 60 Arten, die nicht früher brkannt waren. Es kam deshalb keine Terwumlerung weeken, dass anch in Grïnland mit den rigenthümlichen Verhältnissen, die dal vorhanden simul, nicht so ganz wenige eigenthimlixas Formen anftreten.

Wreitgehentere allgemeine schlïsse will ich nicht giehen Irh habe diese Zusammenstellung grösstentheils deshalb gemacht, weil ich wïnsehte die Anfmorksamkeit kommender Forscher besonders auf diese Fragen zu richten. Trem sie auch selbatrerstïndlich viel an disser meiner Arheit zu anderu und dazn beizufïgen houlen werten, mïssen sie erimmern, dass diese Arbeit, welche wenigstens zmm Theil unter suhr ungiunstigen ïusseren [Tmstänlen ansgeführt worden ist, der erste Versuch war die grönländischen Rotiferen zusammenzustellen und mit denjenigen amberer Crobiete zu vergleirhen.

Zum Arlıluss will i.h anch hervorhehen, wie gïnstig dieses Land sein diirfte, mu einige biologische studien iiber Rïderthiere vorzmmehmen. Wegen

1) (rosse, P. H. Twentyfon new species of Rotifera. Journ. of huy. Micr. Soc. 1887, s. 1. Twelve new species of Rotifera. $13 m$ s. 361.

Twentyfour more species of Rotifera. Ibm. s. 861.

Diese Irten sind anch im Supplement des Hudson schen Werkes aufgenommen, 
des grossen Reichthums an Tömpehn, mul wril dis Wasser, wenn einige sommen-

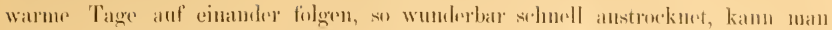

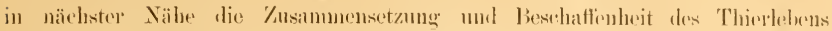

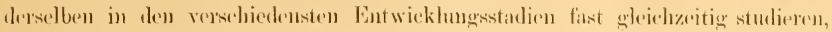
umsl gewiss wärde ain mit der nöthigen literatur und nöthigrın llilfsmitteln und mhigem Arbeitoplatz versebener Forseher da besomders wieditige beiträge zur Lösung der noch immer schwebendens Fargens äher die Fortpflanzung dor liaidlerthiere bolen kïmnen. 


\section{Tabelle}

der von mir in Frönland gesthenen und im Texte hehandelten Rirderthiere mit Ingabe des Fomblorts mol Jinweis zu der seite des Texters, wo sie hespochen sind.

Namen.

Fundort.

Sipite.

I. Floscularia Oken.

1. Fl. ornatia Ehrbg

?. Fil. (ormuta I)obir

3. Fl. eampanulatat Dolie

Vugl. d. Text. s. 17 Ii

4. Fl. corountta ('nlitt

Jakobshaven

II. Melicerta (Ehrbg, Hudson.

5. II. Tubicolarial Iludson Jakolsharn

III. Conochilus Ehrbg.

(i. (' Volvox Ehrbg

Egerlesminde

IV. Philodina Ehrbg.

7. Ph. revthophthalma Ehrog Egedesm., Jakobsh. und Ritenbenk

s. 1'h. rosinula kihrlug

Egedesminde u. Jakolshavn

). P'h. alculeatal Ehrlog

Egerlexm., Jakobsh. u. Ritenb.

16. Ph. tuberenlata fiosiso

Egedesminde (Jakobsh.)

ㄴ)

11. I'h. hexodunta n. spe.

Jakobshavn

V. Rotifer Sehrank Ehrbg.

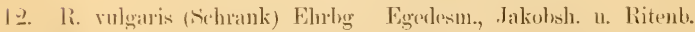

13. Li. materuts (sehrank) Ehrbg dakolshasu u. Ritenbenk 
VI. Callidina Ehrbg.

14. C. elegans Ehrbg.

15. (․ lapvis 11 . ij)

16. C. tentaculata 11. sp.

17. C. sp.
Holstenshorg, Egedesm. u. Jakohsh. 2!)

Egedesminde - ga!

Egedesminde :31)

Egedesminde 32

Asplanchna Gosse.

1. belvetica Imhof (1. priodonta (iosse?) ')

Egedesminde. Tasersuak

32

Triarthra.

Tr. longisetat Elurby

bigerlesminde, Tasersuak

32

VII. Mikrocodon Ehrbg.

Is. M. darus Eluther

Egedesminde, Jakobshavn

$3: 3$

VIII Mikrocodides n. g:

19. I. dubins 11. s.).

Jakobibara

1X. Hydatina Ehrbg.

20). H. senta Elnhy

Nirisilugtok

X. Hypopus n. g.

21. II. Ritenlenki n. sp.

Ritenlunk

XI. Taphrocampa Gosse.

2.). T. ammulusil Gusinte

Egrodesminte

2:3. T. Levinseni n. sp.

dakobsharn

is

XII. Pleurotrocha Ehrbg.

ㄴ. Pl. ㄱ.

Egaredesminde

5.). Pl. sp.

Egedesminde

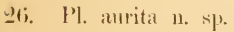

Eigredesmind.

1!)

27. Pl. mariual 11. يp.

Fogelesminde, Jakohsharn

;)

XIII Notommata Gosse (nec. Ehrbg).

28. N. ef. anrita Elırby'

? N. ef. salecigera Ehrthg

1) Vgl. Hyous 1. c. Suppl. \&. 13. 
30. N. tarilat It. -pp.

Egredesminde

31. N. grönlamelióa 11. s\%.

Egedesminde u. Jakobshavn

3.) N. $\mathrm{s}$.).

Jakolshavin

.)!

33. N. reler 11. sp.

Jakobshavn

(i)

34. N. distinctal n. spr.

Jakubhave

(i)

35. N. lomgipes n. sp.

Egedesminde

(XIV). Notostemma n. subgenus.

36. N. makrocephlala n. sp.

Jakohisharn

37. N. altinis 11. sp.

Egedesminde

3.. N. biearinata n. sp.

Jakobshav'n

XV. Monommata Bartsch.

39. M. lomgiseta (Ehrbg) Bartseh Jakobshavn (Egedesminde)

XVI. Copeus Gosse.

40. I: caulatus collins

Egerdesminde

XVII. Proales Gosse.

41. Pr. sp.

XVIII. Diops n. g.

42. 1). marima ก. sp.

Egerlesminde, Jakobshavn

XIX. Furcularia Ehrbg.

43. F. ef. grarcilis Ehrby

Egedesminde

44. F. ef. gibla Ehrbg

Jakobshaven (Egerlesminde)

4.5. F. . s.

Jakobshavn

XX. Eosphora Elurbg.

46. E. ef. Natias Ehrbg

E'gedesminde, Jakohshavu

1.7. E. sp.

Fogdesminde

XXI. Diglena Ehrbg.

4s. I) forcipata Ehrbg

Egedesminde

$4: 3$

49. 1). (1. atellina Ehrog

Egerlesminde, Jakobsharn

io). 1). "Hatams n. sp.

Jakohshavn

(XXII). Arthroglena n. subg.

51. A. Lïtkeni n. sp.

Jakolshaven 
XXIII. Distemma Ehrbg.

5.2. 1). dubia

Egedesminde

(1)

XXIV. Mastigocerca Gosse (nec. Ehrbg).

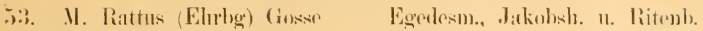

1(1)

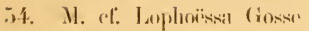

Jakobslavin

$10: 3$

in. M. bienomis (Ehrber) Gosise

Egedesminde

11:3

XXV. Diurella (Bory d. S:t Vine. Eyferth.

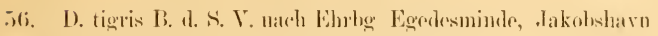

11)'

57. D. el. Rattulus Eyferth Figedesminde

1116

XXVI. Dinocharis Ehrog.

is. [). tertartis Ehrbg

Egedesminde, Jakobsharn

107

59. D. intermedia n. sp.

Figedesminde

107

XXVII. Searidium Ehrbg.

(i). Se. longicantum Ehrbg

Ferdesminde

ii. ?'s. lonuic. f. masulatum n. f. Ritenbenk

XXVIII. Stephanops Ehrbg.

62. St. of. lamellaris Ehrbg

( Egerlesminde) Jakohshavn

63. St. grönlam lieus n. sp.

Egedesminde

fit. Sit. Cblama Gosise

Jakohshavn

XXIX. Salpina Ehrbg.

65. ‥ 'f. mueronata Ehrbg Egenlesm., Jakohsh. u. Ritenl.

XXX. Euchlanis Ehrbg.

iiti. E. dilatata Ehrobs

Eugedesminde, Jakolshavn

$11 \%$

67. ? E. macrma Ehrlog

Egerlesminde, Jakobshavn

116

(is. E. triquetra Elurbs

Jakolshave

117

XXXI. Cathypna Gosse.

(it). (․ sp.

Egradesm., Jakobsh. 11. Ritenb.

XXXII. Monostyla Ehrbg.

70. M. Quemuerstedti n. sp.

Egedesminde, Jakobsharn

71. II. ef. cornuta Elurhg

Egedesin., Jakolsh. u. Ritenb. 
XXXIII. Colurus Ehrbg.

72. ('. Homeinatus Ehrbe Egrotesm., Jakubsh. u. Ritenh.

XXXIV. Monura Ehrbg.

73. M. Amblytelus (Gosise)

Egerlesminile, Jakubsharn

XXXV. Metopidia Ehrbg.

74. M. (ef.) Leparlella Ehrbg

Jakobshave

75. Ml. solirba frosise

Egerlesm., Jakobsh. u. Ritenh.

76. M. affinis n. $\mathrm{sp}$.

Ritenbenk

77. M. aeuminati Ehrog

Eurerlesm., Jakobsh. u. Ritenb.

78. M. triptera Ehrog

Egeslexminde, Jakobsharn

XXXVI. Pterodina Ehrbg.

79. Pt. cf. elliptica Ehrog

Jitkobsharn, Ritenbenk

XXXVII. Brachionus Ehrbg.

80. Br. ef. Pakeri Ehrbg

Egreslesminde

81. Br.? sp.

Jakohihaven

Anuræa (Ehrbg') Gosse.

An. cochleuris Grosse

In. longispina Kellientt
Egedesminde, Tasersuak

128

Egedesminde, Tasersuak

\section{Notholca Gosse.}

82. N. ambigua n. sp.

Egerlesminde

Anmerkung. Während des Druckes der letaten Bogen meiner Ibhandhng habe ich meine studien der hiesigen Rotiferenfauna fortgesetzt. loh werde dariber an anderer Stelle berjebten aber bemerke sehon hier, dass ich jot «t als sicher betrachite, dass ich fopeus Cerlurus frosse in firönland sah. Ebenso hin ieh jetz.t vollstänlig gewiss, dass eine Polya)thra in Jakobshavn oft genug üher das Gesichtsfeld schwamm. Auch in meiner Anffassung, dass Jinocharis intrrmedliu n. sp. umd Monostyla Quennerstedti n. sp. neue Arten sind, bin ich durch diese studien gestäkt worden. Die Seltenheit in den grönländischen (iewïssern von Brachinus- und Ammentarten ist mir withend dieser Arbeit noch bedentungsvoller geworden. lch konnte da recht gern, wie es scheint, auch Triurthro beifügen.

Die grönländischen Rotifcrengatturgrn sollten rlso jetzt mit meincn neuen 42 sein. 


\section{Verzeichniss der für diese Arbeit benutzten Literatur ${ }^{1}$ ).}

Tch gebe hier anch einige Arbeiten an, welehe ieh fïr das Studium einer behandelten Frage benutzt habe, welche aher nicht früher speciell angeführt worden sind.

1. Axprassox, H. II. Jotes on Indian Rotifers. Journ. of the Asiat. Sue of Bengal. Vol. LIXII, Part. II, N:o IT, Calcutta 1889.

2. Balbiaxi, M. Ohservations sur le Notommate de Werneck ots. Amm. d. sei. nat VI Série. Zool. Tome V1I, Paris 1878, Art. 11:0 2.

3. Punols, Тн. Matériaux pour servir à l'étude de la Faune des eaux donees des deores. Lille 1888.

4. Bartsir, S. Die Räderthiere und ihre bei Täbingen beolarhteten Arten. Inang. diss. Stuttgart 1870 .

5. - - Rotatoria Hungaria. Budapest 1877. Lerckarts Bericht in Archiv f. Natgeseh. 1878 , Bi. II.

6. Bergexdal, D. Kurzer Bericht über eine im Sommor d. J. 1890 miternommene \%ool. Reise nach Nordgrönland. Bih, till longl. Sivenska Yet. Ikad. Ihandlingar. Fand 17, Aft. IT, N:o 1.

7. Bucnuax, F. Die mikroskopische Thierwelt des süsswassers. Brannschweig 18s6.

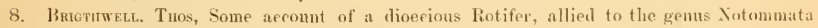
of Eurexbrerg. Ann. and Mag. of nat. hist. II ser. N:o 9. 1848.

9. Burs, W. B. Seienee (tossip 1889. ('itirt nach Journ. of liog. Mier. Soc. London 1890, s. 44.

10. ('utls, C. Üher die Organisation und die systematische Stellung der frattung Seism. Festschrift zur Feier des 25-jilhrigen Bestehens der k. k. zool. hot. (iesellschaft in Wien. 1876 .

1) Ieh halte es aus nahe liegenden Grinden sehr gat eine Znxammenstellung der für

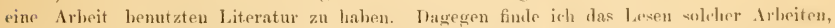
wo die Literaturhinweise nur durch das Anfuhren einer Nummer aus einer am sichlusse der Arbeit befudlichen liste gesehehen, mmothig nubequem, und gerale unzuliissig finche ich die von einigen Verfassern benutzte Methode für ilıre Hinweise uur die Xummer anzuführen. welehe die betreffenden schriften in Literaturverzeiehnixsen anderer Arheiten tragen. Lis muss ziemlich selbstklar sein, dass der leser einer Irbeit nielit nothwendig die linkanutschaft mit und Kugang zu der anderen Arbeit haben soll. Die Biicher sollen doch wohl nicht auswhliesslich fiir die spezialisten auf dem betreffenden Gebiete geschrieben werden.

Lunds Lniv Ärssk. Tom. Xxvm. 
11. Custs, C. Zur Kienntniss der Organisation von Seison. Zool. Anz. 3 Jahrg. 1880.

12. Conx, F. Die Fortpflanzung der Räderthiere. Z. f. w. Z. Bd. VII, 18כ̆6.

1:. - Bemerkungen ïber Rïderthiere. Ibm BA. IX, 1858.

14. - - Bemerkungen ïber Räderthiere. Ibm Bul, XII, 1863.

15. Warmuple, J. Deseription of an infusory animaleule allied to the genus Notommata of Ehrenherg hitherto undeseribed. Phil. Transact of Roy. Soe. London 1849.

16. Donr, M. Deseription of two new speeies of Floseularia with remarks. Ann. and Mag. of nat. hist. Yol. IV. II Ser. london $18+9$.

17. Dusanns, F. Histoires nat. des Zoophytes, Infusoires, Paris 1841.

1.. Ecksters. K. Die Rotatorien der Umgegend von Giessen. Eine von der phil. Faf. der [niv. Giessen gekrönte Preisseluift. Z. f. w. Z. Bd, XXXIX 1883.

19. Enruxzrg, C. G. Die Infusionsthierehen als vollkommene Orgmismen, Leipzig 1838.

20. - Ther die neuerlich bei Berlin vorgekommenen neuen Formen des mikroskapisclien Lebens. Bericht äbes die zur Bekanntmachung geeigu. Verh, der Ak. d. Wissensch. IBerlin 1853.

21. - - Dus jetzige mikroskopisehe Leben der Galapagosinseln. Monatsb. dej Akat. d. Wissenseh. Berlin 1853.

22. - Das organisehe kleiuste Leben iiher dem ewigen Schnee der höchsten C'entralalpen. Ibm 1853.

23. - Ther mene Anschaumgen des kleinsten uördlichen Polarlebens. $13 m 1853$.

24. Fиншасо, L. v. Zweitor Nachtrag zur Infusorienkunde linsslands Bull. d. la fioc. Imp. des Naturalistes de Moseou. Amée 184!.

25. E)ferth, B. Wie einfachsten Lebensformen. Syst. Thersicht der mikrosk Sürswasserhewolner. Braunschweig 1878 .

26. Furel. A. F. La faune profonde des laes suisses. Nonveaux mémoires de la sociétí helvetique des sci. nat. Vol. XXIX 1885.

27. uf (ivfrux, J. Excursiuns zool. dans les ites de Fayal at de San-Mliguel (Acores). Paris 1888.

29. De fitenst. I et Ricuno, J. Sur la fame des eaux douces du Groenland. l'ompteq Reurlus 1889. ‥ 6330.

29. Frusse, I'. H. A Catalogue of liotifera found in liritain. Amm. and Mag. of nat. hist. Vol. PIII, II sir. London 1851.

$30-O n$ the strurture, functions and homologies of the manducatory organs in the elass Rotifera. Phil. Trans, of the Roy. Soc. of Lombon. Vol. 146. London 1856 .

31. - On the dioecious character of the Rotifera. Ibm Vol. 147, London 1858.

32. - Twenty-four new species of Rotifera. Jourd. of Roy. Micr. Soc. London 1887, S. 1.

33. - - Twelve new species of Rotifera. Ibm S, 361 .

34. - Twenty-four more new species of Rotifera. Ihm S. 861.

Guse and Hlonson, Siche IIUnson n:o 16.

35. (fiғхснев, 11. Einige Beobachtungen äher Rülerthiere, \%. t. w. Z. Bd. XIX, 1889.

36. (russon-Thorpk, Y. New and Foreign Rotifera. Jonrn. of the Roy. Mier. Soe. London 1891.

37. Hұимек, R. R. J. Cndersügelser red Jakolsharns lstjord og mermeste Mmegn i Vinteren 1879-1880. Meddelelser om (irönland. Heft. 4, Kjöbenhavn 1883. 
38. Hamuzi, R. R. J. Inctersögelse af tirönlands Vestleyst fra $68^{\circ} 20^{\prime}$ till $70^{\prime \prime}$ X. lir. lbm. lleft. \&, Kjöbenhavn Lss?.

39. Hoom, J. List of lietifera found within a Radius of trenty Miles round Dundoe. Scott. Natural. (3) Vol. 1.

40. Ifuson, C. T. On some male Rotifer's. Monthly Micr. Journ. XII, 1875. Leuekurts Berielit 11, 1874 .

41. - On Asplanchna Ebbeshornii n. sp. Jounn, of Roy. Micr. Soc. Londen 1883.

42. - In Attempt to reclassify the Rotifers Quart. Jouru. of Microse. Sci. Tol. XXIV, New Series, London 1884.

43. - - The presidents adress. Journ. of Roy. Microse. Foe. London 188?.

4. - - (?) Jou'n. of Roy. Mier. Soc. London 1889, s. 99). (Referat uud liritik von Wexnas Arlueit: Notes sur quelques liotateurs etc.).

45. - - The presilents adress on some Doubtful Points in the Natural llistory of the Rotifera. Hom London 18:1.

46. Hous, C. T. assisted by (iosst, P. H. The Rotifera or Wheel animaleules in two Volumes, Iondon 1886. Supplement 1889.

47. 1nhor, 11. F. Studien zur Kenntuiss der pelag. Fiuna der Sichweizerseen. \%ool. Anz. V1 lalurg. 1883, s. 466.

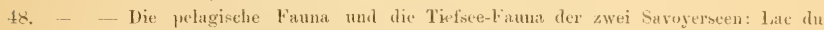
Bourget und Lac d'Ameey. Ihm s. 655.

4:. - Weitere Mithleilung über die pelagische Fauna der Susswasserliecken. Ibm VII Jahrg. 188t, s. 321 .

50. - - Weiter Mittheilnng ïber die pelagisclic und Tielisec-Wauna der Srisswasserbecken. Hm. VIll Jalng. 1885, s. 190.

51. - Die liotatorien als Mitglieder der pelagischen uul Tiefsce-Fauna der Süsswasserbeeken. Ibm s. 322.

52. - - Pelagische Thiere aus Süsswasserbecken in Elsass-Lothringen. Ihm s. 720 .

53. - - Yene Riesnltate über die pelagisehe und Tiefsee-Fauna einiger im Flussgebiet des Po gelegener Süsswasserbecken. lbm IX Jihrg. [s86, s. 41.

54. - Vorluntige Notizen über die horizontale und verticale geographische ferbreitung der pel. Fauna der Susswasserbecken. Hbn s. 335.

55. - C ber mikroskopische pelagixche Thiere aus der Ostsee. Hom s. 612.

56. - - Studien über die Fauna hochalpiner Seen insbesoudere des Kantons liraubünden. Jahresbericht der naturf. Ges. Granbundens Jahrg. XXX. 1887.

Von den zahlorichen anderen Mittheilungen dieses Autors nehme ich mur noch mit:

57. Notizen über die pelagische Fanna der Süsswasserbecken. Kool, Anz. X Jahrug. 1887. \&. 577, und die während des Druckes meiner Arbeit veroffentlichte Zusammentassung des fuhalts vieler anderen Aufsaitze:

58. - - Die Zusammensetzung der pelagischen Fauma der suisswasserbecken uach dem gegenwärtigen Stande der Intersuchungen. liol. Cintralblatt, Bal. XII. 1892, s. 171 .

59. IExsex, J. 1. I). Astronomiske Oloservationer og [ndersögelser over Taudets Saltholdigherl. Moddelelser om (irönland, Heft. 2, kjobenhavu [8 $\mathrm{k}$.

60. Lxvisśx, fi. II. R. Smaa Bidrag til den grönlandske Funa. 2 Nogle bemäkinger 
om Grönlands Rotatoriefauna. Vidensk. Medd. fra d. Naturh. Foren. Kjöbenhavn 1881 .

61. Lexpig, F. Über das Geschlecht dẹ Faderthiere. Verhandl. der physik. medie. Gesellsch. Wiirzburg, Bd. IV, 1854 .

62. - - C̈ber den Ban und die systematische Stellung der Räderthiere. Z. f. w. Z. Bd. VI, 1855 .

63. _- Ther Ilydatina senta. Mällers Mrchiv 1857.

64. Levжוf, II. Lennis' Synopsis der Thierkunde, III Anfl. Bd. Il. Hannover 1886.

65. Natras, M. Sur la multiplication et la fécondation de l'Hydatina senta Ehrhg. Note presentee par M. Lacaze-Duthiers. Comptes Remdus. Tome CXI, Paris 1890, S. 310 .

66. - - Sur la fécondation de l'llydatina senta Ehrbg. Note transmise par M. de Lacaze-1uthiers. Ilom \&. 50 .

67. - - Sur le déterminisme de la sexualité chez l'IIydatina senta. Comprtes Rendus etc. Tome CIII, Paris 1891, s. 388.

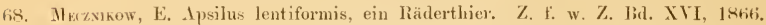

69. Mulve, W. Deseription of a new Rotiferen, Male and Female. Proceedings of the Plit. Soc. of filasgow 1881-1885, Vol. XV1, 1885.

70. Mitur, 6) F. Animalcula Infuseria Fluviatilia et Marina ete. Harnie 178t.

71. Niтнюrs, 1. (;. Polarforskningens bidrag till forntidens växtgeografi. (1 1. F. Nordenskiöld, Studier och forskningar ete.). Stockholm 1883.

72. - Botaniska anteckningar trán nordvestra (bönland. Öfversigt af Kongl. Vet. 1 kad. Förh. Stockholm 1884. N:o 1.

73. - Kritiska annärkningar om den grönländska vrgetationens historia. liilı. t. K. Svenska Vet. Akad. Handlingar, Btl. 16, Afd. III, n:o 6.

74. - - Fortsatta anmärkningar on den grönländska vegetationens listoria. Öfversigt af Kongl. Vet. Akad. Förhandlingar 1891, n:0 4.

75. Хoниеліs, 0 . Die pelagische und Tiefsee-Funna der grösseren finnischen Scen. Zool. Anz. Jahrg. X, 1887, s. 339.

76. Рвктк, М. Zur Kennfniss kleinster Lehensformen. liern 1852.

77. I'tate, L. Beiträge zur Naturgeschichte der Rotatorien. Jen. Zeitsebr. für Naturw. 13d. XIX. 1886.

78. - - Uber einige retoparasitische Rotatorien des Gulfes von Neapel. Mitth. aus der zool. Station zu Neapel, Bd. V11, 1887.

79. Rияов of the Scient. Results of the Voyage of II. I. S. Challenger $1873 \quad 76$. Prepared under the superintendence of sir Wiviue Tnouson and of John Muras. Vol. 1. Narrative of the (ruise.

Ricuna, deles siehe de Gteria n:o 28.

80. lixh, Il. (irönland geographisk og statistisk heskrevet. Kjöbenhavn 1 Ka7.

81. Sesper, C. Trochosphera equatorialis. Was liäderthier der Philippinen. Z. f. w. Z. Bd. XXIl, 1872, s. 311.

82. STws, Rotatoria. Tageblatt der Leipziger Naturforscherversammlung 1872.

83. Trssix-Bìtzow, (r. Rotatorien der Imgegend von Rostock. Arehiv 13 d. Fr. ı. Maturgesch. Mecklenburg.

84. Tómr, I lex. Riotatorien und Daphmien der Umgegend von Pest-ofen. Verh. d. k. k. zool. hot. Gesellsch. Wien XI, 1861 . 
85. Warmisg, Eug. Om frönlauds Vegetation. Meddelelser om (ironl. XlI. Köobenh. 188s.

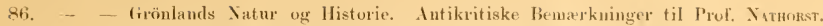
Vidensk. Meddel. tha d. Naturlist. Foren. Kjöbenhavn 18?1.

87. Wrakr, E. F. Notes sur quelques liotateurs des kivirons de (ienève. Arrhives de Biologie Vol. XIll, liege 1885 .

48. Weisse, J. F. Verzeichniss rou 155 in s:t. Petersburg heoh. Infusorienarten uelnet Bemerkuugen iiber dieselben. Bull, math. phys. de l'Acad. S.t Petershoury III, 1845 , S. 19.

89. - - Zweites Verzeichniss Petersburger Infusorien. 1bu 111, 1845, S. 333.

90. - - Drittes Verzeielniss Petersb. Inf. Ihm V, I847, S. 39.

91. - - Viertes Verzeichniss Petersh. Inf. Ilom VI, 1848, S. I06.

13. - Fünftes Verzeichniss Petersb. Inf. Ilm V1, 1848, 8. 353.

93. - - Erste Nachlese Petersb. lut. Hum VII, 184!, S. 310.

94. - Zweite Nachlese P'etersb. Inf. Ibm VIII, 1850, S. 297.

95. - - Iritte Nachlese l'etersh, luf. Ibm IX, 1851, S. T6.

96. - Zur tologie der Raterthiere. Mém. de l'tcad. de Sit Petcrshourg, VII Ser. Tom. IT, n:o \&, 1862, , 1 .

97. _ - Zur Mologie der Riderthiere. Zweiter Beitrag. Bull. d. IAcad Sit Jetersourg. VI11, 1865. S. 2013.

4.8. Zantass, 1). Über Fortpflanzung unl Entwicklung von Rotifer vulgaris. \%. f. w. Z. 1Bd. XL1, 1884.

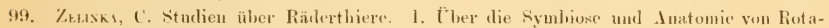

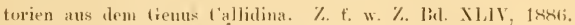

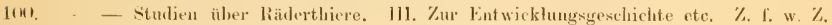
Bd. 1,11I, $18: 1$.

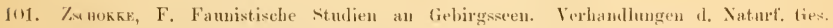
Basel, Bd. 9, Heft. 1. I8:\%.

102. - - Die zwcite zoologische Excursion an dic Scen des Rhatikon. Hom lleft. 2,1891 . 


\section{Erklärung der Abbildungen.}

Sammtliche Figuren sind nach in trönland gemachten Skizzen ausgefuhrt. Tch habe mich lemilht bei den Fertigstellen die skizzen möglielst wenig zu verbessern. Deshall, sind auch viele Figuren sehr primitiv geworden. Einige mussten atuch mitgenommen werden, die absolut nicht für Veröffentlichung berechnet waren und deshalls nur schnell hingeworfene, unvollständige Contourskizzen waren.

Betrefiend die Ansfullrung muss ich leider die Bemerkung zufügen, dass die Correkturtafeln viel besser ansgefülnt waren. Die hinien wie die Schatten waren weicher. die ganzen Abhildungen deshalb oft viel dentlicher. Besonders die auf der Correkturtafel sehr gut ansgefulute Fig. 23 a Taf. $\mathrm{IV}$ ist beim Inucken an manchen Tatelu beinahe verdorben. Ich lahe dem lithografen den Vorsellag gemacht wenigstens diese fatel umzudrucken, wozu er sich auch gern bereit erklïrte. Beim Versuche stellte es sich aber leiter heraus. dass der Stcin selbst in irgend einer. Weise verändert war, und dass es nicht mehr möglich war so gute Tafeln, wie die Correkturtafeln waren, zu bekommen.

Für die stirlicr vergrösserten Figuren sind meistentheils die ('ontouren mit lamera bei einer ungefähr 260-maligen Vergrösserung (Syst. IIl (altere Nummer) (). 1 von Nuch aufgezogen.

\section{Bezeichnungen, die für mehrere Figuren gïltig sind.}

a. Iuge.

ei, Cingulum.

da, Darm.

dt, Dorsaler Taster.

ebl, Exkretionshlaxe.

eg, Exkretionsgefaiss.

ei, Grösseres Li.

fim, Fulerum.

gotr, Geschleclitsdrüse o. Keimdotterstock.

gh, Gehirn.

kdr, Fussdritsen, Kittlräsen.

kh, lialkfülırenter Beutel.

lt. Lateraler Taster.

ma, Mastax.

Die Bedeutung der ibrigen Buchstaben, welche nur eimmal vorkommen, sind in der mg, Magen.

mgd, Magendrüsen.

mu, Mund.

mk, Mundkegel.

mm, Manubrium.

na, Nackenauge.

oes, Oesophagus.

ow, Ohrenförmige Wimperlappen.

$r$, liamus.

stk, Stirnkegel.

stz, (ilien oder Harbuischel an der Stirn.

tr, Trochus.

un, Lucus.

wtr, Wimpertrichter. betreffenden Figurerklärung angegeben. 
Tab. I

Fig. 1-3. Philodina tuberculata Gosse.

Fig. 1. Ilinterster Theil des Fusses etwas schematisch. Fig. 2. Taster. Fing. 3. kontrahirtes Thier.

Fig. 4. Individum von Rolifrr rulgaris (schrank) Ehrhg mit aufgelästen Angenflecken.

Fig. 5. Callidina lavis n. sp. in kontrahirtem Zustande.

Fig. (1. Ilymones Ritentenli; n. sp.

11. Ganzes Thier, etwas schematisirt. Die Lagn der fieschlechtsdriise an meiner Skizze ist eigenthümlich Ich habe picht notirt, ol diesellse bej der lrt nurmal war.

b. Idealer (Qtuerschnitt.

lig. 7. Kleineres Riaderthier, das in manchen Beziehungen Öhereinstimunung mit der in folgender Abbildung dargestellten Art zeigt. mk. Mumdkruel.

Fig. 8. 10 \& 11 . Milivorodide's dubius n. sp. von der Seite gesehen. I'ameraskizze.

stf, llantfalte ïber der Stirn, deren Form geäinlert wurle.

ov? Win üher der Blase liegendes Organ, das ich als rinen Wvidukt auflisste. leh hemerke bei dieser Albildung, dass der mastax sehr roh ansgefulurt war und elonso die grosszellige. Wand dos Magens.

Fig. 10. Kiefer der einen Seite eines efwas zerdrïckten Lxemplares. Starke Vergrössermu.

Fig. 11. Haiderorgan von voru gesehen. ? Etwas zweilellafte ('ilien zwischen dem cinguhm und dem trochus. Dhe Figur ist etwas schematisch.

Fig. 4. Plewrotrocha sp. Siehe den Text S. 49.

Fig. 13. Plearotrorlu marina n. sp.

u. (iestrecktes Thier, ungefähr 150 Mal rergrössert.

hf, IIakenförmiger Stirnfortsatz.

t. Zusammengezogenes Thier nach Zusatz von Kahihydrat. Für das Anssehen der Tiefer zeige ich auf die Figur t, hin.

Fig. 14. Monommata longista Parlsch.

a. Lebendes Lxemplar in Bewegung.

maf, Quergestreife Muskelfasern in den Zehen.

b. Exemplar nach Zu×atz einer schwachen Kalihydratlösung.

Tab. II.

Fig. 12. Tuphrocumpa Lerinseni и. sp.

a. Von oben.

b. Von der Seite gesehen.

sh, llinterer über, dem Finss gelegener fortsatz.

Fig. 15. Plearotrorlen arwita n. sp. Die lage ist schräge seitlich. pl, Seitliche Kopffortsätze.

Fig. 16. Notommatu tarta n1. sp.

a. Von oben.

1. Von der Seite.

f. lilealer Querschnitt durch den Kolf um die eigenthünlichen Längserhehungex darzustellen. 
spf, Zwei scharf hegrenzte, sehr kleine Pigmentflecken, ron denen stärkere Haare, ta, ausgingen.

ma bedentet in dieser Figur den vorderen Theil des Darmkanals hinter dem Oesophagus.

he, Halseinschnürung.

Fig. 17. Notostemma affinis n. sp.

a. Profilbild.

ghb, Kleine Blase gleich hinter dem Gehirn.

b. Nach Zusatz einer Kaliłösung.

c. Die Kiefer nach Einwirkung der Kíalikisung.

Fig. 18. Notostemma bicarinata n, sp.

a. Profillbild.

b. Theile des mastax nach Einwirkung einer Kalilösung. Die Deutung der einzelnen Theile scheint mir nicht olne Zweifel.

c. Irlealer Querschnitt um die kleinen Leisten zu zeigen.

Fig. 19 b. Notostemmu makrorephala n. sp. Nach Kalizusatz mh, Manubrium.

Fig. 20. Notommata longipes n. sp.

a. Profilbild des ganzen Thieres.

b. Kiopf von oben.

f. Fuss von der Seite um den Cuticularfortsatz,

blp, des ersten Fussgliedes zn zeigen

$\mathrm{x}$, zeigt die schwache längslinie des Fusses, welche ich als eine leichte Hautfalte gedentet habe.

Fig. 21. Notommata grönlandira n sp.

11. Thier ron oben.

e. Kogftheil vou oben, muss mit der Fig. $21 a$, f und $g$ rerglichen werden.

$f$. IIinterer Körpertheil und Fuss um die Bildung der Zehen zu veranschaulichen.

\section{Tab. III.}

Fig. 21. Notımmata grönlantliara n. sp.

7. Profilbild.

e und $g$ sollen das Aussehen des Kalkheutels vor und nach dem Ausleeren der lialkköruer zeigen. Fig. $g$ entspricht der Fig. 21 e der vorigen Tafel.

d stellt die vordere Kopffliche von vor'n um unten gesehen dar.

str, die lïngere ('ilien tragende Rimne, welche zwischen dem faltenförmigen Ttirnfortsatz, stf, umd dem itirnkegel sich befindet, und die besonders an den Profilbilden Fig. $21 b$ und $r$ selhr dentlich ist. Da ist sie indessen nicht mit Buchstaben besonders hervorgeholen

Fig. 19. Notostemma malivoerphala n. sp.

a. Profilbild.

ab, Blasenförmiges, schwach pigmentirtes Auge.

mgda, Verdaumnskanal, wo eine Verschiedenheit zwischen Magen und Darm nicht zu heobachten war.

c. Thier ron oben gesehen. 
Fig. 22. Notommata sp.

a. Yon oben.

b. Von der Seite im gestreckten Zustande.

c. Von der Seite etwas kontrahirt.

Fig. 23. Notommata distinctu n. sp.

b. Kopfende vou vorn und unten gesehen.

vpf, Vorderer Pigmentfleck in der Baris des Stirukegels, stk, gelegen.

sa, Seitliche Augentlecken nach imen von den ohrenförmigen Wimperlappen gelegen.

c. Kalkbeutel, von unten gesehen.

d. Etwas kontrahirtes Thier nach lange fortgesetzter Untersuchung, von oben gesehen.

Tab. IV.

Fig. $23 u$. Notommata distinctu n. sp.

An einigen Tafeln ist der mastax so dunkelsehwarz geworden, dass es fast so aussieht, als läge derselhe auf dem Gehiru, obgleich das Thier von oben gesehen wurde. Ehenfalls ist an denselben Tafeln der Kalkbeutel recht undeutlich geworden.

sa, vpf, siehe Fig. $23 \quad b$ der vorigen Tafel.

we, Winterei (eplippial egg lluds.).

mhf, Mittlerer hinterer Pigmentfleck.

shp, Seitliche, hintere Pigmentflecke, die sehr scharf begrenzt waren.

am, Ausmündungsstellen der Kittdrüsen.

Fig. 24. Notholea ambigua 11. sp.

a. Von oben,

b. Von der Seite.

Die Sculptur des Panzers ist nur theilweise angedeutet, weil ich darüber sehr wenig notirt hatte. $\mathrm{Vgl}$. den Text S. 128 .

Fig, 25. Copens caudatus Collins.

a. Thier von der Seite.

vdt, Vorderer dorsaler Taster.

ht, Hinterer dorsaler Taster.

Vgl. übrigens deu Text s. 81 .

b. Fuss um die Querlinien am letzten Fussgliede und an den Zehen zu zeigen.

c. Rüickenhaut des Kopfes mit dem vorderen dorsalen Taster.

c. Hinterer dorsaler Taster und Ausmündungsstelle des Enddarmes.

Fig. $26 a, b$. Die Kiefer von Furculurin of. gibbn.

Fig. 27. Diops marina n, sp.

a. Thier von der Seite.

b. Fuss und Zehen mit den Ausmündungsstellen der Kittdrïsen.

c. Fuss mit eingezogenen Zehen.

d. Doppelauge.

Fig. 34. Salpina of. mucronata Elrbg.

a. Vorderer Theil des Panzers.

b. Hinterer Theil desselben, beide von der Seite gesehen.

Lunds Univ, Arsskr. Tom. XXVIII. 
Tab. V.

Fig. 27. Diops marina n. sp.

g. Thier von unten gesehen.

$c$ und $f$. Die Kiefer.

Fig. 28. Münnchen ron ciner Furculariu.

u. In ausgestrecktem Zustande stark vergrössert.

stkt, Stirnkegel mit von demselben ansgehenden Haaren.

$\mathrm{lm}$, Längsmuskeln.

vd, Yas deferens.

p, Penis.

$\mathrm{t}$, Testis.

?, Zweifelhafte rentral gelegende Körnerhaufen.

vdkr, Blase mit schwärzliehen Körnern, die als Reste des Inhalts des Verdaumgskanals gedeutet worden sind.

$b$ und $c$. Dasselbe Thier mit Camera gezeichnet bei selnwächerer Vergrösserung.

Fig. 29. Eosphiora cf. Naias Ehrhg.

a. Kopf um die Lage der Stirnaugen und der mit steifen Haaren besetaten, kleinen Stirnfortsätze, stf, zn veranschanlichen.

b. Yorderer Theil des Yerdaungskanals um die Erweiterung des oesophagus und die kleinen Anhangsbildungen, ?, des Magens, welche zwischen den Magendräseu und dem oesophagus sitzen, darzustellen.

Fig. 38. Cathypna sp.

Panzer eines schon seit einiger Zeit todten Thieres, worine einige Eier sich befanden. Iie gekrümmten Klanen der Zehen sind sehr deutlich. Die Seulptur des Panzers ist anch hier sehr unvolkt ändig gezeichnet.

Fig. 30. Arthroglena Lütheni 11. sp.

b. Yorderende bei etwas zurückgezogener Lage des liopfes. Eine (irenze zwischen dem Kopfende und der Unterseite tritt scharf hervor.

c. Kiopf ron vorn und unten gesehen.

sth, Stirnhaken.

dl, Hantfalte über dem Stirnhaken.

stf, Auf einer kleinen Erhebung sitzende Cilien.

An den zu dunkel ansgeführten Tafeln ist diese Erhebung nebst Cilien wenig deutlich.

Tab. VI.

Fig. 30 a. Arthroglena Lülleni n. sp. Yon der Seite.

dl, sth, vgl. Fig. $30 \mathrm{c}$ der rorigen Tafel.

?, Eine kleine Blase etwas hinter dem Gehirn, die wohl ohne Zweifel den oft

kalkführenden Anhangsbenteln bej vielen anderen Notommataden entspricht.

$g l$, Gelenk an den Zehen.

Fig. 31. Distcmma dubia n. sp.

Fig. 32. Mastigocerca of. Lophoëssa Gosse?

Hinterer Theil des Körpers um die stacheln zu zeigen. 
Fig. 33. Dinochar is intermedia n. sp.

Ich habe bei der Ausführung nnr auf die für diese Art charakteristischen Verhältnisse Gewicht gelegt. Die Form der Felder des Panzers und dgl. ist nicht genauer ausgeführt. Ebenfalls habe ich nicht alle kleinen spitzen an der dorsalen Panzerfläche dargestellt. An beiden Thieren war der liopf eingezogen.

a. Thier von der Seite.

b. Yon oben.

vh, Vordere Haken der Seitenränder.

sh, Seitliche Haken der Seitenränder.

dh, dorsale Spitzen des Panzers.

Vgl. übrigens den Text s. 107 .

Fig. 35. MIonura Ambtytelus (Gosse).

a. Thier von der Seite.

sth, Stirnhaken.

b. Die zusammengewachsenen Zehen, von oben

Fig. 36. Pterodina off. elliptica Ehrbg.

a. Von der Seite.

c. Yon unten.

b. Idealer Querschnitt.

Fig. 37. Metopidia Lepadella Ehrbg.

a. Von oben.

b. Idealer Querschnitt.

Fig. 39. Monostyla quennerstedti n. sp.

a. Ganzes Thier.

b. Der Fuss eines zweiten Individuums.

Fig. 40. Mastigoceren cornuta (Ehrbg) Gosse.

Hinterende mit Stacheln.

Fig. 41. Stciphanops grönlandicus n. sp.

Fig. 42. Metopidia affinis n. sp.

Panzer.

Fig. 43. Zweifelhaftes Thierchen, wahrscheinlich ein Männchen. Vyl den Text $\$ .140$. 


\section{Inhaltsverzeichniss.}

Einleitung

Seite.

Zur Rotatorienfauna.

1.

ther einige in Grönland beobachtete Rotiferenmännchen etc.

Vergleichnngen und Schlussbemerkungen. . . . . . . . . . . . . 150.

Tabelle, die man um die Arten zu finden benutzen dürfte............ 164.

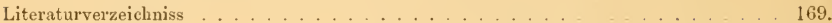

Figurenerklärung . . . . . . . . . . . . . . . . . 174.

\section{Nachträgliche Bemerkungen.}

Bei der Diskussion (S. 19) über die Berechtigung der Gattung Meliecrta Ehrbg sollte hervorgehoben sein, dass auch Oecistes pilula für Hunsox's Anordnung spricht.

Unter Hydutina senta S. 43 sollte auch die Synonyme: Vorticella senta 0. F. Müller l. e. S. 290, Tab. XLI, Fig. 8-14 mitgenommen sein.

Bei der Besprechung des Stephanops Chlena Gosse S. 113 füge ich zu, dass zwar in der Familie Coluritce zu einer Gattung Arten mit einem und mit zwei ziemlich weit getrenuten Angen gefübrt werden. Diese Formen zeigen aber, insofern bis jetzt bekannt ist, in übrigen Hinsichten sehr grosse Ühereinstimmung. Übrigens sind sie bisher nicht gerade genau untersucht.

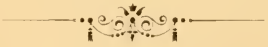






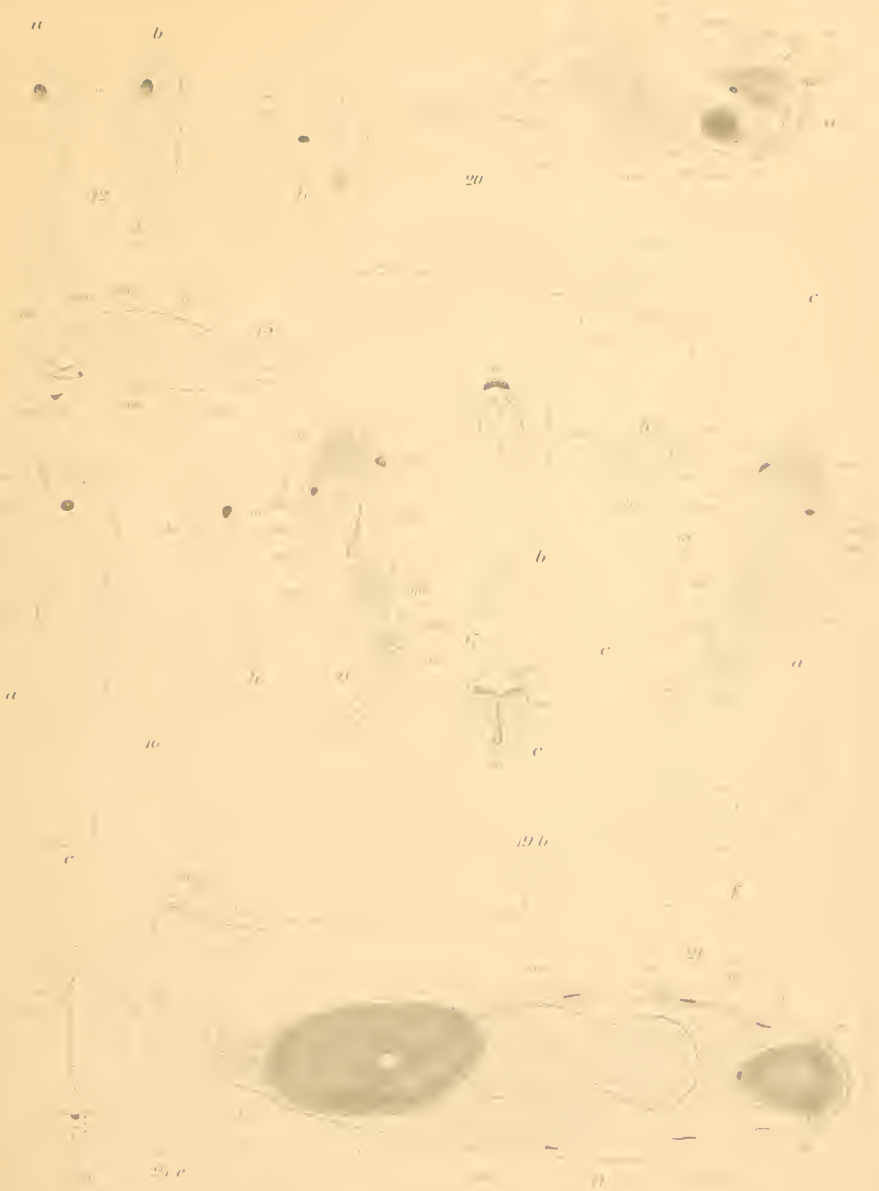





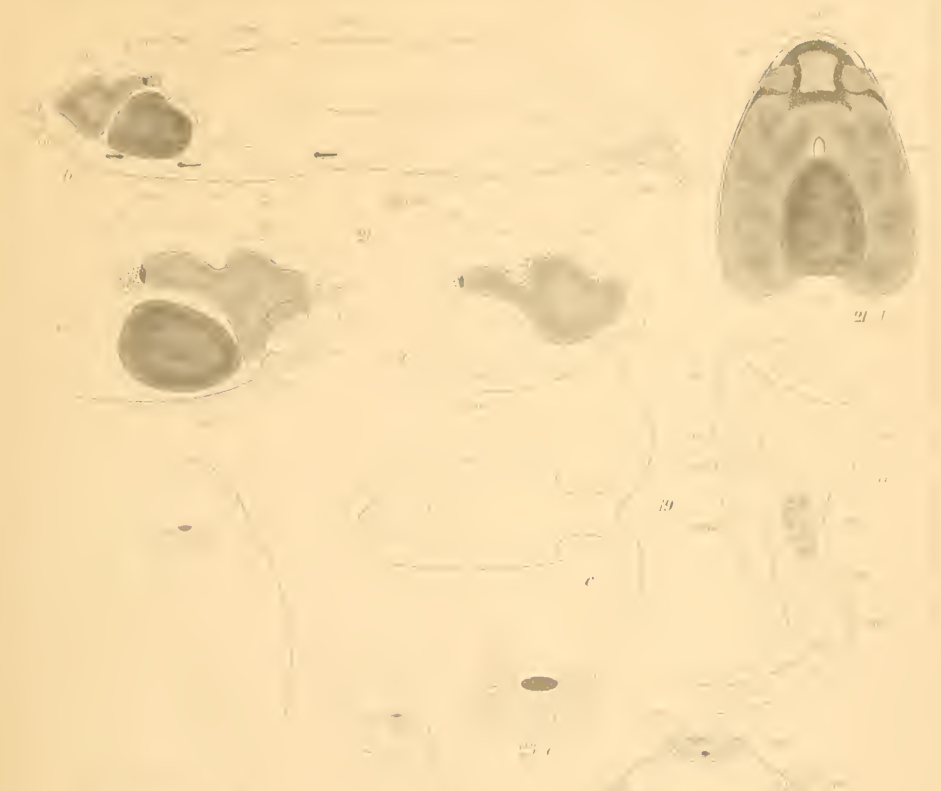

21,1 20
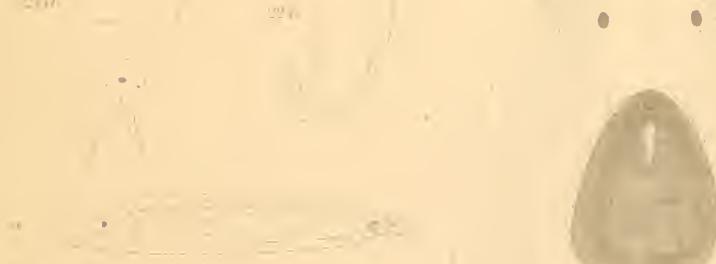

wit
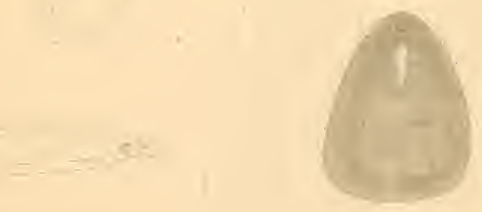

h. 





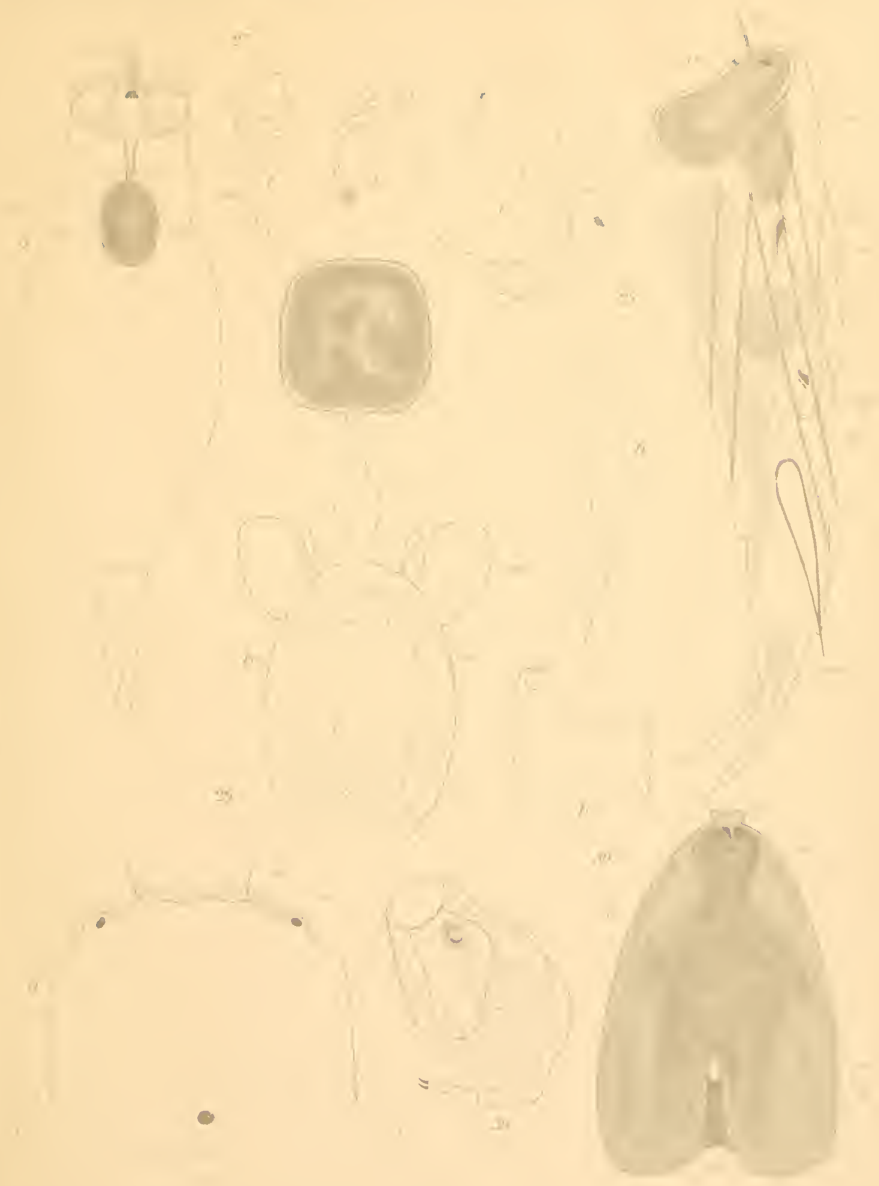





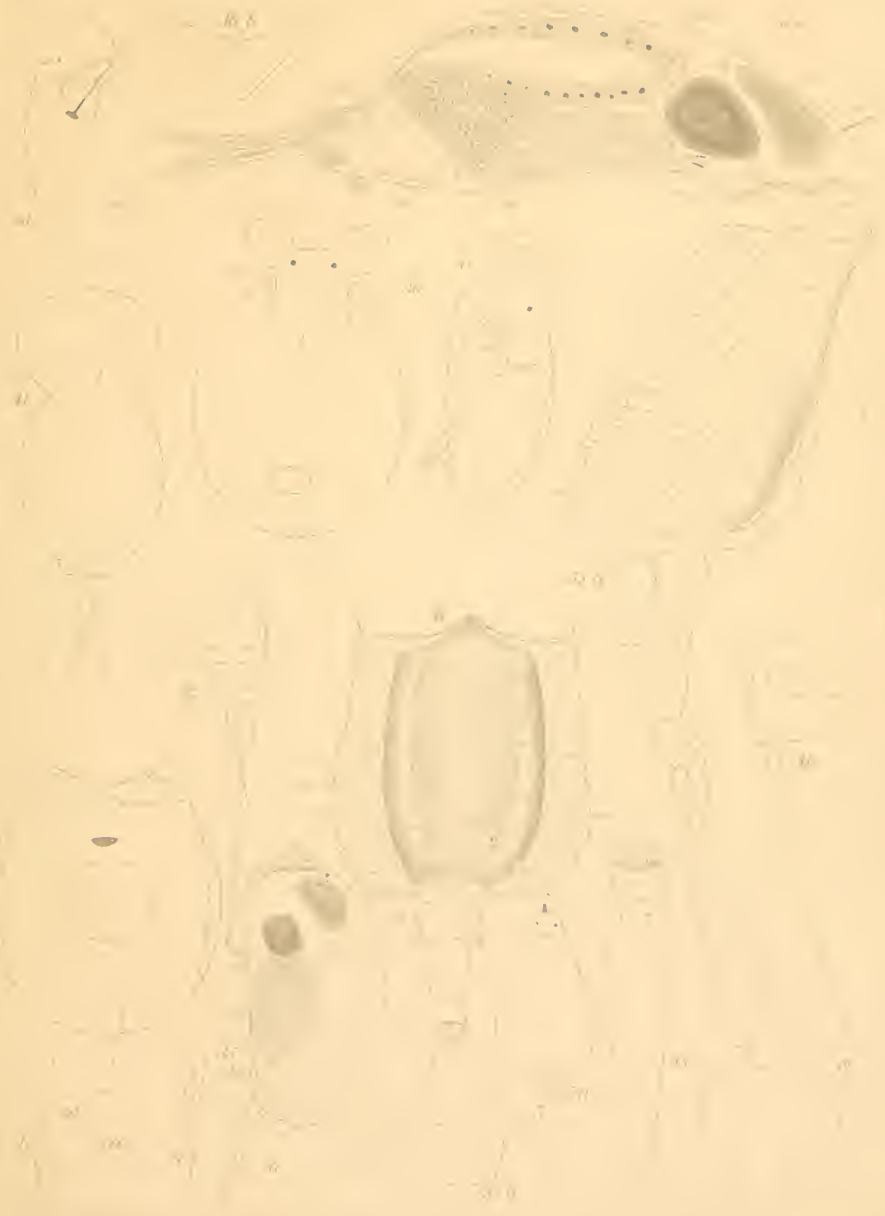








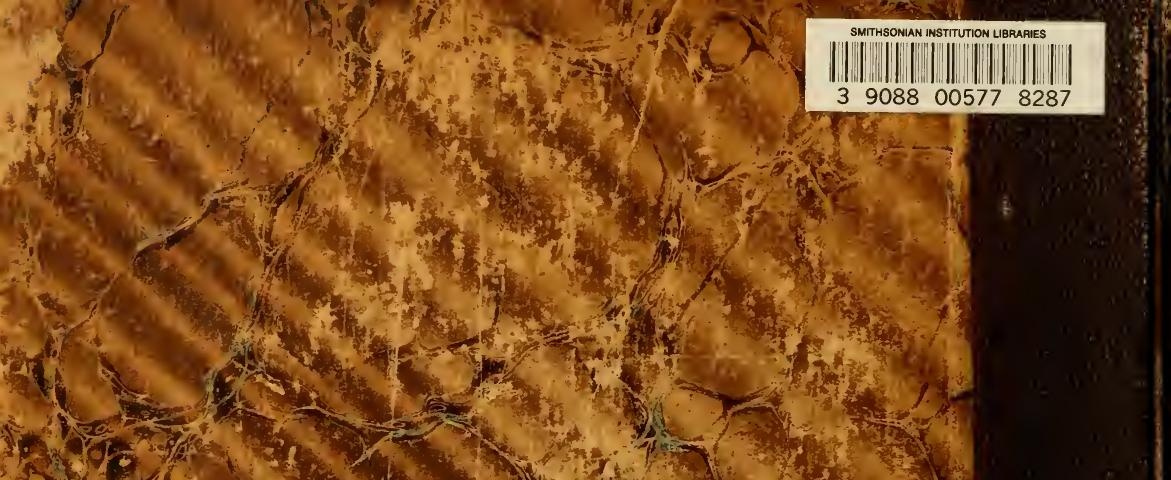

6.

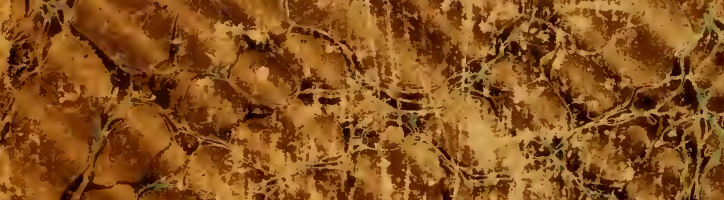

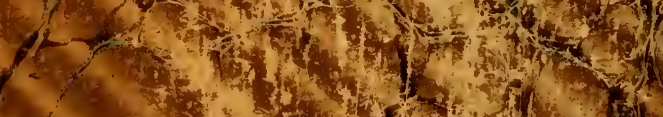

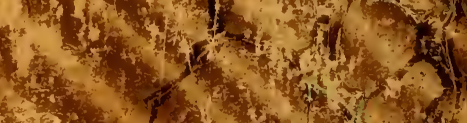

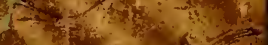

(2)

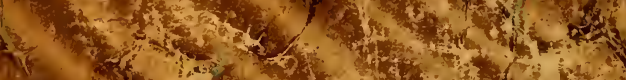

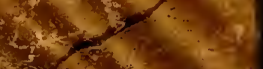

(2)

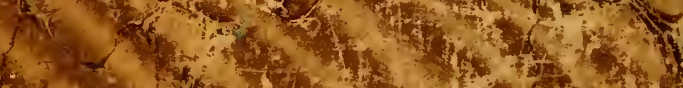

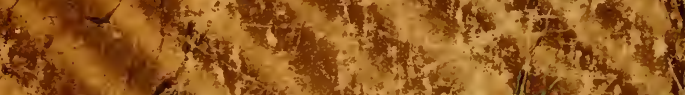

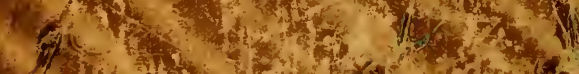

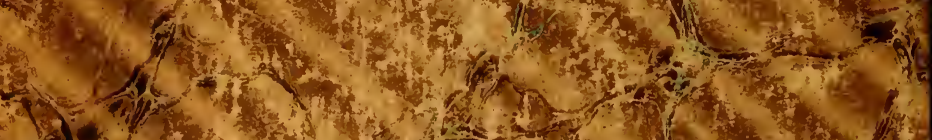

(1.

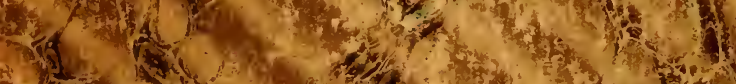

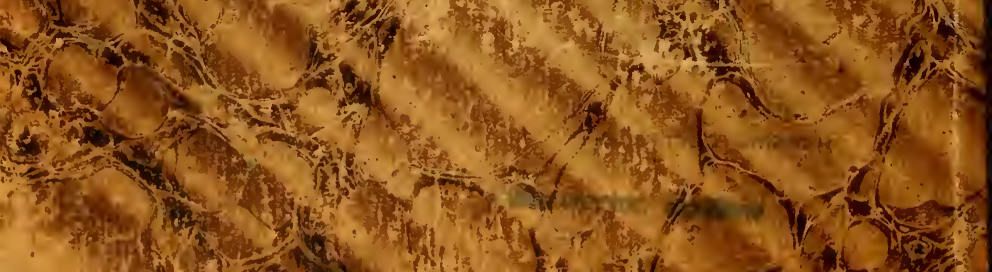

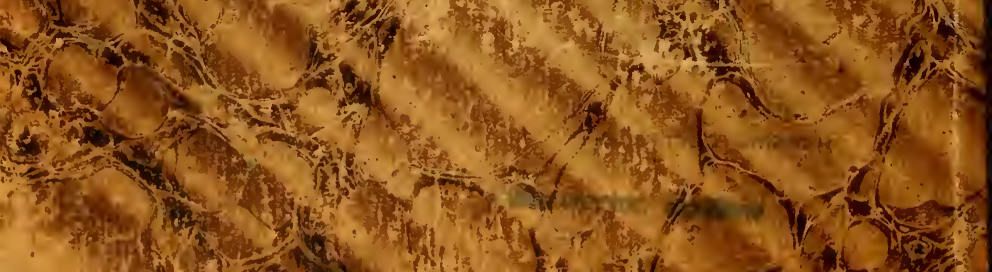

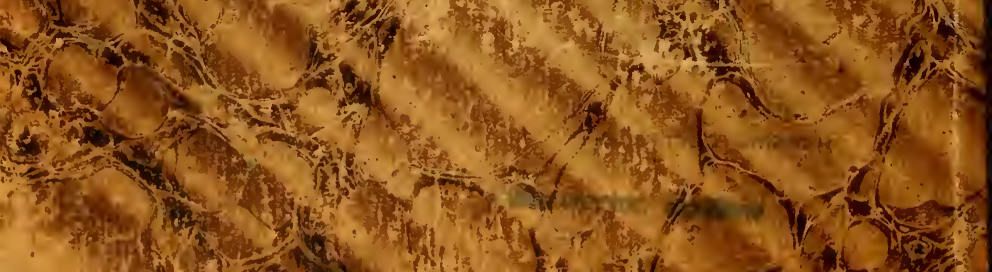
(x) 1 y 